Beach morphology and its dynamism from remote sensing for coastal management support

Carlos Cabezas Rabadán

UNIVERSITAT
POLITÉCNICA
DE VALĖNCIA

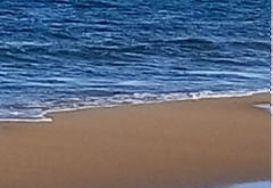

DE VALĖNCIA 



\title{
Beach morphology and its dynamism from remote sensing for coastal management support
}

\author{
Thesis dissertation
}

submitted by

\section{Carlos Cabezas Rabadán}

in fulfillment of the requirements for the Degree of Doctor of Philosophy at

Universitat Politècnica de València

Advisors:

Dr. Josep E. Pardo Pascual

Dr. Miguel Rodilla Alamá

València, March 2021

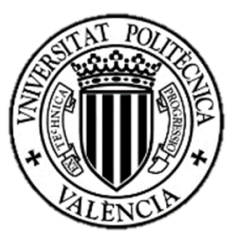





\section{Summary}

Beaches are coastal spaces that perform numerous environmental functions. They provide important benefits to society and coastal communities, including the ecological function, the provision of protection for coastal territories, and constitute a basic resource for the tourism industry. Due to climate change and human actions that alter the natural dynamism of the coast, beaches are experiencing increasingly harmful erosive processes that affect their physical integrity and the maintenance of their ecological functions.

Beach management is often not adapted to the particularities of the different coastal segments. Decision-making is not based on sufficient information about characteristics, dynamism, and current state of beaches, resulting in short or ineffective solutions. Geomorphological characteristics are essential in the development of beach functions as they condition their physical dimensions and their behavior in response to the action of the sea. Therefore, their detailed and updated characterization is necessary to carry out efficient actions, allowing a more ecosystemic and sustainable coastal management.

Remote sensing techniques have a great capacity for acquiring data from the land surface. In particular, Sentinel-2 and Landsat (5, 7, and 8) satellites freely provide medium resolution images with global coverage and high-revisit frequency. The algorithms for extracting the water/land interface recently developed by the Geo-Environmental Cartography and Remote Sensing Group (CGAT - UPV) allow defining the position of the shoreline on these images, constituting potentially useful data to describe beach morphology and dynamics. Universalizing their application requires testing and validation at different coastal types. For this purpose, the extraction process has been adapted for exploitation in tidal environments, and the resulting shorelines have been assessed under different oceanographic conditions offering an accuracy close to $5 \mathrm{~m}$ RMSE (Root-Mean-Square Error). From these shorelines, and taking into account the existing information needs for management, it is proposed to derive indicators to characterize the geomorphology of the beaches and to monitor their changes. To this end, the proposed methodologies ensure the efficient management of large volumes of shorelines, being able to characterize the beaches along broad coastal segments and periods. Thus, beach width and sediment grain size are derived as objective and easily understandable indicators of the beach geomorphology. Spatial-temporal modeling of the state and changes of shoreline position and beach width makes it possible to monitor the response to storms and anthropogenic actions, allowing to analyze changes that occur every few days or over decades. The large spatial coverage together with the integration with other cartographic databases allows characterizing the influence of beach geomorphology in the performance of its functions, offering a holistic view of the coast from a regional scale.

The methodologies developed in this thesis and the indicators derived from remote sensing provide support and criteria for prioritizing the actions of managers. This contributes to fill the gap between the availability of techniques to obtain remote information and its application in the coastal decision-making process. 


\section{Resum}

Les platges són espais costaners que desenvolupen nombroses funcions ambientals. Aquestes proporcionen importants beneficis a la societat i comunitats costaneres, entre les quals destaquen la funció ecològica, el subministrament de protecció per als territoris costaners i el fet que constitueixen un recurs bàsic de la indústria turística. De forma lligada al canvi climàtic, així com a accions humanes que alteren el dinamisme natural de la costa, les platges estan experimentant processos erosius cada vegada més nocius que afecten la seua integritat física i al manteniment de les seues funcions.

La gestió de les platges en moltes ocasions no es troba adaptada a les particularitats dels diferents segments costaners. La presa de decisions no es sustenta en informació suficient sobre les característiques, el dinamisme i l'estat actual de les platges, donant Iloc a solucions curtterministes o ineficaces. Les característiques geomorfològiques són essencials en el desenvolupament de les seues funcions en condicionar les seues dimensions físiques i el seu comportament enfront de l'acció de la mar. Per això, la seua caracterització de manera detallada i actualitzada és necessària per a dur a terme accions eficients, permetent virar cap a una gestió costanera més ecosistèmica i sostenible.

Les tècniques de teledetecció presenten una gran capacitat per a l'adquisició de dades de la superfície terrestre. En concret, els satèl-lits Sentinel-2 i Landsat $(5,7$ i 8$)$ permeten disposar de manera gratuïta d'imatges de resolució mitjana amb cobertura mundial i alta freqüència de captura d'informació a un mateix punt. Els algorismes d'extracció de la línia de costa desenvolupats recentment pel Grup de Cartografia Geo-Ambiental i Teledetecció (CGAT - UPV) permeten definir sobre aquestes imatges la posició de la línia de costa, constituint dades potencialment útils per descriure la morfologia de les platges i el seu dinamisme. Universalitzar la seua aplicació requereix el seu testatge i validació en diferents tipus de costa. Per a això, el procés d'extracció ha sigut adaptat per a la seua explotació en entorns mareals, i les línies de costa resultants han sigut avaluades davant diferents condicions oceanogràfiques oferint una precisió pròxima als $5 \mathrm{~m}$ RMSE (arrel de l'error quadràtic mitjà). Tenint en compte les necessitats d'informació per a la gestió existents, a partir d'aquestes línies de costa es proposa derivar indicadors que permeten caracteritzar la geomorfologia de les platges i monitorar els seus canvis. Per a això, les metodologies proposades asseguren una gestió eficient de grans volums de línies de costa, sent així capaces de caracteritzar les platges cobrint grans territoris i períodes de temps. Així es deriven l'ample de platja i la grandària dels grans de sediment com a indicadors objectius i fàcilment comprensibles de la geomorfologia de la platja. La modelització espai-temporal de l'estat i els canvis de la línia de costa i de l'amplària possibilita monitorar la resposta de les platges a temporals i a actuacions antròpiques, permetent analitzar els canvis ocorreguts cada pocs dies fins a cobrir dècades. La seua cobertura espacial al costat de la integració amb altres bases de dades cartogràfiques permet caracteritzar la influència de la geomorfologia de la platja en l'acompliment de les seues funcions, permetent una anàlisi holística de la costa a escala regional.

Les metodologies desenvolupades en aquesta tesi i els indicadors derivats des de la teledetecció brinden suport per a dotar de criteris i prioritzar les accions dels gestors. Es contribueix així a omplir l'espai existent entre la disponibilitat de tècniques per a obtenir informació remota i la seua aplicació en els processos de presa de decisions sobre la costa. 


\section{Resumen}

Las playas son espacios costeros que desarrollan numerosas funciones ambientales. Éstas proporcionan importantes beneficios a la sociedad y a las comunidades costeras, entre las que destacan la función ecológica, el suministro de protección para los territorios costeros y el hecho de que constituyen un recurso básico de la industria turística. De forma ligada al cambio climático, así como a acciones humanas que alteran el dinamismo natural de la costa, las playas están experimentando procesos erosivos cada vez más dañinos que afectan a su integridad física y al mantenimiento de sus funciones.

La gestión de las playas en muchas ocasiones no se encuentra adaptada a las particularidades de los diferentes segmentos costeros. La toma de decisiones no se sustenta en información suficiente sobre las características, el dinamismo y el estado actual de las playas, dando lugar a soluciones cortoplacistas o ineficaces. Las características geomorfológicas son esenciales en el desarrollo de sus funciones al condicionar sus dimensiones físicas y su comportamiento frente a la acción del mar. Por ello, su caracterización de forma detallada y actualizada es necesaria para llevar a cabo acciones eficientes, permitiendo virar hacia una gestión costera más ecosistémica y sostenible.

Las técnicas de teledetección presentan una gran capacidad para la adquisición de datos de la superficie terrestre. En concreto, los satélites Sentinel-2 y Landsat $(5,7$ y 8$)$ permiten disponer de forma gratuita imágenes de resolución media con cobertura mundial y alta frecuencia de revisitado. Los algoritmos de extracción de la línea de costa desarrollados recientemente por el Grupo de Cartografia GeoAmbiental y Teledetección (CGAT - UPV) permiten definir sobre estas imágenes la posición de la línea de costa, constituyendo datos potencialmente útiles para describir la morfología de las playas y su dinamismo. Universalizar su aplicación requiere su testeo y validación en diferentes tipos de costa. Para ello, el proceso de extracción ha sido adaptado para su explotación en entornos mareales, y las líneas de costa resultantes han sido evaluadas ante diferentes condiciones oceanográficas ofreciendo una precisión cercana a los 5 m RECM (raíz del error cuadrático medio). Teniendo en cuenta las necesidades de información para la gestión existentes, a partir de estas líneas de costa se propone derivar indicadores que permitan caracterizar la geomorfología de las playas y monitorizar sus cambios. Para ello, las metodologías propuestas aseguran una gestión eficiente de grandes volúmenes de líneas de costa, siendo así capaces de caracterizar las playas cubriendo grandes territorios y periodos de tiempo. Así se derivan el ancho de playa y el tamaño de los granos de sedimento como indicadores objetivos y fácilmente comprensibles de la geomorfología de la playa. La modelización espacio-temporal del estado y los cambios de la línea de costa y de la anchura posibilita monitorizar la respuesta de las playas a temporales y a actuaciones antrópicas, permitiendo analizar los cambios ocurridos cada pocos días hasta cubrir décadas. Su cobertura espacial junto a la integración con otras bases de datos cartográficas permite caracterizar la influencia de la geomorfología de la playa en el desempeño de sus funciones, permitiendo un análisis holístico de la costa a escala regional.

Las metodologías desarrolladas en esta tesis y los indicadores derivados desde la teledetección brindan apoyo para dotar de criterios y priorizar las acciones de los gestores. Se contribuye así a llenar el espacio existente entre la disponibilidad de técnicas para obtener información remota y su aplicación en los procesos de toma de decisiones sobre la costa. 


\section{Content}

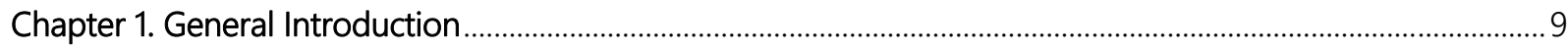

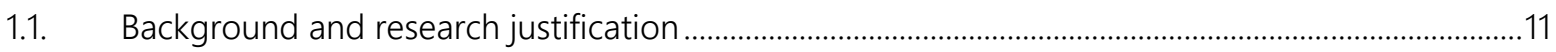

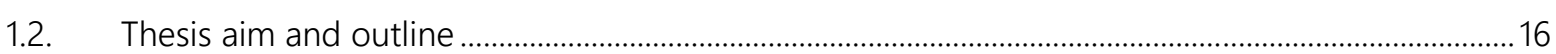

Chapter 2. Assessing user's expectations and perceptions on different beach types and the need for diverse management frameworks

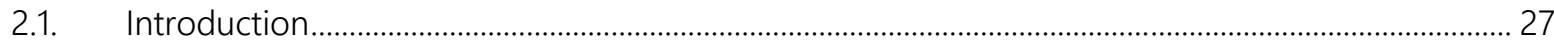

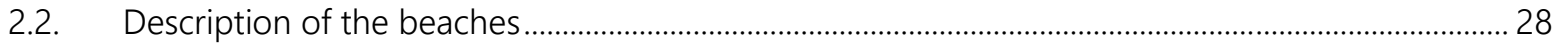

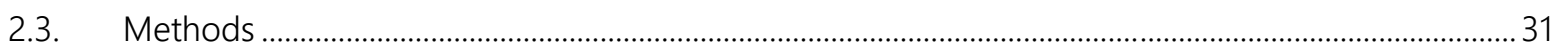

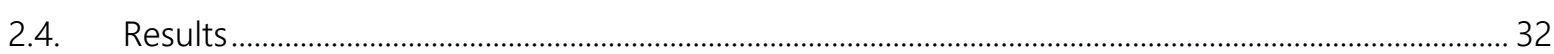

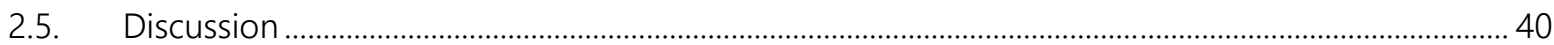

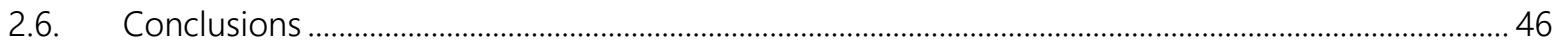

Chapter 3. Satellite-derived shorelines at an exposed mesotidal beach ................................................................49

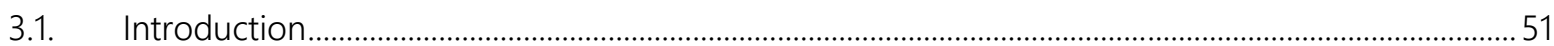

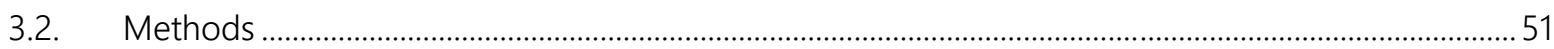

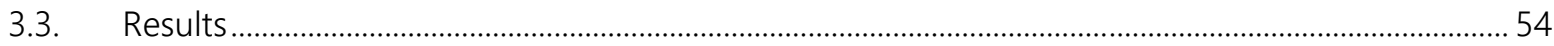

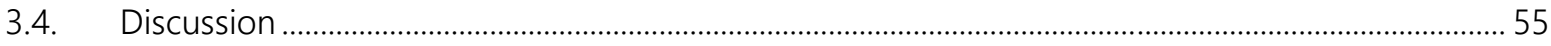

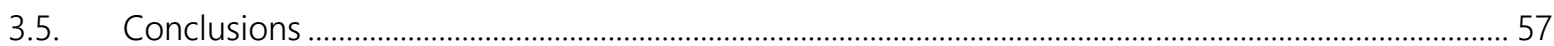

Chapter 4. Characterizing beach changes using satellite-derived shorelines .....................................................59

Part I - Characterizing beach changes using high-frequency Sentinel-2 derived shorelines on the Valencian coast (Spanish Mediterranean) ............................................................................................................ 62

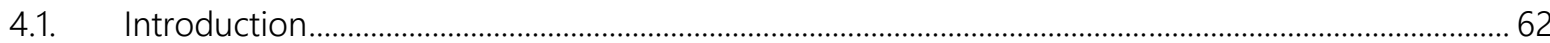

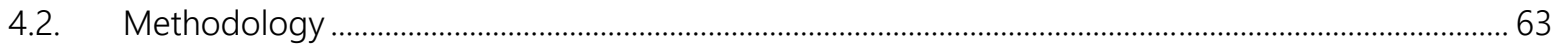

4.3. Study area

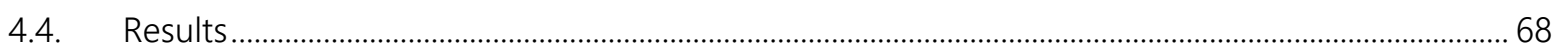

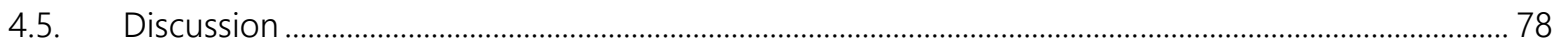

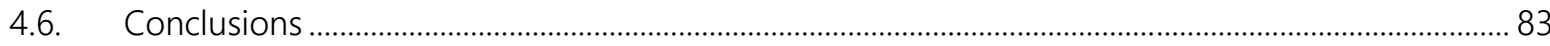

Part II - Monitoring the response of Mediterranean beaches to storms and anthropogenic actions using

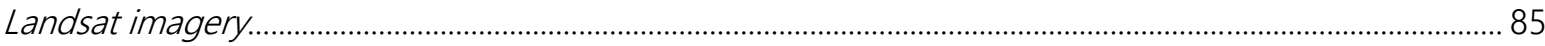

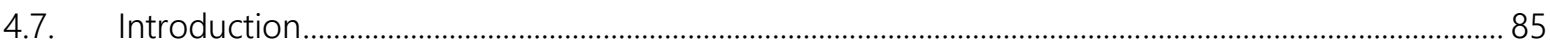

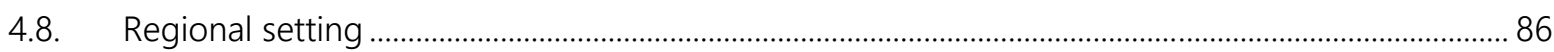

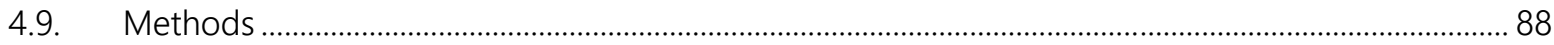

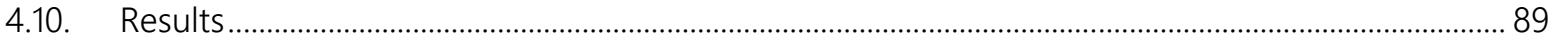

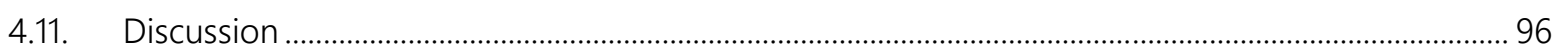

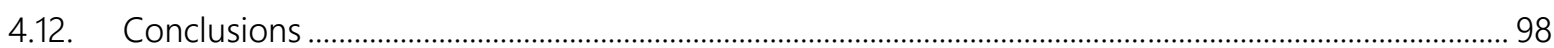


Chapter 5. Detecting problematic beach widths for the recreational function from subpixel shorelines........101

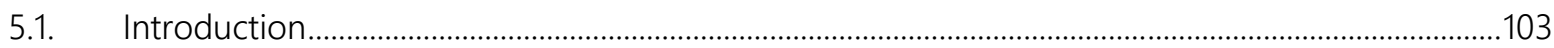

5.2. Study area

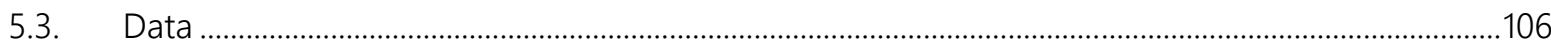

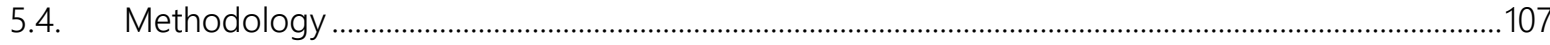

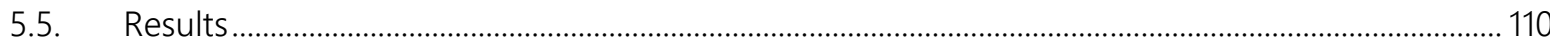

5.6. Discussion ……………………………………………………………………………………………… 119

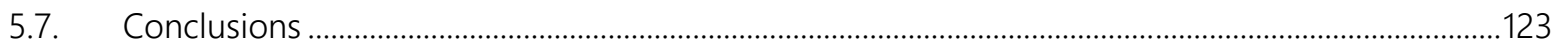

Chapter 6. Shoreline variability from Sentinel-2: an approach for estimating beach sediment size? ...............125

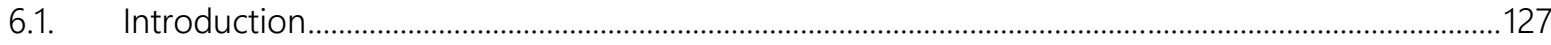

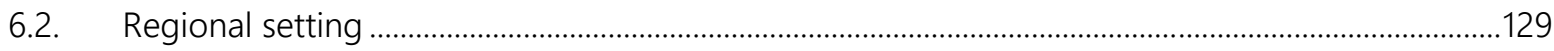

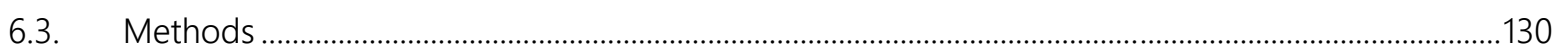

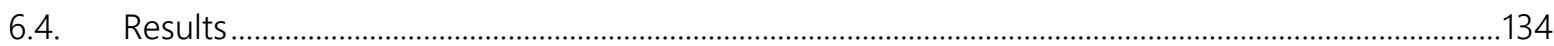

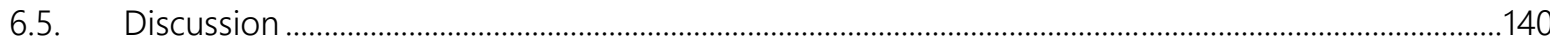

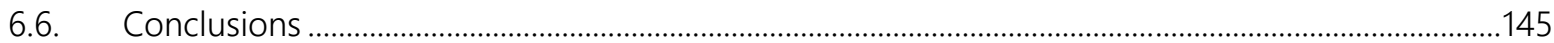

Chapter 7. Conclusions, management implications and future perspectives ....................................................147

7.1. The necessity of geomorphological indicators for improving beach management .......................149

7.2. Adaptation and validation of SDS extraction at different coastal types .........................................149

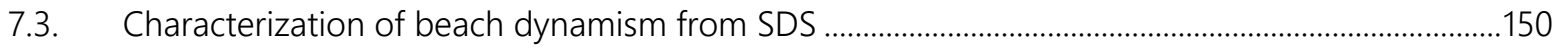

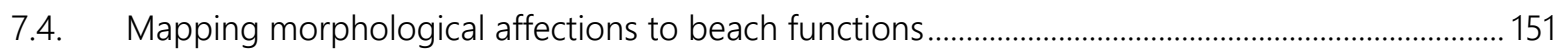

7.5. Exploring beach-face geomorphology from SDS variability .......................................................... 151

7.6. Future perspectives \& management implications .................................................................................. 151

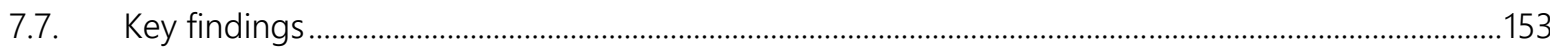

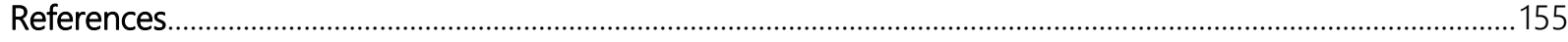

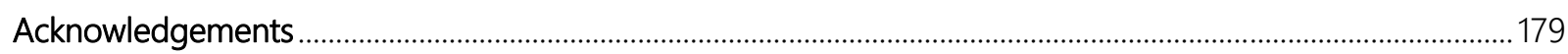

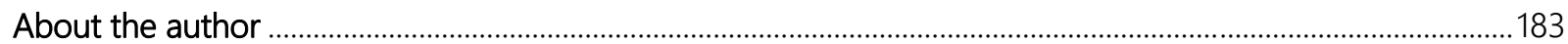





\section{Chapter 1}

\section{General Introduction}

"Sobre el color ala de mosca que envolvía todas las cosas había una línea azul que abría el horizonte. Esa línea no sólo era el mar como símbolo de la libertad y de la belleza, también era el destino final de todos los deseos y placeres. [...]

En verano el tranvía azul con jardinera llevaba a la playa de la Malvarrosa a una gente que todo lo que esperaba de la vida era el regalo de pasar un día en el mar."

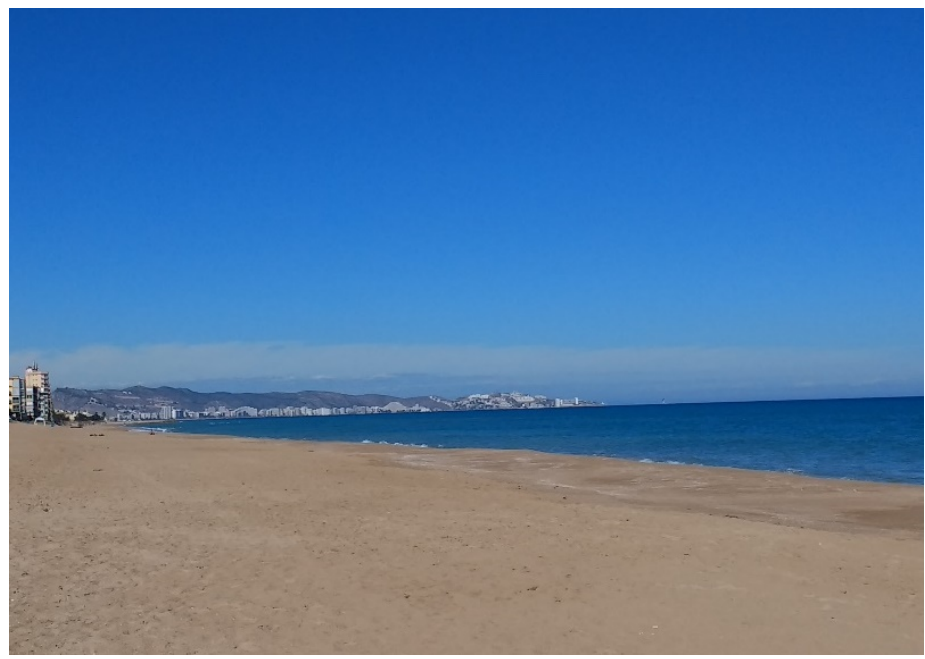





\subsection{Background and research justification}

Beaches are natural spaces that provide at least three key functions to coastal societies. Firstly, beaches are a type of coast that constitute some of the most diverse and productive ecosystems of the planet (Ray, 1988). They offer a unique habitat for a large variety of organisms (McLachlan \& Brown, 2006) and host numerous ecosystem services (Barbier et al., 2011). Due to the resources they provide, the coast has been intensively inhabited by humans for tens of thousands of years (Cooper \& Jackson 2019). Half of the world's population is currently living within $60 \mathrm{~km}$ from the shore, and this quantity is projected to continue growing (United Nations projections, 2015). Beaches offer protection as they act as a natural defensive system (Carter, 1988) safeguarding the hinterland and human settlements from direct wave action. In many regions of the world, the urbanization of coastal territories has increased in recent decades because of the recreational function of the beaches. This growth, particularly notable in the Mediterranean, is linked to the arrival of millions of tourists based on the 'sun, sea and sand' tourism, making this sector an essential economic resource of those regions (Alexandrakis et al., 2015).

\subsubsection{Beaches under climate change and human pressure}

Beaches are highly dynamic spaces that undergo changes at different spatial and temporal scales (Pardo-Pascual \& Sanjaume, 2001). They are under threat from a wide variety of human pressures (Brown \& McLachlan 2002; Schlacher et al., 2008) both direct and indirect. The associated effects can be noticeable in local settings or have a global reach (Defeo et al., 2009). Among those impacts, geomorphological changes may jeopardize the physical integrity of these spaces and the maintenance of their functions.

Naturally, coastal spaces experiment geomorphological changes on a scale of millions of years linked to global sea-level variations. However, the process may be accelerated by the human being through climate change and global warming phenomena. Recent research has reinforced concerns about a substantial sea-level rise (SLR) accelerated by global warming (Hinkel et al., 2018). From a morphological perspective, its main effect on the coast is erosion (Le Conzannet al., 2020). It is a global problem (Bird, 1996) that causes significant damage to ecosystems, economic loss, and societal problems such as infrastructure and property losses (EC, 2004). Sea-level rise is expected to increase its effects in the future, being stronger at gentle sloping coasts (Rao et al., 2008). It will bring great changes to the world's coastlands, leading to important retreatments or even the disappearance of numerous sandy beaches by the end of the century (Brooks et al., 2020; Vousdoukas et al., 2020a). Furthermore, it is expected that coastal flooding and erosive processes will increase linked to more frequent and of greater magnitude storms (IPCC, 2014; Schlacher et al., 2008). All this means that over the next few decades the problem of coastal erosion will only pose more challenges to the world's beaches.

Erosive processes are also caused by sedimentary imbalances at regional and local scales. Humans disturb coastal environments through indirect actions such as changes in land use, channel rigidification, dam construction, and regulation of water flows, all of them preventing the arrival of sediment from river basins to the coast (Willis \& Griggs, 2003). The existence of a sustained situation with more outputs than inputs to the coastal system causes a negative sediment budget 
and sediment scarcity in the littoral cell (Marchand et al., 2011). Besides, humans are creating direct impacts on the coastal environment by extracting sediment, occupying the beach-dune system, and building artificial obstacles to alongshore sediment transport (e.g. groins, jetties, breakwaters). All these can lead to fast and local unbalances to the sedimentary distribution along coastal cells. The Spanish Mediterranean constitutes a paradigmatic example of how human actions disturb coastal system and beaches (Morales et al., 2019).

Coasts, especially in the long term, are not necessarily in balance, but rather are evolving systems (Klein et al., 1998). Nevertheless, erosive processes linked to SLR in combination with the existence of the narrow beaches without possibilities for adaptation will increase the impacts on beach morphology and inner land (Jiménez et al., 2017). This combination of factors may jeopardize their capacity to accommodate the changes and to maintain their functions, being the case of many Spanish Mediterranean beaches.

\subsubsection{Current management practices and lack of appropriate information}

Given its environmental and economic importance, the problems faced by the beaches are tackled from different administrative scales. At the European level, European Union Recommendation on Integrated Coastal Zone Management (hereafter ICZM) and the Protocol on ICZM for the Mediterranean suggest adopting a proactive, strategic and integrated approach to the management of the coast, taking into consideration the coastal erosion problem (Marchand et al., 2011). In Spain, coastal protection is a responsibility of the Administration. It is explicitly included in the Coastal Law 22/1988, modified by Law 2/2013 of protection and sustainable use of coasts. The legislation indicates that the Administration is responsible for defining the Maritime Terrestrial Public Domain (DPMT), which includes beaches, and ensuring its integrity, conservation, protection, restoration, and adaptation according to climate change effects. Within the so-called Maritime Terrestrial Public Domain, decisions are taken by the Spanish Central Government, while the Regional Government is in charge of land-use planning outside that domain, while urban planning is a responsibility of the local municipalities (Muñoz, 2003; Ariza, 2011).

Erosive processes lead to beach losses that force managers to take action both in the short term (as a consequence of storm episodes) and in the long term (sustained sediment scarcity along some stretches of a coastal cell and, to a lesser extent, progressive sea-level rising). In regions such as the Mediterranean, the maintenance of the physical characteristics of beaches is a major concern for managers (Ariza et al., 2008a). This is because tourism industry, an important economic resource of coastal areas, strongly relies on beaches to attract tourists (White et al., 2010). Actions are generally aimed at maintaining the capacity of beaches to host leisure activities or, where this is not feasible, protecting coastal properties. The lack of criteria defining when and what actions are most appropriate, together with insufficient information on the response of beaches to the measures taken (Cooke et al., 2012; Palazón et al., 2016) and the gap between the data provided by scientists and the capacity of managers to implement them (EC, 2004) result in many inefficient actions. The standard practice is counteracting shoreline erosion with artificial nourishments that replace the eroded sand (Jiménez et al., 2017), sometimes accompanied by the construction of groins to stabilize the sediment. Many of these actions only offer local and short- 
term solutions to regional or global problems (Parkinson \& Ogurcak, 2018). Beach nourishment constitutes a more environmentally-friendly option than armoring the shore (Finkl \& Walker, 2004) the standard solution before the 1980s (Pardo-Pascual, 1991). Nevertheless, nourishments leave the problems unsolved, sometimes transferring or even aggravating the issues at down-drift beach segments. Their effectiveness is questioned even more considering their potential impact on both the habitat and the biota (Martin \& Adams, 2020; Schlacher et al., 2012; Speybroeck et al., 2006) together with their not negligible economic cost (Muñoz-Pérez, 2001; Parkinson \& Ogurcak, 2018).

\subsubsection{Indicators for a more efficient decision making}

Actions and adaptation strategies to face erosion should be based on updated characterizations of the coastal state. Improving beach management requires closing the existing gap between the acquisition of information on the environment and its utilization by the end-users (EC, 2004). Beach characterization must be carried out through objective parameters truly useful for decisionmaking processes. They must represent significant realities of the beach state in a simple and comprehensible way. With this purpose in mind, the Coastal State Indicators (CSIs) appear with the purpose of describing the dynamics and evolutionary trends of a coastal system in simple, appropriate, and quantitative terms (Archetti, 2009; Van Koningsveld et al., 2005). They constitute an essential management tool and a bridge between data acquisition and their application.

Considering the goal of maintaining beach functions, it is compulsory to understand the role that the different beach characteristics play in their performance. Among the different characteristics especially interesting are the geomorphological aspects as they are strictly linked to the physical maintenance of the space and the beach functions: the ecosystemic function through the density of living biota (Lastra et al., 2006); the recreational function by conditioning the capacity of hosting beachgoers (Cifuentes, 1992; Williams \& Micallef, 2009), influencing their perception (Rodella et al., 2017) and safety (Benedet et al., 2006); and the protective function by defining beach response to oceanographic action, the ability to dissipate waves, and to recover the morphology prior to storm episodes (Qi et al., 2010). Considering that, shoreline position and beach width appear as parameters potentially useful for describing the physical state of the beach in a simple and comprehensible way (Bernatchez \& Fraser, 2012). Together with them, beach slope and sediment grain size are fundamental (and interrelated) properties that condition the behavior of the beach (Bascom, 1951; Carter, 1988; Davidson-Arnott, 2010). Understanding the role of these geomorphological features in the beach functions will be a first step towards identifying indicators useful for management purposes.

The position of the shoreline appears as a main representative feature of the beach morphology, useful to describe its trends (Boak \& Turner, 2005). Shoreline changes may allow defining beach mobility (Dolan et al., 1978), which is related to its morphodynamic state (Short \& Hesp, 1982). Due to their potential usefulness, it is a parameter that has been employed to characterize the beach state, its dynamism, and for forecasting purposes (e.g. Hansen \& Barnard, 2010; Miller \& Dean, 2007; Mole et al., 2012; Stieve et al., 2002; Turki et al., 2013). However, the punctual and bidimensional measurements associated with the shoreline position may be insufficient to describe a dynamic and three-dimensional environment. On the one hand, shoreline position is affected 
by variations in beach morphology. It changes as a result of short-term cross-shore morphological changes (sometimes with seasonal patterns), but also because of cumulative/erosive trends that alter the volume of sediment on the beach in the long term (Farris \& List, 2007). On the other hand, the land/water interface is defined according to the total water level, which is conditioned by cyclic tides, instantaneous changes in oceanographic conditions (setup and runup), and to a lesser extent, long-term changes in SLR. Taking all this into account, different punctual shoreline position measurements are not always comparable. This makes it difficult to discern cyclical oscillations of the shoreline from seaward/landward trends when using a dataset with a limited volume of measurements.

Limitations of beach state indicators such as shoreline position are inherent in the techniques used to capture the information. Mapping techniques have evolved from ground-based surveys to air and space-based images (Morton, 1991). Traditional and moderately accurate methods such as land-based historical photographs, coastal charts, and maps have been replaced by beach surveys and remote sensing techniques (Boak \& Turner, 2005). Over the past few decades, DGPS field measurements have constituted a standard in-situ technique for highly-accurate characterization of beach morphology, although at expenses of being labor-intensive (Baptista et al., 2008; PardoPascual et al., 2005; Psuty \& Silveira, 2011). In contrast to this, remote sensing offers great spatial coverage photointerpretation of aerial photographies (Stafford, 1971), ortophotographies (Jones et al., 2009; Pajak \& Leatherman, 2002; Pardo-Pascual et al., 2019), and LIDAR (Pye \& Blott, 2016; Stockdon et al., 2002). These techniques provide coverage of large territories although they are limited temporarily. On the contrary, video-monitoring makes it possible to acquire highlyaccurate information continuously (Holman et al., 1993; Sánchez-García et al., 2017) allowing to study the response of the beaches along time (Angnuureng et al., 2017; Bouvier et al., 2017; Miller \& Dean, 2007; Sancho-García et al., 2013) or their topography (Andriolo et al., 2018; Vousdoukas et al., 2011) but on delimited segments. More recently, unmanned aerial vehicles (UAV) have appeared as a versatile tool for deriving three-dimensional datasets or ortophotographies that allow analyzing changes of certain places at desired moments (Casella et al., 2016; FernándezSarría et al., 2018; Gonçalves \& Henriques., 2015; Turner et al., 2016). Although these remote sensing techniques avoid or minimize fieldwork, data acquisition is spatially and/or temporally restricted.

Thus, although scientific knowledge and techniques have recently experienced significant development, there exist limitations concerning data and observations that make it difficult to apply the best management solutions (Marchand et al., 2011). The absence of up-to-date and continuous data collection systems applicable to large territories and homogeneously along the world's coasts has contributed to heterogeneous decision-making supported by diverse data sources.

Among remote sensing techniques, satellite imagery stands out as an extremely useful alternative for coastal monitoring given its large planetary coverage and high-revisited frequency (Castelle et al., 2015; Vandebroek et al., 2017). This technique has the potential to overcome the limitations in temporal or spatial coverage shown by other techniques (Do et al., 2018). This is especially 
important considering the large dimensions and dynamism of the beaches, as well as the fact that erosion is a phenomenon that operates at a wide variety of scales and makes it necessary to foster a holistic approach (Ballesteros et al., 2018; Marchand, 2010).

Remote sensing may become a real opportunity to improve beach management efficiency. However, to make this happen it is necessary to close the gap that exists between the acquisition of the information and its use by end-users, the coastal managers (EC, 2004). The information supplied by the satellite images must be derived into objective indicators truly useful for decisionmaking processes. Providing information as the shoreline position can contribute to mitigate the lack of data on the coastal environment.

Over the past few years, the mapping of the water/land interfase has been pursued in different works (e.g. Chen \& Chang, 2009; Foody et al., 2003; Gens et al., 2010; Ghosh et al., 2015; Luijendijk et al., 2018; Wang et al., 2010). The identification of the shoreline position from satellite imagery (Satellite-Derived Shorelines, hereafter SDS) has been mainly sustained from the mid-resolution Landsat series and Sentinel-2 due to the robustness of the missions, with worldwide coverage and long-term perspectives. At the present time, both sets of images are freely available from the United States Geological Survey (USGS) and Copernicus program of the European Space Agency (ESA) and offer high revisit frequencies (16 and 5-day revisit for Landsat 5, 7, 8, and Sentinel respectively). These images allow defining SDS covering large territories and periods. This large abundance of SDS data can overcome the lack of representativeness attributed to punctual measurements of the shoreline position that traditional techniques allow, also providing data at areas that would otherwise not be monitored.

Based on the different spectral responses water and land offer in the infrared band, an algorithm has been developed by the Geo-Environmental Cartography and Remote Sensing Group (CGAT) to identify the position of the shoreline (Pardo-Pascual et al., 2012, Almonacid-Caballer, 2014). This algorithmic solution defines SDS with sub-pixel accuracy, overcoming the restrictions caused by the coarse pixel size of those satellite images (pixel size of 10 to $30 \mathrm{~m}$ ). Taking this algorithm as its core, the SHOREX system offers a complete and efficient workflow capable of processing a large volume of images and defining their associated shorelines (Palomar-Vázquez et al., 2018; SánchezGarcía et al., 2020). SDS obtained by this method show subpixel accuracy close to $3 \mathrm{~m}$ (3.04 m and $3.57 \mathrm{~m}$ RMSE for Sentinel-2 and Landsat-8 imagery respectively, according to Sánchez-García et al., 2020).

However, the evaluation of SDS obtained by this method has been restricted to low energy, microtidal Mediterranean beaches. Similarly, the methodological proposals carried out by other authors on different tidal conditions have been scarcely evaluated (e.g. Hagenaars et al., 2018; Liu et al., 2017; Vos et al., 2019a), offering worse accuracy levels. Therefore, there is a lack of adaptation of SDS extraction, comprehension of the exact morphological reality they represent, and evaluation of their accuracy at and exposed or energetic beaches. These tasks are necessary to ensure an adequate representativity of the shoreline and to validate the use of SDS as indicators of the beach state. 
SDS constitute by themselves indicators of the punctual state of the beaches. Nevertheless, the ensemble formed by large datasets of SDS could be representative of the beach variability. These packages may offer more complex information than individual positions of the shoreline, as well as being complementary to them. This is in line with Almonacid-Caballer et al. (2016) that proposed the annual mean shoreline position as a robust indicator of mid-term beach changes.

Herein lies the challenge of developing methodologies to take advantage of long series of midresolution satellite images, to efficiently define SDS, and from them, to derive other useful indicators for managers. SDS packages open up the possibility of monitoring beach changes at a wide variety of scales. This could allow studying the short-term response of the beach to disruptive events (either natural or human) or long-term trends from a holistic approach. With this regard, it will be necessary to evaluate until which point the accuracy of SDS and the derived indicators allow recognizing and quantifying the effects of the different events on beach morphology. Mapping these indicators along the coast may provide support for decision-making. Their integration with pre-existing databases would enable identifying segments in which beach functions are jeopardized. This information may be essential for prioritizing actions. Finally, an accurate characterization of shoreline variability from SDS would allow exploring its relationship with geomorphological characteristics as beach-face slope and sediment grain size.

\subsection{Thesis aim and outline}

The abovementioned shows the existence of gaps in the availability of morphological data that impede a more efficient management of the beaches. Remote sensing and especially satellite imagery constitute sources of data that may enable to define indicators for improving the characterization of these spaces.

The main goal of this research is to employ remote sensing sources of data and geomatics for obtaining, organizing, and integrating data about beach characteristics to define homogeneous and updated indicators of the beach state at a regional scale. They will allow monitoring beach changes both in the short term (sub-annual) and in the mid-term (decades), increasing the scientific knowledge of these spaces and assisting the decision-making processes. All this is expected to contribute to shifting towards a more efficient and integrated management of the coast and the beaches.

This research aims to derive methodologies and offer solutions with worldwide applicability. Having in mind this global perspective, the accuracy of the SDS extraction methodology is tested at the exposed and mesotidal coast of Algarve (south Portugal). The goal of this test is to evaluate the reliability of this source of data in a challenging environment, allowing to discuss their applicability under different environmental conditions at different beach typologies. At the same time, different research questions have been addressed at the Gulf of Valencia (Eastern Spain, Mediterranean Sea, microtidal coast). Those analyses have made it possible to develop, apply and assess the proposed methodologies at beaches with different geomorphological characteristics, erosion/accretion trends, and in which the human interventions and recreational usage condition the management and the behavior of the beaches. 


\subsubsection{Document structure}

The dissertation is divided into 7 Chapters, being the first one a general introduction, and the final one the synthesis of the research. Taking as their core the compilation of articles listed below this section, chapters 2 to 6 constitute the body of the research (Fig. 1.1). Each chapter tries to answer one research question and to validate the associated hypothesis by addressing certain objectives, being all of them defined in the next section.

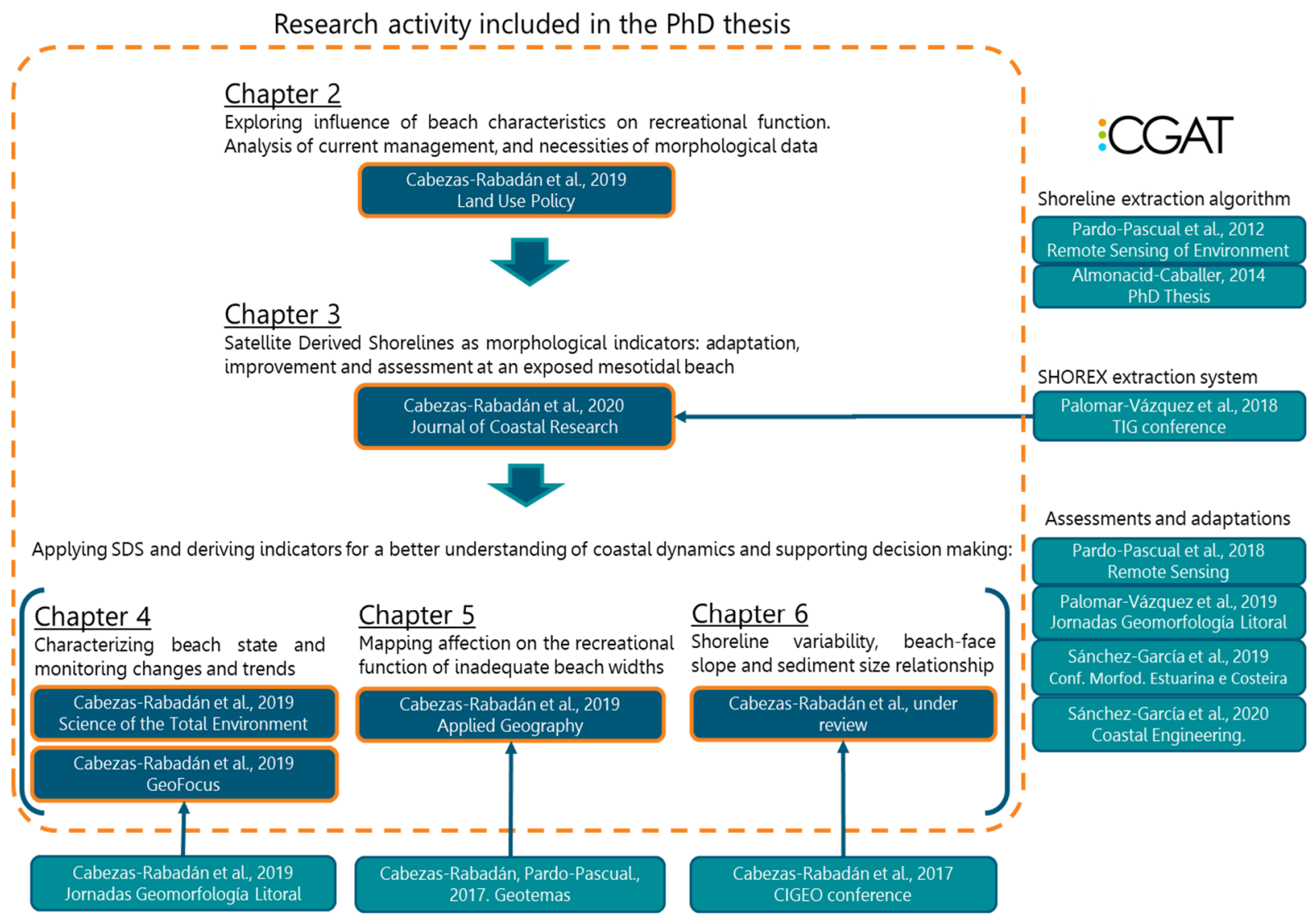

Fig. 1.1. Diagram of publications that constitute the dissertation (in dark blue and surrounded by orange) together with other complementary works carried out by the candidate and CGAT researchers (turquoise). 
Chapter 2 deals with the influence of beach characteristics on beach functions. It focuses on the recreational function through users' preferences, perceptions, and expectations, paying special attention to beach morphology. The current beach management and the availability of morphological data are critically analyzed. These issues were addressed by analyzing Valencian beaches of different typology, and has led to a publication in the journal 'Land Use Policy'.

Chapter 3 deals with the adaptation and assessment at an exposed mesotidal beach of the shoreline extraction system SHOREX (Palomar-Vázquez et al., 2018). The work assesses the extracted shorelines against close GNSS field data at the barrier beach of Faro (South Portugal). It constitutes the first validation of SDS at a beach with these characteristics considering a significant number of points/profiles and hydrodynamic conditions. The obtained accuracy is compared with previous evaluations at microtidal beaches, and the potential utility of SDS extracted with the system SHOREX at new beach types is discussed. The work derives from a research stay in the Universidade do Algarve (Portugal) with the collaboration of Ó. Ferreira and S. Costas from the host institution, and has led to a publication in the 'Journal of Coastal Research'.

Chapter 4 applies SDS for characterizing the beach state and its changes. The chapter tests the potential for obtaining useful data for monitoring the beach response to natural events and anthropic interventions on two temporal and geographical scales: (i) In high temporal detail using Sentinel-2 covering a large coastal segment along one and a half years, leading to a work published in the journal 'Science of The Total Environment'; and (ii) describing medium-term (three decades) changes on three beaches using Landsat images, leading to a publication in the journal 'GeoFocus'.

Chapter 5 applies SDS for characterizing beach width and its variability throughout the year to define the affection of the recreational function of the beaches. The intra-annual variability was quantified through statistical descriptors considering changes in the shoreline position throughout the year. This information was linked with two public and open national databases allowing to map segments in which beach width negatively affects the recreational function throughout the year. This work has led to a publication in the journal 'Applied Geography'.

Chapter 6 deals with the definition of the shoreline variability from Sentinel-2 imagery, and explores its relationship with beach-face slope and sediment grain size. It also discusses the potential estimation of sediment grain size characteristics from shoreline variability defined from SDS.

Chapter 7 gathers the main conclusions of the research, implications for coastal management that can be derived, and different lines for future research.

Apart from these chapters, several works comprise significant preliminary or complementary work to them (articles in the journal 'Geotemas', and conferences 'CIGEO' and 'Jornadas de Geomorfología Litoral'). Although they have not been included in the dissertation, they are cited and discussed both at the corresponding chapters and the general synthesis. 
This thesis has been conducted within the activity of the CGAT research group (Fig. 1.1). Shoreline extraction algorithms (Pardo-Pascual et al., 2012; Almonacid-Caballer, 2014) were developed before this thesis. In parallel to it and with the collaboration of the candidate, different tools for managing and processing the satellite imagery and remote sensing raw data have developed. Especially remarkable is the system SHOREX for the shoreline extraction (Palomar-Vázquez et al., 2018). The resulting SDS have been assessed in different environments (Palomar-Vázquez et al., 2019; Sánchez-García et al., 2019, 2020). Thus, the definition of shoreline extraction techniques remains outside the framework of the thesis. The present thesis is complementary to these works as it aims to apply these algorithms and solutions for defining methodologies able to derive geomorphological information useful to improve beach management according to current necessities (chapter 2). However, the thesis includes the adaptation, assessment, and validation at new coastal environments of SDS and the derived information (chapter 3), while SDS constitute basic data for different applications (chapters 4 to 6 ).

It is important to remark that not all the works that apply SDS (Chapters 4-6) have extracted them following the same methodology. In turn, it was used the most accurate methodology already assessed for the time each work was carried out (Fig. 1.2). Thus, the application works published in 'GeoFocus' (Chapter 4) and 'Journal of Applied Geography' (Chapter 5) employed SDS defined according to Pardo-Pascual et al. (2018). On the contrary, the work published in 'Science of the Total Environment' (Chapter 4) and the one currently under review (Chapter 6) considered SDS extracted according to the improvements of the SHOREX system proposed by Sánchez-García et al. (2020), that offer a slightly higher accuracy. The work published in the 'Journal of Coastal Research' (Chapter 3) assesses SDS at a new environment outside the Mediterranean in an attempt to validate the employment at different beach types of both SDS and the associated applications.

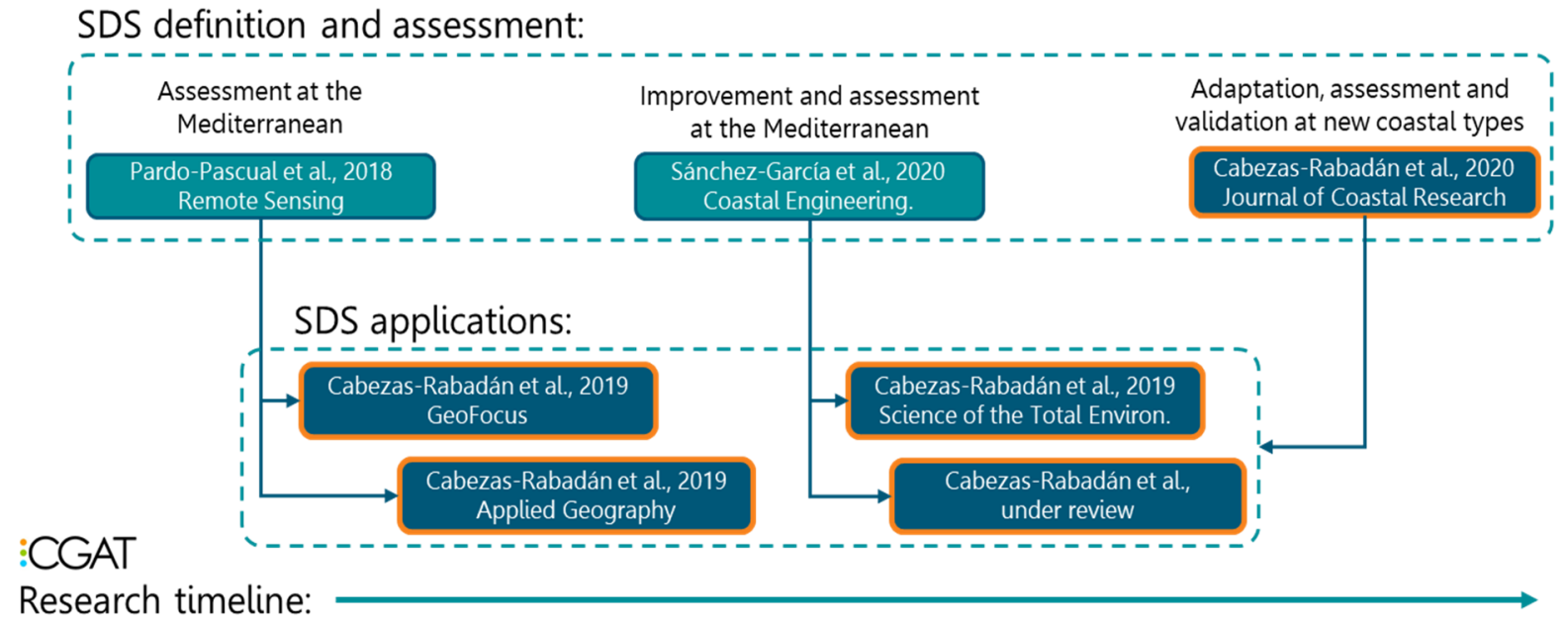

Fig. 1.2. Chronological diagram of the research activity related to shoreline extraction and its application. The publications included in this thesis appear surrounded by orange. 


\subsubsection{Research questions, hypothesis, and objectives}

Linked to the main goal of this thesis the following research questions were defined:

A. How do beach characteristics condition the recreational function? Which morphological information may be of interest for improving the management? Is the current management adapted to beach characteristics? (Chapter 2)

B. Is it possible to define Satellite-Derived Shorelines from Landsat and Sentinel imagery? With which accuracy and limitations? Which morphological reality do SDS represent? (Chapter 3)

C. Is it possible to characterize the morphological state of the beaches and their changes from SDS? What spatial and temporal coverages do they offer? (Chapter 4)

D. Can morphological state indicators derived from SDS be used to map the affection of an inadequate morphology to the recreational function of beaches? (Chapter 5 )

E. Which relationship does shoreline variability have with beach-face slope and sediment grain size? Is it possible to estimate sediment size from remote sensing? (Chapter 6 )

Hypothesis:

A. Decision-making processes lack of enough criteria to rigorously define the needed actions. It follows a rigid and homogeneous approach that ignores the particular aspects and values of the different beaches. It is expected that several beach aspects as its width and sediment type play a significant role in conditioning the recreational function through users' perceptions and expectations. (Chapter 2)

B. Shoreline extraction may be carried out from mid-resolution satellite imagery at as mesotidal and exposed beaches. It is expected that SDS accuracy will be affected by oceanographic conditions, but will remain high enough to constitute a useful source of beach-face morphological data. (Chapter 3 )

C. Large packages of Satellite-Derived Shorelines may be efficiently extracted and managed at a regional scale to be used as descriptive beach state indicators. They may allow to characterize the morphological state of the beaches and their short-term changes with sufficient accuracy to monitor storm episodes and anthropogenic actions. (Chapter 4)

D. SDS may allow to define the sub-annual variability of the beach width. In combination with data of the beach use it may be possible to map sections in which the morphology interferes with the maintenance of the recreational function. (Chapter 5 )

E. There is a relationship among the grain size of the sediment, beach-face slope, and shoreline changes in the shoreline. Quantifying shoreline variability will offer information about the other geomorphological parameters. (Chapter 6 ) 
In order to validate the previous hypothesis the following objectives were proposed:

\section{Chapter 2}

A.1 - to determine how different beach characteristics condition the recreational function through the perceptions and expectations of beachgoers.

A.2 - to define to what extent beach management is adapted to particular characteristics of each beach.

A.3 - to explore how geomorphological and physical characteristics affect the recreational function, and which challenges they bring to management.

A.4 - to determine if and how the availability of more beach morphology data could be beneficial for decision making.

\section{Chapter 3}

B.1 - to adapt and improve the shoreline extraction methodology from Landsat 8 and Sentinel 2 imagery to different coastal environments as mesotidal exposed beaches.

B.2 - to assess the accuracy of the extracted shorelines on real scenarios by comparing them against high-precision validation data obtained on close dates or simultaneously.

B.3 - to determine sources of error and limitations of the SDS in order to define potential applications and methodological improvements.

\section{Chapter 4}

C.1 - to derive the Beach Width (BW) from SDS as an intuitive indicator for describing beach morphology.

C. 2 - to create a spatiotemporal model of BW and its changes as an intuitive representation of the state of the beach morphology along time and space.

C.3 - to determine if SDS obtained from Sentinel-2 allow to monitor along wide coastal segments short-term changes as the response to storms and anthropogenic actions.

C.4 - to assess if SDS obtained by the combination of the imagery of different Landsat missions allow analyzing beach changes and trends on the mid-term, covering three decades.

\section{Chapter 5}

D.1 - to define intra-annual variability of the shoreline from SDS using statistical indicators.

D.2 - to identify beach segments where width may be inadequate for recreational function.

D.3 - to define the recreational function of the different beaches from open databases about beach use and equipements.

D.4 - To integrate the indicators of adequacy of the width of the recreational function, as well as to categorize the affection according to the width measurements recorded throughout the year. This will allow to define cartography at a regional scale as support information for prioritizing the need for measures for maintaining the recreational function.

\section{Chapter 6}

E.1 - To define the shoreline variability from SDS and explore its relationship with beach-face slope and sediment grain size.

E.2 - to examine the effect of using different proxies, shoreline segment lengths, and amount of SDS for defining the shoreline variability, as well as the role of the oceanographic conditions.

E.3 - to discuss the potential for estimating sediment grain size from shoreline variability. 


\subsubsection{Articles that constitute this dissertation}

This compilation of papers has the approval of co-authors, and meets the requirements of the Universitat Politècnica de València for a Ph.D. dissertation.

\section{Chapter 2}

Cabezas-Rabadán, C., Rodilla, M., Pardo-Pascual, J.E., Herrera-Racionero, P. (2019a). Assessing user's expectations and perceptions on different beach types and the need for diverse management frameworks along the Western Mediterranean. Land Use Policy, 81, 219 - 231. ISSN 0264-8377. https://doi.org/10.1016/j.landusepol.2018.10.027

\section{Chapter 3}

Cabezas-Rabadán, C., Pardo-Pascual, J.E., Palomar-Vázquez, J., Ferreira, Ó., Costas, S. (2020). Satellite derived shorelines at an exposed meso-tidal beach. In: Malvárez, G. and Navas, F. (eds.), Global Coastal Issues of 2020. Journal of Coastal Research, Special Issue No. 95, pp. 1027-1031. Coconut Creek (Florida), ISSN 0749-0208. https://doi.org/10.2112/SI95-200.1

\section{Chapter 4}

Cabezas-Rabadán, C., Pardo-Pascual, J. E., Palomar-Vázquez, J. M., Fernández-Sarría, A. (2019b). Characterizing beach changes using high-frequency Sentinel-2 derived shorelines on the Valencian coast (Spanish Mediterranean). Science of The Total Environment, 691, 216-231. https://doi.org/10.1016/j.scitotenv.2019.07.084

Cabezas-Rabadán, C., Pardo-Pascual, J.E., Palomar-Vázquez, J., Almonacid-Caballer, J., FernándezSarría, A. (2019c). Monitorización de la respuesta de playas Mediterráneas a temporales y actuaciones antrópicas mediante imágenes Landsat. GeoFocus. No 23. http://dx.doi.org/10.21138/GF.640

\section{Chapter 5}

Cabezas-Rabadán, C., Pardo-Pascual, J. E., Almonacid-Caballer, J., Rodilla, M. (2019d). Detecting problematic beach widths for the recreational function along the Gulf of Valencia (Spain) from $\begin{array}{lllll}\text { Landsat } & 8 & \text { subpixel shorelines. }\end{array}$ https://doi.org/10.1016/j.apgeog.2019.102047

\section{Chapter 6}

Cabezas-Rabadán, C., Pardo-Pascual, J. E., Palomar-Vázquez, J. M. (Under review in the journal 'Marine Geology'). Shoreline variability from Sentinel-2: an approach for estimating beach sediment size? 


\subsubsection{Affiliations of co-authors}

Almonacid-Caballer, Jaime
Fernández-Sarría, Alfonso
Palomar-Vázquez, Jesús
Pardo-Pascual, Josep E.

Herrera-Racionero, Paloma

Rodilla, Miguel

Costas, Susana

Ferreira, Óscar
CGAT Research Group Dept. Cartographic Engineering, Geodesy \& Photogrammetry Universitat Politècnica de València Valencia, Spain

Institut d'Investigació per a la Gestió Integrada de Zones Costaneres Universitat Politècnica de València Grau de Gandia, Spain

CIMA - Centre for Marine and Environmental Research, FCT Universidade do Algarve Faro, Portugal

\section{Copyright disclaimer}

The present Ph.D. dissertation is an edited compilation from the listed papers listed below with the approval of co-authors. This compilation satisfies the Ph.D. requirements of the Universitat Politècnica de València 



\section{Chapter 2}

\section{Assessing user's expectations and perceptions on different beach types and the need for diverse management frameworks}

The content of this chapter has been published as:

Cabezas-Rabadán, C., Rodilla, M., Pardo-Pascual, J.E., Herrera-Racionero, P. (2019). Assessing user's expectations and perceptions on different beach types and the need for diverse management frameworks along the Western Mediterranean. Land Use Policy, 81, $219-231$. ISSN 0264-8

"Plantem les tovalloles, convido a un gelat juguem a pala grega, esquivant passejants

a l'horitzó es divisen les veles

d'uns nens que fan optimist a la cala del costat $[\ldots]$

És abusiva tanta calor

t'incorpores i et poses bé el banyador amb el peu calcules com està l'aigua

i tot està llest per tal que entrem al mar [...]

Molt lluny d'aquí, a l'altra banda del món hi ha un xiringuito amb quatre pins al fons

tu i jo asseguts a la barra d'un bar sona bona música i som davant del mar"

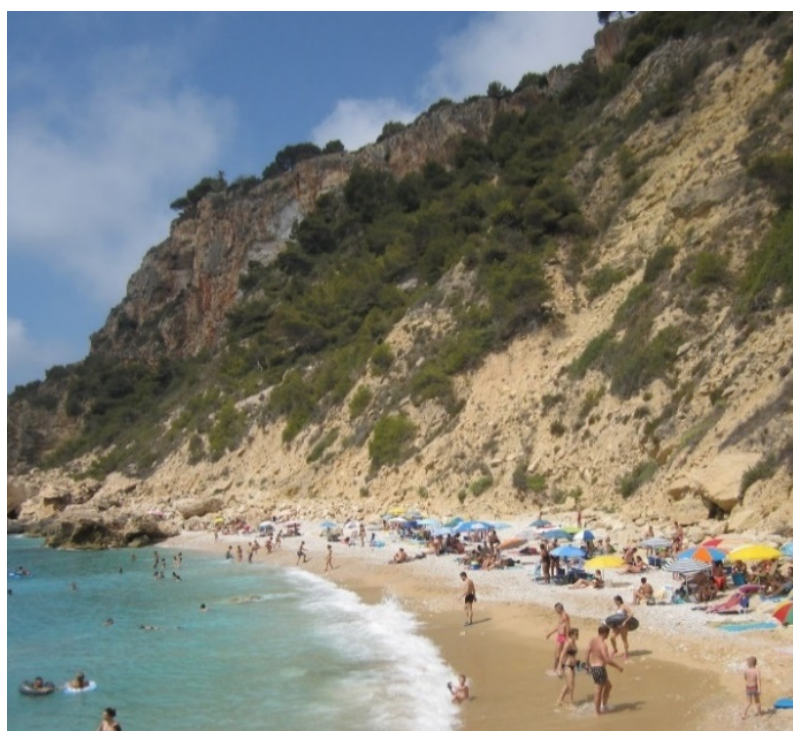


Understanding the role beach characteristics play on the performance of beach functions is essential to offer proper management of these spaces.

Considering the socio-economic importance the recreational function has for coastal societies, it is of interest to identify differences in the recreational function from beachgoers perspective in relation to beach characteristics. At the same time, it is important to determine whether the current management responds adequately to the diversity of aspects that appear along the coast. Although different works have dealt with the recreational quality of beaches through issues as users' density, frequentation and crowding, opinions, perceptions, and expectations, the vast majority have been focused on urban, mass tourism-oriented, sandy beaches without considering beaches with different characteristics.

This chapter aims to define users' profiles, expectations and perceptions on six Valencian beaches with both different degree of artificialization and sediment type, establishing a comparison between semi-natural and urban beaches, and between pebbly and sandy beaches. Differences between beach types and characteristics are observed, and a critical analysis of the current management framework and practices, as well as their limitations, is carried out.

Results show how beach management follows a homogeneous and rigid decision-making process that tries to fulfill expectations assumed from mass tourism without really getting to know the real users' perception. Decisions are usually taken without considering the diversity of values of the beaches, leading to impacts on the environment and the function and recreational potential of beaches. Management actions should be adapted to the diversity of beaches and their particularities, leading to a differential beach management. Considering the influence that certain aspects as beach physical characteristics have on the recreational function, the availability of more morphological data would be helpful for the decision-making on these spaces. 


\subsection{Introduction}

Beaches present a great diversity in their degree of development, anthropogenic pressure, touristic exploitation, conservation, sediment type and geomorphology. Some characteristics, such as physical aspects, landscape, flora and fauna can enhance the potential attractiveness of the beaches (Micallef \& Williams, 2002). They bring great economic benefits to society because of their recreational value (Gormsen, 1997; Sardá et al., 2009), by developing a tourism sector based on the 'sun, sea and sand' resource. In the Mediterranean, 500 million tourists per year are forecasted for 2030 (UNWTO, 2013). This means that on coasts such as Valencian, in the Western Mediterranean, tourism constitutes an essential economic product (Obiol-Menero \& PitarchGarrido, 2011; Yepes \& Medina, 2005) that guides the coastal policies and decision-making.

This takes place in a context in which climate change and rising global temperatures are altering hydrodynamics and rising sea levels, affecting coastlines and increasing beach erosion (Bird, 1996; Gössling \& Hall, 2006; Nicholls \& Cazenave, 2010; Slott et al., 2006). That is the case of Valencian coast, affected by erosion over $26 \%$ of its length (EC, 2009). These phenomena affect the basic resource that sustains tourist activity since the beach width required for user comfort is reduced or disappears (Valdemoro \& Jiménez, 2006). Given their importance, and in order to maintain the benefits of the recreational use of beaches (Alexandrakis et al., 2015), erosion processes receive great attention from coastal managers. There are numerous nourishment projects and implementation of hard structures as protection measures against coastal and beach erosion, which entail the consequent economic cost and environmental impact (Aragonés et al., 2015; Peterson \& Bishop, 2005; Rumbold et al., 2001; Speybroeck et al., 2006). In Spain, competences over the coast are distributed at local and national level (defined by the Spanish Coastal Law $2 / 2013)$. The physical maintenance of the beaches is taken at a national level, with nourishments focused on maintaining the beach size (Hanson et al., 2002). On the contrary, municipalities are responsible for managing the facilities and supplying the equipment, usually following beach award standards (Mir-Gual et al., 2015). Management may affect both the recreational function of the beaches (Ariza et al., 2010; Roca \& Villares, 2008; Williams \& Micallef, 2009) and the environment. As an example, this may happen with the seagrass residues removal (Cocozza et al., 2011; Duarte, 2004).

Beaches should be managed as the complex systems they are, guaranteeing the integrity of their natural values while ecological services are provided (Sardá et al., 2015), following an Ecosystem Approach (Olsen et al., 2009). Nevertheless, in many cases, the current management does not accomplish the environmental policy principles (Katsanevakis et al., 2011), and decisions are taken exclusively from the recreational point of view (Ariza et al., 2008a; James, 2000; Sardá et al., 2015). A priori, the offer of facilities and equipment is made according to users' attendance, preferences, and needs (Peña-Alonso et al., 2018). However, managers infer users' desires without really knowing their opinion before adopting changes (Nelson et al., 2000). Therefore, decision-making follows a non-inclusive and rigid process (Areizaga et al., 2012) with local vision and short-term perspective. Decisions try to please the mass tourism industry, receiving important pressure from the private sector and other influential stakeholders policy (Bramwell, 2011). This management 
model entails homogenization of the beaches (Lozoya et al., 2014), applying similar measures despite the diverse nature and different sediment type. These actions promote a tourism model where environmental care is a secondary concern (Obiol-Menero \& Pitarch-Garrido, 2011), damaging and overexploiting the coast (Amelung \& Viner, 2006; Sardá et al., 2009).

Therefore, for a management adapted to beaches' diversity it is fundamental to have more information about their environment and users. Regarding the beach as a physical space, up-todate knowledge of the width is essential for determining the available surface area, the carrying capacity (Cifuentes, 1992; Williams \& Micallef, 2009), and thus, to deal with density and overcrowding issues. With regard to users, it is necessary to know their affluence, but also their profile, interests, expectations, and opinions about the management measures adopted (Rodella et al., 2017). As stakeholders, their participation is essential for an Integrated Coastal Zone Management (ICZM) (Areizaga et al., 2012) with sustainable results (Milligan et al., 2009; Schmidt et al., 2013). Different studies have tried to answer the previous questions: some works have been carried out on recreational quality of beaches (Ariza et al., 2010; Peña-Alonso et al., 2018; Williams \& Micallef, 2009), and dealing with users' density, frequentation and crowding (Chen \& Teng, 2016; DeRuick et al., 1997; Pereira da Silva, 2002; Roig-Munar, 2003; Sardá et al., 2009). Other authors have tried to define their opinions, perceptions and expectations (Alves et al., 2014; Cervantes et al., 2008; Lozoya et al., 2014; Marin et al., 2009; Mas-Parera \& Blázquez-Salom, 2005; Monioudi et al., 2017; Roca \& Villares, 2008; Rodella et al., 2017; Vaz et al., 2009). However, the vast majority of the studies focus on urban sandy beaches, without considering beaches with different substrate or artificialization degree. On the Valencian coast, despite the importance the tourism has for the region's socioeconomics, studies of this nature are extremely scarce.

The objectives of this study are to identify differences in the expectations and perceptions of the users on different beach types, as well as to determine whether the current management responds adequately to this diversity.

\subsection{Description of the beaches}

Six Valencian beaches, on the Eastern coast of the Iberian Peninsula, were selected as representatives for this study. All six beaches have both different sediment size and artificialization degree in order to allow a comparison between different beach types (Fig. 2.1, 2.2). 


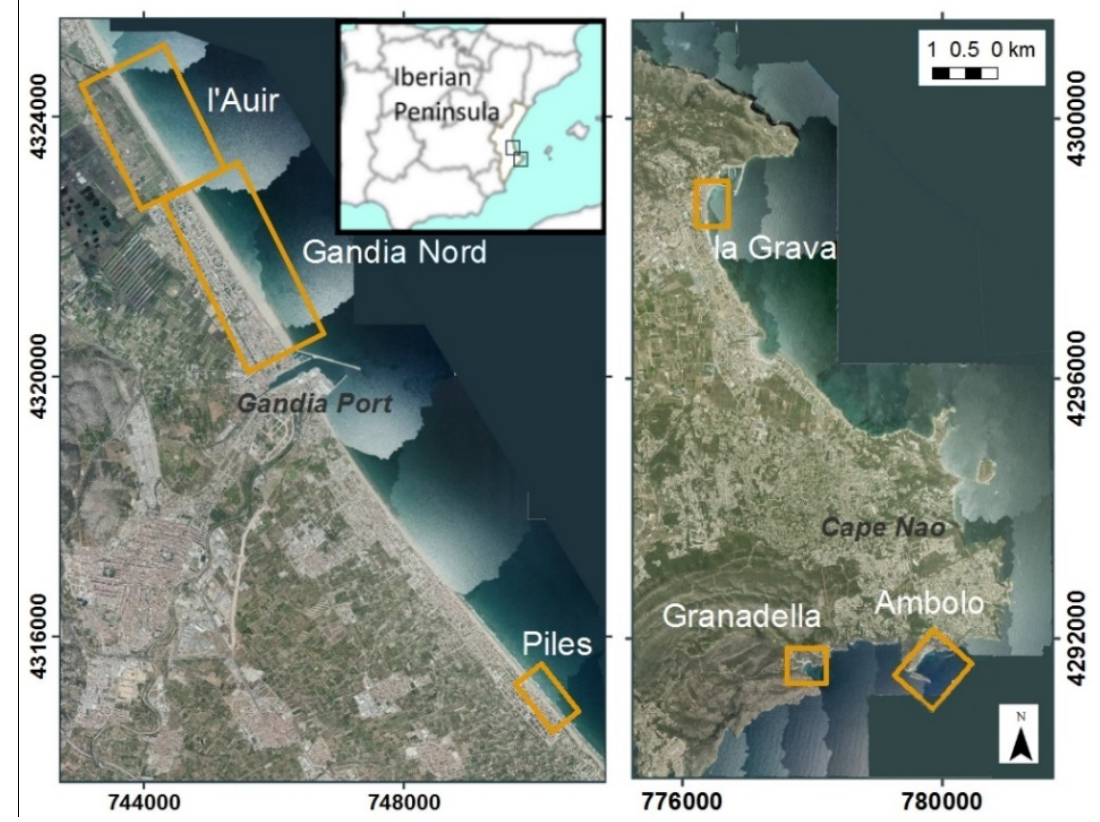

Fig. 2.1. Location of the six beaches assessed. Valencian coast, Western Mediterranean (ETRS89 UTM30N).

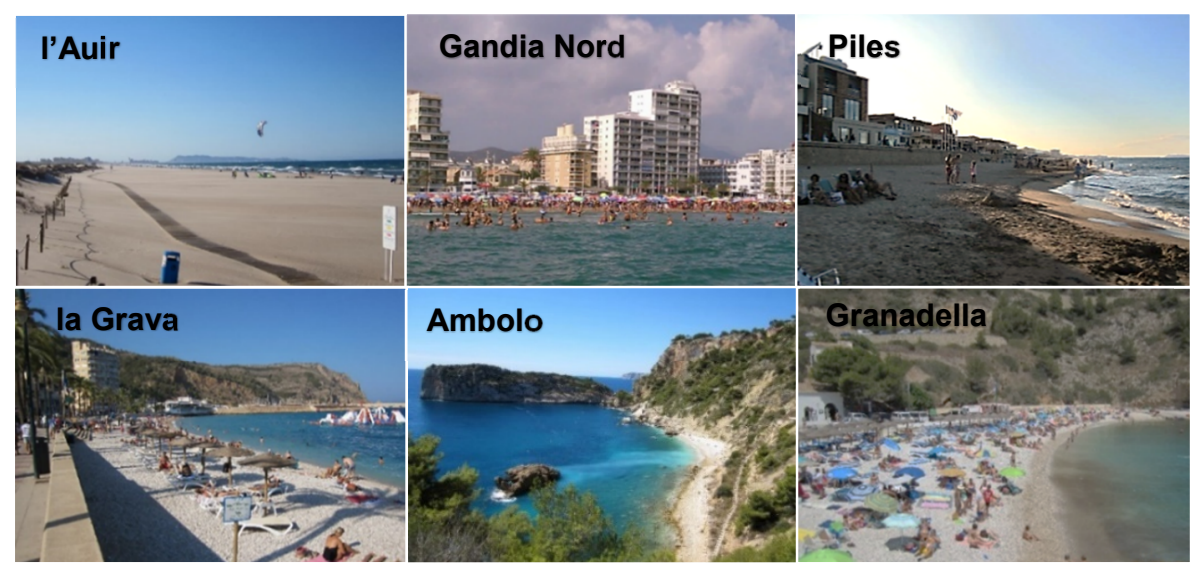

Fig. 2.2. Studied beaches: I'Auir, Gandia Nord, Piles, la Grava, Ambolo and Granadella.

Beaches were classified based on beach features, facilities and surroundings. These aspects were defined from the information available in the Spanish Catalogue of Beaches (MAPAMA, 2017), by fieldwork, and by a GIS analysis of the land use in the coastal hinterland (Table 2.1). Urban and semi-natural beaches were distinguished according to their degree of artificialization. Urban beaches were defined as those located in dense urban areas, with easy access and touristic accommodations, high level of services, and limited by a promenade. On the contrary, seminatural beaches are those with scattered settlements in the hinterland, low level of touristic facilities and accessibility, and without promenade. These criteria are in line with previous beach classifications (Ariza et al., 2008a; Roca \& Villares, 2008; Vaz et al., 2009). At the same time, beaches also have been classified according to the sediment size between sandy and pebbly beaches. 
Table 2.1. Beach classification and main characteristics. The information has been partly obtained from the Catalogue of beaches (MAPAMA, 2017).

\begin{tabular}{|c|c|c|c|c|c|c|}
\hline Beach & l'Auir & Gandia Nord & Piles & La Grava & Ambolo & Granadella \\
\hline Municipality & Gandia & Gandia & Piles & Xàbia & Xàbia & Xàbia \\
\hline Sediment & Sand & Sand & Sand & Pebbles & Pebbles & Pebbles \\
\hline Artificialization & Semi-natural & Urban & Urban & Urban & Semi-natural & Semi-natural \\
\hline Coastal front & Dunes & $\begin{array}{c}\text { Dense } \\
\text { urbanization }\end{array}$ & $\begin{array}{c}\text { Dense } \\
\text { urbanization }\end{array}$ & $\begin{array}{c}\text { Dense } \\
\text { urbanization }\end{array}$ & Cliff & Mountains \\
\hline $\begin{array}{l}\text { Length } \mathrm{x} \text { mean } \\
\text { width }(\mathrm{m})\end{array}$ & $1760 \times 70$ & $3000 \times 80$ & $1160 \times 25$ & $500 \times 16$ & $150 \times 15$ & $200 \times 20$ \\
\hline Blue Flag & No & Yes & Yes & Yes & No & Yes \\
\hline Promenade & No & Yes & Yes & Yes & No & No \\
\hline Barrier-free & No & Yes & Yes & No & No & No \\
\hline $\begin{array}{c}\text { Public } \\
\text { transport }\end{array}$ & No & Yes & Yes & Yes & No & No \\
\hline Zoning & $\begin{array}{l}\text { Nudist, dog- } \\
\text { friendly }\end{array}$ & No & No & No & Nudist & No \\
\hline
\end{tabular}

From North to South, the first three beaches are sandy. The first one, l'Auir is a semi-natural wide beach located at the northern end of the municipality of Gandia, with a coastal front not urbanized and with dunes. It offers minimum services and activities related to water sports (like windsurfing and kitesurfing) and has a nudist area and a dog-friendly area. To the South, it borders on Gandia Nord, a very wide urban beach with a highly developed coastal front. The beach is delimited by a promenade, with numerous establishments, terraces, hotels and apartments. This beach also offers a wide range of services, activities, sports areas and kiosks. Some kilometers to the South, Piles is another urban beach, bordered by a promenade with few establishments, followed by low-rise apartments. It is a relatively narrow beach with erosive problems (Cabezas-Rabadán et al., 2018).

In the South, three pebbly beaches are considered. La Grava is an urban beach supported by the port of Xàbia and the promenade, in front of low buildings. The last two beaches are located on the coast of Cap de la Nao. They are both semi-natural, surrounded by a scattered low-density urbanization, and "Penya-segats de la Marina" Site of Community Importance and Special Protection Area (CMA, 2015). Ambolo shows a mixture of pebbles and coarse sand, supported by a cliff. Access is complicated and only possible on foot. The beach does not offer services or Blue Flag, and nudism is common in one area. Finally, Granadella is surrounded by mountains, offers services and aquatic activities, and has Blue Flag.

As they are located close to each other, the main regional socioeconomic and environmental conditions are similar. Nevertheless, some differences appear on the tourist sector: it is developed especially focused on the so-called quality tourism in the southern part of the study area, apparently more linked to natural values and the landscape, while on the contrary Gandia Nord constitutes an example of tourist resort oriented towards the sun, sea and sand mass tourism (Cambrils-Camarena \& Nácher Escriche, 2005). 


\subsection{Methods}

\subsubsection{Questionnaires}

Questionnaires were conducted in order to assess user's profile, the reasons for choosing a certain beach, activities carried out, priorities and perceptions. A simple random sampling following a zigzag pattern was carried out on each beach after determining the sample size with a confidence level of 95\%, maximum variance (0.5) and an error of 15\% (Camarero, 2006). A total number of 264 useful oral interviews, 44 for each beach, were carried out between July $15^{\text {th }}$ and August $15^{\text {th }}$, in the middle of the peak season. Questionnaires took between 10 and 15 minutes and were conducted mainly in Spanish, but also in English, French and Catalan. Questions (available at: https://github.com/carcara4/project1/raw/main/questionnaire.pdf) were grouped into the following sections:

(a) Basic questions oriented to the definition of users' profile such as their age, origin, educational level, residence, companions and aspects related to their visit to the beach;

(b) Users' main reason for choosing the visited beach;

(c) Recreational activities on the visited beach;

(d) Prioritized characteristics when choosing a beach, as well as identifying the most important one;

(e) Perception of facilities supply and environmental aspects.

Afterward, a descriptive analysis for each beach was carried out employing frequency diagrams. With the aim of assessing differences among beach types, the results of urban, semi-natural, pebbly and sandy beaches were aggregated. The proportion of answers in different beach types was conducted using a Z-test (Fleiss et al., 2004; Zar, 1999). Finally, users' perceptions were also analyzed through frequency diagrams, and a weighted arithmetic mean was calculated in order to assess the perception of facilities supply.

\subsubsection{Frequentation measures}

During the same days the interviews were conducted, the number of users at each beach was determined between 12 a.m. and 3 p.m., as this time slot registers the greatest number of people on Mediterranean beaches (Breton et al., 1996; Mas-Parera \& Blázquez-Salom, 2005; Roig-Munar, 2003). On each beach, and perpendicularly to the shoreline, 5-meters-wide stripes were defined covering both emerged and submerged beach areas. It was identified that the vast majority of users were located in a narrow stretch of $25 \mathrm{~m}$ close to the shore, which was defined as the useful beach area from the recreational point of view. This corresponds with the findings of previous studies (Alemany, 1984; Sardá et al., 2009; Yepes \& Medina, 2007). Therefore, beach surface was defined up to that distance or, in narrower beaches, up to their inner limits. For this purpose, GIS software and PNOA orthophotos were used. From the number of users and the useful beach area an average beach density was calculated. 


\subsection{Results}

\subsubsection{Users' profile}

The answers of 44 questionnaires allowed describing users' profiles through their age (Fig. 2.3a), companions (Fig. 2.3b), origin (Fig. 2.4a), residence (Fig. 2.4b), educational level (Fig. 2.5a), usual beach (Fig. 2.5b), travel time (Fig. 2.6a) and time spent on the beach (Fig. 2.6b). Each beach showed a particular user profile.

L'Auir was mostly visited by adults (64\%), who attended in pairs (46\%), mostly from other parts of Spain (52\%), or the municipality of Gandia (23\%). Several users expressed that they came "from the coastal urban area of Gandia" where they stayed at their second residence (48\%) or temporary residence as hotels or rental apartments (21\%). However, they preferred to visit this beach instead of Gandia Nord. For the majority (71\%), it was their usual beach and the time spent there was about 3-4 hours.

Gandia Nord received a large number of elderly (23\%) and young people (48\%), most of them from outside the Valencian Community (75\%). The majority stayed in hotels and apartments (50\%), although some users reported "long trips in public transport" for a beach day trip (11\% spent more than $60 \mathrm{~min}$ ). People spent long days on the beach ( $50 \%$ more than $5 \mathrm{~h}$ ) and considered it as their usual beach (60\%).

Piles hosted a high percentage of users that considered it as their usual beach (80\%), mainly families (71\%) from Valencia province (68\%). They came from their second residences (39\%), habitual homes (34\%), or rented close to the beach (27\%).

La Grava was frequented mainly by families (73\%), inhabitants of the municipality (23\%), that made short trips (77\% less than fifteen minutes) from their habitual residence (34\%) to spend little time on the beach (46\% less than $2 \mathrm{~h}$ ). There were also foreigners and people from the Valencian community in second homes or temporary residences.

Ambolo was mainly frequented by young people (59\%), possibly due to its complicated access, without considering it as their usual beach (91\%). They came with friends (66\%), from the Valencian community (66\%), directly from their home to spend a day at the beach, with no other accommodation nearby (75\%). moving from long distances (66\% of travels longer than one hour).

Granadella was mainly visited by young (52\%) groups of friends (48\%), itinerant visitors attending to spend the day from their usual homes (20\%), in the Valencian Community (34\%). There were also visitors staying in hotels, campsites and apartments (41\%), or in second homes (30\%), many of whom were foreigners (18\%).

Considering the different beach types, differences appeared in users' profile: Young people preferred semi-natural and pebbly beaches, while elderly preferred the urban and sandy ones. Regarding the company, more families appeared on urban beaches, while groups of friends attended to semi-natural and pebbly beaches such as Ambolo and Granadella. Urban and sandy were chosen as the most visited beach, while on the contrary, foreigners and long day trips were linked to semi-natural and pebbly beaches. These differences are probably related to the 
particularities, services and activities that can be carried out on each beach and that may condition the beach choice.

(a) Age

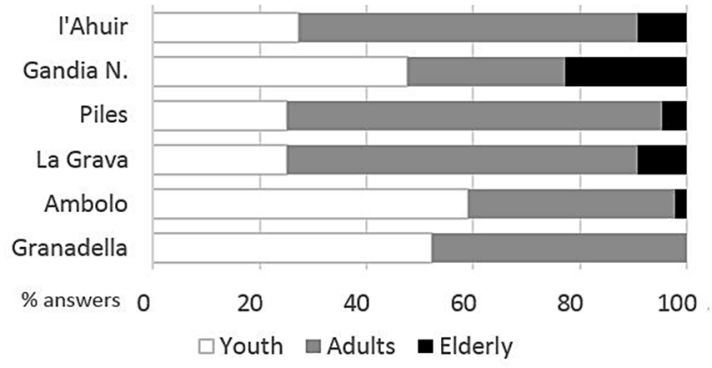

(b) Companions

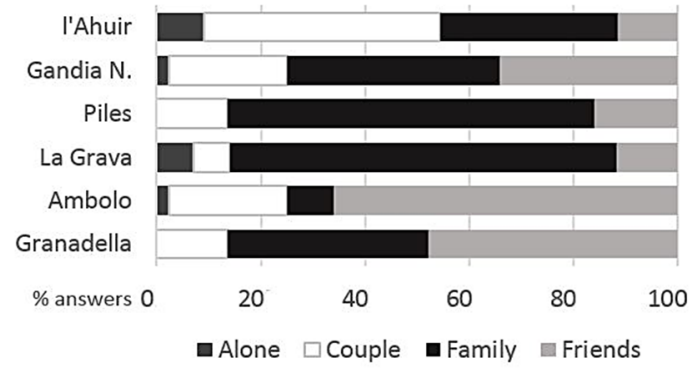

Fig. 2.3. (a) Users' age: youths (<30 years old), adults (30-60 years old) or elderly ( $>60$ years old). (b) Companions: alone, couple, family or friends.

(a) Origin

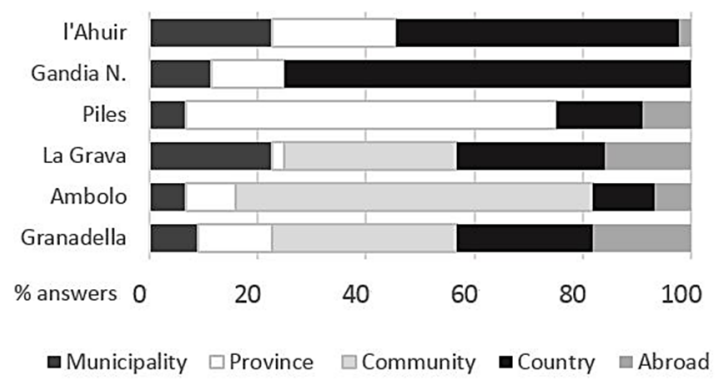

(b) Residence

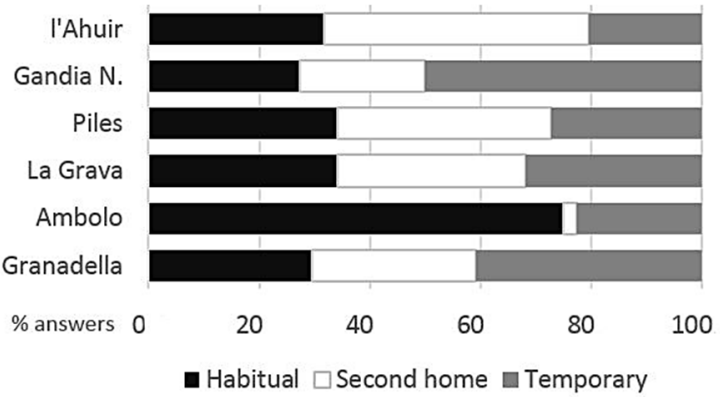

Fig. 2.4. (a) Hometown: same municipality, province, community or country where that beach is located, or abroad. (b) Residence or accommodation while they are visiting the beach.

(a) Educational level

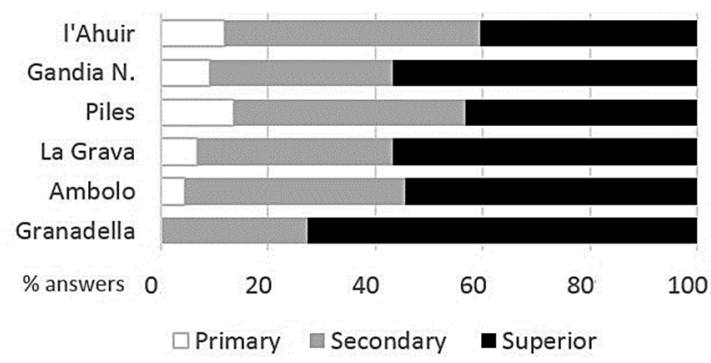

(b) Usual beach

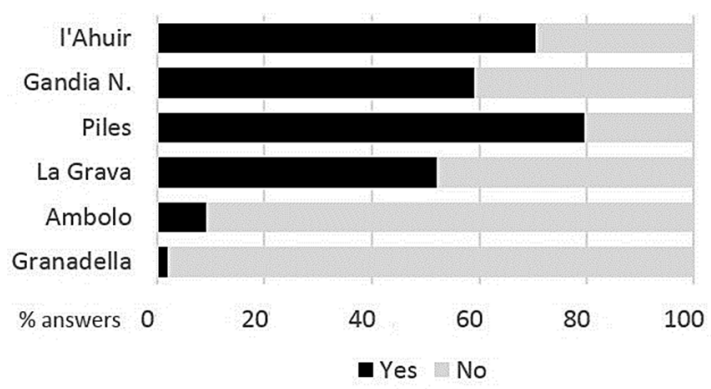

Fig. 2.5. (a) Educational level: primary, secondary or post-secondary. (b) Usual beach.

(a) Travel time

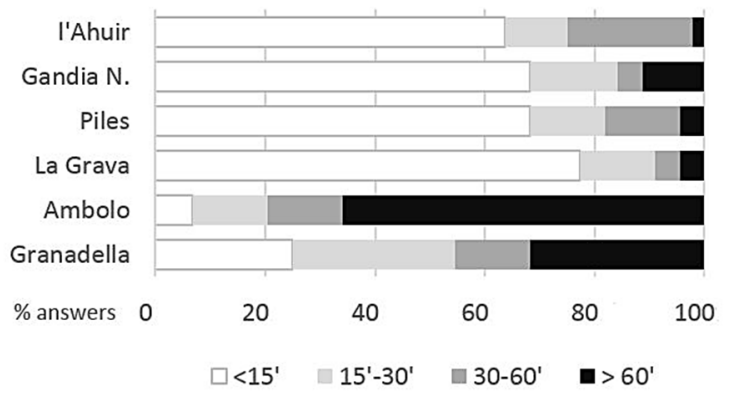

(b) Time spent on the beach

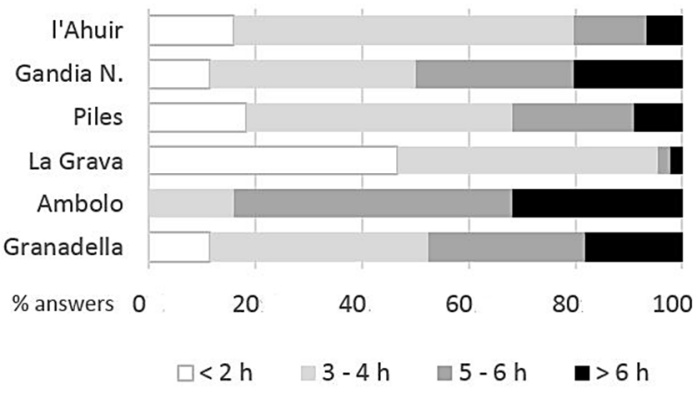

Fig. 2.6. (a) Travel time to the beach (minutes): Less than 15, between 15 - 30, between 30-60, and more than 60 . (b) Time spent on the beach (hours): less than two, three - four, five - six, more than six. 


\subsubsection{The main reason for choosing the visited beach}

Users expressed their main reasons for choosing one beach, which differed a lot between them (Fig. 2.7). People attended to I'Auir mainly because of the quietness, being the only semi-natural beach in the area (52\%). Gandia Nord users were attracted by its proximity and easy access (30\%), and the atmosphere and "ease of meeting people and partying" on the beach and surrounding areas (23\%). The tradition of attending every year was also very common, in several cases related to owning a holiday home (14\%). Due to this same reason, the tradition was also the main reason for choosing Piles (41\%), in addition to quietness (41\%) and proximity (16\%). La Grava received most of their users because of its proximity to their dwellings (50\%), while tradition and quietness also played an important role (both $9 \%$ ). Ambolo and Granadella attracted users mainly because of their landscape (55\% and 57\% respectively).

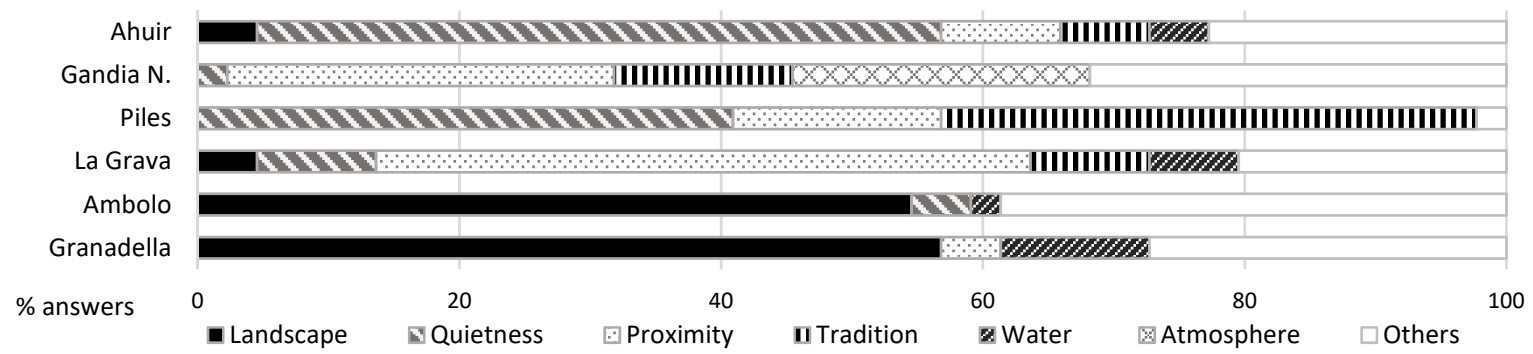

Fig. 2.7. Users' main reason for attending to the visited beach.

There were also other remarkable reasons for several users in certain beaches. Among them, some people visited l'Auir due to its dog-friendly (20\%), while others went to pebbly beaches just because they prefer that type of sediment (7\% on la Grava and Granadella). Other users chose the beach due to friends' recommendations (11\% Granadella), the flora and the fauna (9\% Ambolo), or the quality of the sand ( $16 \%$ Gandia Nord).

\subsubsection{Recreational activities on the visited beach}

The comparison between the proportion of activities in each beach type was carried out with a Ztest. Table 2.2 highlights statistically significant differences between semi-natural and urban beaches, and between sand and pebbly beaches.

Table 2.2. Results of the Z-test comparing the proportions of the main activities carried out in different beach types. Differences have been identified with $95 \%$ of confidence $(*)$.

\begin{tabular}{c|ccccccc} 
& \multicolumn{9}{|c}{ Proportion of users: } & \multicolumn{7}{c}{ Proportion of users: } \\
Activity & Semi-natural & Urban & p-value & Sand & Pebbles & p-value & Significantly higher \\
\hline Relax \& sunbathing & 0.2045 & 0.4697 & $0.0000^{*}$ & 0.3258 & 0.3485 & 0.6965 & urban \\
Walking & 0.1591 & 0.2045 & 0.3371 & 0.3561 & 0.0076 & $0.0000^{*}$ & sand \\
Playing with kids & 0.0530 & 0.0530 & 1.0000 & 0.0909 & 0.0152 & $0.0000^{*}$ & sand \\
Beach paddle ball & 0.0303 & 0.1439 & $0.0011^{*}$ & 0.1591 & 0.0152 & $0.0000^{*}$ & urban, sand \\
Aquatic sports & 0.0379 & 0.0000 & $0.0238^{*}$ & 0.0076 & 0.0303 & 0.1770 & semi-natural \\
Snorkeling \& diving & 0.4848 & 0.0530 & $0.0000^{*}$ & 0.0000 & 0.5379 & $0.0000^{*}$ & semi-natural, pebbles \\
Volleyball/football & 0.0000 & 0.0379 & $0.0238^{*}$ & 0.0379 & 0.0000 & $0.0238^{*}$ & urban, sand \\
\hline
\end{tabular}


Recreational activities are often linked to different beach characteristics. Significant differences were found in sand sports, such as volleyball and football (4\%) and beach paddle ball (14\%), besides relax and sunbathing (47\%), all of them much more common in urban beaches. Meanwhile, semi-natural beaches fostered in higher proportion aquatic sports (as windsurfing and kite surfing) (4\%) and snorkeling and diving (49\%). Comparing sediment types, snorkeling and diving only appeared in pebbly beaches, such as volleyball and football on sandy ones, where there were also far more popular walking (36\%), beach paddle ball (16\%) and playing with kids (9\%).

\subsubsection{Prioritized characteristics when choosing a beach}

Beach users consider some elements when they choose a certain beach. They classified each characteristic as very important, relevant or not important (Fig. 2.8). In general, the most valued characteristics were water quality and sediment cleanliness, while facilities, the presence of flora and fauna, and seashore slope did not have that much importance. Differences appeared in certain characteristics when comparing the users of different beach types.

Urban beach users prioritized more water quality and sediment cleanliness, proximity from their residences, and the facilities offered by the beach more than semi-natural ones. On the contrary, semi-natural users paid more attention to quietness, landscape and the presence of flora and fauna. With regard to pebbly beach users, they paid closer attention to water quality, landscape, and the presence of flora and fauna, while users on sandy beaches considered sediment cleanliness, proximity and facilities.

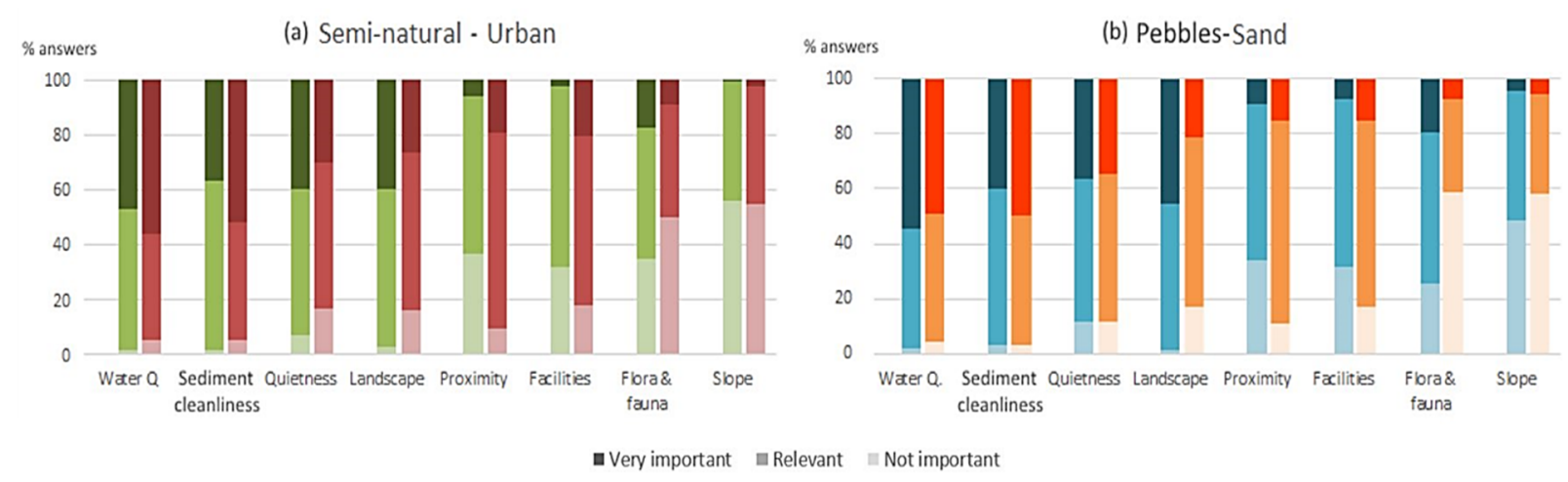

Fig. 2.8. Priorities when choosing a beach: water quality, sediment cleanliness, quietness, landscape, proximity, facilities, flora and fauna, and slope on different beach types: (a) semi-natural vs. urban, (b) pebbly vs. sandy beaches.

In order to determine if there were significant differences between diverse beach types, each user identified their most valued characteristic. Table 2.3 compares the proportions of users on each beach type, and the Z-test allows identifying differences for some characteristics.

The proportion of users who chose sediment cleanliness (25\%), facilities (5\%) and atmosphere (4\%) as the most important element was significantly higher on urban beaches, while on seminatural the most important factor was water quality (35\%) and landscape (16\%). In relation to sediment, sandy beach users paid significantly more attention to sediment cleanliness (25\%) and quietness (32\%), while pebbly users focus their choices on water quality (44\%) and landscape (17\%). 
Table 2.3. Results of the Z-test with $95 \%\left(^{*}\right)$ and $90 \%\left({ }^{* *}\right)$ of confidence, comparing the proportion of users that chose each characteristic as the most valued when choosing a beach.

\begin{tabular}{|c|c|c|c|c|c|c|c|}
\hline \multirow{2}{*}{ Characteristic } & \multicolumn{2}{|c|}{ Proportion in: } & \multirow{2}{*}{$p$-value } & \multicolumn{2}{|c|}{ Proportion of users: } & \multirow{2}{*}{$p$-value } & \multirow{2}{*}{ Significantly higher: } \\
\hline & Semi-nat. & Urban & & Sand & Pebbles & & \\
\hline Sediment clean & 0.11364 & 0.25000 & $0.00410^{*}$ & 0.25000 & 0.11364 & $0.00410^{*}$ & urban, sand \\
\hline Water quality & 0.35606 & 0.20455 & $0.00614^{*}$ & 0.12121 & 0.43939 & $0.00000 *$ & semi-natural, pebbles \\
\hline Quietness & 0.25758 & 0.18939 & 0.18352 & 0.31818 & 0.12879 & $0.00022^{*}$ & sand \\
\hline Slope & 0.00000 & 0.01515 & 0.15560 & 0.00000 & 0.01515 & 0.15560 & - \\
\hline Flora \& fauna & 0.00758 & 0.00000 & 0.31732 & 0.00758 & 0.00000 & 0.31732 & - \\
\hline Landscape & 0.15909 & 0.05303 & $0.00512^{*}$ & 0.04545 & 0.16667 & $0.00138^{*}$ & semi-natural, pebbles \\
\hline Facilities & 0.00758 & 0.05303 & $0.03156^{*}$ & 0.03788 & 0.02273 & 0.47152 & urban \\
\hline Proximity & 0.03788 & 0.06061 & 0.39532 & 0.06061 & 0.03788 & 0.39532 & - \\
\hline Atmosphere & 0.00758 & 0.03788 & $0.09894^{\star *}$ & 0.02273 & 0.02273 & 1.00000 & urban \\
\hline
\end{tabular}

\subsubsection{Frequentation and density}

Table 2.4 shows the affluence of users and the density during the peak periods. There were important differences in user density between the different beaches. L'Auir had the lowest occupancy level (24.5 $\mathrm{m}^{2} /$ user), while Gandia Nord had the highest $\left(2.3 \mathrm{~m}^{2} /\right.$ user). The lowest amount of users was detected on Ambolo and Granadella, both semi-natural, small and narrow beaches. However, due to their little available surface area their densities were higher than expected (7.6 and $5.1 \mathrm{~m}^{2} /$ user respectively), comparable to the urban beaches of la Grava (4.5 $\mathrm{m}^{2}$ /user) and Piles (7 $\mathrm{m}^{2} /$ user).

Table 2.4. Useful beach area $\left(\mathrm{m}^{2}\right)$, estimation of the total amount of users and the density (users $/ \mathrm{m}^{2}$ and $\mathrm{m}^{2} / \mathrm{users}$ ).

\begin{tabular}{c|cccc} 
Beach & Useful beach area $\left(\mathrm{m}^{2}\right)$ & Total No. users & Density (users $\left./ \mathrm{m}^{2}\right)$ & Density $\left(\mathrm{m}^{2} /\right.$ users $)$ \\
\hline I'Auir & 44000 & 1795 & 0.04 & 24.5 \\
Gandia Nord & 75000 & 32700 & 0.44 & 2.3 \\
Piles & 25600 & 3642 & 0.14 & 7.0 \\
la Grava & 4229 & 941 & 0.22 & 4.5 \\
Ambolo & 2049 & 270 & 0.13 & 7.6 \\
Granadella & 2567 & 507 & 0.20 & 5.1 \\
\hline
\end{tabular}

\subsubsection{Beach width perception}

Fig. 2.9 shows users' perception of the beach width, sometimes inadequate for the recreational functions.

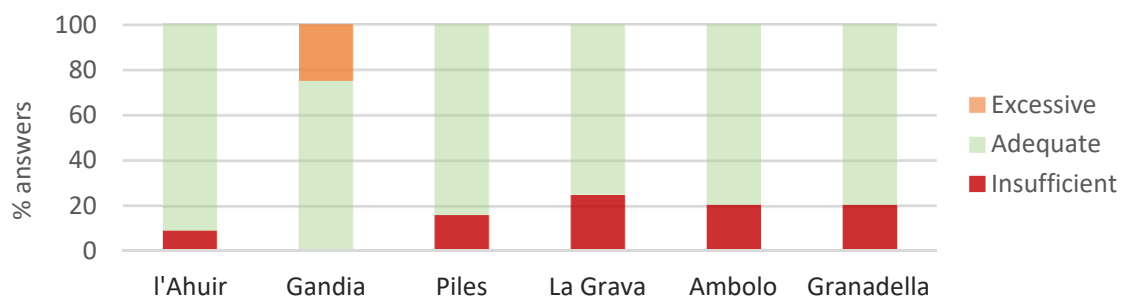

Fig. 2.9. Users' perception of beach width. 
On pebbly beaches (La Grava, Ambolo and Granadella), between 20\% and 25\% of the users considered the beach as too narrow. Those are small pebbly beaches and users occupy a large part of their surface during peak seasons. Piles, a sandy beach with erosive problems, registered similar answers and $16 \%$ of its users stated that it did not present appropriate dimensions. On the contrary, $25 \%$ of the users on Gandia reported that the beach was too wide, "making uncomfortable to reach the seashore".

\subsubsection{Users' density and overcrowding perception}

Users were asked to classify the perceived amount of people as "many", "quite a lot", "few" or "very few", as well as if they experienced discomfort because of overcrowding. Figure 2.10 compares the densities with the percentage of users perceiving "many people" and overcrowding discomfort.

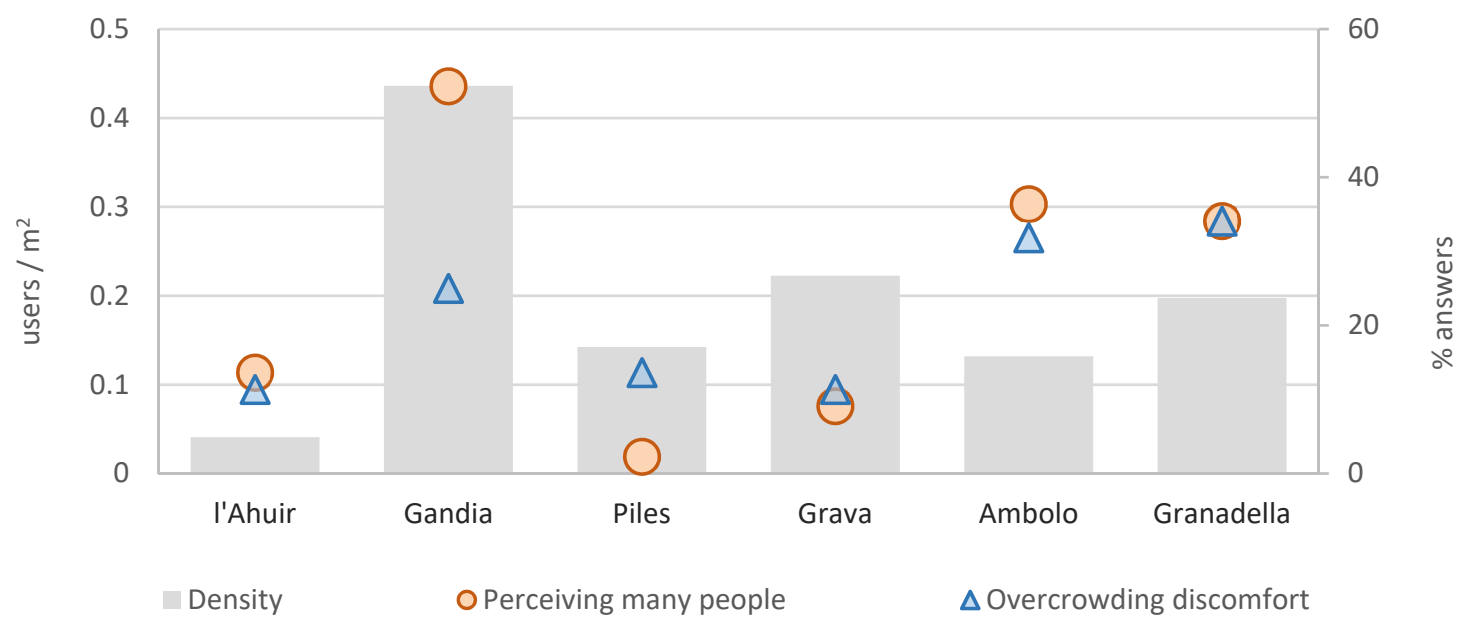

Fig. 2.10. On the left axis: density of users (users $/ \mathrm{m}^{2}$ ). On the right axis: percentage of users perceiving "many people" and overcrowding discomfort.

Apparently, users' density was not necessarily related to the perception of crowding, or at least to the discomfort it caused. Gandia Nord reported a very high density $\left(0.44\right.$ users $\left./ \mathrm{m}^{2}\right)$, and a large proportion of the users was aware of this situation, and 52\% perceived many people. Nevertheless, they were not so dissatisfied with that as only $25 \%$ perceived overcrowding. On the contrary, the highest proportions of overcrowding perception were recorded on the semi-natural beaches of Ambolo (36\%) and Granadella (34\%), although the densities ( 0.13 and 0.20 users $/ \mathrm{m}^{2}$ respectively) were considerably lower than on Gandia Nord. The situation was similar on the other beaches: I'Auir experienced the lowest density $\left(0.04\right.$ users $\left./ \mathrm{m}^{2}\right)$, but the percentage of users perceiving many people and overcrowding was similar and higher than on Piles and la Grava, that on the contrary showed far higher densities ( 0.14 and 0.22 users $/ \mathrm{m}^{2}$ respectively). Therefore, considering the actual densities and the beach type, semi-natural users showed a higher perception of people on the beach and higher overcrowding discomfort, while urban users were more satisfied with the situation.

\subsubsection{Facilities perception}

For each service, users classified the offer into four categories. Values were assigned to each category: excessive (-1), unimportant $(0)$, adequate $(+1)$, insufficient $(-1)$. They allowed assessing 
the suitability of the offer, penalizing in equal measure if the offer is perceived as excessive or insufficient. From these values and the proportions of users associated with each category, a satisfaction score was calculated as a weighted average (ranging from +1 to -1 ). Figure 2.11 ranks the facilities according to the satisfaction score.
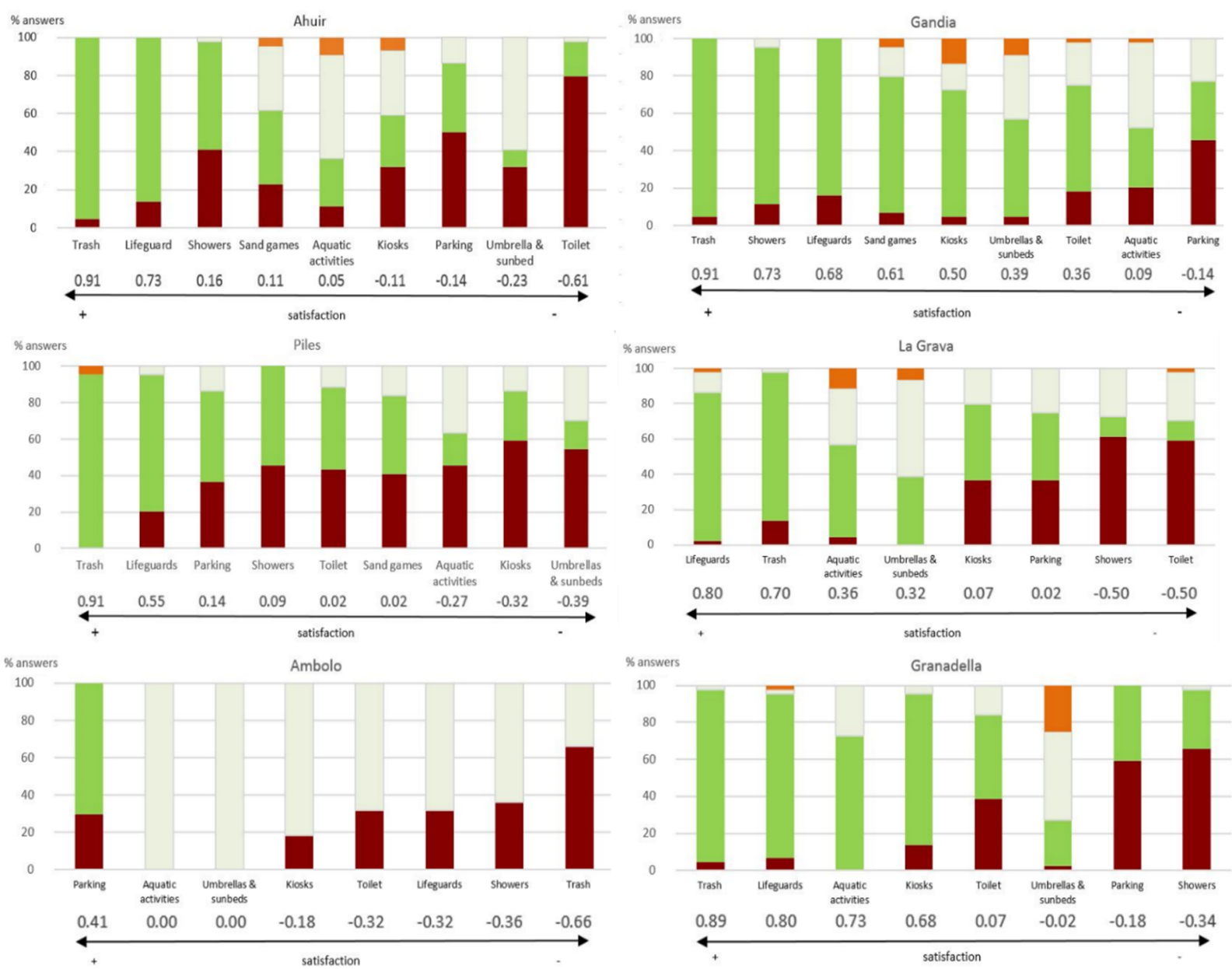

$\square$ Excessive $\square$ Unimportant $\square$ Adequate $\square$ Insufficient

Fig. 2.11. Facilities offer perceived as insufficient, adequate, not interested and excessive. The facilities are ranked from left to right according to their satisfaction score.

The differences in facilities supply on each beach were reflected in users' perceptions. However, other factors seemed to influence this perception, impeding the assertion that the more services are provided, the better the satisfaction. The users of Gandia, a mass tourism-oriented beach that offers a huge amount of services, appeared as very pleased, and only complained about the insufficient parking (48\%). The situation was different on Piles, where several users complained about the lack of services (more than $50 \%$ perceived insufficiency of kiosks and umbrellas). Ambolo, without facilities on the beach, had some users complaining the same way, although the majority showed no interest in the facilities and considered their presence as unimportant. The lack of certain facilities could also be identified on l'Auir (80\% considered a lack of toilets), la Grava (more than $60 \%$ considered insufficient showers and toilets) and la Granadella (showers and toilets, but also the lack of parking). On the contrary, on Granadella a significant proportion (25\%) 
complained about the excessive number of parasols and sunbeds, also registered on Gandia Nord (9\%) and la Grava (7\%). Similarly, on I'Auir (9\%) and la Grava (11\%), the aquatic activities caused complaints about altering the tranquility, one of the most valued characteristics of those beaches.

\subsubsection{Blue Flag perception}

Users showed a significant lack of knowledge with regard to beaches' possession of Blue Flag: only $43.2 \%$ knew if the beach had the award. The perception of Blue Flag differed between beach types (Fig. 2.12). For example, urban users were more conscious about the presence of Blue Flag on the beach $(55 \%)$ than semi-natural users (31\%). This lack of knowledge was in line with the low influence that the award had in people's beach choice: only $40 \%$ on urban and $28 \%$ on seminatural beaches considered it. At the same time, it is important to point out that several users asserted not knowing the function of that award.

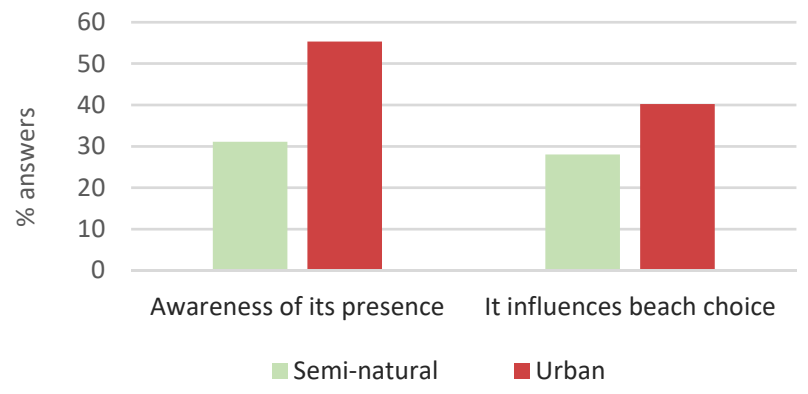

Fig. 2.12. Beach users' awareness and perception regarding the Blue Flag.

\subsubsection{Seagrass residues perception}

The presence of Posidonia oceanica residues on the shore is common on the three southern beaches, and they are routinely removed as solid waste. Figure 2.13 shows users' perception about seagrass residues on those beaches.

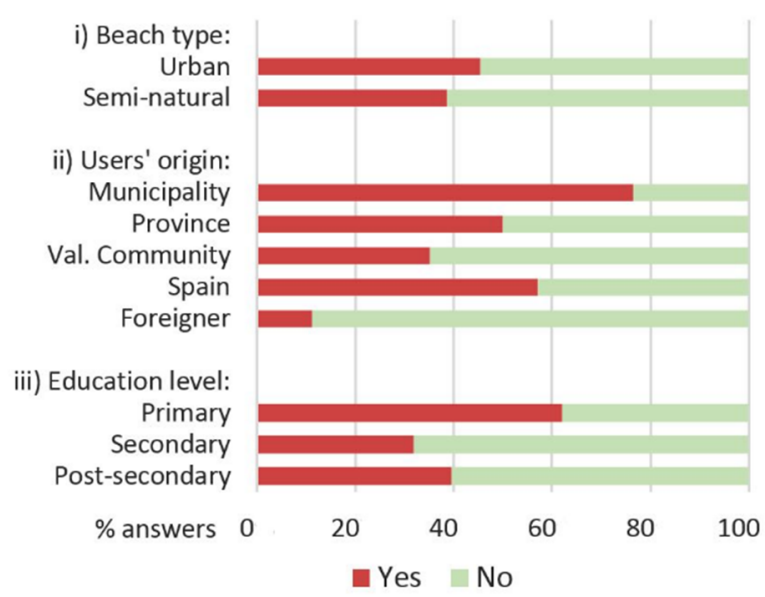

Fig. 2.13. Perception of disturbance by residues of the seagrass Posidonia oceanica, according to i) Type of beach where the survey was done, ii) Users' origin in relation with that beach, iii) users' education level.

Most people were not bothered by the presence of residues (57\%), especially on semi-natural beaches (61\%). About users' origin, disturbances affected fewer foreigners (11\%) and visitors from distant places in the Community (35\%) than those coming from shorter distances, such as locals 
(77\%) or people from other parts of Spain (57\%). Disturbances have also been compared considering the level of education, and greater rejection was found among people with primary level (62\%), compared to secondary (32\%) and higher education (40\%).

\subsection{Discussion}

Users' profiles, expectations, activities and perceptions have been defined on different types of beach. Some results were similar on all the studied beaches, and therefore some general trends can be identified. Most users attended the beach in order to relax and sunbathe, and to walk in the case of sandy beaches. This is consistent with previous studies, which show that majority of users tend to be restful, and only a small proportion engage other activities (Alves et al., 2017; Breton et al., 1996; Lozoya et al., 2014). Nevertheless, each beach has different values, either environmental or recreational, that may constitute users' main reason for attending to a certain beach. Sometimes they are linked with specific recreational activities as certain sports. The tradition was another common reason, with users attending to the same beach every year. In many cases, that was related to the proximity of their residence, which reduces the time to reach the beach. This issue can be especially remarkable for people attending with their families. In the study area, approximately two-thirds of the users (except those on Ambolo) were accommodated either in a temporary or in second homes. It is linked to the common presence of second residences on Western Mediterranean coast (Roca et al., 2008; Yepes \& Medina, 2005), also reported in other Mediterranean beaches (Rodella et al., 2017). Thus, practical criteria such as the distance to the beach nearby act several times as the main reason for the election. However, these reasons must be differentiated from the most prioritized or valued elements on a beach. In this regard, water quality and beach quality and cleanliness are the most common prioritized elements when choosing a beach (Fig. 2.8). This matches other recent studies according to which water quality and cleanliness are essential factors in the choice (Rodella et al., 2017; Vaz et al., 2009). Despite this, they are not the ultimate reason for choosing one beach over another (Nelson et al., 2000; Vaz et al., 2009).

\subsubsection{Differences between beach types}

Regardless of these general trends, differences appear when grouping beaches with the same degree of artificialization (urban or semi-natural) and sediment size (sand or pebbles). Differences in users' profile may be observed, with more youths and groups of friends on semi-natural beaches, and more elderly people and families on urban beaches. This is probably related to the level of comfort that children require. On urban beaches, users attended on foot to their usual beach, in short trips, commonly from their second residence, while on semi-naturals travels were longer and more time was spent there. That was especially remarkable on Ambolo, where $66 \%$ of the users spent more than 60 min traveling to spend the day there. Probably that constitutes the motivation for considering it as a complementary beach, chosen "from time to time to have different experiences".

Sediment size constituted a basic conditioner of the activities carried out. Therefore, a significantly higher percentage of users went to sandy beaches to walk, play with children or practice sports like beach paddle, volleyball or football. On the contrary, many users visited pebbly beaches to 
practice diving and snorkeling, which is a widespread activity. With regard to the degree of artificialization, relaxation and sunbathing were the most common activities and took place significantly more frequently on urban beaches, followed by beach paddle and sand sports. On the other hand, semi-natural beaches were dominated by water sports such as windsurfing and snorkeling.

Prioritized characteristics are also different on each beach type. On pebbly beaches, a significantly higher number of users considered water quality and landscape as their most prioritized characteristic. At the same time, flora and fauna, were apparently also more valued (Fig. 2.8). On sandy beaches, sediment cleanliness, facilities and quietness were strongly prioritized, with more interest also in proximity. Semi-natural users appreciated more water quality, landscape, quietness, flora and fauna, while on urban beaches sediment cleanliness, facilities and the atmosphere were preferred.

Our results show how urban beaches have a fairly defined and more traditional user profile that gives more priority to comfort, in line with previous works (Lozoya et al., 2014; Vaz et al., 2009). Furthermore, on semi-natural beaches, we found a particular user profile attracted to environmental values. These natural features, not available in the nearest beaches, seem to justify longer displacements, and lead us to think these users give a greater value to this type of beach, something defended by other authors (Lozoya et al., 2014; Peña-Alonso et al., 2018; Rodella et al., 2017; Vaz et al., 2009). This could be related to growing public interest in nature and other aspects beyond facilities and infrastructure (Lucrezi \& Saayman, 2014), as well as the existence of different segments of tourist demand for coastal destinations that pay different attention to the environment (Onofri \& Nunes, 2013).

It is important to note that, in the Valencian coast, sandy beaches have constituted the main recreational resource and attraction for the sun, sand and sea tourism (López-Olivares, 2003). Pebbly beaches traditionally have a lower level of artificialization, urbanization, and exploitation, linked to a lower level of accessibility, and have focused less attention on managers, offering fewer services and comfort. All this causes that certain similarities between pebbly and semi-natural beaches may be observed.

Individually, each beach shows specific values, either environmental or recreational, that may constitute the main reason for attending to it (Fig. 2.7). The landscape was the most important reason for attending to certain beaches (55\% on Ambolo, 57\% on Granadella), as well as the practice of diving and snorkeling associated with the presence of interesting aquatic flora and fauna ( $9 \%$ on Ambolo). The socio-economic environment surrounding each beach also played an essential role. The leisure possibilities on Gandia Nord, with music and parties in kiosks, as well as the nightlife in the surroundings, constitutes a good attraction for certain type of user. Other authors have described similar phenomena in Catalan (Roca et al., 2009), Italian (Rodella et al., 2017) and Mexican resorts (Cervantes et al., 2008). Sometimes management responds or encourages specific interests, creating great success in the affluence to the beach: the possibility of attending with pets justified the attendance of some users to I'Auir (20\%). Similarly, the presence 
of several users practicing nudism in the authorized areas on l'Auir and Ambolo leads us to think that this practice is an important motivation for many users.

Therefore, getting to know individuals' preferences and perceptions, together with site characteristics becomes an important issue for tourism management, as they determine beach choice (Halkos \& Matsiori, 2012), and they are not as homogeneous as traditionally considered.

\subsubsection{Beach width, density and overcrowding perception}

Widths were sometimes perceived as insufficient on the pebbly beaches, naturally narrow (15$20 \mathrm{~m}$ ), but also on Piles (25 m width) and even on l'Ahuir (70 m wide). Users seem to be quite demanding about the width of the beach and perceive the current situation as negative for their enjoyment. Previous works do not define a preferred beach width, and differences have been found in different study areas (Rodella et al., 2017). Nevertheless, it is assumed that width must be maintained over 30 - 35 m for the proper recreational use (Jiménez et al., 2011; Sardá et al., 2009). Either way, the physical maintenance of a surface capable of accommodating users and recreational functions constitutes an essential issue for managers (Rodella et al., 2017), and therefore, widths' perception is essential to define the need for actions. The insufficient width on Piles associated to erosive processes, familiar to all Valencian coast (EC, 2009) hinders a stronger development of the economy in these areas, closely linked to sun, sand and sea tourism (Gormsen, 1997; Sardá et al., 2009). This has led to different nourishment actions by the Spanish Ministry of Environment (Dirección General de Costas, DGC) in order to maintain the width during the tourist season. When width starts to be perceived as insufficient, the private sector and local governments force coastal managers to take measures to confront erosion, sometimes leading to emergency actions without long-term planning or perspectives (Jiménez et al., 2011), sometimes ineffective after a short period. In general, these interventions are associated with important economic cost and environmental impacts (Aragonés et al., 2015; Hanson et al., 2002; Peterson \& Bishop, 2005; Speybroeck et al., 2006). Considering the high attractiveness of pebbly beaches for some users, on irremediably erosive beaches it could be proposed to increase the sediment size during nourishments as a more durable alternative.

However, on Gandia Nord, (wider than $80 \mathrm{~m}$ ) the opposite situation was registered, and 25\% of the users identified it as excessive, forcing them to walk more to reach the shore. This possibility has only been superficially explored (CEDEX, 2000; Villares, 1999) and contrasts with the current management, that does not consider this possibility and even suggests nourishments to exceed $60 \mathrm{~m}$ wide (Hanson et al., 2002). Users' perceptions should be included for more efficient decisionmaking. At the same time, the identification of beaches exceeding the acceptable width may be proposed and, given the shortage of sand along the coastline, they may be defined as donors of sediment.

Users' density is another key parameter for the management, as it conditions the facilities that must be offered and can cause discomfort due to crowding (Breton et al., 1996; Rodella et al., 2017; Yepes, 2002). Several authors have suggested the saturation or overcrowding limit around values of 4-5 $\mathrm{m}^{2}$, while under $2 \mathrm{~m}^{2} /$ user would be unacceptable (Alemany, 1984; MOPU, 1970; Yepes, 2002; Yepes \& Medina, 2007). In our study area, L'Auir registered a very low density (24.5 $\left.\mathrm{m}^{2} / \mathrm{user}\right)$ 
comparable to the natural beach of Son Saura, in Menorca (Roig-Munar, 2003). Ambolo (7.6 $\mathrm{m}^{2}$ /user), Piles ( $7 \mathrm{~m}^{2} /$ user) y Granadella (5.1 $\mathrm{m}^{2} /$ user), were also over the comfort threshold. On the contrary, la Grava (4.5 $\mathrm{m}^{2} /$ user) was under the comfort level, and Gandia Nord, with about $2 \mathrm{~m}^{2} /$ user was overcrowded. This value is lower than those registered in other Spanish urban beaches (Mas-Parera \& Blázquez-Salom, 2005; Roig-Munar, 2003; Sardá et al., 2009), and comparable to Lloret de Mar (2.14 $\mathrm{m}^{2} /$ user) (Roca et al., 2008), constituting an example massive tourism beach. Piles is a beach suffering significant erosion, unable to recover in the absence of nourishments. A decrease in its width may increase the density and consequently affect its recreational use (Jiménez et al., 2011; Valdemoro \& Jiménez, 2006). It can also occur on the pebbly beaches of Granadella and la Grava: Although they are stable, sea level rising or increased frequentation can increase their density, already in the overcrowding limit, reducing their recreational attractiveness.

It is generally assumed that less crowded and less dense beaches are perceived as calmer and therefore more attractive (Vaz et al., 2009). Nevertheless, the problems associated with high density are ultimately defined by users' overcrowding perception, and this one seems to be different depending on the type of beach. On semi-natural beaches, high densities seem to be perceived, and they generate overcrowding discomfort. On the other hand, this relation is not appreciated on urban beaches, and higher densities of users are not perceived and/or do not generate disturbances (Fig. 2.10). This could be due to the different users' prioritization of beach characteristics: while users of semi-natural beaches value tranquility very much, on urban beaches this is not such an important aspect. In fact, one of the main motivations for coming to Gandia Nord, which has the highest density, is its atmosphere. Hence, as perceptions regarding density and comfort are not the same on all beaches and each one presents different characteristics, managers' responses should not be the same either.

The highest perception of overcrowding appeared on Ambolo and Granadella (more than 30\% of the users). They are both semi-natural and pebbly beaches with high environmental value. There, measures should be aimed at reducing the number of users, and in no case at increasing their width. Nevertheless, this is not usually contemplated on sandy beaches, where nourishments are typically considered. However, given their economic and environmental cost, measures should not systematically or exclusively focus on increasing the width so that it can accommodate all the desired users. An alternative solution is to reduce density by lowering the frequentation. The difficulty of access already acts as an efficient regulator on Ambolo, maintaining acceptable densities despite its small size. On the contrary, higher densities on la Grava and Granadella were related to their facility of access. In fact, a car restriction measure has recently been adopted on Granadella together with the implementation of public transport. This difficulty in accessing and parking has been shown to be related to lower frequentation (Pereira da Silva, 2002; Roig-Munar, 2003). Indirectly, it is possible to act on the tourist offer in the surroundings of the beaches, either by limiting the offer as it happens in the Balearic Islands (Mas-Parera \& Blázquez-Salom, 2005) or with environmental taxation measures (Sanz-Blas, 2006). However, the most direct option is to implement an entrance fee, that at the same time can generate an economic resource for its 
environmental protection and maintenance \{Formatting Citation\}. The acceptance of a fee has recently been assessed through the Willingness to Pay (Alves et al., 2014; Lozoya et al., 2014).

\subsubsection{Facilities}

The analysis of perceptions has allowed the identification of facilities causing discomfort between users (Fig. 2.11). Different perceptions appeared between beach types. On urban beaches, a greater number of facilities were perceived as a positive aspect and their absence as an unfavorable factor. On the contrary, several users on semi-naturals showed indifference or rejection towards the facilities: they described the offer as excessive, generating rejection for altering the landscape or the tranquility. This lack of interest in facilities was also observed when analyzing the prioritized characteristics for choosing a beach. Considering this, the current management strategy is inadequate: Despite managers' efforts to increase beach facilities, users did not necessarily perceive it as a positive issue, and it even entails the risk of discomfort. This occurs because the decision-making process is carried out without user feedback to verify the adequacy of the measures taken.

This contrasts with the homogeneous management carried out based on mass tourism, which seeks to offer as many services as possible on the beaches, trying to satisfy all users, and entails a very significant financial expense. Municipalities have the autonomy to implement measures for managing beaches related to leisure and recreational activities, services or facilities. Theoretically, the provision of infrastructures and facilities is determined by users' attendance, preferences, and expectations (Peña-Alonso et al., 2018), at least. As the particular management practices carried out on each beach cause differences on users' perception and recreational experience (Ariza et al., 2010; Peña-Alonso et al., 2018; Roca et al., 2008) the analysis of perceptions carried out in this work appears as a useful tool to highlight facilities that beach managers should pay more attention to.

\subsubsection{Blue Flag}

The Blue Flag is a performance award that attempts to guarantee a certain level of beach quality (Ariza et al., 2008b) in order to attract users. Nevertheless, results showed a high lack of knowledge and consideration of the award status of the visited beach, and several users did not know its purpose (Fig. 2.12). The Blue Flag also showed a small influence on beach choice, both on seminatural and urban beaches. This is in line with previous studies, that reported a general lack of awareness (CREM, 2000; Dolch \& Schernewski, 2002; Lucrezi et al., 2015). The higher awareness on urban beaches may be linked, on one hand, to a higher number of regular users and, on the other hand, to a higher prioritization of characteristics such as "cleanliness" and "safety and access" (Lucrezi \& Saayman, 2014). Coastal towns compete for this award (Mir-Gual et al., 2015) due to its apparent effectiveness attracting foreign tourists (Capacci et al., 2015). Nevertheless, that contrast with the division in academic literature, with recent studies indicating a small influence attracting visitors and revenues (McKenna et al., 2011; Nelson et al., 2000).

The award is criticized due to not consider the heterogeneity of users' expectations and perceptions (Morgan, 1999). It may contribute to the implementation of undesired facilities (Lucrezi \& Saayman, 2014) as it has happened in the studied beaches (Fig. 2.11). The Blue Flag, 
similarly to other performance awards, is highly focused on the recreational function, leaving aside important environmental and ecosystem aspects of the beaches (Ariza et al., 2008b). The associated management practices carried out have received critics, as they may bring environmental costs and contribute turning beaches into "solariums" (Mir-Gual et al., 2015). There are doubts about the usefulness of this award as an indicator of good environmental condition (Lucrezi et al., 2016) and, in fact, awarded beaches sometimes have lower environmental values (Roig-Munar et al., 2018). These award schemes consider the same quality standards on any type of beach (Roca \& Villares, 2008) leading to homogenization, and therefore they should not be taken as a reference standard in the management of these spaces.

\subsubsection{Seagrass offshore residues}

An example of the confrontation between the recreational function and the environment is the mechanical cleaning of the beaches, carried out to please the users (Lucrezi \& Saayman, 2014). This practice removes seagrass residues, as it occurs with Posidonia oceanica (Roig-Munar et al., 2018), bringing negative effects by removing nutrients from the system and affecting the stability of beaches and the shallow meadows (Díaz-Almela \& Duarte, 2008; Roig-Munar, 2001). Nevertheless, the results showed that the majority of users did not consider it as a nuisance. Differences appeared related to the type of beach, and rejection was higher on urban beaches (Fig. 2.3). About users' origin, those from the municipality perceived the highest rejection while, on the contrary, foreigners registered the lowest percentage. The idea that foreigners may be attracted by the natural values when choosing their tourist destination (Onofri and Nunes, 2013) is possibly linked with higher levels of environmental awareness (CREM, 2000). Furthermore, seagrass residues were considered as a nuisance by a lower percentage of users with postsecondary than primary education. It may be caused by their higher knowledge of seagrass environmental values, in line with the relationship between educational level and environmental awareness already defined by different authors (Aminrad et al., 2011; Santos et al., 2005).

That confrontation between rejection of seagrass residues and environment shows how users' preferences should be included in decision-making, but with caution. Some pretensions are based on the imaginary of sun, sand and sea tourism, and they are short-sighted, misinformed, impossible to accomplish, or conflict with the environment (Lozoya et al., 2014). Environmental consciousness may play a very important role in the perception of the seagrass, especially significant considering the general unawareness of Posidonia's functions (Roig-Munar, 2001). Environmental education could bring a higher knowledge of seagrass importance, reducing users' rejection and constituting an alternative to the withdrawal.

\subsubsection{Public awareness and differential beach management}

Coastal management should aim to satisfy beach users, but also to educate and raise their awareness of environmental values. Education and public awareness have been proved as effective tools for handling the relation of tourists with the environment (Orams, 1997; Padua, 1994) and can raise public awareness about coastal problems and ICZM (Koutrakis et al., 2011). Once users are informed, their opinions and perceptions are undeniably valid and can be integrated into management processes (Lozoya et al., 2014). This is essential in order to avoid the current rigid 
and top-down approach that sometimes conflicts with users (Prati et al., 2016), as well as to supply guidelines for management schemes (Lucrezi et al., 2016). Users, together with local managers and formal stakeholders are necessary for implementing an Ecosystem Approach (Ariza et al., 2012; Sardá et al., 2015). It is currently the dominant paradigm (Olsen et al., 2009) attempting a sustainable use of natural resources while maintaining their ecosystem integrity. Schemes as Blue Flag award have proven not to be useful for guiding the management, and they should act as complementary tools in order to take advantage of their educational component (Lucrezi \& Saayman, 2014). More integrated systems with a holistic vision should be adopted for monitoring and managing the beaches (Lucrezi et al., 2016; Sardá et al., 2015). These tools should be able to consider all the characteristics of these ecosystems, as well as users' opinions, favouring a management adapted to the diversity of beaches, promoting their natural values and enhancing or emphasizing their particularities (Lozoya et al., 2014; Peña-Alonso et al., 2018; Vaz et al., 2009). However, it should be noted that the higher number of visitors on the urban beaches, Gandia Nord in particular, suggests that mass tourism-oriented management is now meeting the interests of many more beachgoers. Spanish Coastal Law 2/2013 supports a differentiation between the exploitation of urban beaches and the preservation of values on those isolated from urbanized areas. Managing the coast as a whole and strategic zoning (Lucrezi et al., 2016) can help in this task, and emphasizing values as landscape, flora and fauna can increase its attractiveness (Lozoya et al., 2014; Micallef and Williams, 2002). This can bring tourist benefits since the existence of beaches with different characteristics can enhance the diversity of experiences offered and attract different segments of visitors (Onofri \& Nunes, 2013).

\subsection{Conclusions}

Management must maximize recreational use and tourism benefits without sacrificing environmental values. In order to do it, it must be adapted to the values of each beach and to its users. Our results demonstrate that users' interests are not homogeneous, and management is based on assumptions sometimes uncertain that compromise the environment. Therefore, a change in the policies adopted and in the decision-making is mandatory. It is necessary to adopt mechanisms to know stakeholders' opinions, instead of inferring and assuming them. This makes essential to study not only the generalist expectations and perceptions typical in sand mass tourism but also those related to the diversity of beaches and users.

In order to respect the environment, a more diversified and individualized management has to be developed, considering the coast as a whole, and its diversity as a potential. Moreover, when recreational interests are in conflict with natural values, education may be a great ally increasing environmental awareness and changing users' expectations. All this may lead to a better conservation of the coast, especially important considering the value these areas have for our society. 




\section{Chapter 3}

\section{Satellite-derived shorelines at an exposed mesotidal beach}

The content of this chapter has been published as

Cabezas-Rabadán, C., Pardo-Pascual, J.E., Palomar-Vázquez, J., Ferreira, Ó., Costas, S. (2020). Satellite derived shorelines at an exposed meso-tidal beach. In: Malvárez, G. and Navas, F. (eds.), Global Coastal Issues of 2020. Journal of Coastal Research, Special Issue No. 95, pp. 1027-1031. Coconut Creek (Florida), ISSN 0749-0208

"Vuela al viento espuma del mar, vuela al viento y vuélvelo a volar.

Mezcla el mundo, ruge mistral, mezcla el mundo y mezclanos con él

\section{$[\ldots]$}

Ruge mistral, medio dios, llevaté el mundo de aquí, peina la espuma del mar y llévanos muy lejos" -El último de la fila-

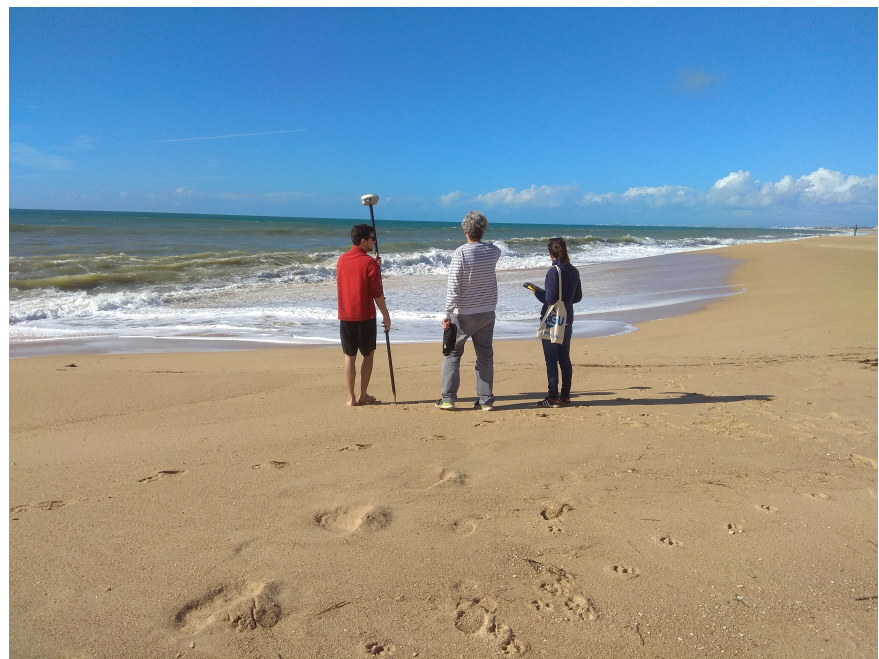


As it is shown in the previous chapter, beach geomorphological characteristics are basic conditions for the functions of the beaches. In particular, their role in the recreational function stands out, focusing the attention of managers in many touristic coasts around the world. Having up-to-date information on the geomorphological aspects of the beach is therefore essential for offering the most efficient and sustainable management possible.

In this context, remote sensing techniques constitute a useful source of data allowing mapping the position of the shoreline along time and space. Satellite-Derived Shorelines (SDS) obtained from medium resolution satellite images as Sentinel-2 and Landsat series constitute a potentially useful tool to provide quantitative, continuous information at regional scale to fill the current information gap for understanding coastal dynamism and beach changes. The research group CGAT (Universitat Politècnica de València) has developed different tools for an automatic definition of Satellite-Derived Shorelines (SDS). This is the case of the extraction system SHOREX (Palomar-Vázquez et al., 2018) that allows defining SDS over large regions and periods.

Nevertheless, assessments of SDS extraction methodologies on real scenarios are scarce and mainly restricted to low energy and microtidal beaches. That is the case of SHOREX and the resulting SDS, that have recently been successfully validated at Mediterranean beaches (SánchezGarcía et al., 2020) and only very preliminarily at a Pacific microtidal beach (Sánchez-García et al., 2019). Nevertheless, many coastal typologies have not been considered yet, and SDS validations at tidal coast and relatively energetic are still pending. In order to expand the application of these SDS worldwide, it is essential to adapt the extraction methodology, understand the morphological reality they represent, and evaluate the accuracy of SDS resulting from Sentinel and Landsat sensors to coast with different morphologies and oceanographic characteristics. These tasks are necessary in order to ensure an adequate representativity of the shoreline and to validate the use of SDS as indicators of the beach state.

This chapter focuses on broadening the environments in which the extraction methodology and the derived SDS may be applied. In order to do so, SDS defined using the extraction system SHOREX are assessed at the mesotidal and moderate to highly energetic beach of Praia de Faro, a barrier beach located in Ria Formosa (Algarve, south Portugal). Accuracy was defined for 14 SDS derived from Sentinel-2 and 10 from Landsat-8 by measuring the differences in position with respect to the shoreline inferred from profiles obtained on close dates (or simultaneously) to imagery acquisition. For non-simultaneous datasets, the water level was estimated for the time of the satellite images acquisition using oceanographic data and run-up formulations. The measured and estimated shoreline positions were then compared with the extracted SDS. The overall accuracy is good, with errors about $5 \mathrm{~m}$ RMSE, supporting the application of the used methodology to define shoreline dynamics and evolution at challenging environments, as mesotidal exposed and dynamic beaches. Because of its usefulness, SDS have been applied repeatedly in many of the processes that constitute the present doctoral thesis, both being used as a beach monitoring tool per se, as well as to derive geomorphological and coastal hydrodynamic indicators as discussed in following chapters. 


\subsection{Introduction}

Beaches are highly dynamic natural spaces, often facing sudden changes or long-term evolution trends, which can be strongly conditioned by anthropogenic pressure. Monitoring those changes is of paramount relevance to understand coastal evolution and potential hazards, as well as to define coastal management actions. The continuous acquisition of accurate shoreline position is of outmost importance for the monitoring of coastal areas. For this purpose, it is therefore essential to have efficient methodologies that correctly define and extract the shoreline position with low and known errors. Those methodologies can use traditional sources of information as aerial photography, GNSS, LiDAR, UAV and, more recently, video-monitoring (e.g. Sánchez-García et al., 2017). All these sources of information allow recording the shoreline position with high precision but always with limitations inherent to the coverage and the frequency of data acquisition. Landsat-8 (L8) and Sentinel-2 (S2) medium resolution satellites offer free images quasi-continuously (one each 2.9 days combining both platforms, Li \& Roy, 2017) and covering large coastal areas. Taking advantage of the differences in the land/water edge in IR (infrared) bands, several algorithms have emerged to obtain Satellite-Derived Shorelines. For the moment, only a few extraction methodologies have achieved subpixel accuracy (e.g. Liu et al., 2017; PardoPascual et al., 2012; Song et al., 2019; Viaña-Borja \& Ortega-Sánchez, 2019; Vos et al., 2019a). Their assessments are very limited on real scenarios, as they require large sets of high-precision reference data. Thus, only few extraction methodologies have been tested on beaches, using for validation purposes aerial photographs (Viaña-Borja \& Ortega-Sánchez, 2019), UAV (PalomarVázquez et al., 2019), terrestrial photogrammetry (Pardo-Pascual et al., 2018) and, more commonly, in-situ topographic profiles (e.g. Hagenaars et al., 2018; Liu et al., 2017; Vos et al., 2019a). SDS extracted with the system SHOREX (Palomar-Vázquez et al., 2018) have been recently compared with simultaneous video extracted shorelines on Cala Millor beach, Balearic Islands (Sánchez-García et al., 2020), reaching 3.57 m RMSE for L8 and 3.01 m for S2 imagery. Nevertheless, due to the nature of this Mediterranean beach, the assessment has been constricted to low energy conditions and an almost negligible tidal range. Extraction methodologies should be tested and improved for different types of coasts, facing a wider range of tides, waves and swash processes. Such improvement will allow a robust and validated acquisition of the SDS for the vast majority of coastal areas, as well as understanding the influence of the oceanographic processes on the location (and dynamism) of the shoreline.

This work aims to adapt, improve and validate the accuracy of SDS from L8 and S2 imagery using data from an exposed mesotidal beach in order to fill the current lack of assessments on different types of coasts. This would facilitate the applicability of the method to a wider range of coasts worldwide.

\subsection{Methods}

\subsubsection{Field site}

The field work was conducted at Faro Beach, located in Ancão Peninsula, a relatively narrow sand barrier in Algarve, South Portugal. This exposed steep-beach commonly develops beach cusps and it is backed by a dune ridge (Fig. 3.1). It is a mesotidal beach with semi-diurnal tides with an 
average range of $2.8 \mathrm{~m}$ for spring tides, and $1.3 \mathrm{~m}$ for neap tides. Average annual significant offshore wave height is $0.92 \mathrm{~m}$ with $8.2 \mathrm{~s}$ of average peak period (Costa et al. 2001).
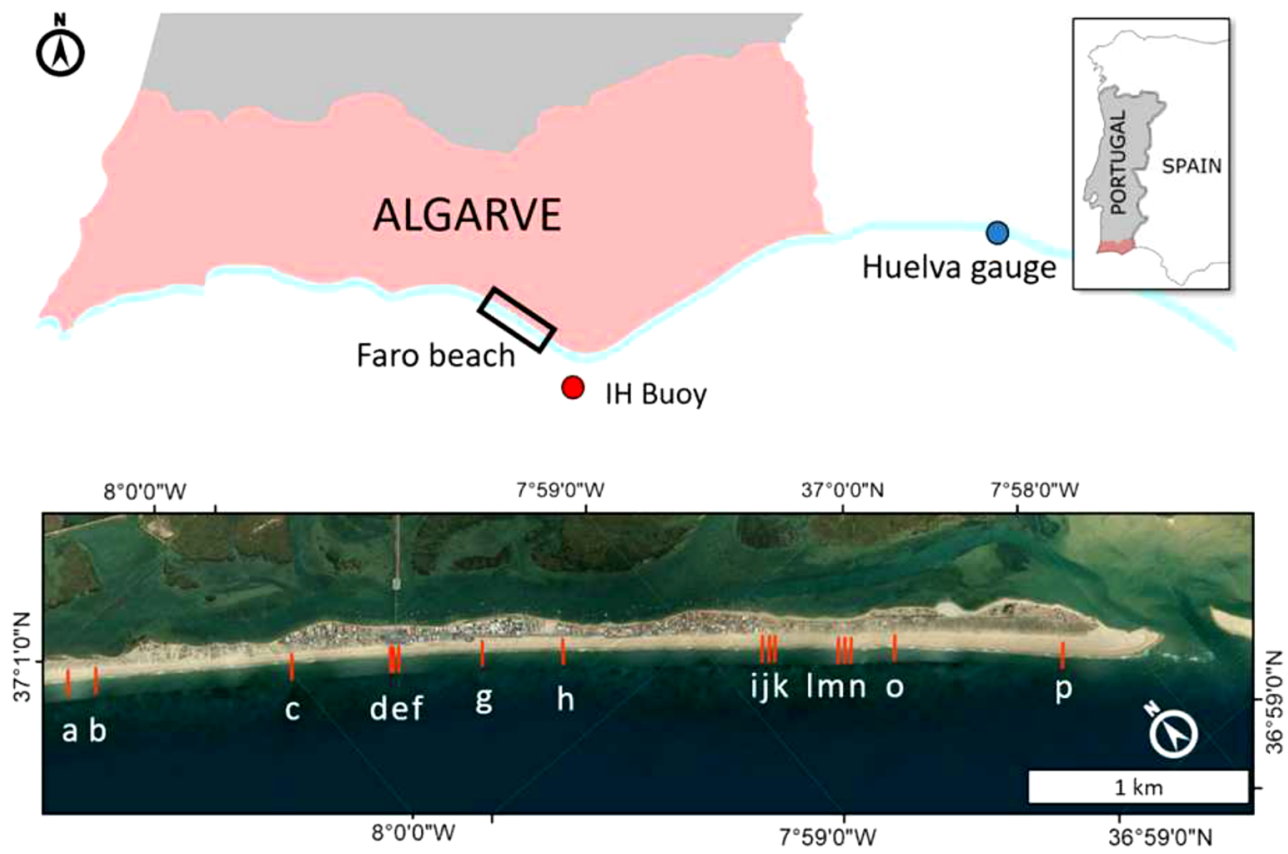

Fig. 3.1. Location of the study area in Faro Beach, as well as the tide gauge and the wave buoy. Detail of the location of the topographic cross-shore profiles.

\subsubsection{Field data}

In-situ RTK-GNSS surveys were carried out 14 different days defining cross-shore profiles at 16 selected locations distributed over $4.5 \mathrm{~km}$ alongshore. A variable number of profiles (between 1 and 7) was used per date (see Fig. 3.1, Table 3.1).

Table 3.1. Date of the topographic surveys, used profiles per date, and associated satellite imagery.

\begin{tabular}{cccc} 
Sentinel-2 & Landsat-8 & GNSS survey & Profiles \\
\hline $19 / 07 / 2016$ & $23 / 07 / 2016$ & $22 / 07 / 2016$ & a, b, p, o \\
$17 / 10 / 2016$ & $11 / 10 / 2016$ & $17 / 10 / 2016$ & a, b, p, o \\
$15 / 01 / 2017$ & $15 / 01 / 2017$ & $15 / 01 / 2017$ & a, b, p, o \\
$05 / 04 / 2017$ & $05 / 04 / 2017$ & $29 / 03 / 2017$ & a, b, p, o \\
$09 / 07 / 2017$ & $10 / 07 / 2017$ & $07 / 07 / 2017$ & a, b, p, o \\
$02 / 10 / 2017$ & $28 / 09 / 2017$ & $03 / 10 / 2017$ & $p, o$ \\
$11 / 11 / 2017$ & $15 / 11 / 2017$ & $09 / 11 / 2017$ & $p, o$ \\
$20 / 01 / 2018$ & $18 / 01 / 2018$ & $23 / 01 / 2018$ & b \\
$19 / 02 / 2018$ & - & $26 / 02 / 2018$ & c, d, e, f, g, h, p \\
$05 / 04 / 2018$ & - & $05 / 04 / 2018$ & b, c, d, e, f, g, p \\
$25 / 04 / 2018$ & - & $20 / 04 / 2018$ & c, d, e, f, g, h \\
$15 / 05 / 2018$ & $10 / 05 / 2018$ & $17 / 05 / 2018$ & $b, c, f, g, h$ \\
$17 / 10 / 2018$ & $17 / 10 / 2018$ & $17 / 10 / 2018$ & i, j, k, l, m, n \\
$21 / 11 / 2018$ & - & $21 / 11 / 2018$ & $i, j, k$ \\
\hline
\end{tabular}

The position of the shoreline was estimated for each profile in order to be used as validation data. To do so, the total water level (considered as the run-up excursion) was determined as:

$T W L=T L+S S+R$ 
where TL is the tidal level, SS is the storm surge and setup, and R is the run-up (by incident waves). Sea level $(T L+S S)$ was obtained from a tide gauge deployed at Huelva Harbor (Spanish Port Authorities, see Fig. 3.1, Table 3.2), while offshore wave conditions were obtained from a buoy (Portuguese Hydrographic Institute, Fig. 3.1, Table 3.2) for the nearest possible conditions in relation to the satellite imagery acquisition. The sea level was corrected to the Portuguese vertical datum.

Table 3.2. Significant wave height $(\mathrm{Hs})$, peak period $(\mathrm{Tp})$ and Sea Level $(\mathrm{SL}=\mathrm{TL}+\mathrm{SS})$ associated with the satellite imagery acquisition.

\begin{tabular}{ccccc} 
Date & Satellite & $\mathrm{Hs}(\mathrm{m})$ & $\mathrm{Tp}(\mathrm{m})$ & $\mathrm{SL}(\mathrm{m})$ \\
\hline $19 / 07 / 2016$ & $\mathrm{~S} 2$ & 1.18 & 7.5 & 0.89 \\
$23 / 07 / 2016$ & $\mathrm{~L} 8$ & 0.65 & 8 & -0.86 \\
$11 / 10 / 2016$ & $\mathrm{~L} 8$ & 0.41 & 10 & 1.01 \\
$17 / 10 / 2016$ & $\mathrm{~S} 2$ & 0.55 & 10.8 & -0.02 \\
$15 / 01 / 2017$ & $\mathrm{~L} 8$ & 1.41 & 6.2 & -1.29 \\
$15 / 01 / 2017$ & $\mathrm{~S} 2$ & 1.35 & 5.85 & -1.16 \\
$05 / 04 / 2017$ & $\mathrm{~L} 8$ & 1.08 & 14.3 & 0.79 \\
$05 / 04 / 2017$ & $\mathrm{~S} 2$ & 1.03 & 13.8 & 0.73 \\
$09 / 07 / 2017$ & $\mathrm{~S} 2$ & 0.53 & 6.6 & 0.41 \\
$10 / 07 / 2017$ & $\mathrm{~L} 8$ & 0.48 & 11.8 & -0.09 \\
$28 / 09 / 2017$ & $\mathrm{~L} 8$ & 0.53 & 5.5 & 0.2 \\
$02 / 10 / 2017$ & $\mathrm{~S} 2$ & 0.89 & 6.2 & 1.31 \\
$11 / 11 / 2017$ & $\mathrm{~S} 2$ & 0.52 & 3.5 & 0.17 \\
$15 / 11 / 2017$ & $\mathrm{~L} 8$ & 1 & 4.5 & 1.34 \\
$18 / 01 / 2018$ & $\mathrm{~L} 8$ & 1.11 & 16.7 & -0.42 \\
$20 / 01 / 2018$ & $\mathrm{~S} 2$ & 0.6 & 13.8 & -0.88 \\
$19 / 02 / 2018$ & $\mathrm{~S} 2$ & 0.5 & 10.9 & -0.97 \\
$05 / 04 / 2018$ & $\mathrm{~S} 2$ & 1.11 & 13.32 & -0.74 \\
$25 / 04 / 2018$ & $\mathrm{~S} 2$ & 0.7 & 9.1 & 1.26 \\
$15 / 05 / 2018$ & $\mathrm{~S} 2$ & 0.45 & 11.1 & 0.54 \\
$17 / 10 / 2018$ & $\mathrm{~L} 8$ & 0.73 & 7 & 0.47 \\
$17 / 1 / 2018$ & $\mathrm{~S} 2$ & 0.77 & 7.5 & 0.37 \\
$21 / 11 / 2018$ & $\mathrm{~S} 2$ & 1.43 & 14 & 1.22 \\
\hline
\end{tabular}

R was determined following the empirical formulation proposed by Vousdoukas et al. (2012):

$\mathrm{R}=0.58 \mathrm{Ho} \xi+0.46$

(2)

where $\mathrm{R}$ is the run-up, Ho is the deep water significant wave height, and $\xi$ is the Iribarren number. This model was selected since it was developed specifically for Faro Beach. Since SDS do not necessarily reflect neither the maximum run-up excursion nor the starting of the swash, it was necessary to identify the run-up excursion that better represents the location of the extracted SDS. Thus, four test cases were analyzed: (i) the estimated run-up level, (ii) 2/3 of it, (iii) half of it, and (iv) $1 / 3$ of it. TWL was defined according to these test cases, and the points of the profiles intersecting the respective TWL were identified as the estimated shoreline position (Fig. 3.2). The estimation is sustained under the assumption of invariant beach profiles between the acquisition of GNSS and satellite data. 


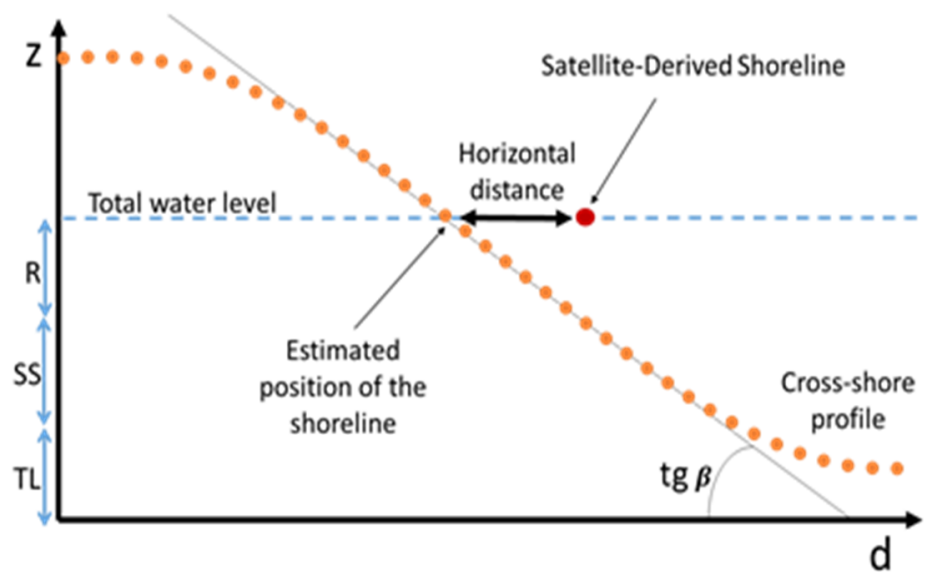

Fig. 3.2. Scheme of a cross-shore profile defined by GNSS points with certain elevation ( $z$ ) along distance (d). TWL is defined for the instant the SDS are acquired, and the point intersecting the profile constitutes the estimated position of the shoreline. The horizontal distance between the estimated position and SDS defines the error of the extracted shorelines.

\subsubsection{Experimental data \& accuracy assessment}

Twenty-four mid-resolution S2 and L8 images were downloaded free of charge from Copernicus Open Access Hub and USGS explorer respectively (see Table 3.1). Covering the period 22 July 2016 - 21 November 2018, the selected images were the closest in time to the available GNSS surveys, with a maximum temporal mismatch of seven days and a percentage of clouds below $30 \%$. The SDS was defined as the water/land intersection at the instant of the image acquisition. The extraction followed the workflow described by Palomar-Vázquez et al. (2018) using the SHOREX system. It applies the sub-pixel algorithmic solution proposed by Pardo-Pascual et al. (2012), and uses Short-Wave Infrared bands (SWIR1) and a third-degree polynomial in order to extract the shoreline from the kernels of analysis. An equivalent kernel size was defined for both satellites (7x7 and 5x5 pixels for S2 and L8 respectively), while a mask was used to cover the inner lagoon and focus the extraction on the desired interface.

SDS positions were horizontally compared against the estimated position of the shore over the GNSS profiles, employed as reference data for validation and error assessment (see Fig. 3.2). Thus, SDS from S2 were compared against the estimated shorelines defined in up to 55 profiles while SDS from L8 were compared against up to 36 shoreline positions. The error was described for each run-up test case using: bias (average distance), precision (standard deviation, hereafter $\sigma$ ), and accuracy (RMSE).

\subsection{Results}

Bias and accuracy registered by the SDS differed both in relation to the satellite source and the run-up test case considered (Table 3.3). On the contrary, precision values were similar for all the run-up test cases, being slightly lower for L8 ( $\sigma$ about $5.5 \mathrm{~m}$ ) than for S2 ( $\sigma$ about $4.5 \mathrm{~m}$ ). For both satellites, bias (and associated with that, the accuracy) changed remarkably when considering different partial values of the run-up proposed by the model. Bias showed a dominating seaward displacement of the SDS with the highest values when considering the total run-up level (test case i), with estimated shorelines displaced more than $6 \mathrm{~m}$ inland from the position of the SDS derived 
both from L8 and S2. The bias decreased for both satellites when considering 2/3 of the calculated run-up (case ii), and even more when considering half of it (case iii) (see Table 3.3). The smaller differences were obtained when considering $1 / 3$ of the calculated run-up (case iv) being the bias landward directed. L8 presented, for all cases, a slightly smaller bias than S2.

Results suggest that accuracy is linked to the bias. Thus, for both satellites the highest accuracy occurs at test cases iii and iv, being higher for \$2 (smaller value) than for L8.

Table 3.3. Bias (average distance), precision (standard deviation), and accuracy (RMSE) for each satellite source and different run-up test cases (I to iv). Positive values show a landward displacement of the SDS. Values at bold highlight the best results.

\begin{tabular}{c|c|cccc} 
Satellite & Test case & i & ii & iii & iv \\
\hline \multirow{5}{*}{ L8 } & no. profiles & 35 & 36 & 36 & 36 \\
& Bias (m) & -6.29 & -3.05 & -1.41 & 0.12 \\
& Precision (m) & 5.55 & 5.47 & 5.69 & 5.67 \\
& Accuracy (m) & 8.33 & 6.19 & 5.78 & 5.77 \\
\hline \multirow{5}{*}{ S2 } & no. profiles & 55 & 49 & 44 & 42 \\
& Bias (m) & -6.59 & -3.25 & -1.29 & 0.53 \\
& Precision (m) & 4.61 & 4.48 & 4.44 & 4.75 \\
& Accuracy (m) & 8.01 & 5.50 & 4.58 & 4.72 \\
\hline
\end{tabular}

\subsection{Discussion}

Despite the recent progress in shoreline extraction techniques, quality assessments using as reference in-situ data on beaches are scarce and often limited to low energy, microtidal coastal areas (e.g. Hagenaars et al., 2018; Liu et al., 2017; Pardo-Pascual et al., 2018; Sánchez-García et al., 2019, 2020; Vos et al., 2019a). When considering higher energy and meso/macrotidal beaches the comparison is mostly limited to a reduced number of points/profiles or hydrodynamic conditions (e.g. Vos et al., 2019a).

The present assessment of SDS extracted from both L8 and S2 satellites contributes to fill the general lack of in-situ tests in diverse coastal types. This work assesses SDS extracted with SHOREX using a relatively large data set (between 35 and 55 compared shorelines depending on the test case) obtained at an exposed mesotidal beach experiencing $\mathrm{Hs}$ up to $1.43 \mathrm{~m}$ and Tp over $14 \mathrm{~s}$ during the evaluation days. The accuracy for the extracted shorelines is about $5 \mathrm{~m}$ RMSE (Table 3.3). While bias showed a similar pattern for the images acquired by both satellites, precision was slightly higher in S2 (Table 3.3), and it was translated to the values of accuracy. Nevertheless, it should be highlighted that the temporal difference between $L 8$ images and the reference data was greater, potentially enhancing the inaccuracy. Under the most favorable run-up scenarios, results appeared in line with the preliminary test of SDS extracted with SHOREX at the energetic and microtidal Reñaca Beach, Central Chile. In that work, coincident shorelines derived from photogrammetric surveys were used as validation data, being the obtained accuracy of the SDS about 4.55 m RMSE for the combination of S2 and L8 (Sánchez-García et al., 2019). Accuracy results are comparable to those obtained in more robust assessments performed on Mediterranean beaches with low wave energy conditions and reduced tidal range. In those works, SDS extracted with SHOREX were compared against alongshore GNSS surveys on el Saler Beach, Spain (Pardo- 
Pascual et al., 2018) and, more recently, against a large package of video monitored shorelines (91) on Cala Millor Beach, Balearic Islands (Sánchez-García et al., 2020). This latter assessment defined accuracy values of $3.57 \mathrm{~m}$ and 3.01 RMSE for SDS derived from L8 and S2 imagery respectively. Nevertheless, that beach experiences almost negligible tides (below $0.25 \mathrm{~m}$ ) and low waves (Hs usually below $0.9 \mathrm{~m}$ and Tp between 4 and $7 \mathrm{~s}$ ). Those conditions contrast with the present assessment in Faro Beach, in which higher waves and especially longer peak periods may cause larger horizontal excursions.

When comparing with the assessments performed for other extraction methodologies, SHOREX seems to present good results even considering a mesotidal and moderately energetic coastal area, like Faro Beach. Hagenaars et al. (2018) assessed SDS from S2 and Landsat 5, 7 and 8 along $4.5 \mathrm{~km}$ of the microtidal Dutch coast (average tidal range of $1.7 \mathrm{~m}$ and mean $\mathrm{Hs}$ of $1.3 \mathrm{~m}$ ). They reported average errors (expressed as average bias \pm standard deviation) for L8 and S2 images of $9.5( \pm 16 \mathrm{~m})$ and $10.5( \pm 12 \mathrm{~m})$ respectively when filtering measurements associated with calm wave conditions (wave heights below $0.5 \mathrm{~m}$ ) and $21.9( \pm 49 \mathrm{~m})$ for S2 and $19.9( \pm 44 \mathrm{~m})$ when no filters were applied. Liu et al. (2017) evaluated SDS from L5, L7 and L8 on the $3.6 \mathrm{~km}$ microtidal Narrabeen Beach, Australia (tidal range below $2 \mathrm{~m}$, mean $\mathrm{Hs}$ and $\mathrm{Tp}$ of $1.6 \mathrm{~m}$ and $10 \mathrm{~s}$ respectively), and reported about $10 \mathrm{~m}$ RMSE when comparing full series of SDS, while annual mean shorelines were within 5.7 m RMSE. More recently, Vos et al. (2019a) carried out tests on four microtidal beaches (Australia, New Zealand, and the USA) with accuracy values ranging from $7.2 \mathrm{~m}$ to $11.6 \mathrm{~m}$ RMSE. This same work also included a test on the meso/macrotidal Truc Vert Beach, France (3.7 $\mathrm{m}$ of mean spring tidal range and $1.4 \mathrm{~m}$ of $\mathrm{Hs}$, using one single reference profile) with accuracy results of 12.7 m RMSE.

Oceanographic conditions and wave characteristics may act as important inaccuracy drivers during SDS extraction. Higher Hs and Tp are associated with higher run-up and larger excursions. Some authors have pointed out the existence of a relationship between accuracy, the foam of the breaking waves and the wave period (Hagenaars et al., 2018; Pardo-Pascual et al., 2018). For a better assessment of shoreline definition accuracy from satellite imagery it is key to know which position of the beach-face is being identified by the SDS. The instantaneousness of the image, together with the spatial and temporal oscillations of the shoreline resulting from the alternation of swash and backswash processes makes it difficult to tell. The image is a snapshot that often includes an alongshore undulated shoreline as a function of swash/backwash processes, and/or the existence of beach cusps or any other coastal undulations. The extracted SDS integrate different degrees of humidity or water inundation, not being easy to define the exact process or beach position they represent. The tests of the present study have allowed approaching the uncertainty about the exact location of the extracted shoreline on the beach-face, contributing to understand what the extraction systems are actually mapping. The role of the swash on the shoreline definition has been evidenced as large differences appeared in the measured errors, depending on the values considered for the run-up. The lowest bias and the highest accuracy were reached when considering half and one third of the run-up level defined according to the empirical model proposed by Vousdoukas et al., 2012 (Table 3.3, test case iii and iv). In fact, if a 
simple regression analysis is performed to the results, the zero bias is attained for a position representing $35-37 \%$ of the total run-up. These results seem to indicate that SDS represent a line following positions sometimes covered by the water sheet created by swash processes, and not necessarily a clear separation between wet/dry portions of the beach.

The definition, use and exploitation of SDS for coastal monitoring, already viable at Mediterranean beaches, require extra considerations when working on other types of coast. On the one hand, and with regard to the shoreline definition, the high variability experienced by the shoreline position on a beach like Faro Beach brings some requirements to the extraction workflow directly imposed by the specific characteristics of the studied zone. Thus, kernel sizes have been adapted (7x7 and 5x5 pixels for S2 and L8 respectively) based on previous tests (Pardo-Pascual et al., 2018; Sánchez-García et al., 2020) in order to ensure an extraction process focused on the desired pixels. On the other hand, and with regard to the application of the extracted shorelines, an appropriate comparison of SDS from different dates makes it necessary to deal with the effect of variant oceanographic conditions. The knowledge of wave and tide data at the time of acquisition of the satellite images together with information on the beach-face morphology may allow horizontal corrections of the SDS position, making compatible the use of shorelines of dates with different conditions. Once SDS accuracy is quantified for new environments, many applications can be potentially explored, as the characterization of mid-term (Almonacid-Caballer et al., 2016) or decadal shoreline changes (Liu et al., 2017). The availability of many individual shoreline positions may allow robust studies of coastal evolution for different time scales (days to decades), based on large data sets. Thus, SDS make it possible to define the beach state before and after impacts, either of natural origin, as storms (Pardo-Pascual et al., 2014), or anthropogenic, as sand nourishments or coastal protection works (Cabezas-Rabadán et al., 2019a,b).

\subsection{Conclusions}

This study constitutes the first assessment of SDS extracted using SHOREX on an exposed mesotidal coast, employing for this purpose a large dataset of oceanographic conditions and measured beach profiles. The accuracy (5.77 $\mathrm{m}$ and $4.58 \mathrm{~m}$ RMSE for L8 and S2 respectively) was in the same order of magnitude, or even slightly lower, than in previous assessments on microtidal Mediterranean beaches, and lower than in previous studies for other meso-macrotidal beaches. This is a very positive result considering that the test took place in an exposed beach with moderate Hs (up to $1.43 \mathrm{~m}$ ) and long peak periods (up to $14 \mathrm{~s}$ ). The validation of the accuracy of the SDS in more challenging coastal types widens the potential applications of this extraction methodology, constituting a low-cost source of data with high spatial and temporal resolution helpful for studying the coast and monitoring beach changes. 



\section{Chapter 4}

\section{Characterizing beach changes using satellite-derived shorelines}

\section{Part I}

The first part of the chapter has been published as:

Cabezas-Rabadán, C., Pardo-Pascual, J. E., Palomar-Vázquez, J. M., Fernández-Sarría, A. (2019). Characterizing beach changes using high-frequency Sentinel-2 derived shorelines on the Valencian coast (Spanish Mediterranean). Science of The Total Environment, 691, 216-231.

\section{Part II}

The second part of the chapter has been published as:

Cabezas-Rabadán, C., Pardo-Pascual, J.E., Palomar-Vázquez, J., Almonacid-Caballer, J., FernándezSarría, A. (2019). Monitorización de la respuesta de playas Mediterráneas a temporales y actuaciones antrópicas mediante imágenes Landsat. GeoFocus. Nº 23.

\footnotetext{
"Quizás porque mi niñez sigue jugando en tu playa escondido tras las cañas duerme mi primer amor llevo tu luz y tu olor por donde quiera que vaya y amontonado en tu arena guardo amor, juegos y penas
}

\section{[...]}

¡Qué le voy a hacer si yo nací en el Mediterráneo...!"

-J. M. Serrat-

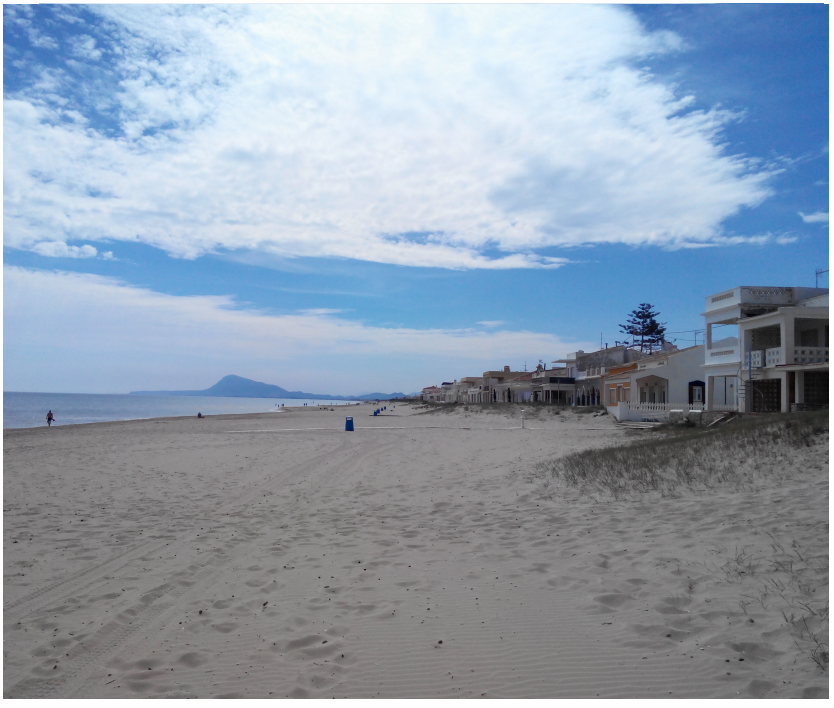


Shoreline positions are extremely interesting data for studying coastal dynamism through characterizing changes in beach morphology. The large scale and continuous monitoring of these changes is of great interest for coastal management.

As it has been shown in the previous chapter, the extraction of SDS is now developed enough to offer sufficient accuracy to contribute to the characterization of the beach state and their changes. The availability of this methodology poses the challenge of developing procedures to take advantage of long series of SDS, as well as deriving from them other useful indicators. This is a necessary step in order to transform SDS in truly useful data for the management. These indicators would open up the possibility of monitoring natural changes or those caused by the human being at a wide variety of temporal and spatial scales. It is necessary to evaluate until which point the accuracy of SDS and the derived indicators is useful for recognizing and quantifying the effects of the different events on the morphology of the beach, as well as their subsequent evolution.

Taking this into account, this chapter applies SDS automatically extracted with the system SHOREX from mid-resolution satellite imagery in order to show their monitoring potential. The chapter is composed by two complementary parts. They are scientific publications that respectively have obtained the SDS from different satellites, and they approach the application of SDS from different temporal and geographical scales:

- Part l: the first work (Cabezas-Rabadán et al., 2019b) covers a wide coastal segment over a period of one and a half years using Sentinel-2 imagery, providing high revisit frequency and the highest possible accuracy. A preliminary test of the methodology was presented in the conference 'Jornadas de Geomorfología litoral' (Cabezas-Rabadán et al., 2019e).

The research shown in this chapter applies SHOREX for the automatic extraction of the shoreline position from mid-resolution satellite imagery. Shorelines were defined from 60 Sentinel-2 images throughout two and a half years at a regional scale $150 \mathrm{~km}$ of the Gulf of Valencia, Western Mediterranean). It is a coastal segment composed of open sandy beaches with high recreational use, erosive problems, and numerous human interventions conditioning the sediment distribution.

Widths were defined throughout two and a halfyears from 60 shorelines (3.04 m RMSE) covering $50 \mathrm{~km}$ of the Gulf of Valencia. Important width contrasts appeared along the study site associated with sediment imbalances motivated by sediment traps and other anthropic actions. Segments too narrow for maintaining the recreational function were located and mapped (16\% narrower than $30 \mathrm{~m}$ ). Short-term width changes appeared linked to storm events, with fast retreatments and slow recoveries. Punctually, even small-magnitude nourishments created perceptible changes in width $\left(12,830 \mathrm{~m}^{3}\right.$ were associated with a $4 \mathrm{~m}$ increase).

This novel description of the beach state and its changes from Satellite-Derived Shorelines is useful for coastal management, especially considering the global coverage of these free satellite images. It may improve the comprehension of coastal processes as well as monitor human interventions on the coast, helping in the decision-making. 
- Part II: the second work (Cabezas-Rabadán et al., 2019C) focuses on three particular beaches along three decades using the entire Landsat series by combining Landsat satellites to show the potential for studying trends along medium-term scales.

The position of the shoreline was defined at three beaches located in the Gulf of Valencia on multiple dates during the period 1984-2014 based on Landsat images 5, 7, and 8 and again using the SHOREX system for the shoreline extraction. The possibility of defining historical series of SDS offers the possibility of quantifying coastal trends along the medium term and to analyze the influence of human interventions. At the same time, the availability of information in the short term shows great potential for monitoring beach response to storm events and the subsequent recovery, as well as to punctual human actions as sand nourishments. 


\section{Part I- Characterizing beach changes using high-frequency Sentinel-2 derived shorelines on the Valencian coast (Spanish Mediterranean)}

\subsection{Introduction}

Coastal areas are essential for humans, as they hold important and diverse productive habitats for their settlement, subsistence and development (Schlacher et al., 2008). Therefore, the monitoring of coastal dynamics is critical for the society and economy of these areas. The availability of information is necessary for both scientists and managers in order to understand its functioning and to plan human settlements. In this regard, the analysis of shoreline changes and its evolutionary patterns appears as an essential issue (Boak \& Turner, 2005).

Coastal erosion is a global problem (Bird, 1996) that in Europe affects up to $20 \%$ of the coasts (EC, 2004). Erosive processes and coastal flooding are expected to increase associated with climate change and sea-level rise (IPCC, 2014; Schlacher et al., 2008). Erosion, coupled with the presence of landward barriers of human origin will reduce space for natural life (Feagin, 2005; Nordstrom, 2004) causing important ecosystem loss along the coast. With regard to a recreational function that beaches offer to human beings, erosion will negatively affect the economic exploitation of the beaches and tourism revenues (Alexandrakis et al., 2015). In order to maintain them, monitoring the beach morphology and their physical characteristics will become increasingly necessary (Ballesteros et al., 2018; Jiménez et al., 2011). The beach loss will force coastal managers to respond both in the short term (e.g. to occasional episodes of storms) and in the long term to the progressive sea-level rise scenarios. As an example, planned retreatment and sacrifice areas (Williams et al., 2018) appear as more viable options than pure engineered structures along the coast (Song et al., 2018). All the possible responses and adaptation strategies should be based on updated data of the coastal state, which must be transferred to managers through objective and simple indicators.

However, there is a lack of knowledge about the state of the beaches. Traditional techniques for shoreline-change studies are photointerpretation (Jones et al., 2009; Pajak \& Leatherman, 2002), continuous video-monitoring (Bouvier et al., 2017; Sánchez-García et al., 2017), DGPS field measurements (Baptista et al., 2008; Pardo-Pascual et al., 2005; Psuty \& Silveira, 2011), LIDAR (Pye \& Blott, 2016) and UAV (Casella et al., 2016; Turner et al., 2016). They are limited in temporal or spatial coverage, as well as being both costly and labor-intensive (Do et al., 2018; Sánchez-García et al., 2020). Thus, the lack of continuous and up-to-date data collection systems applicable homogeneously on a large scale has contributed to the lack of widespread adoption by administrations.

In this scenario, previous works have investigated the potential of optical satellite imagery for coastal surveillance. Different evolutionary studies are sustained in the identification of the water/land position from free mid-resolution satellite imagery (Gens et al., 2010; Ghosh et al., 2015; Luijendijk et al., 2018), mainly Landsat series (Almonacid-Caballer, 2015; Do et al., 2018). Since 2017, the Sentinel-2 mission offers improvements in both resolution and revisit frequency. With the 
combination of the Sentinel-2A and 2B satellites, ESA has been providing worldwide coverage of free images with a 5 -day revisit. Given the large planetary coverage and high revisiting frequency of the satellites, they appear as an extremely interesting source of information for studying changes in coastal morphology (Castelle et al., 2015; Pardo-Pascual et al., 2014; Vandebroek et al., 2017), more versatile, cheaper and simpler than videomonitoring systems. However, in order to detect relatively small changes, it is necessary to overcome the coarse pixel size of the Landsat and Sentinel-2 satellites. By the moment, only a few authors have achieved the definition of the shoreline position at sub-pixel level (Almonacid-Caballer, 2014; Foody et al., 2005; Li \& Gong, 2016; Liu et al., 2017; Pardo-Pascual et al., 2012, 2018). A proper definition of the Satellite-Derived Shorelines (SDS) requires to adapt the subpixel extraction algorithm to the images of the different satellites, as well as to follow an efficient workflow capable of dealing with a large volume of images. With that in mind, SHOREX system has been developed for the shoreline extraction (Palomar-Vázquez et al., 2018; Sánchez-García et al., 2020). As its core, it takes the algorithmic solution for the sub-pixel extraction originally described in Pardo-Pascual et al. (2012) and Almonacid-Caballer (2014). The algorithm has been surrounded by the necessary tools for an efficient management of large volumes of mid-resolution satellite images, creating a system for automatically defining the SDS. Sánchez-García et al. (2020) assessed the accuracy of SDS on the Mediterranean beach of Cala Millor (Balearic Islands) by comparing their positions with shorelines derived from simultaneous video-monitoring. After testing the combination of different extraction parameters, the highest accuracy for Sentinel-2 imagery was defined as $3.01 \mathrm{~m}$ RMSE. This way, SHOREX system follows a complete and efficient workflow ranging from the acquisition of images to the definition of SDS with high accuracy. It can offer big packages of shorelines (tens per year) along large coastal areas and at the same pace as satellite images are acquired. This poses the challenge of how to exploit the high potential of the SDS for deriving descriptors of the beach morphology. Only this way will SDS constitute an effective source of information for monitoring and understanding the coastal dynamism and thus helpful for the management of coastal areas.

The main objective of this work is to propose a methodology capable of taking advantage of highfrequency SDS data to quantify and characterize the dynamism of beaches by means of a spatiotemporal model of their widths. This approach is applied over two and a half years to $50 \mathrm{~km}$ of microtidal coastline in the south of the Gulf of Valencia, evaluating the utility of the model for (1) characterizing the state of the beaches, (2) studying the impacts caused by specific events, both natural as storms and artificial as sand nourishments, and (3) locating and mapping of problematic segments.

\subsection{Methodology}

\subsubsection{SDS and beach width definition}

For this work, the data source was the freely available mid-resolution images of the satellite Sentinel-2 (S2). The analysis employed the SWIR 1 band (1565 - $1655 \mathrm{~nm}$, band 11) with $20 \mathrm{~m}$ of spatial resolution. The images were captured in 60 different dates between 06/07/2015 and 18/01/2018, covering 925 days (Fig. 4.1). These are all the available images from the launch of the first of the two S2 satellites (23/06/15 and 7/03/17 respectively) until the beginning of 2018 . 


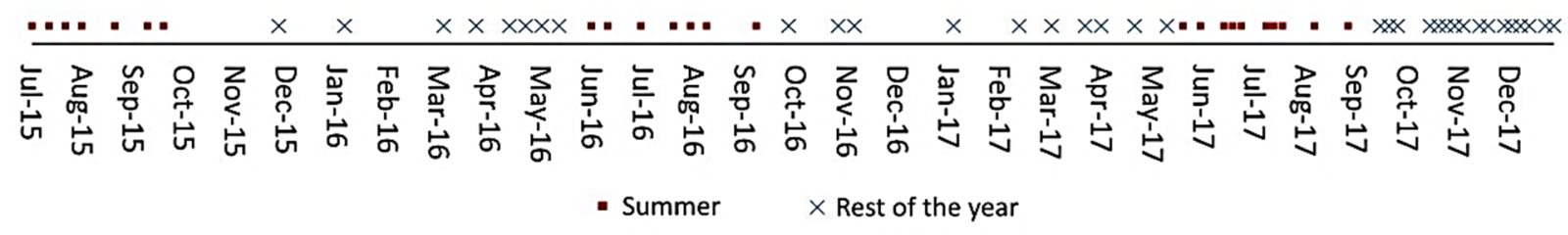

Fig. 4.1. Imagery employed in the analysis differentiated between summer dates (June - September) and the rest of the year (October - May).

Throughout the study period, there were small gaps caused by the existence of cloudiness. When the clouds did only affect one part of the coastal area, it was possible to take profit of the rest of the image. Nevertheless, an irregular distribution of the images appears along the year, with more available images during summer months. Therefore, the scarcity of images is remarkable along certain periods (24/09/2015 - 3/12/2015, and 17/11/2016 - 25/02/2017).

For each image (and date), Satellite-Derived Shoreline (SDS) and beach width (BW) were defined along the coast. SDS was defined as the intersection between water and land at the instant in which each image was acquired. The shoreline extraction followed the methodology described by Palomar-Vázquez et al. (2018) and Sánchez-García et al. (2020). The SHOREX system was used with a SWIR1 band, fitting a third-degree polynomial in order to detect on a $5 \times 5$ kernel the shoreline position with an accuracy of $3.01 \mathrm{~m}$ RMSE. The process started from an approximate line photo-interpreted from a 2015 aerial orthophotography with $25 \mathrm{~cm}$ resolution (PNOA, www.pnoa.ign.es). As the protocol is fully automatic the extraction efficiency increases - 8 hours of calculation time for the entire extraction workflow- while the subjectivity and bias associated with human intervention disappear. After discarding sections of shore without interest for this study (rigid structures, mouths of rivers, streams, irrigation canals, and intercalated small spaces) $41.5 \mathrm{~km}$ of shoreline were defined.

For defining the BW, the inner edge of the beach was defined from the same aerial orthophotography. Constituted by elements both natural (dunes and cliffs) and artificial (promenades, buildings, and roads), this inner limit is considered stable at the time scale of this work. In order to facilitate the management, the inner line of the beach was segmented into 519 segments of $80 \mathrm{~m}$ length. They constitute the basic spatial units on which the study has been carried out. For each segment, the shortest distance between the inner limit and the SDS was defined as the instantaneous width of the beach. Throughout the study period, 591,441 widths measurements were registered, and the average width was calculated on each date for each segment.

\subsubsection{Spatiotemporal model of beach widths}

Beach width measurements were organized and led to a continuous spatiotemporal model (Fig. 4.2). In order to overcome the unequal distribution of records and to have continuous records throughout space and time, BW was deduced in instants and locations without real measurements. For this purpose, from the average width values (about 55 per segment) a TIN interpolation was carried out following the Delaunay triangulation (Tsai, 1993). Coastal segments with no width 
values or without morphodynamic connection were not considered for the interpolation. For a more efficient analysis, the TIN was rasterized generating the spatiotemporal model.

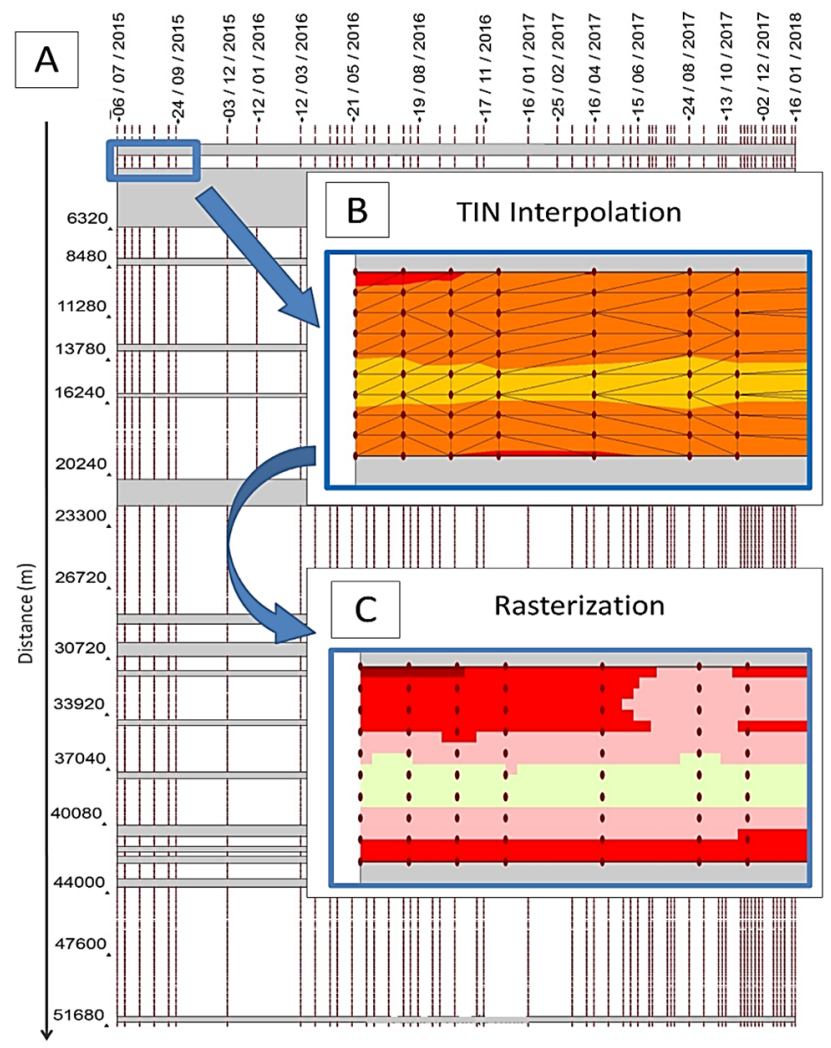

Fig. 4.2. Creation of the spatiotemporal model: (A) Width measurements along space ( $Y$-axis, distance from the North) and time (X-axis, date). (B) Interpolation. (C) Rasterization leads to the spatiotemporal model: a Hovmöller diagram with $80 \mathrm{~m}$ and 1.2 days cells and colors representing width values. It allows identifying changes in beach morphology.

\subsubsection{Characterization of beach state and changes}

GIS analysis operations were carried out for characterizing beach state and changes in the morphology. The union of the width values of the same segment allowed defining the changes over time (925 days) in the same geographical position. On the contrary, values defined on the same date also allowed defining the width state along the whole coast.

The state of the beaches was characterized through their current width values, as well as their distribution and frequency in which they appear. The dynamism of the coastal area was analyzed through the short-term width changes that were defined by comparing an instant width with the value at the beginning of the monitored period. This way, episodes of change were detected, quantified, and analyzed, trying to identify different typologies according to their magnitude and area of affection (local or large sectors). The relation between width changes and impact events as storms and artificial sediment movements was analyzed. For this purpose, the data about nourishment actions were integrated into a GIS in order to locate them temporally and spatially. The actions of greatest magnitude were selected and their effect was studied, as they potentially have the biggest capacity to affect the morphology of the coast and the shoreline position.

In order to identify coastal segments susceptible to experience problems in maintaining their beach functions, a minimum width threshold was defined. According to some studies on 
Mediterranean beaches, widths below 30-35 m may be detrimental to the development of recreational beach functions (Alemany, 1984; Jiménez et al., 2011; Sardá et al., 2009; Yepes, 2002). Therefore, the problematic segments were defined as those with a width below $30 \mathrm{~m}$ at least once throughout the study period. They were classified according to the number of days experiencing widths below the threshold. Furthermore, based on their locations they were grouped in different sections and sectors. According to their characteristics, the most problematic segments were identified. At the same time, their geographical distribution was analyzed together with the coastal morphology in the surroundings, trying to get a better understanding of the cause of their problems.

\section{A case of study from the Valencian coast}

\subsection{Study area}

The study area comprises the southern half of the Gulf of Valencia (Eastern Spain), in the western Mediterranean, the coastal segment between the Cape of Cullera and the port of Dénia (Fig. 4.3). Given the high anthropic and recreational pressure coupled with recent erosion problems, this sandy coast is a perfect example to apply this methodology to provide data potentially useful for coastal management.

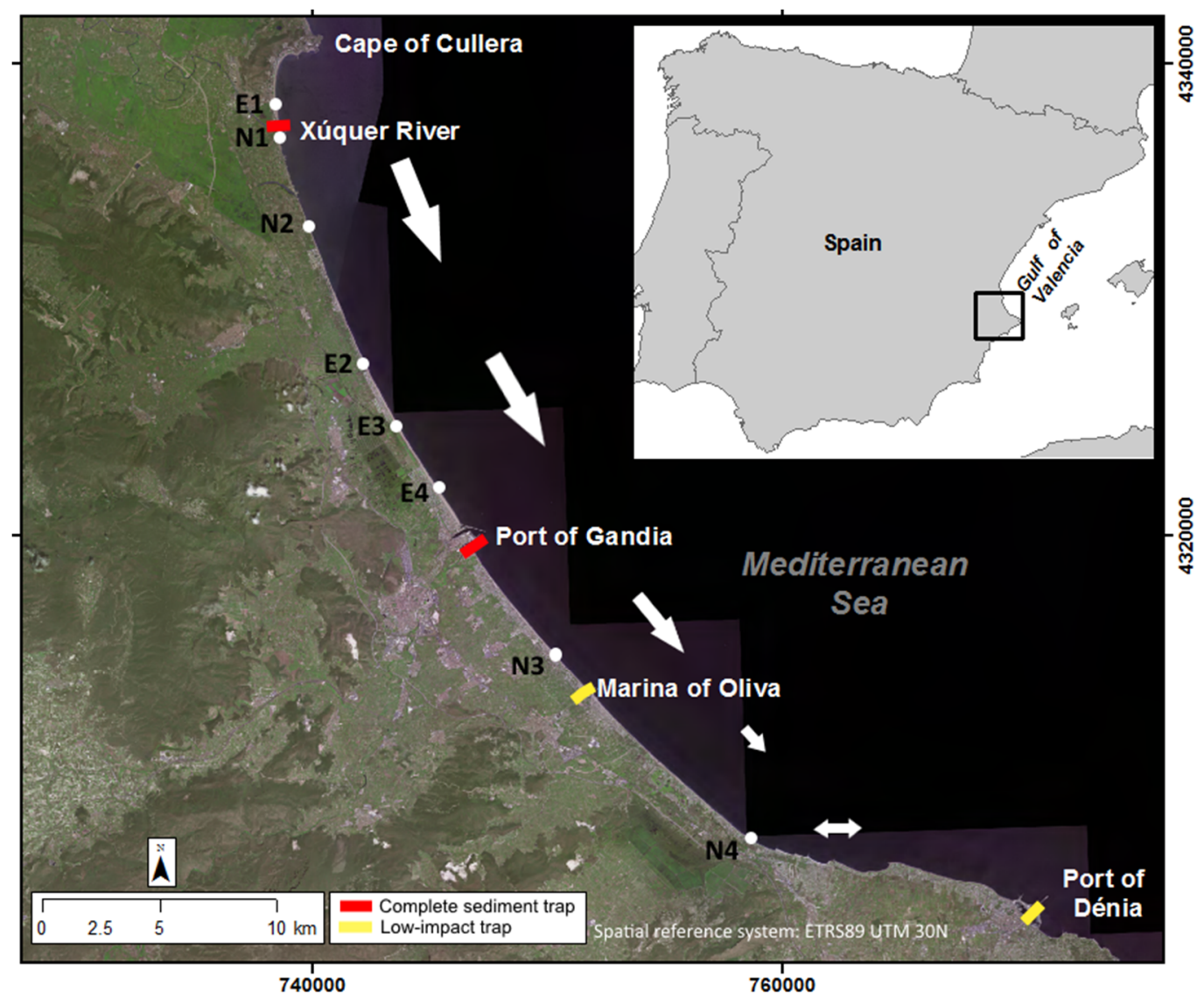

Fig. 4.3. Littoral drift (arrows), sediment traps (squares) and artificial sand movements (points) along the study area. Extractions: E1) Sant Antoni beach, E2) Séquia la Ratlla canal mouth, E3) Vaca river mouth, E4) Gandia beach. Nourishments: N1) South of Xúquer river mouth, N2) El Brosquil and la Goleta beaches, N3) Piles beach, N4) El Molinell beach. 
It is a microtidal coast (average range of $0.3 \mathrm{~m}$ and maximum of $0.7 \mathrm{~m}$ ), with significant wave height (Hs) of $0.7 \mathrm{~m}$ and peak period (Tp) of $4.2 \mathrm{~s}$ on average (Pardo-Pascual et al., 2018). During storm events waves sometimes reach $5 \mathrm{~m}$ (Pardo-Pascual et al., 2014) as it happens during the study period (Fig. 4.4), with seasonal variations showing a magnitude clearly lower than the specific episodes of high waves (always considering the microtidal Mediterranean environment). These peaks appeared mainly between autumn and the end of winter.

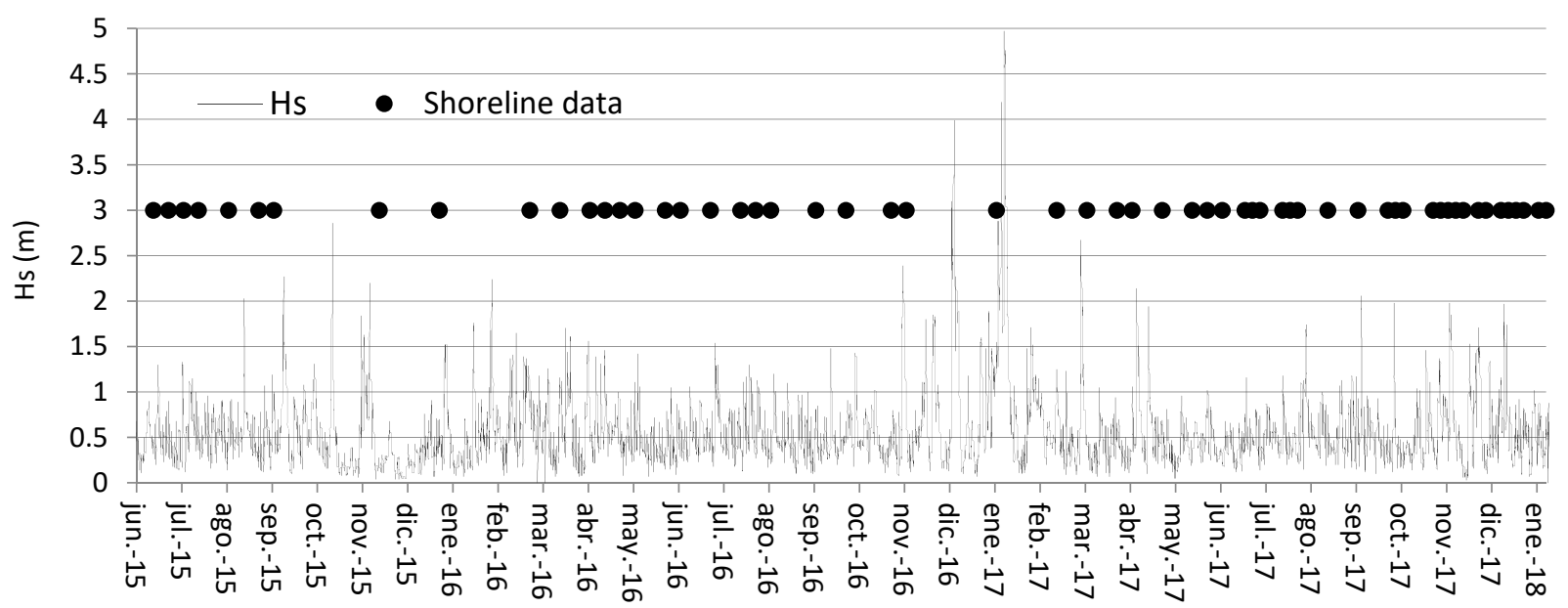

Fig. 4.4. Significant wave height (June 2015-January 2018) in the SIMAR point 2083108, derived from numerical modeling for deep waters by the Spanish Port Authorities (www.puertos.es). Dates with available shoreline data highlighted.

The morphology evidences a historical accumulation of sediment along this coast that allowed the development of double-barred beaches and wide dune ridges (Sanjaume \& Pardo-Pascual, 2003; Sanjaume et al., 2019). The region presents southerly transport caused by its orientation in combination with the direction of the waves during storms. The study area belonged to the Gulf of Valencia coastal cell (between the Ebro Delta and the Cape of Sant Antoni, about $400 \mathrm{~km}$ length). However, the construction of port docks has caused its subdivision in smaller coastal cells (Pardo-Pascual, 1991; Sanjaume \& Pardo-Pascual, 2005) as these infrastructures constitute artificial barriers for the sediment transport along the coast. The most important obstacles are the jetties that protect the mouth of the Xúquer river (the northern one reaches $7 \mathrm{~m}$ depth) and the dikes of the port of Gandia (11 m depth). In both cases, they usually act as complete sediment traps, although the jetties in the Xúquer can allow a by-pass during big storms. The marina of Oliva and the port of Dénia present breakwaters, but they are located in coastal segments with different orientations, smaller sediment transport and, therefore, lower impact on the surrounding beaches. The magnitude of the longshore transport varies geographically a lot: it is greater in the northern part and it decreases substantially to the south, especially beyond the port of Gandia, and it ends south of the marina of Oliva. Finally, the southernmost section does not present a clear transport direction (Pardo-Pascual \& Sanjaume, 2019).

In the Valencian coast, 26\% of the beaches suffer erosive processes (EC, 2009). In the study area erosion has become a problematic issue during the last decades (Cabezas-Rabadán et al., 2018; Pardo-Pascual \& Sanjaume, 2019). The situation is especially remarkable because those beaches 
constitute the basic resource for sun, sand and sea tourism (Cabezas-Rabadán et al., 2019a; ObiolMenero, 2003). Due to their recreational function, they constitute an essential source of economic benefits for the Valencian region, where the tourism industry contributes to more than $14 \%$ of the gross domestic product (Rico-Amorós et al., 2009).

As a response to coastal erosion, sand nourishment has been the defensive action most widely used in recent decades (Obiol-Menero, 2003). The artificial extraction and dumping actions carried out by the Administration were identified along the vast majority of the study area (Table 4.1, Fig. 4.3). Most of the interventions were sand movements from sediment-surplus beaches to segments experiencing erosive problems. Between 2015 and January 2018, 191,297 $\mathrm{m}^{3}$ of sand were extracted and $217,002 \mathrm{~m}^{3}$ were poured. Two areas recorded the largest artificial sand movements: $72 \%$ of the sand was extracted from Sant Antoni de Cullera beach and $64 \%$ was dumped in El Brosquil and La Goleta beaches.

Table 4.1. Artificial sediment movements on beaches in the province of Valencia (Source: Directorate General of Sustainability of the Coast and of the Sea). Data of the southernmost $15 \mathrm{~km}$ of the study area (Alicante province) were not available.

\begin{tabular}{cccccc} 
Location & Municipality & Volume $\left(\mathrm{m}^{3}\right)$ & Action & Start & Finish \\
\hline Sant Antoni beach & Cullera & 137,489 & Extraction & June-15 & June-18 \\
Séquia la Ratlla canal mouth & Tavernes/Xeraco & 21,796 & Extraction & March-15 & May-18 \\
Vaca river mouth & Xeraco/Gandia & 8,944 & Extraction & May-18 & June-18 \\
Gandia beach & Gandia & 23,068 & Extraction & November-17 & June-18 \\
South Xúquer river mouth & Cullera & 63,561 & Nourishment & April-15 & June-18 \\
Brosquil/la Goleta beaches & Cullera/Tavernes & 138,099 & Nourishment & December-15 & June-18 \\
Piles beach & Piles & 14,822 & Nourishment & November-15 & November-17 \\
El Molinell beach & Dénia & 520 & Nourishment & October-15 & November-15 \\
\hline
\end{tabular}

\subsection{Results}

\subsubsection{Beach widths}

Figure 4.5 shows a spatiotemporal model of the BW over the whole study area and the period analyzed, useful for understanding the beach state. All the narrow coastal segments (below $30 \mathrm{~m}$ ) appear in reddish colors differentiated according to their magnitude. Blue and purple indicate, on the other hand, very wide segments (over $60 \mathrm{~m}$ and up to $159 \mathrm{~m}$ ). Green tones represent widths between 30 and $60 \mathrm{~m}$.

Wide beach segments appear located updrift of artificial obstacles to coastal transport. Their cumulative effect is associated with the progressive width increase when approaching the infrastructure as it can be seen between Séquia de la Ratlla canal and the port of Gandia, and northern of the jetties protecting the mouth of the Xúquer river. Narrow beach segments (below $30 \mathrm{~m}$, red colors) appear only partially related to the interruption of longitudinal transport. In fact, a clear relationship with a sedimentary trap only appears south of the Xúquer jetties, between Brosquil breakwaters and la Goleta canal. The port of Gandia, with a strong cumulative effect on its north, clearly does not show the opposite effect on its south. Although the beach segments are quite narrow there, most of them are usually between 30 and 50 m wide. Segments narrower than 
$30 \mathrm{~m}$ have a specific but well-defined character. Fig. 4.6 shows the width of the beach on a given day throughout the whole study area, and narrow widths can clearly be appreciated (close to 20 $\mathrm{m}$ ) in Bellreguard ( $\mathrm{km} \mathrm{25}$ ) and Piles ( $\mathrm{km} \mathrm{28).} \mathrm{The} 12 \mathrm{~km}$ in the southern end present a continuous contrast of very wide and extremely narrow beach segments (below $10 \mathrm{~m}$ both in $\mathrm{km} 43$ and km $50)$.

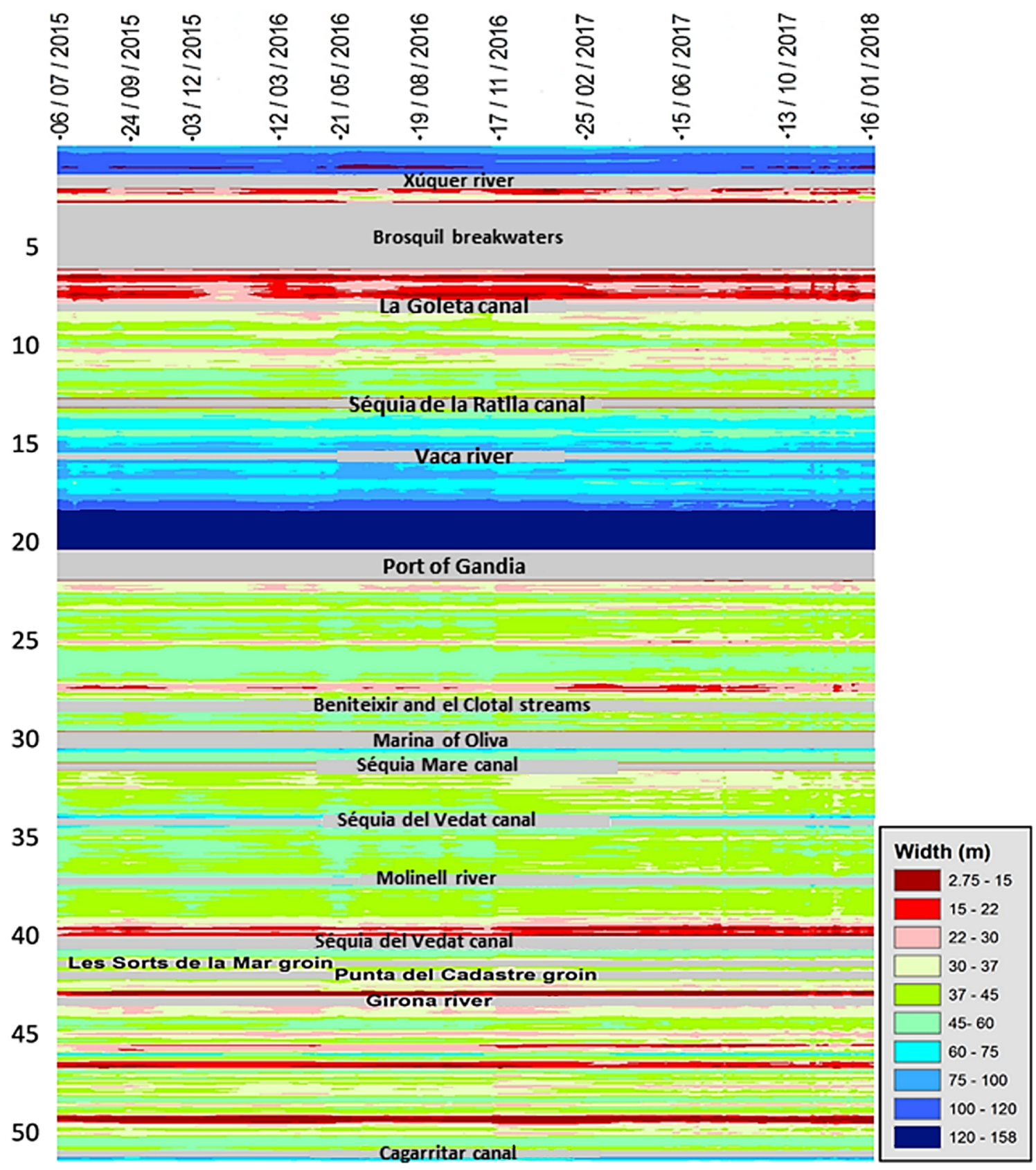

Fig. 4.5. Spatiotemporal model of beach widths. Y-axis represents the location (distance from North, in $\mathrm{km}$ ), and X-axis the time. Cells have $80 \mathrm{~m}$ and 1.2 days. BW magnitude appears in different colors. Segments not considered appear in grey. 


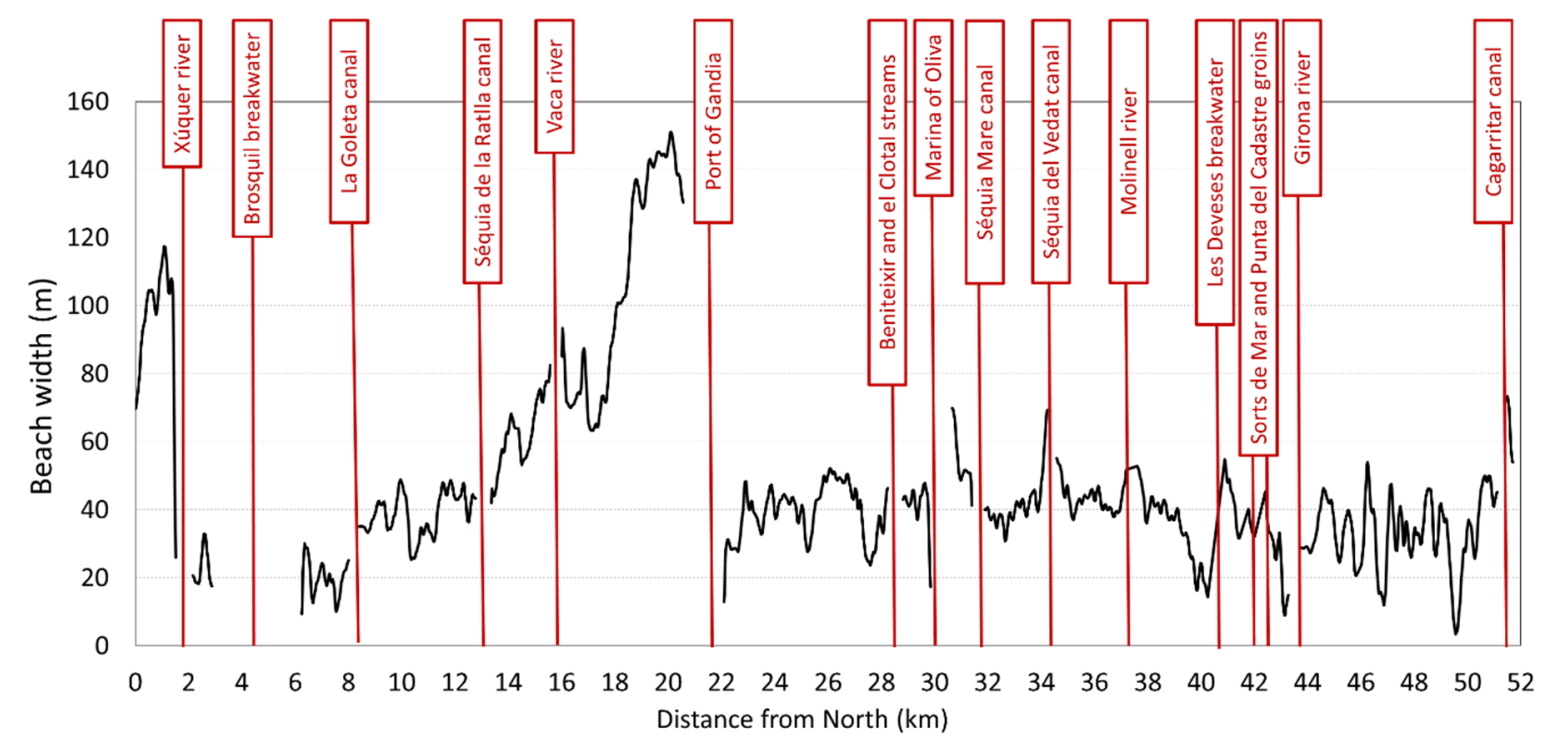

Fig. 4.6. Beach width along the study area on 17/11/16. Infrastructures, rivers, and canals highlighted.

Figure 4.7 shows a strong asymmetry in the BW distribution. Although the widths range between $3 \mathrm{~m}$ and $159 \mathrm{~m}$, only $11.45 \%$ of the beach segments are wider than $80 \mathrm{~m}$. More than a half (55.5\%) have between 30 and $50 \mathrm{~m}$. The percentage below $30 \mathrm{~m}$ reaches $15.9 \%$, while $2.1 \%$ are critical below 15 meters. Nevertheless, these data hide the variation along time: when considering the summer dates of the different years, important variations appear in the percentage of beach segments narrower than 30 m meters (14.76\%, $14.34 \%$, and $17.62 \%$ for 2015, 2016 and 2017 summers respectively).

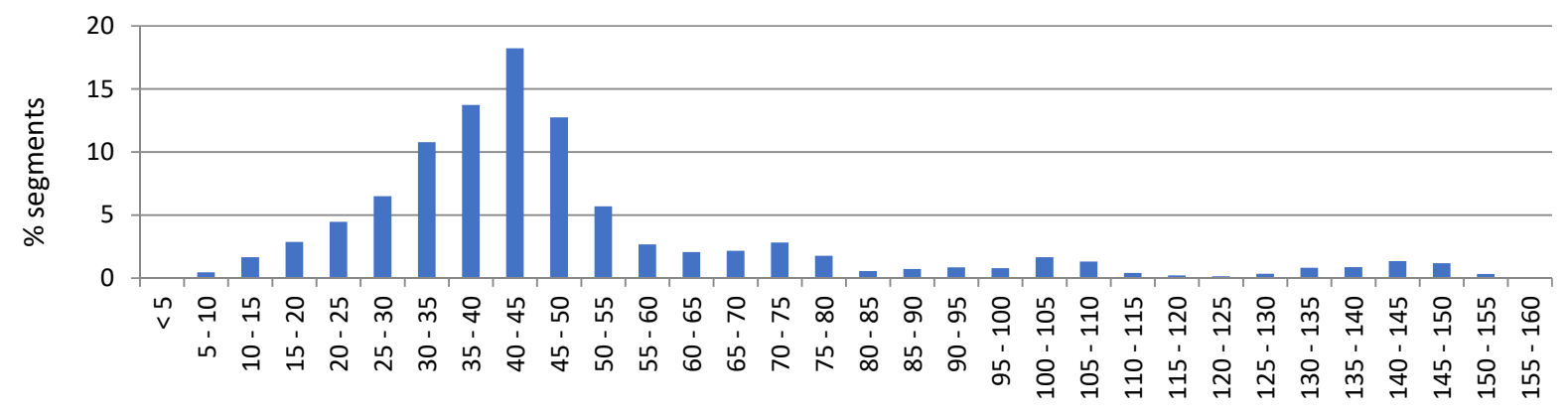

Fig. 4.7. Histogram of widths $(\mathrm{m})$ registered in the different segments of analysis.

\subsubsection{Beach changes}

Short-term beach changes were characterized along the study period by comparing the instantaneous width of each segment against the width on the first date analyzed. Figure 4.8 shows a spatiotemporal model that simultaneously represents all the changes. There was a predominance of width loss processes (yellow to red). The average change for the whole study area is $-3.4 \mathrm{~m}$, with the first three quartiles registering negative values. Figure 4.9 shows a distribution of the types of changes that resembles a normal curve but with a clear negative bias. Changes between -3 and $-4 \mathrm{~m}$ are the most abundant (13\%). 


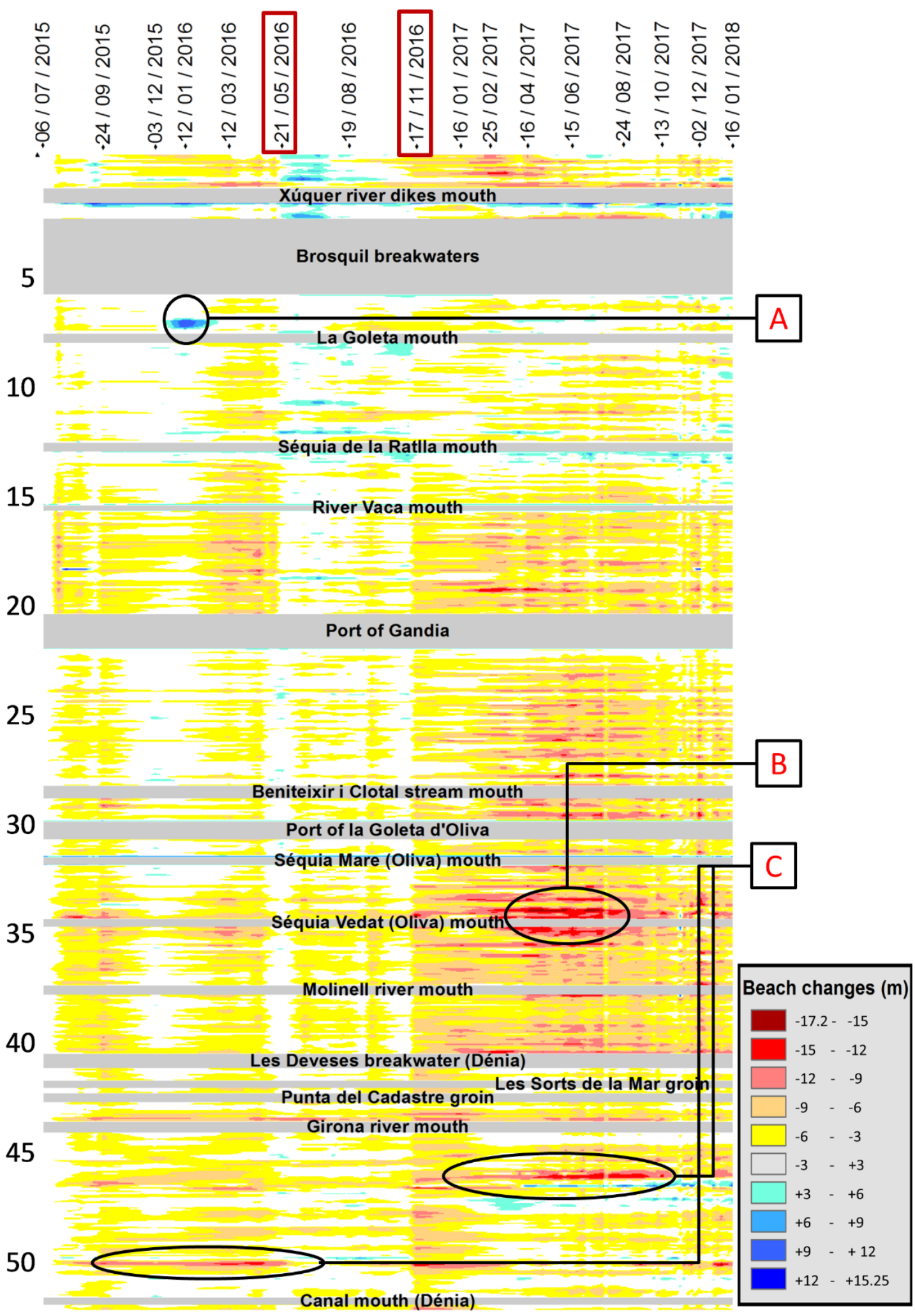

Fig. 4.8. Changes along the study area (distance from North, in $\mathrm{km}$ ). Width on 6/07/2015 as a reference. Three episodes of local change (A, B, C) and general changes in 21/05/2016 and 17/11/2016 are highlighted. 


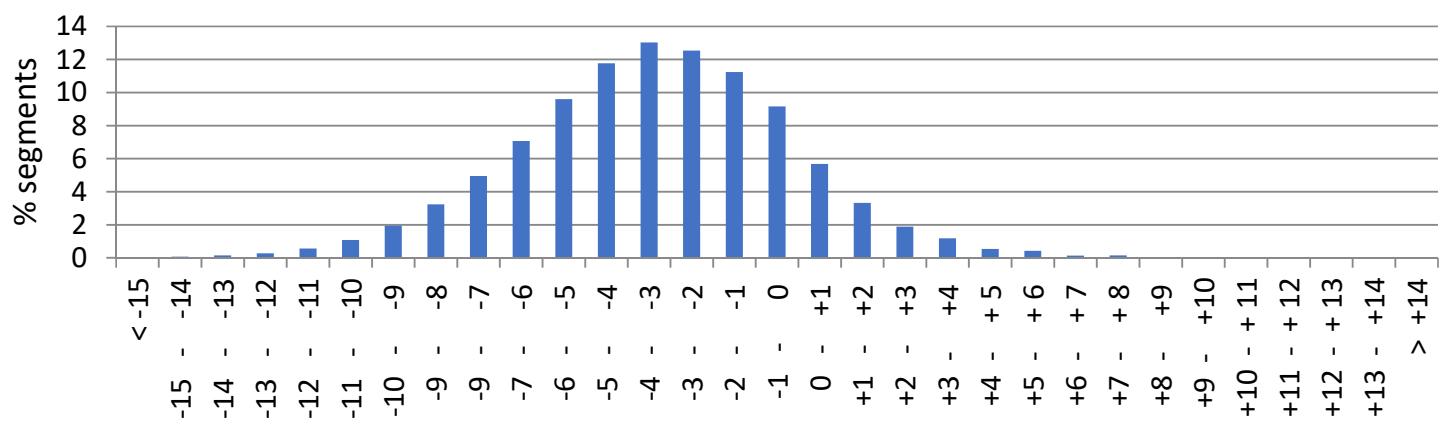

Fig. 4.9. Beach changes and their direction

Width changes showed different magnitudes and directions in space and time (Fig. 4.8). At least two particular episodes caused short-term changes that affected large portions of the study area, although with different magnitudes. Figure 4.10 shows in detail the magnitude and direction of the width changes associated with these two episodes. For each one, the width was compared between two dates, associated with the start and end of the episode respectively.

The first episode took place approximately on 21/05/2016 and had positive values, with beaches generally widening. The changes did not affect the whole study area but were reflected in the 20 $\mathrm{km}$ further north of the study area and in the last $4 \mathrm{~km}$ to the south (Fig. 4.8, 4.10). It took place at the end of a calm period (Hs was below $1 \mathrm{~m}$ for approximately 20 days, Fig. 4.4).

The second episode occurred around 17/11/2016 and it was even more evident because it affected the entire study area (Fig. 4.8, 4.10). On the contrary, it clearly presented negative values, and the majority of the segments registered erosion. The changes were negative for the whole area (mean erosion of $-3.5 \pm 1.8 \mathrm{~m}$ ), which suggests a general cause affecting the whole coast. This episode occurred associated with a storm (Hs reached $2.32 \mathrm{~m}$ on 15/11/2016, Fig. 4.4) that could be considered the first important one of that autumn. Similarly, other episodes seem to show a general response to the changing oceanographic conditions. This is the case of a recovery process along December of 2015, a long period without high waves.

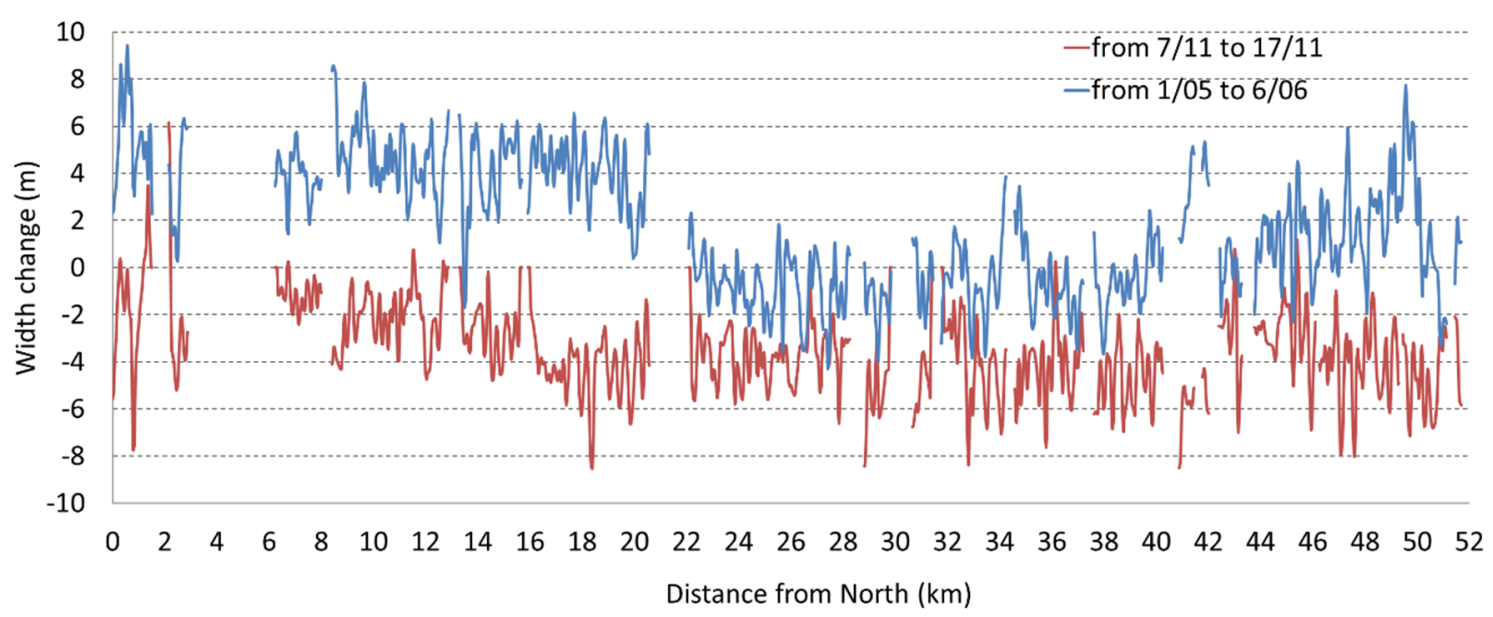

Fig. 4.10. Short-term width changes associated with two specific episodes: 21/05/2016 and 17/11/2016. The changes were quantified between $1^{\text {st }}$ of May and 6th June (blue) and between 7 th and $17^{\text {th }}$ of November (red). 
The detailed analysis of the change model (Fig. 4.8) also made it possible to recognize changes on a local scale, with a much smaller spatial dimension. Three types of local change episodes have been differentiated:

(A) Those with an inverse tendency to the one observed in close areas and even in the same spot at another time. The clearest example is the one observed in position A (focused on $\mathrm{km} \mathrm{8)}$ associated with a strong widening of the beach (up to $10 \mathrm{~m}$ ) around on 12/01/2016.

(B) Those affecting an entire sector, and although obvious, they are not excessively punctual either in space or time. Thus, it is possible to recognize the places and moments in which the changes were of greater magnitude. As an example, North and South of Séquia del Vedat canal between 18/03/17 and 13/10/2017, we can see setbacks of about -15 m with respect to the initial situation and this substantial alteration was maintained for months.

(C) Those in which it is possible to simultaneously identify completely opposite dynamics in very near locations. The example is paradigmatic since, on the same beach, a $13 \mathrm{~m}$ recession took place while, at a distance of only $400 \mathrm{~m}$, an advance of $10 \mathrm{~m}$ was registered.

Short-term changes linked to artificial sediment mobilization were also analyzed. The analysis was focused on the two beaches that registered the major actions of sand removal and dumping (Fig. 4.11, 4.12). On Sant Antoni beach (Cullera) 137,489 m3 of sand were dredged between June 2015 and June 2018. On the contrary, 138,099 m3 were used for the nourishment El Brosquil and la Goleta beaches, in which actions started in December 2015 and were repeated in the next winters.

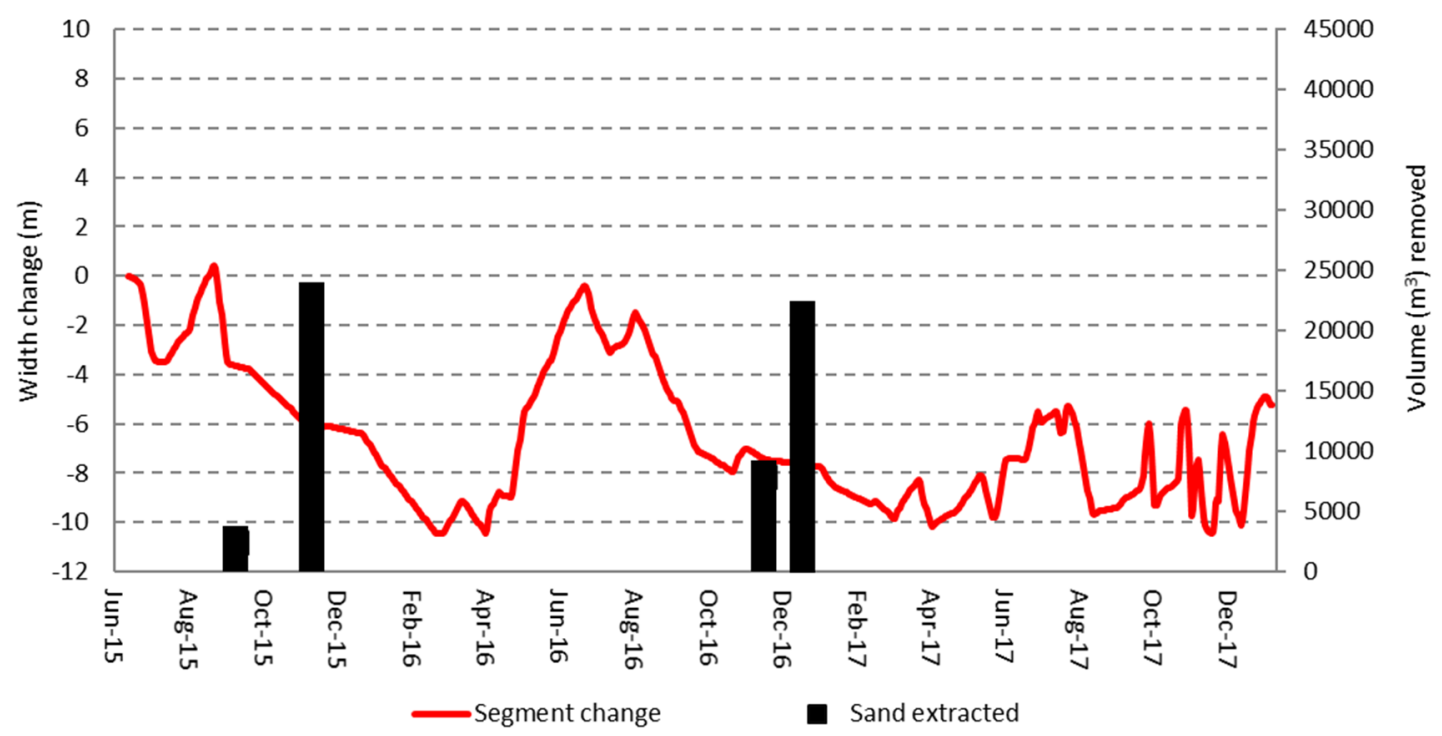

Fig. 4.11. Sand extractions in Sant Antoni beach (Cullera) and width change in the associated $80 \mathrm{~m}$ segment (red). 


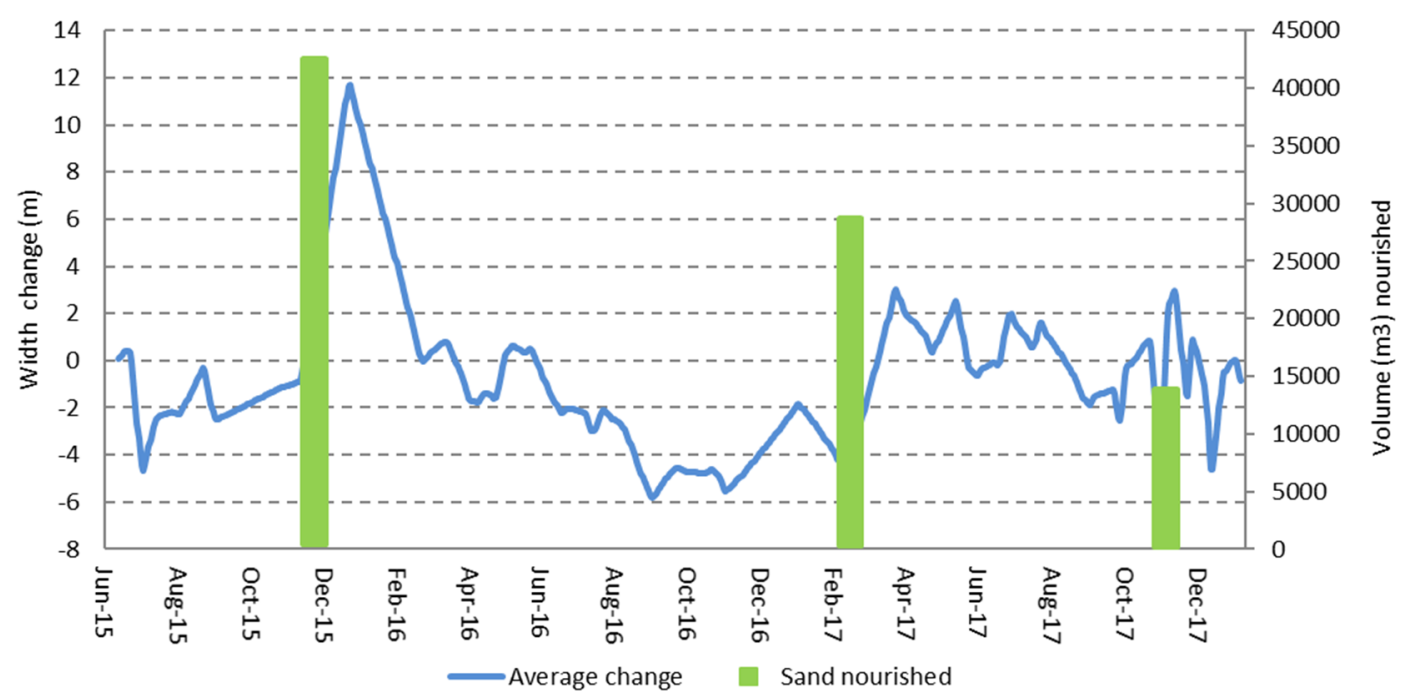

Fig. 4.12. Sand nourishment (green color) in la Goleta beach (Tavernes) and the associated width change of the beach (blue).

The effects on the width were clear in both cases. On the one hand, erosive episodes were registered coincident in time with the sand removal activities. Width loss took place on the whole beach, especially remarkable in one of its segments. On the other hand, la Goleta showed accretion episodes coincident with three different sand nourishments. The first one, the most remarkable (41,600 $\mathrm{m}^{3}$ about 15 December 2015), was associated with a positive mean change of the shoreline of around $12 \mathrm{~m}$. It can be clearly seen in the spatiotemporal model as a local change episode (Fig. 4.8, A). A second action (27,800 $\mathrm{m}^{3}$ at beginning of March 2017) was followed by a positive mean change of more than $6 \mathrm{~m}$. Finally, a smaller nourishment $\left(12,830 \mathrm{~m}^{3}\right.$ about 15 November 2017) seemed to be associated with a positive change close to $4 \mathrm{~m}$.

\subsubsection{Problematic narrow segments}

Beach segments with insufficient width and therefore likely to cause conflict with beach functions were identified. At least once along the study period, 15.2\% of the analyzed segments registered a width below $30 \mathrm{~m}$, while 1.5\% showed a critical situation below $15 \mathrm{~m}$.

The amount of time experiencing a problematic narrow situation varied a lot between segments (Table 4.2), and it was used to classify them. Along the study area, a width below the $30 \mathrm{~m}$ threshold was registered continuously along $3.84 \mathrm{~km}$, while it was maintained more than $75 \%$ of the time along $2.16 \mathrm{~km}$.

Table 4.2. Classification of beach segments with problematic width according to the proportion of measurements lower than $30 \mathrm{~m}$ throughout the study period.

\begin{tabular}{ccc} 
Percentage of days & Code & Length $(\mathrm{m})$ \\
\hline $1 \%-25 \%$ & 5 & 3840 \\
$25 \%-50 \%$ & 4 & 1440 \\
$50 \%-75 \%$ & 3 & 640 \\
$75 \%-99 \%$ & 2 & 2160 \\
$100 \%$ & 1 & 3840 \\
\hline
\end{tabular}


Problematic segments appeared grouped in three large coastal sectors with different orientations and characteristics (Fig. 4.13). The first one, Sector 1, appeared southern of the Xúquer river along $9.7 \mathrm{~km}$, with an orientation NNW-SSE. Sector 2 appeared along $11.5 \mathrm{~km}$ and with NW-SE orientation between the port of Gandia and the beaches south of the marina of Oliva. Sector 3 appeared at the southern end of the study area, along $10.5 \mathrm{~km}$ of Dénia coast, oriented W-E $\left(100^{\circ}\right)$. At the same time, inside these three large sectors, several problematic segments (with width records below $30 \mathrm{~m}$ ) appear arranged continuously (or almost) along the coast. When grouping these segments it is possible to identify 19 sections with problematic situations that cover up to $13.36 \mathrm{~km}$ (although few segments were not identified as problematic).
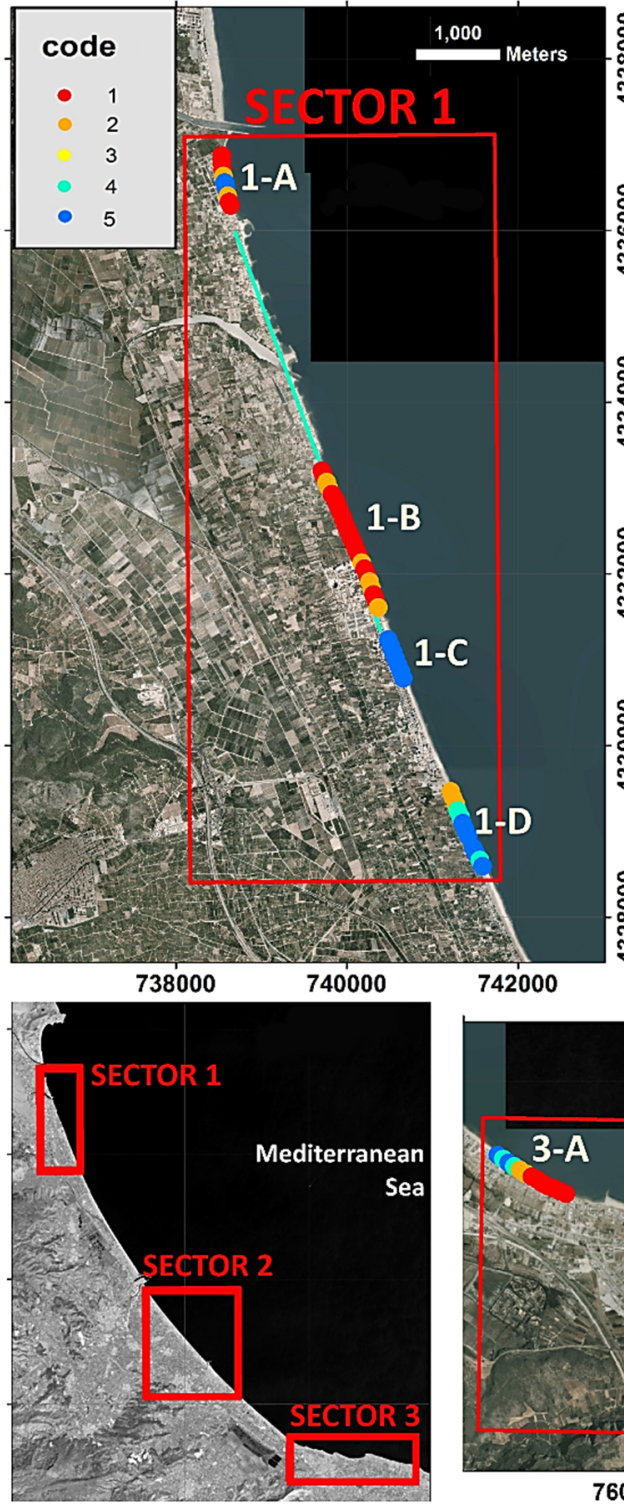

742000

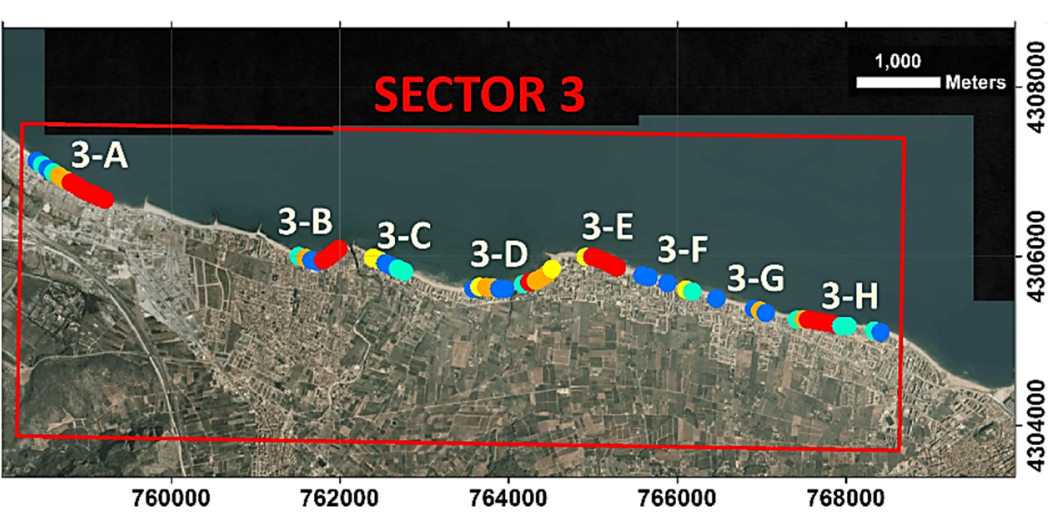

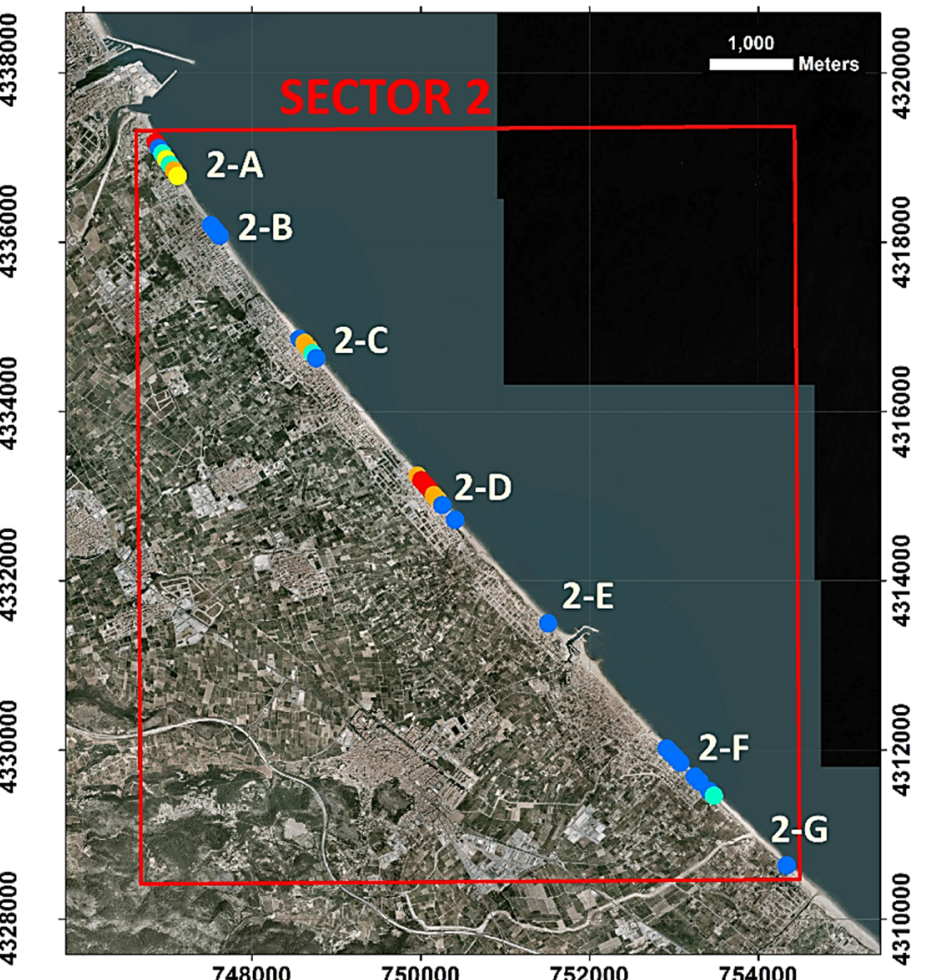

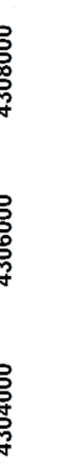

Fig. 4.13. Geographical distribution of the problematic segments classified according to the percentage of days registering BW below $30 \mathrm{~m}$. They appear grouped in three large sectors. A line in cyan shows a long rigid segment not included in the analysis.

Sections 1-A, 1-B, 3-A, 3-B, 3-E and 3-H present average widths below $30 \mathrm{~m}$ over the entire period. Among them, as particularly problematic appear the section 1B (Brosquil and la Goleta beaches) 
with the narrowest average width $(21.5 \mathrm{~m})$ along $1.8 \mathrm{~km}$, and 3- $\mathrm{H}$ with the narrowest segment (6.6 $\mathrm{m})$.

Sector $1(9.7 \mathrm{~km})$ is located south of the Xúquer river jetties and includes four sections covering $4.16 \mathrm{~km}$ of beach with an average width of $26 \mathrm{~m}$. Sections 1-A and 1-B are the narrowest ones and, between them, there is a coastal stretch with artificial structures (seawall, breakwaters and small groins) that aim to stop the erosion. Section 1-B (Brosquil and La Goleta beaches), located downdrift of the artificially protected area, is the longest of all the areas studied $(1.84 \mathrm{~km})$ and the one with the smallest average width $(21.5 \mathrm{~m}$ ). Section $1-C$ shows substantially greater widths (33.4 $\mathrm{m}$ on average), and it is separated from 1-B by a small structure protecting the mouth of an old inlet that connects with the wetland.

Sector $2(11.7 \mathrm{~km})$ includes seven sections with extremely variable dimensions. In general, the segments are wider (32.9 $\mathrm{m}$ average) than in the other sectors and there is a smaller proportion of problematic segments. In fact, only $22.4 \%$ of the segments in this sector have at some point widths below the $30 \mathrm{~m}$ threshold. Problematic sections show three different typologies in relation to the presence of obstacles and rigid structures. (i) Sections located downdrift of an obstacle. That is the case of section 2-A (0.5 km length) south of the port of Gandia with an average width of $30.6 \mathrm{~m}$. (ii) Sections linked to artificial rigid structures too close to the shoreline spatially constraining the beach. That happens with sections 2-B (0.18 km length) in Daimús beach, 2-C $(0.37 \mathrm{~km})$ in Bellreguard beach and more remarkably in 2-D $(0.7 \mathrm{~km})$ in Piles beach $(26.8 \mathrm{~m}$ average). (iii) Sections not associated with obstacles or structures as $2-E, 2-F$, and $2-G$. Section $2-$ $\mathrm{F}$, the largest one, extends $0.85 \mathrm{~km}$ with an average width is $35.4 \mathrm{~m}$ but at various times has recorded widths less than $30 \mathrm{~m}$. It should be noted that its inner edge is largely constituted by dunes.

Sector $3(6.16 \mathrm{~km})$ has an average width of $28.78 \mathrm{~m}, 8$ problem sections. Although the sector presents great heterogeneity of typologies, $47.7 \%$ of the segments at some point have presented less than $30 \mathrm{~m}$. The segments with the greatest problems have been analyzed in depth (Fig. 4.14). In several cases they show a punctual sedimentary deficit linked to artificial or natural barriers to the littoral drift, as it happens in 3-A, B, C, and D. In section 3-A, the width increases from the jetty progressively towards the west. Sections $3-B$ and $3-C$ show very narrow beach segments at the fan-delta of the Girona river, which widen to the east and west. Section 3-D shows a beach supported by the Punta dels Molins breakwater, which most problematic point may remain narrower or unsupplied depending on the direction of transport.

However, sections $3 \mathrm{E}$ and $3 \mathrm{H}$ show no barriers to transport, and therefore the cause of the problems does not seem clear. In the case of section $3 \mathrm{H}$, given the possible relation with the artificial occupation of the active beach, an analysis from a historical perspective was carried out. For that purpose, a 1956 orthophotography was combined with recent shoreline positions and the current inland limit of the beach (Fig. 4.15). The analysis determines that the current inland border coincides with the one existing back in the 1950 decade when the beach was already extremely narrow. 

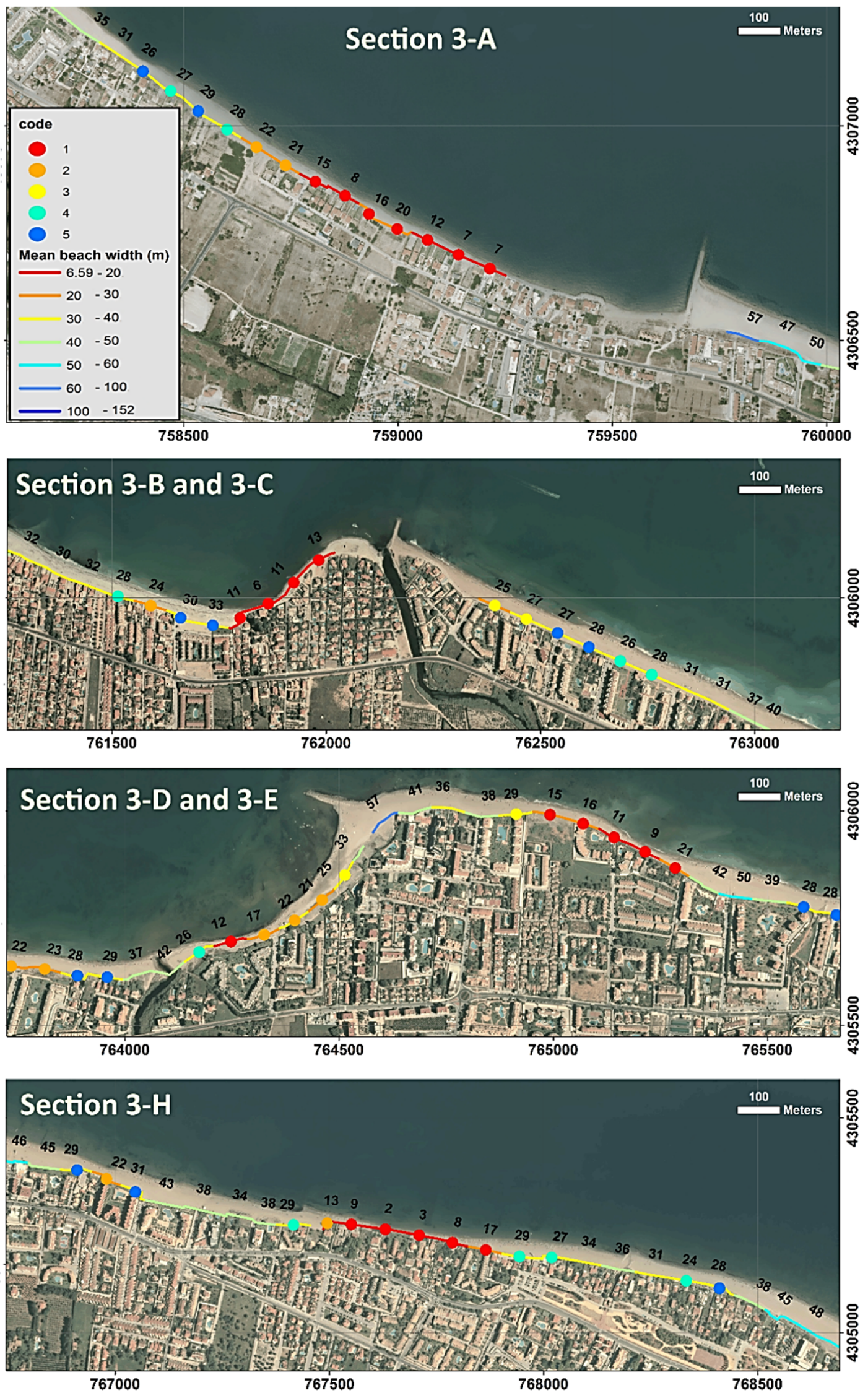

Fig. 4.14. Problematic sections. Different colors represent the percentage of days with widths below $30 \mathrm{~m}$ and the mean beach width, and the numbers show the minimum width recorded. 


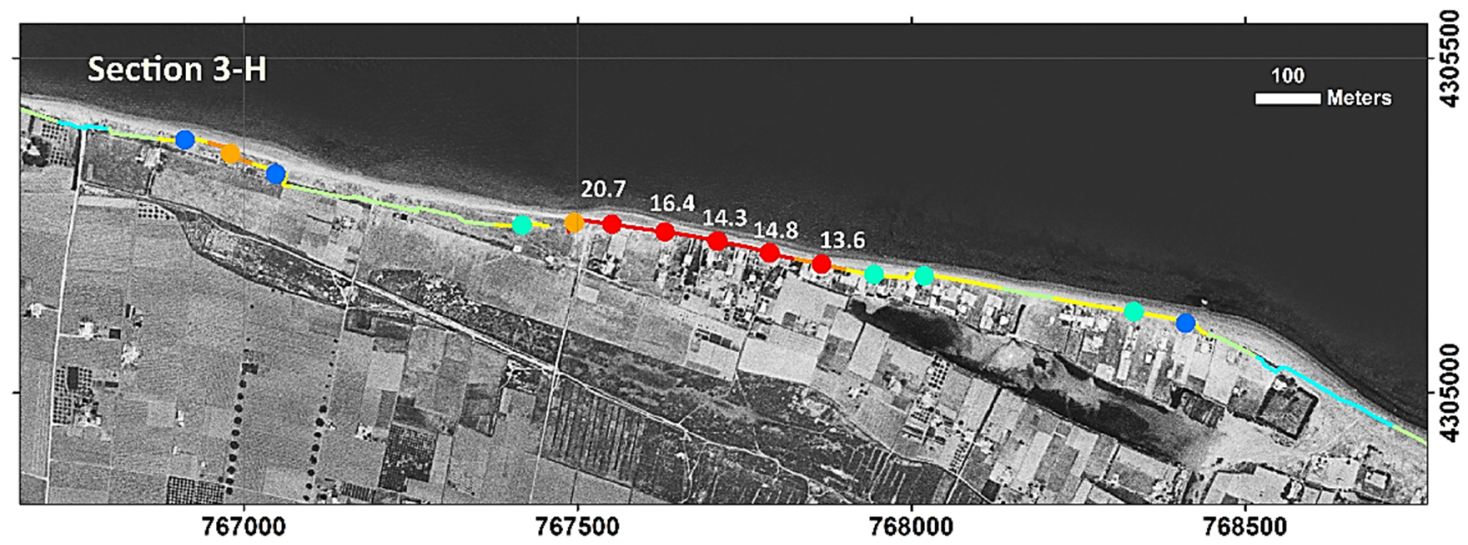

Fig. 4.15. Orthophotography with $0.5 \mathrm{~m}$ resolution created by the Valencian Cartographic Institute (ICV) from a photograph from May 1956. The inner edge of the current beach appears overlayed with the percentage of days with widths below $30 \mathrm{~m}$, as well as the minimum width recorded.

\subsection{Discussion}

This study shows the potential of applying a large package of Satellite-Derived Shorelines (SDS) for monitoring large coastal sectors. The extraction algorithm and the automatic protocol SHOREX developed in previous works (Pardo-Pascual et al., 2012, Almonacid-Caballer, 2014; SánchezGarcía et al., 2020) constitute a time-efficient solution for this purpose. It may supply up-to-date information at a regional scale at the same pace as satellite platforms acquire the images. This has made possible to monitor the shoreline position along the Valencian coast using 60 records for a period of two and a half years.

Starting from Sentinel-2 mid-resolution images, SDS are defined with great accuracy-RMSE 3.01 m. Although other data acquisition methods such as video-monitoring may obtain higher accuracies they do not possess the large spatial coverage offered by satellite imagery. From SDS, beach widths are derived as an intuitive indicator of the punctual state of the beaches on microtidal environments. The raster model organizes a large amount of morphological information in the spatial and temporal continuum. This model makes it possible to characterize the beach state and to identify narrow segments that may conflict with beach functions. The possibility of visualizing in great detail the changes throughout space and time facilitates their interpretation. It allows the analysis of short-term changes and their relationship with both natural events and human actions. Thus, it is possible to identify episodes that affect large sections of the Valencian coast and to differentiate them from those local, as well as making an approach to identify their causes.

Results show a relation between major width changes and wave conditions. High-energy episodes have repercussions over large areas causing beach retreatments. On the contrary, calm periods seem to result in seaward movements of the shoreline and beach recovery. This dynamic is well known and is associated with changes in the morphology of the beach profile (Jara et al., 2015). The proposed methodology makes it possible to quantify the changes and measure the different responses of each beach. In other cases, wave conditions seem to present more local impacts, to which should be added other elements such as the coastal orientation and the incident waves, the distribution of anthropogenic obstacles, as well as the accumulation of different storm episodes, that should be considered for a deeper analysis. Previous works had already shown the possibilities 
that SDS offer for recognizing the unequal response to storms due to the local factors that modulate those impacts (Cabezas-Rabadán et al., 2018; Pardo-Pascual et al., 2014). However, the availability of a greater number of data per year and the methodological improvements implemented in the SDS definition process (Sánchez-García et al., 2020) allows a more robust and reliable definition of the coastal response.

Defining the shoreline position by satellite imagery during the maximum impact of the storm is a difficult task due to the usual cloud cover. Radar images could be an alternative, but the evaluations carried out show lower precisions (Lubczonek, 2017). Another strategy consists in modeling the behavior of the beach and foreseeing the response. This requires calibrating the model with real data about the morphological change, which can be obtained by topobathymetric surveys (Yates et al., 2009) or video-monitoring (Jara et al., 2015). For these calibrating purposes, it has recently been demonstrated that SDS are equally effective than video-monitoring (Jaramillo et al., 2020). Thus, SDS could potentially be used to test and adjust the models in many more areas generalizing their applicability.

The response to actions more limited in space and time as sand extractions and nourishments was studied on two beaches. Despite the absence of in situ high precision measurements, it is possible to identify changes coincident in space and time with sediment movements. It is important to remark that in both cases and unlike other previous works (Cabezas-Rabadán et al., 2018; Hagenaars et al., 2018; Pardo-Pascual \& Sanjaume, 2019; Vandebroek et al., 2017) the detected changes are associated with actions of very small magnitude. Thus, in contrast with the movement of $252,000 \mathrm{~m}^{3}$ of sediment previously detected in this same coast (Pardo-Pascual \& Sanjaume, 2019), now it has been possible to detect movements even below $15,000 \mathrm{~m}^{3}$. The results prove that this type of actions can be identified with the SDS. At the same time, it is possible to monitor the effects in the surrounding area and the durability of the action (and therefore, the investment made). It is well known that anthropogenic actions influence the state and behavior of beaches (Pagán et al., 2016, 2017; Sanjaume \& Pardo-Pascual, 2005; Stronkhorst et al., 2018). In light of sealevel rise, nourishment actions appear as a common solution for the beach loss preventing shore retreat (Stive et al., 1991). Sometimes beach retreatment events lead managers to take hasty decisions with insufficient data. Nevertheless, these actions have an important cost and environmental impact (Peterson \& Bishop, 2005; Speybroeck et al., 2006), and the benefits may be of short duration (Cabezas-Rabadán et al., 2018). The real effects of these interventions are generally not monitored and well defined. It is essential to quantify their effect on space and time. This is the only way to assess the cost-benefit for society, and thus be able to support critical decision-making by managers. SDS seem to serve this purpose and could be applied for monitoring both large-scale sectors punctual segments, allowing assessing the environmental impact of specific actions.

The spatiotemporal models allow characterizing the state of the beaches and its problematic segments with higher frequency and more rigorously than only a few specific measurements. This makes it possible to identify in advance sectors likely to conflict with beach functions. It may be used for identifying segments without a sufficient width for sustaining the recreational use of the 
beach, or for protection purposes at the arrival of the storm season. This is important as pre-anycrisis event management is very advantageous compared to crisis management, which entails high risk and cost (Williams et al., 2018). Following the criteria of the literature, the recreational function may be especially affected in beaches below a $30 \mathrm{~m}$ threshold. Taking advantage of continuous measurements, segments narrower than $30 \mathrm{~m}$ at least once along the study period were identified as problematic. They represent a significant percentage of the coast (15.2\%), while only a small percentage show a critical condition (1.5\%). This is in line with the Valencian erosive trend over the last decades (Pardo-Pascual, 1991; Sanjaume \& Pardo-Pascual, 2005; EC, 2009). Moreover, the results have evidenced that storm events can strongly affect the available width for recreational purposes as demonstrated in 2017 summer, after the 2016-17 winter storms, when the percentage of beaches too narrow for the maintenance of this function increased $3.28 \%$.

The analysis of problematic segments in its geographical context makes it possible to define specific problematic typologies as well as offering hints to the causes of imbalances in sediment distribution. Firstly, there is a clear relation between widths and sedimentary traps due to the N-S transport along the larger coastal cell. Barriers to longitudinal transport cause local sediment shortages (sections 2-A, 3-A, 3-B, 3-C, 3-D, Fig. 4.13). In some cases, seawalls built with the aim of stopping erosive processes (sector 1 ) appear linked to erosive problems downdrift. These results are consistent with previous studies that show that high anthropogenic pressure has degraded greatly the littoral and contributed to a significant coastal retreat (Yepes \& Medina, 2005; ObiolMenero \& Pitarch-Garrido, 2011).

Natural causes also bring sediment imbalances. As an example, the fan-delta created by the Girona river (sections 3-B and 3-C in Fig. 4.14) causes a punctual coastal progradation (Segura-Beltrán \& Pardo-Pascual, 2019) evidenced by the subsequent displacement of sediment away on both sides. The mouth marks a turning point, the edge of a small sedimentary cell. The west coast of the fan delta shows smaller widths as it is not being fed by longitudinal transport under practically no circumstances. The waves from the west that would provide sand towards that point do not have sufficient fetch as the wave height is minimal and the magnitude of the transport is practically non-existent. On the contrary, although the east face also is deficient, in some cases it may receive sand form eastern beaches, basically during NE storms.

In recent decades, the coastal urbanization process has led to the construction of artificial structures too close to the shoreline (Obiol-Menero, 2003), constraining the beach and preventing its natural readjustment (Fig. 4.13, 2-B, 2-C y 2-D). This would also be the case of section $3-\mathrm{H}$, where the occupation of the waterfront several decades ago left doubts with regard to the cause of the narrowing. The evolutionary analysis of the morphology of the coast shows that the inner edge of the beach coincides with that of the 1950s when the beach was already extremely narrow (Fig. 4.15). The cause of the problems in that section is therefore very probably due to the construction of houses fixing the inner limit of the beach before 1956. In this case, the "problem" remains for decades because in fact the beach area has been artificially occupied. Segment 3-E also presents constricting urbanization, but the presence of rocky outcrops close to the shore plays an essential role as natural protection for the shore: waves break at a certain distance 
impeding a freely sedimentary transport and minimizing beach mobility. By this reason, the beach width remains much more stable than the segment $3-\mathrm{H}$.

Problems in segments $2-E, 2-G$, and especially $2-F$ seem not to be related to the previous causes: they suffer neither the interruption of the downdrift nor the occupation of the beach system (in fact, they present a well-developed foredune) (Fig. 4.13). Furthermore, during the last centuries, the sector has globally experienced a clearly cumulative trend as evidenced by a double-barred beach and archaeological remains (Pardo-Pascual \& Sanjaume, 2003; Sanjaume et al., 2019). In contrast, recent changes indicate the existence of a stable or slightly recessive dynamic (Sanjaume \& Pardo., 2007). This work also states that the sediment size has suffered a slight increase with respect to the mid-'80s (Sanjaume, 1985) mostly linked to an erosive trend. The existence of excessively narrow segments to the south of the marina of Oliva (2-E, 2-F, 2-G) reinforces this idea. Figure 4.16 shows problematic segments with retreatments over $10 \mathrm{~m}$ : precisely the sector with greatest losses coincides with the problematic segments in Oliva. These results suggest that the monitoring method used is sufficiently refined to detect erosive trends, even if they are still very tenuous.

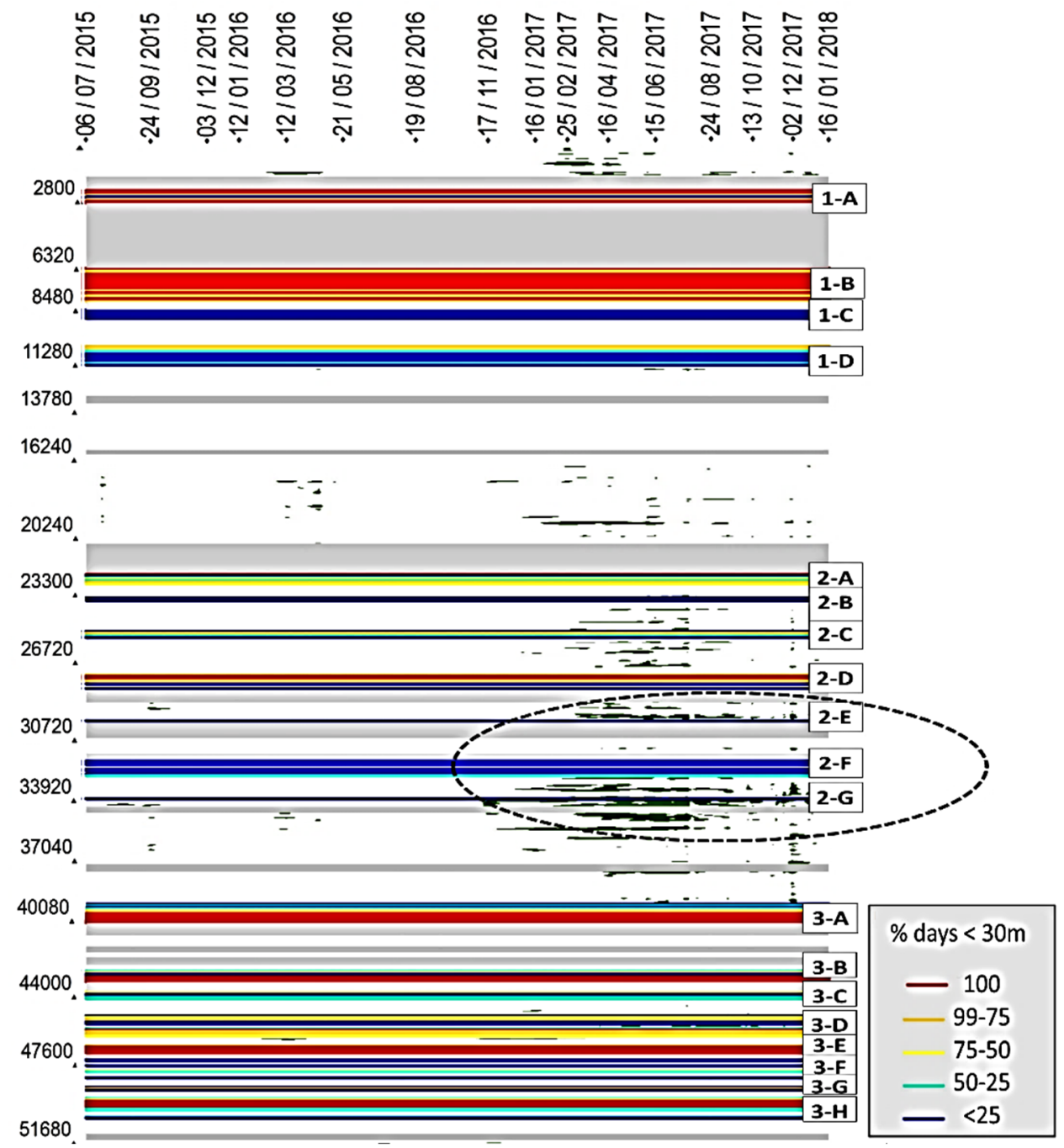

Fig. 4.16. Shoreline retreatments greater than $10 \mathrm{~m}$ with respect to its initial position (dark green). At the same time, $\%$ of days in which the segments are narrower than $30 \mathrm{~m}$. 
Continuous and large-scale monitoring of the morphological changes of the coast through indicators as shoreline position and beach width is fundamental for understanding coastal dynamics (Song et al., 2018). It may fill the shortage and fragmentation of available long-term data (Defeo et al., 2009) providing the holistic and homogeneous approach required by coastal monitoring systems, facilitating the analysis of changes and the subsequent management (Cabezas-Rabadán et al., 2019a).

If the erosive trend continues in the Valencian coast narrow sectors will expand affecting the beach functions. Among them, the recreational one constitutes the major concern for coastal managers (Micallef \& Williams, 2002). This is especially remarkable along the area of the case study, where the management of most of the beaches is oriented for sustaining recreational activities as sun and beach tourism plays a huge role in the economy (Cabezas-Rabadán et al., 2019a). In fact, the regional Administration has just started using the beach width in order to organize the beach exploitation through the Territorial Action Plan for Green Coastal Infrastructure of the Valencian region (GVA, 2018). The sea-level rise is likely to put beach functions at risk, and it will further force coastal areas to take measures. Planned retreat seems to be the most viable solution, especially in regions where engineered structures can destroy the tourism-related industry (Song et al., 2018). Nevertheless, this measure requires reliable data of the coastal state, and there is a shortage of means to obtain them, especially remarkable in developing countries (Saleem \& Awange, 2019). In such cases, obtaining data from satellite imagery appears even more suitable given its costeffective approach.

Among the limitations of this methodology, one of the severest constraints appears linked to the number of days with satellite images and, therefore, available data. At the same time, given the influence of clouds, there is an irregular distribution of images along the year, higher in the summer months. All this influences the study of the response of beaches to specific actions and episodes since in microtidal beaches the recovery can take place in a few days (Ranasinghe et al., 2012) making the changes unnoticed if it occurs in periods with no available data. However, the available Sentinel-2 (5 days of revisit time) can potentially be combined with Landsat 8 images resulting in a scenario with very low revisit intervals (average of 2.9 days combining both platforms according to Li \& Roy, 2017).

About the accuracy when defining SDS, assessments with real data hardly appear in the literature (Do et al., 2018). Nevertheless, Sánchez-García et al. (2020) estimated the accuracy of this methodology from Sentinel-2 images by comparing them with simultaneous in situ and independent observations on a Mediterranean microtidal beach similar to those studied in the present work. It gives credibility to the method and delimits its potential usefulness. The obtained SDS accuracy is considered more than sufficient to record the magnitudes of the changes with the necessary degree of certainty for the purposes of this paper. The water/land indicator of the shoreline position presents uncertainty associated with punctual changes generated by oceanographic variables such as waves and tides. This effect has been minimized due to the conditions of the Mediterranean coasts, as well as due to the availability of a more or less continuous series of data. Nevertheless, bearing all this in mind, and in the absence of assessments 
on coasts with different tidal levels, the application of the methodology in meso and macrotidal coasts would not be immediate. Likewise, the width as beach state indicator may be meaningless at changeable environments.

\subsection{Conclusions}

The availability of SDS obtained from Sentinel-2 with high frequency and sufficient degree of precision poses the challenge of taking advantage of this new source of information to improve knowledge of the morphology and dynamics of the beaches. This work offers a methodological proposal based on the measurement of the width in short beach segments (80 $\mathrm{m}$ long) using the SDS and the inner limit of the beach. From these data, a spatiotemporal model of the beach widths and their changes was created for easy consultation of the coastal state and the dynamism of the microtidal beaches at different spatial and temporal scales.

The methodology has been applied along $50 \mathrm{~km}$ of the Valencian coast, as it constitutes a representative example of a coast highly exploited and modified by the human being, and threatened by erosive processes. Results show how the methodology is able to characterize changes in the shoreline position in response to both natural events and artificial actions, either locally or in large regions. It has been demonstrated that even small-magnitude sediment movements create perceptible changes in beach width -only $12,830 \mathrm{~m}^{3}$ caused $4 \mathrm{~m}$ width increaseevidencing the potential of SDS and other derived morphological indicators as tools for monitoring the effects of anthropogenic actions. At the same time, SDS are also able to register the beach response to natural events. Storm episodes exceeding certain magnitudes create general shoreline retreatments, with variable effects along the coast related to the beach characteristics. The spatiotemporal model allows recognizing where storm impact is bigger and where the recovery process is more rapid.

Therefore, the spatiotemporal model offers a better understanding of the functioning of the beaches, as well as sometimes recognizing the cause of the sediment imbalances. The methodology offers a rigorous, robust and detailed characterization of the state of the beaches through a large coastal area, making it possible to identify segments of $80 \mathrm{~m}$ length too narrow for the maintenance of beach functions as the recreational one. The analysis of these segments in their geographical context allows establishing relations with the morphology of the beaches and their location with respect to artificial structures or natural landforms, offering a diagnosis of the causes of the local lack of sediment. All this information is essential for understanding the dynamics of beaches. It constitutes the first step to adopt solutions to the erosive processes, supporting the coastal planning and the decision-making of the managers. 



\section{Part II - Monitoring the response of Mediterranean beaches to storms and anthropogenic actions using Landsat imagery}

\subsection{Introduction}

Beaches are natural spaces essential to our society. They provide protection from storms, constitute the habitat of fragile ecosystems and, without doubt, represent an essential resource for sustaining the economy of coastal regions (Alexandrakis et al., 2015; Prodger et al., 2016). However, many beaches have been suffering from severe erosive processes for decades. This is especially noticeable on the Valencian coast (Pardo, 1991; Sanjaume \& Pardo-Pascual, 2005) where $26 \%$ of the beaches present problems (EU, 2009). These processes are mostly driven by human actions by altering the sedimentary transport (Obiol-Menero \& Pitarch-Garrido, 2011), limiting their entry into the system or building on dune ridges and excessively close to the sea. This eliminates possible adaptations of the beach-dune system and immobilizes sand reservoirs. Likewise, the processes are aggravated by the sea-level rise associated with climate change (Nicholls \& Cazenave, 2010; Sutherland \& Gouldby, 2003).

In this erosive context, significant losses may occur in these spaces (Anfuso \& Martínez, 2009; Ballesteros et al., 2018), both in terms of flooding and vulnerability of the waterfront, as well as reducing the available recreational space. The physical maintenance of the beach is an important focus of attention for managers as they try to achieve a beach morphology positively perceived by users and tourists (Valdemoro \& Jiménez, 2006). Nevertheless, this sometimes results in actions without adequate planning. These interventions usually constitute short-term solutions that can aggravate the situation in distant coastal segments. Regardless of their purpose, the effects of actions carried out in the coastal space should be monitored over long periods employing objective and quantifiable records covering broad coastal segments. This is supported by the requirement to carry out surveillance and monitoring programs associated with environmental impact studies (Law 21/2013). However, it is common that actions lack adequate follow-up, making it impossible to know their true effectiveness or impact on the coast (Ludka et al., 2018). On the other hand, coastal storms are the events with the greatest capacity to alter the beach morphology within short periods. Their impact and subsequent recovery have aroused the interest of the scientific community (Ferreira, 2006; Karunarathna et al., 2014; Sénéchal et al., 2017; Splinter et al., 2014 , 2011), especially in the case of consecutive storms, leaving important questions unsolved so far.

No matter whether they are human interventions or storm events, questions regarding their effects on beaches must be answered by means of morphological data acquired before and after the impacts. This is the only way to define a stable beach situation, its maximum erosion, and to determine when and to what extent recovery has been achieved. Likewise, given the importance of beaches, and given the erosion risk that will potentially increase in the near future, it is imperative to implement monitoring systems that systematically record the state of the coast over large areas and periods. The availability of a continuous monitoring system would facilitate and homogenize the analysis of changes. 
However, obtaining data on beach morphology is costly and complicated. The techniques traditionally used to track changes (photo-interpretation, DGPS surveys, video-monitoring) do not provide data on large coastal sections with sufficient frequency. An interesting alternative comes from medium resolution satellite images, as they systematically record the entire territory with high revisit frequency. Thus, nowadays and considering the combination of Landsat 8 and Sentinel-2 platforms, it is possible to acquire images of the same location every 2.9 days (Li \& Roy, 2017). Different automatic shoreline extraction methodologies have been designed to overcome the constraints of limited image resolution. Almonacid-Caballer (2014) evaluated 348 lines from Landsat scenes on breakwaters, resulting in an average bias below $1.47 \mathrm{~m}$ (and errors below 5.8 m), while Pardo-Pascual et al. (2018) established that the error was of $8 \mathrm{~m}$ and $7.4 \mathrm{~m}$ RMSE for high and low gain Landsat 7 images respectively. Lines extracted from Landsat 8 or Sentinel-2 showed an RMSE of $6.6 \mathrm{~m}$. From this solution, SHOREX system has been developed (PalomarVázquez et al., 2018), allowing to define shorelines efficiently.

This work shows the application of SHOREX to analyze the shoreline changes that occur at three sandy beaches of the southern Gulf of Valencia along three decades (1984-2014). At the same time, it is evaluated to what extent the defined shorelines allow the recognition of the effects that natural alterations, such as storms, and human alterations, such as artificial sediment movements, have on the beaches.

\subsection{Regional setting}

The work has been carried out on three sandy beaches in the same coastal sector covering a total of $8 \mathrm{~km}$ of coastline. They are located in the southern half of the Gulf of Valencia (Fig. 4.17), a microtidal coast (mean tide range of $0.3 \mathrm{~m}$ and maximum of $0.7 \mathrm{~m}$ ) with low waves, significant wave height ( $\mathrm{Hs}$ ) of $0.7 \mathrm{~m}$ and peak period (Tp) of $4.2 \mathrm{~s}$ on average, although during storms $\mathrm{Hs}$ of $5 \mathrm{~m}$ and Tp of $15 \mathrm{~s}$ have been reached (Pardo-Pascual et al., 2014).

These beaches are located in the same coastal sector, relatively close to each other. They constitute the basic resource for 'sun, sea and sand' tourism that takes place in this region (Cabezas-Rabadán et al., 2019a). Beaches are located in a historically cumulative sector as shown by their morphology, with double-barred beaches and wide dune ridges (Sanjaume \& PardoPascual, 2003; Sanjaume \& Pardo-Pascual, 2019). This sector has suffered different human interventions and shows obstacles to the longitudinal transport of sediment that have led to distinct geomorphology on each beach (Table 4.3, adapted from Cabezas-Rabadán, 2015) and, a priori, different response to the impacts. 


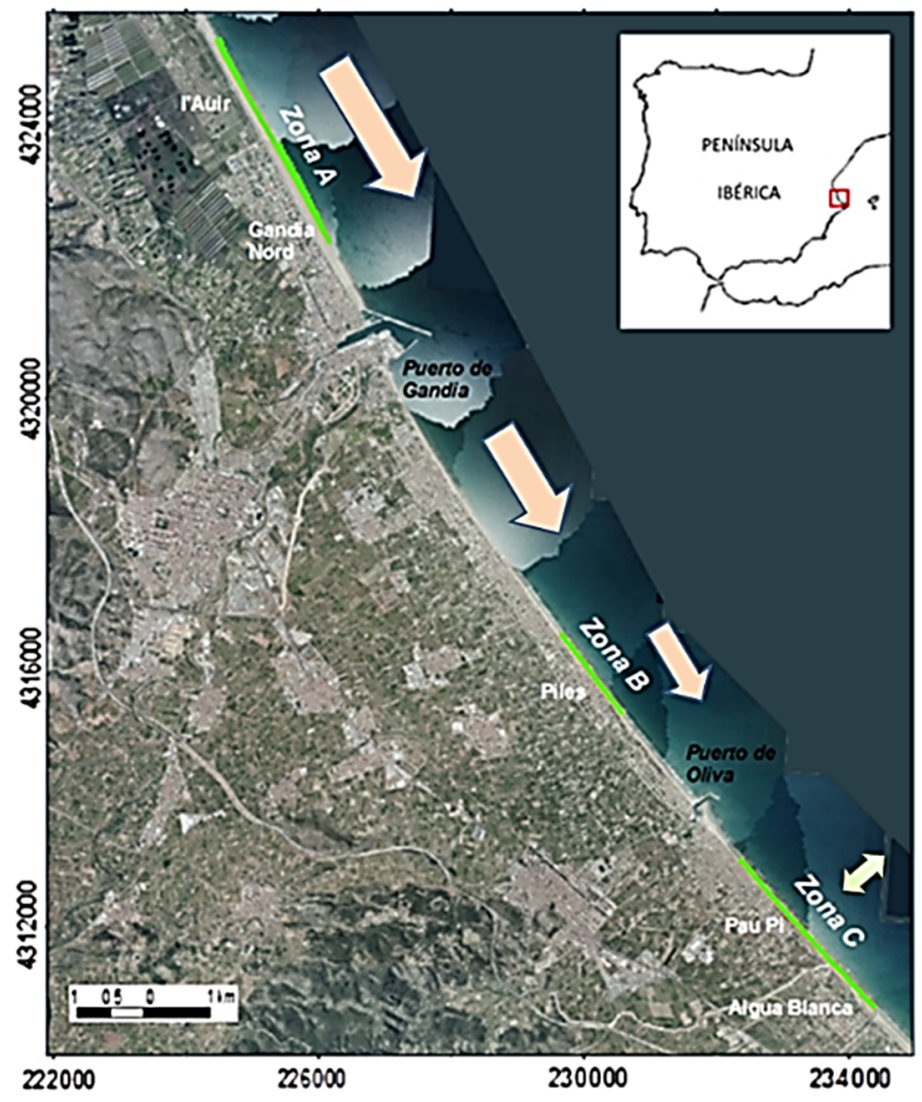

Fig. 4.17. Location of the zones, and the sedimentary drift along the sector with arrows (PNOA, UTM ETRS89 31N).

Table 4.3. Average sediment size and average beach slope at the three studied beaches.

\begin{tabular}{c|ccc} 
Zone & Beach-face avg. size $(\mu \mathrm{m})$ & Backshore avg. size $(\mu \mathrm{m})$ & Avg. slope 2009 $(\operatorname{tg} \boldsymbol{\alpha})$ \\
\hline A & 227.20 & 213.19 & 0.070 \\
B & 268.48 & 228.19 & 0.106 \\
C & 251.20 & 188.79 & 0.050 \\
\hline
\end{tabular}

From north to south, firstly appears zone A (length of $3.6 \mathrm{~km}$ ), a cumulative section supported by the northern dike of the port of Gandia that includes the beaches of l'Auir and Gandia Nord. The most northern beach has a relatively natural state, without buildings and with a foredune alignment, while the second one is limited inland by a promenade. Zone B contains Piles beach $(1.7 \mathrm{~km})$, with problems of insufficient width from a recreational point of view (Cabezas-Rabadán et al., 2019a). These phenomena are related to its location in the port of Gandia and to the construction of the promenade on the old foredune alignment, which prevents the natural readjustment of the beach (Sanjaume \& Pardo-Pascual, 2005). Zone C covers Pau-Pi and Aigua Blanca beaches, in Oliva $(3 \mathrm{~km})$, that maintain a dune ridge in its southern part.

It is worth noting the presence of two ports: Gandia, larger, and Oliva, much smaller. While the first one acts as a trap for the transport of sediments towards the south, the second one does not due to the progressive change of orientation of the coast, from NNW-SSE to NW-SE. This is due to the fact that, while the two most northerly located zones (A and B) are affected by a north- 
south drift, the most southerly zone (C) is at the limit of this sediment transport (Pardo-Pascual \& Sanjaume, 2019).

Over the last few decades, the sector has been subjected to various direct anthropogenic actions within the coastal system (port dikes that interrupt the longitudinal transport of sediments, promenades that artificially shorten the mobile space of the beach, etc.). This work focuses on the movements of sand on the beaches of Gandia and Piles, with Piles acting in many cases as the receiver of the sand extracted from the beaches of Gandia Nord and I'Auir (Cabezas-Rabadán, 2015).

\subsection{Methods}

\subsubsection{Defining the shoreline position and its changes}

This work takes as its starting data the images from the Landsat 5, 7, and 8 satellites taken between June 1984 and September 1987, and between July 1999 and June 2014, available free of charge on the servers of the USGS (United States Geological Survey). SHOREX system (Palomar-Vázquez et al., 2018) was used to automatically obtain the shoreline positions. It should be noted that zone A, located at the overlap of two satellite paths, has twice as many images as zones B and C (with an influence on the analyses discussed below). Thus, SHOREX has allowed obtaining 257 shorelines in zone A, and 125 in zones B and C. Changes its position were subsequently analyzed using the Digital Shoreline Analysis System (DSAS) software (Thieler et al., 2009), by measuring cross-shore transects distributed every $100 \mathrm{~m}$. All changes were quantified in relation to the position of the first available shoreline (June 26, 1984) which is taken as a reference. Results regarding the position of the shoreline have been derived from previous works in the sector (Cabezas-Rabadán, 2015; Cabezas-Rabadán et al., 2018).

\subsubsection{Identification of storms and human interventions}

The most significant storm events were identified from historical wave data over the period 19992014. For this purpose, significant wave height data from the SIMAR point 2083108, in front of the studied beaches $\left(0.08^{\circ} \mathrm{W}, 39.00^{\circ} \mathrm{N}\right)$, were used, obtained from Puertos del Estado (www.puertos.es/es-es/oceanografia/Paginas/portus.aspx). Given the proximity of the three beaches, it was possible to assume common wave conditions. The storm episodes were selected by applying the POT (peak over threshold method) on the wave data set (Dorsch et al., 2008). A $5 \%$ probability of occurrence was used, following the criteria accepted in the literature (Angnuureng et al., 2017). This allowed the identification of episodes with Hs equal or greater than $1.4 \mathrm{~m}$. Likewise, the time duration was defined as greater than one tidal cycle $(12 \mathrm{~h})$ (Angnuureng et al., 2017; Sénéchal et al., 2015). The intensity of each of the episodes $\left(\mathrm{m}^{2} \mathrm{~h}\right.$ ) was defined as a product of the maximum Hs (in meters) by its duration (in hours), thus obtaining an approach to the total energy (Dolan \& Davis, 1992; Sénéchal et al., 2015). Following these criteria, 181 storms were selected, of which the $10 \%$ with the highest intensity were finally considered to be presumably those that could potentially generate the greatest changes in the position of the shoreline. 
Concerning the anthropic actions, the data referring to interventions carried out in the surroundings of the beaches studied were supplied by the Spanish Directorate General of Sustainability of the Coast and the Sea. The actions, divided into nourishments and sand dredgings were integrated into GIS software to locate them temporally and spatially. Based on these data, actions carried out near the studied beaches and which presented the greatest magnitude were selected based on the volume of sand displaced, since they are those with the greatest capacity to affect the morphology and the shoreline.

\subsubsection{Analysis of mid-term trends}

The defined shorelines made it possible to identify, map, and quantify changes over three decades (1984-2014) in the three studied zones. The rate of change in each transect was calculated by the DSAS software by relating the shoreline position to a constant reference line over time, adjusting a linear function (Linear Regression Rate, in m/year).

\subsubsection{Analysis of short-term changes}

Short-term changes were also studied, analyzing the beach response to storm events and anthropogenic actions. For that purpose, each of the three study areas was considered as a whole. In each of the transects, the distances from the different shorelines to the first one were defined, which was used as a reference. These distances were subsequently averaged for the three zones. Thus, for each zone, the temporal sequences of shoreline changes from its initial position were defined. This evolution over time was used to identify (i) the largest storm events, and (ii) the most significant sand dredgings and nourishments. Once identified, the sequences of changes were analyzed, paying special attention to its position before and after these events.

\subsubsection{Comparative analysis between beaches}

Finally, the evolution of the shoreline in the three selected sites was compared, in an attempt to evaluate how different the behavior of each beach was in relation to the others. For this comparison, only the shorelines acquired in the three zones on the same date were considered, so that for zone $A$ the same number of shoreline positions were considered as for zones $B$ and $C$. At the same time, since shorelines correspond to the same instant, wave and sea-level conditions have been assumed to be common, making the results comparable.

\subsection{Results}

Results are divided, in the first place, according to their time scale between mid-term and shortterm changes. The latter, in turn, are separated considering the response to storms and anthropogenic actions. Finally, a comparative analysis of the changes between the three beaches is presented.

\subsubsection{Medium-term changes (1984 - 2014)}

First, the rates of change (m/year) recorded in each transect over the period 1984-2014 are shown (Fig. 4.18). Positive values are associated with an increase in the width of the beach (accretion) while, conversely, negative values are linked to width reductions (erosion). In general, it is noteworthy the dominance of erosive trends in the three studied zones. Zone A (beaches of I'Auir and Gandia Nord) recorded erosion in the majority of the transects (75\%), although also accretion 
rates in some of them (25\%). Erosion rates were less than $0.25 \mathrm{~m} /$ year in $70 \%$ of the transects, while they exceeded it in the remaining 30\%. At the same time, accretion rates were greater than $0.25 \mathrm{~m} /$ year in $77 \%$ of transects, and lower in 33\% of transects. The map evidences a different behavior along the zone. Thus, while erosion was predominant in the north (gradually more aggressive), accumulation was more pronounced in the south. In zone B (Piles), all transects suffered a clear erosive trend, with a retreat greater than $0.25 \mathrm{~m} /$ year in $65 \%$ of the transects. Finally, zone C (Oliva) registered erosion in almost all transects (93\%), and only two of them showed accumulation. Erosion was below $0.25 \mathrm{~m} / \mathrm{year}$ in $68 \%$ of the cases, while in $32 \%$ it exceeded this magnitude. In this zone, there was also a clear geographical differentiation, with erosion in the southern part of the zone standing out.

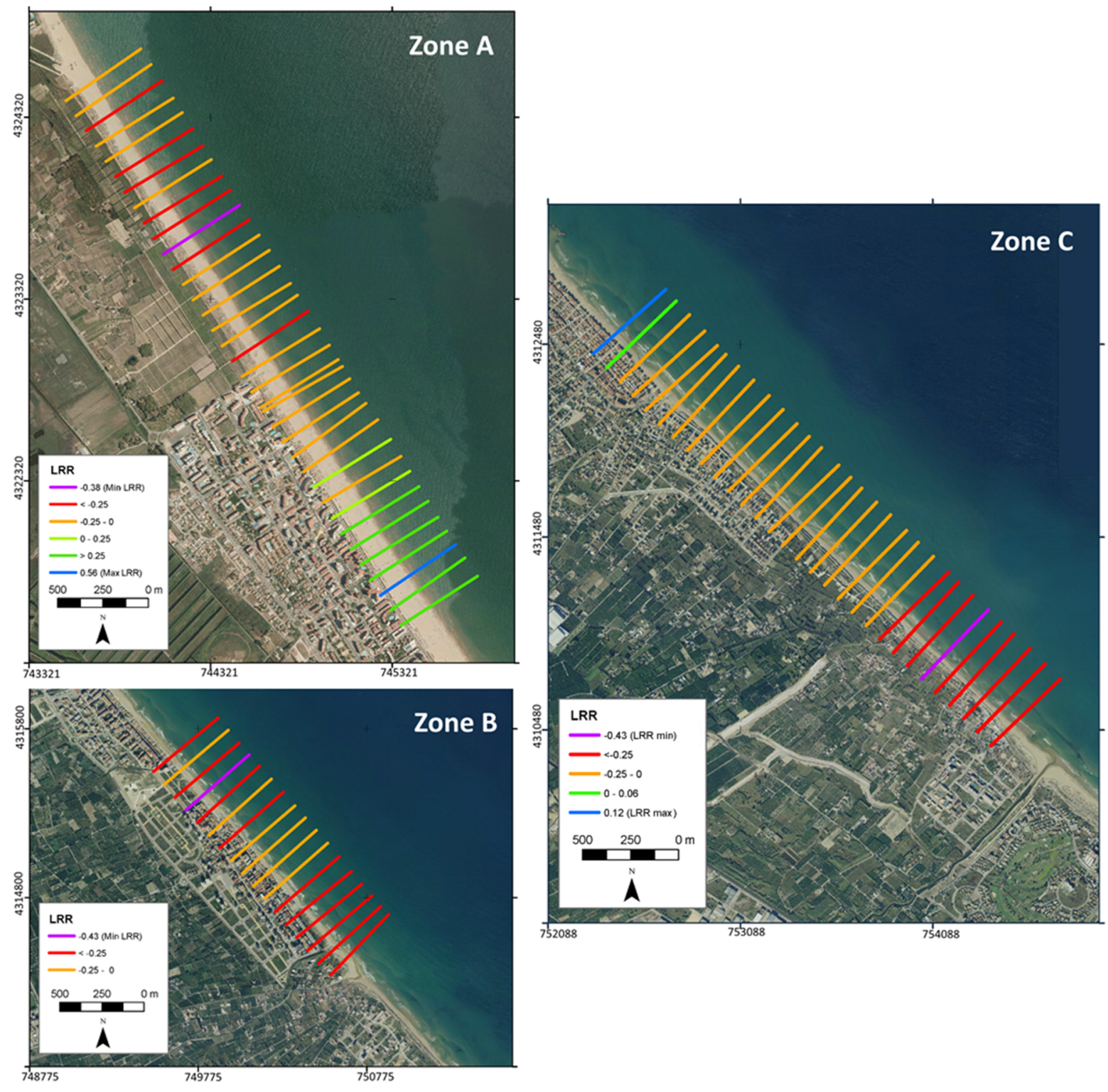

Fig. 4.18. Rate of change (1984-2014) in each transect according to the Linear Rate of Change (m/year): Positive values in green, with the maximum of each zone in blue. Negative values in orange and red, with their minimum in purple. (PNOA, UTM ETRS89 30N). 


\subsubsection{Beach response to storms}

Firstly, it is shown the identification of storms between 1999 and 2014 from wave data, recognizing their frequency for each year, as well as their energy characteristics (Table 4.4). This has allowed the categorization of each year according to the average intensity of its storms (Fig. 4.19).

Table 4.4. Storms identified between 1999 and 2014 and their average annual duration (h), Hs (m), Hs max (m) and intensity (m2h).

\begin{tabular}{c|ccccc} 
Year & $\mathrm{N}^{\circ}$ storms & Avg. duration $(\mathrm{h})$ & Avg. Hs $(\mathrm{m})$ & Avg. Hs max $(\mathrm{m})$ & Avg. intensity $\left(\mathrm{m}^{2} \mathrm{~h}\right)$ \\
\hline 1999 & 7 & 26.7 & 1.8 & 2.1 & 56.4 \\
2000 & 8 & 22.1 & 1.7 & 1.9 & 44.9 \\
2001 & 14 & 38.1 & 2.0 & 2.6 & 111.9 \\
2002 & 7 & 30.0 & 2.0 & 2.6 & 85.1 \\
2003 & 17 & 34.5 & 1.9 & 2.2 & 84.4 \\
2004 & 15 & 29.2 & 1.8 & 2.1 & 62.3 \\
2005 & 6 & 29.7 & 1.9 & 2.4 & 78.8 \\
2006 & 9 & 36.6 & 1.9 & 2.3 & 92.3 \\
2007 & 16 & 32.4 & 1.9 & 2.4 & 81.2 \\
2008 & 11 & 29.7 & 1.8 & 2.2 & 75.8 \\
2009 & 9 & 25.0 & 1.9 & 2.4 & 79.3 \\
2010 & 10 & 35.8 & 1.9 & 2.6 & 107.9 \\
2011 & 9 & 27.9 & 1.8 & 2.2 & 62.8 \\
2012 & 18 & 33.6 & 1.9 & 2.4 & 96.0 \\
2013 & 20 & 29.1 & 1.9 & 2.5 & 75.1 \\
2014 & 5 & 30.8 & 1.9 & 2.4 & 80.3 \\
\hline
\end{tabular}

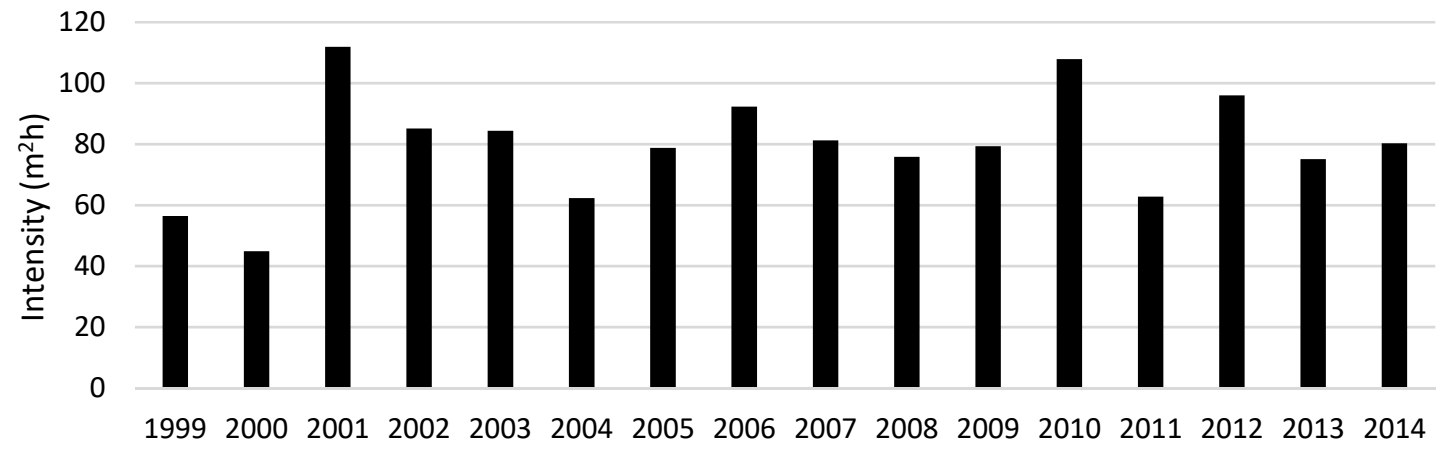

Fig. 4.19. Average annual intensity (expressed in $\mathrm{m}^{2} \mathrm{~h}$ ) of the recorded storms.

There are large differences in the total number and intensity of storms recorded in each of the studied years. About the number of events, it is worth noting that, while in certain years such as 2014 and 2005 only 5 and 6 storm events were recorded, during 2012 and 2013 there were as many as 18 and 20 respectively. The average intensity also shows great changes between the different years. Thus, the enormous jump in the intensity recorded during 1999 and 2000 (56.4 and $44.9 \mathrm{~m}^{2} \mathrm{~h}$ respectively) is striking, compared to 2001, when the highest intensity was recorded (111.9 $\left.\mathrm{m}^{2} \mathrm{~h}\right)$, followed by 2010 and 2012 (107.9 and $96.0 \mathrm{~m}^{2} \mathrm{~h}$ ).

Of the whole set of storms detected using the above methodology, the $10 \%$ with the highest intensity were selected (Table 4.5), with the aim of studying their impact on the shorelines. 
Table 4.5. The most intense storms recorded between 1999 and 2014, in chronological order, constitute the short-term analysis. Their duration (h) is shown, as well as their $\mathrm{Hs}(\mathrm{m}), \mathrm{Hs} \max (\mathrm{m})$ and average intensity (m2h).

\begin{tabular}{ccccccc} 
Date (DD/MM/MY) & Duration $(\mathrm{h})$ & $\mathrm{Hs} \operatorname{med}(\mathrm{m})$ & $\mathrm{Hs} \min (\mathrm{m})$ & $\mathrm{Hs} \max (\mathrm{m})$ & Range $(\mathrm{m})$ & Intensity $_{\left(\mathrm{m}^{2} h\right)}$ \\
\hline $09-11-01$ & 70 & 2.49 & 1.45 & 3.8 & 2.3 & 262.5 \\
$14-11-01$ & 62 & 2.759 & 1.45 & 6.1 & 4.65 & 378.2 \\
$06-05-02$ & 54 & 2.349 & 1.45 & 3.3 & 1.89 & 180.36 \\
$15-10-03$ & 108 & 2.17 & 1.41 & 3.0 & 1.54 & 318.6 \\
$17-11-03$ & 69 & 2.49 & 1.42 & 3.2 & 1.74 & 218.0 \\
$19-12-06$ & 122 & 2.26 & 1.45 & 3.1 & 1.69 & 383.1 \\
$26-01-07$ & 56 & 2.32 & 1.5 & 3.8 & 2.25 & 210 \\
$25-11-07$ & 89 & 1.93 & 1.42 & 2.4 & 1.01 & 216.27 \\
$04-03-08$ & 69 & 2.35 & 1.46 & 3.2 & 1.74 & 220.8 \\
$09-10-08$ & 59 & 2.14 & 1.47 & 3.4 & 1.96 & 202.4 \\
$13-12-09$ & 66 & 2.86 & 1.42 & 5.8 & 4.39 & 383.5 \\
$07-01-10$ & 60 & 2.32 & 1.43 & 3.7 & 2.22 & 219 \\
$25-01-10$ & 64 & 2.46 & 1.41 & 4.5 & 3.08 & 287.4 \\
$11-10-10$ & 49 & 2.22 & 1.43 & 3.8 & 2.38 & 186.7 \\
$02-02-12$ & 99 & 2.39 & 1.58 & 3.5 & 1.89 & 343.5 \\
$06-02-12$ & 61 & 2.22 & 1.41 & 3.1 & 1.69 & 189.1 \\
$11-11-12$ & 95 & 2.68 & 1.44 & 4.1 & 2.7 & 393.3 \\
$30-11-13$ & 46 & 2.61 & 1.43 & 4.1 & 2.68 & 189.1 \\
\hline
\end{tabular}

It is interesting to pay attention not only to the value of the intensity but also to the maximum significant height and the dates. Thus, there are "critical moments" when events are very close in time and waves show great height. Thus, in November 2001, two storms were observed in a period of five days, the second of which had a maximum significant height of more than $6 \mathrm{~m}$ (the highest in the series). Similarly, in the period between December 2009 and January 2010, three large storms coincided, the first with waves with a significant height of up to $5.81 \mathrm{~m}$, while the last one approached $4.5 \mathrm{~m}$.

To recognize the different impacts of the storms on the evolution of the three studied beach sections, the 18 selected storms and the changes registered by the shorelines defined by SHOREX from Landsat images have been highlighted along the time axis (Fig. 4.20).

During most of the study period, the shoreline maintained a negative trend or retreating behavior compared to the original position. Such an erosive process had a starting point clearly associated with the storms of November 2001. Following these, the three studied zones recorded very marked losses, between 10 and $20 \mathrm{~m}$, greater in zone A than in the other two. The retreat of the shoreline associated with the impact of these storms continued for several years. Until the autumn of 2006, the situation prior to these storms was not reached in zone A, while the other two zones did not recover. 


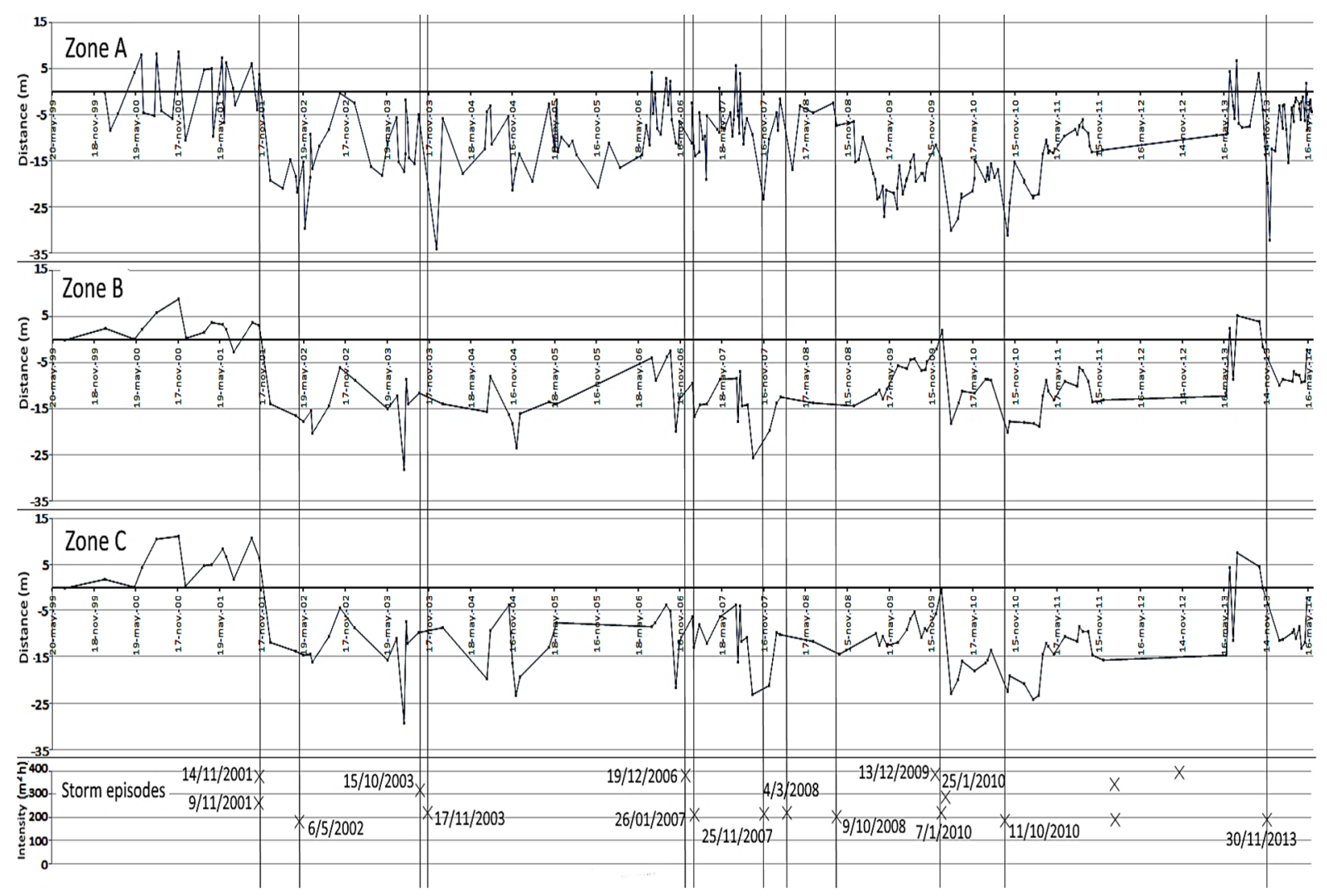

Fig. 4.20. Shoreline evolution $(\mathrm{m})$ in the three studied zones together with the 18 highest intensity storms (m2h) identified in the graph below (together with vertical lines for interpretative purposes). As a reference, we start from the positions on 6/1/2000 (Zone A) and 14/7/1999 (B and C). No records appear during 2012 due to the lack of Landsat images.

Between December 2009 and January 2010 a second critical moment consisting of three highintensity events established a new general erosion at the three studied zones. The effects, besides being perceptible, were, as in 2001, sustained over time. In this case, they are less evident due to the lack of shoreline position records during 2012. It is remarkable the impact of the first storm $(13 / 12 / 09)$ in the three zones, because although in zone A erosion was registered, in zones B and $C$ there were very slight accretions. However, after the other two storms, the erosive effect was very pronounced in all zones.

Minor storm events, as well as those that appear isolated, also presented interesting effects. Some, such as the one in May 2002, simply reinforced the maintenance of a receding trend, without generating major losses. The storm in October 2003, one of the longest (108 h), had a highintensity value $\left(318 \mathrm{~m}^{2} \mathrm{~h}\right)$. However, despite another storm a month later, the impact on the beaches was quite limited. This was practically negligible in zones $B$ and $C$, although in zone $A$ it did cause a sharp decline from which it quickly recovered. the events of December 2006 and January 2007 had a very low impact despite their long duration (122 $\mathrm{h}$ the one in December 2006 event). The storms of March and October 2008 caused a very sharp recession in zone A that was not sustained over time (in the other two zones there are no coincident shoreline records). The effect of the storm of 11/10/10, when the beaches were much wider than usual, was very low. On the contrary, the storm of 30/11/13 when beaches had recovered a good part of their usual width, caused a strong erosion in all zones. 
A comparison of the evolution of the beach and the average intensity of the storms per year (Fig. 4.19) shows that years with the least intense storms (1999, 2000 and 2011) are those in which beaches tend to widen, in clear contrast to those years with more intense storms, which show erosion.

\subsubsection{Response to anthropogenic actions}

The artificial displacement of sands -dredging on beaches with excess sediment and nourishing where there are erosion problems- causes punctual alterations in the width of the beaches and, therefore, displacements on the shoreline. Fig. 4.21 shows the evolution of the shoreline in zones A and B, between May 2005 and May 2011, in association with the period in which sand was extracted and artificially nourished. Between February and May 2009 more than 150,000 $\mathrm{m}^{3}$ of sand dredged from Gandia beach (zone A) was nourished on Piles beach (B) and on Bellreguard and Miramar, adjacent beaches to the north. During this period, significant erosion of the shoreline was registered in zone A, coinciding with a widening in zone B. Similarly, between January and June 2008, another transfer of sand of much smaller magnitude (about $46,500 \mathrm{~m}^{3}$ ) was carried out from Gandia beach (A) to Piles beach (B), the effects of which are not so appreciable: a retreat of about $10 \mathrm{~m}$ appears in zone $A$, which is rapidly recovering, while zone $B$ shows no change, although it is true that by the date on which this retreat is observed in zone A no data are available for zone B. Similarly, 38,000 $\mathrm{m}^{3}$ were nourished between May and June 2010, coinciding with a slight progression in Piles. Various sand displacements were also carried out in zone $A$, and the one carried out in July 2007 in Gandia Nord, over 23,000 $\mathrm{m}^{3}$ of sediment, is followed by the maximum progression reached in the last six years.

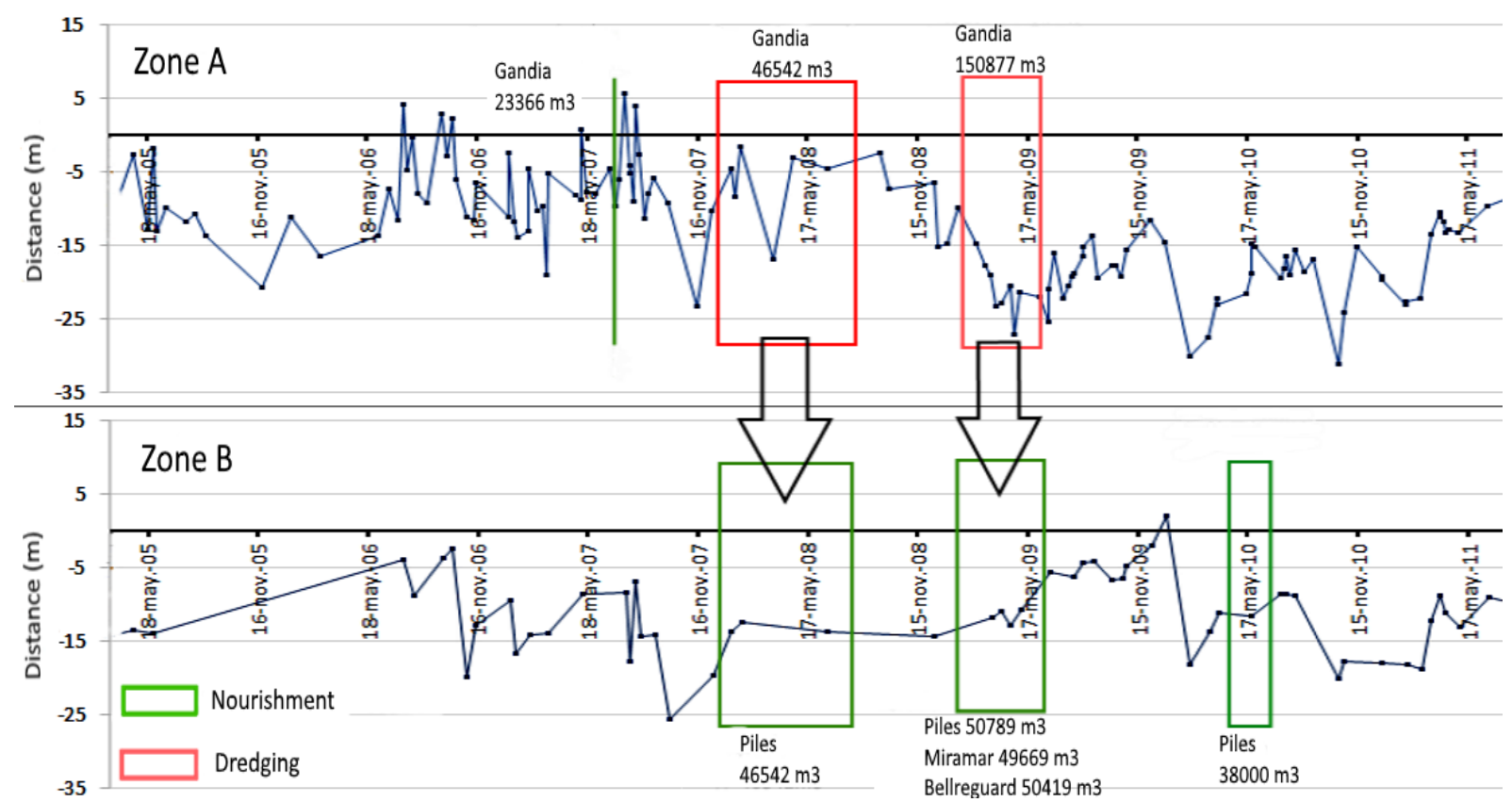

Fig. 4.21. Average evolution of the shoreline in zones $A$ and $B$. Dredging actions in zone $A$ and nourishment in zone $B$ and other annexed beaches. As a reference, the positions on 6/1/2000 (A) and 14/7/1999 (B). 


\subsubsection{Comparison of the response between the different beaches}

This analytical procedure aims to highlight the similarities and differences between the responses to the various actions (natural or human) to which beaches are exposed. The recognition and quantification of these differences make it possible to recognize the causes that explain the different responses of the beaches (Fig. 4.22).

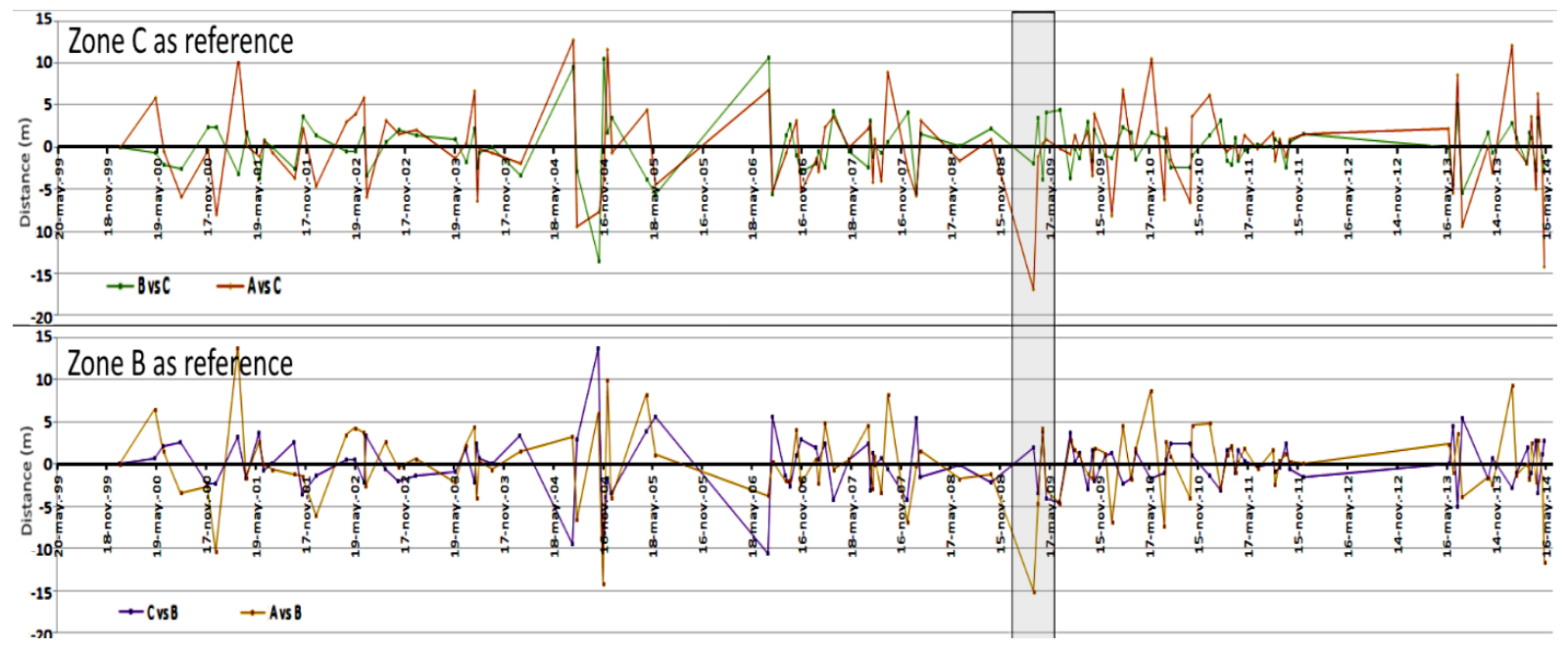

Fig. 4.22. Comparison of the magnitude and direction (erosion/accretion) of change of the shoreline in the different zones. For each of the common dates, the change in the average position of the shoreline in one zone was subtracted from that of the others. In this way, a change that affects only (or to a greater extent) one of the zones is translated into positions further away from the horizontal axis. The upper part shows the changes of zones A (brown tone) and B (green tone) against $C$ (acting here as a reference line). The lower graph compares zones $A$ (brown) and $C$ (purple) versus $B$ (reference). The main movement of sand from $A$ to $B$ is shown highlighted between vertical lines.

The comparison shows that, in most cases, all beaches follow a common evolution, which explains why their differences usually do not exceed $5 \mathrm{~m}$. This magnitude, close to the uncertainty of definition of each of the shorelines, would indicate that there are no significant changes. It should be noted that events such as the storms of November 2001, which caused major alterations in the width of the beach, are not noteworthy when comparing the different zones. It highlights the idea that their impacts occurred in the three zones with similar dimensions. However, there are particular dates in which one zone registers major changes or changes in the opposite direction than the others. Thus, it can be seen that zone A presents greater changes than the other two, indicating greater variability, which in turn suggests that the slope of the beachfront is lower. This is perfectly expected given that zone $A$ is located on the beach supported by the dikes of the port of Gandia, and therefore it is a clearly cumulative beach. We can also observe dates in which zone C follows a pattern of change radically different to the other two zones (summer-autumn 2004, summer 2006) which would be explained by the different orientation of these coastal sections which, in turn, cause a substantial modification in the direction and magnitude of the longitudinal transport of sediments. Finally, this method of analysis allows to record the retreat caused by the extraction of 150,000 $\mathrm{m}^{3}$ of sand from zone $A$ as opposed to the other two zones. On the other hand, concerning the other actions that mobilized smaller volumes of sand, it is not possible to distinguish associated changes, reinforcing the idea that they did not have appreciable repercussions. 


\subsection{Discussion}

Based on Landsat 5, 7, and 8 images, that offer lower accuracy than conventional sources such as orthophotos or DGPS (Pardo-Pascual et al., 2018, 2012), it has been possible to obtain numerous records of the position of the shore covering the period 1984-2014. This has made it possible to characterize the variability and interannual dynamics of beaches on a regional scale with a high level of automatism and to support the evolutionary analyses with a greater amount of data. Despite the high variability of the shoreline, even in very short periods, the use of up to 257 measurements (125 in zones B and C) provides great robustness to the results comparing to other more precise techniques that are based on very few records over time.

Shoreline position data allow establishing relationships with the morphological characteristics of each beach and with the anthropic interventions, caused by the construction of obstacles to the longitudinal transport of sediments and by artificial nourishments (Pardo-Pascual \& Sanjaume, 2019; Sanjaume \& Pardo-Pascual, 2005). After analyzing changes over three decades, it is clear that the accretion observed in the southern part of zone $A$ is associated with the accumulation forced by the northern dyke of the port of Gandia, while the erosion of zone B is directly related to this obstacle too. On the other hand, Zone C appears located at the end of a traditionally cumulative sedimentary cell (Pardo-Pascual \& Sanjaume, 2019) and shows mild erosion. This change of trend would confirm the shift from a cumulative status to another where the lack of sediment in the system is dominant. This idea, already suggested by other previous works (Sanjaume \& Pardo-Pascual, 2005), would be confirmed by the increasing size of the sediment on these beaches (Cabezas-Rabadán, 2015; Pardo-Pascual \& Sanjaume, 2019).

The comprehensive analysis of large packages of shorelines is useful to recognize, quantify, map and compare the short-term effect of phenomena such as coastal storms or artificial sand movements, in line with other previous work (Cabezas-Rabadan et al., 2018; Pardo-Pascual et al., 2014). Most of the large storm events analyzed have been associated with shoreline recession. Apparently, these effects only last for days or, at most, a few weeks. There is still uncertainty in aspects such as the action of storm clusters (Sénéchal et al., 2017) and their subsequent capacity to recover (Angnuureng et al., 2017). Therefore, having quantitative information to monitor the coast is extremely useful to improve the understanding of beach response (Anthony, 2013).

On even larger time scales, it is of great interest to study the relationship with the storm regime. The accumulation or succession of storm events seems to play an essential role in the evolution of beaches. As an example of this, 2001 which is particularly rich in the number and magnitude of coastal storms (Fig. 4.19), constitutes a turning point in the time series, as it generates major erosion in the three zones from which beaches seem to take years to recover and return to previous states (Fig. 4.20). This sustained erosive action over time is largely linked to the fact that one of the most severe storms occurred in the western Mediterranean in November 2001. As highlighted in different works (Obiol-March, 2003; Ramis et al., 2001; Julià, 2003), this event (or set of events) generated important erosion processes by mobilizing large amounts of sediment, and was followed by storms until spring 2002 (Pardo-Pascual et al., 2014). A similar, though lesser, erosive phenomenon occurred in all three studied zones between late 2009 and early 2010 (Fig. 
4.20). Conversely, most of the medium-term progradations seem to be a consequence of a progressive accumulation of sediment over time, possibly due to periods of greater marine calm, as they appear simultaneously and similarly in the three zones.

With regard to the anthropic actions, results have shown that sand nourishments and dredging actions that mobilized the greatest volume of sediment have been reflected in shoreline changes. Despite this, the research has been limited by the lack of definition regarding the exact place and time at which the actions were carried out, adding uncertainty to errors associated with the shoreline definition.

Construction projects and human interventions on the coast must follow the environmental impact assessment procedure in order to keep the impacts on the environment under control. The position of the shoreline could provide basic information for the associated monitoring and surveillance programs. Similarly, in order to maintain the width of the beach, it is common that emergency actions as nourishments are carried out without the necessary planning and vision (Cabezas-Rabadán et al., 2019a; Jiménez et al., 2011). However, despite the major environmental and economic impacts involved, on many occasions, they turn out to be ineffective after short periods (Aragonés et al., 2015; Hanson et al., 2002; Peterson \& Bishop, 2005; Speybroeck et al., 2006). For a proper management of the coast, these actions must be adequately monitored to assess their suitability and real effectiveness.

In this work, we have shown the differential analysis of the dynamics followed by each of the studied zones. The defined shorelines are coincident in time, with common wave and sea-level conditions, which makes them comparable. Thus, different changes at beaches with similar characteristics can be associated with local actions such as nourishments or dredgings. This type of analysis could be useful to define the spatial and temporal effect of anthropic interventions along the coast, even allowing the quantification of the imbalances generated by obstacles to sediment transport. On the other hand, changes in the position of the shoreline are linked to the morphological characteristics of each beach. Thus, it seems that the intra-annual variability of the shoreline defined by remote sensing is linked both to the slope of the beach and to the sediment grain size (Cabezas-Rabadán et al., 2017). Thus, this methodology can provide key information on the nature of the beaches, and could be used to estimate other relevant parameters.

Intra-annual changes may offer an approach to the most unfavorable situations for the maintenance of beach functions throughout the year (Cabezas-Rabadan et al., 2019; CabezasRabadan \& Pardo-Pascual, 2017). This may be useful for managers as it would allow them to identify when the width is inadequate for recreational use, as has happened at Piles beach (Cabezas-Rabadan et al., 2019). Likewise, continuous monitoring would be useful for the early detection of erosive trends, as well as for defining the appropriate moment to intervene.

In terms of methodological limitations, given that the recovery of microtidal beaches can take place in a few days (Ranasinghe et al., 2012) the retreat and recovery after storms may occur in periods when no data are available, making the detection impossible. The ability to track shortterm changes may be strongly influenced by insufficient data density. For example, in zone A, 
where twice as many images have been available due to the overlap between Landsat passes, it has been possible to detect changes of shorter scale (e.g. a strong erosion after a storm and a rapid recovery) that are not reflected in zones $B$ and $C$. However, the availability of a new data source such as Sentinel-2 images with which even higher levels of accuracy can be achieved (Pardo-Pascual et al., 2018) will presumably minimize this problem. The current availability of Sentinel-2 along with Landsat 7 and 8 satellites sets a new scenario with increased data availability. This opens up new possibilities in the use of SHOREX for the analysis and monitoring of changes caused by storms and human actions.

Another remarkable limitation is the precision with which the shorelines are defined. The present study has been carried out using the SHOREX extraction system following the methodology described in Pardo-Pascual et al. (2018) with inaccuracies in the order of $7.5 \mathrm{~m}$ for shorelines from Landsat 7 (and a priori also Landsat 5) images and $6.6 \mathrm{~m}$ for Landsat 8 images. This means that the recorded changes have been defined considering this uncertainty. Taking into account the possible applications of the methodology, improving the accuracy is key, but also possible with the methodological solutions proposed in the new versions of the SHOREX. It is expected that very soon it will be possible to apply these methods with greater precision, which will allow recording the magnitudes of changes with a greater degree of certainty and security.

\subsection{Conclusions}

The methodology presented here provides the technical capacity to study coastal dynamics from the novel source of medium spatial resolution satellite images constituted by the Landsat and Sentinel-2 series. The present study evidences the utility of SHOREX to provide wide series of shorelines. Although these data are less accurate than other methods, they are very valuable due to their high repeatability, allowing a systematic record of the state of the beaches over large areas and periods. Shoreline data, very costly to obtain by other methods, provide key information on the evolution and nature of beaches, and allow monitoring the coast in a detailed and relatively simple way. This is of great interest given the importance that beaches have for society, together with the existence of erosive processes that climate change will potentially increase in the future. Updated shoreline data would provide the holistic and homogeneous approach required by coastal monitoring systems, facilitating the analysis of changes and the subsequent work of managers. 




\section{Detecting problematic beach widths for the recreational function from subpixel shorelines.}

The content of this chapter has been published as:

Cabezas-Rabadán, C., Pardo-Pascual, J. E., Almonacid-Caballer, J., Rodilla, M. (2019). Detecting problematic beach widths for the recreational function along the Gulf of Valencia (Spain) from Landsat 8 subpixel shorelines. Applied Geography, 110.

"He always thought of the sea as 'la mar' which is what people call her in Spanish when they love her. Sometimes those who love her say bad things of her but they are always said as though she were a woman. Some of the younger fishermen [...] spoke of her as 'el mar' which is masculine. They spoke of her as a contestant or a place or even an enemy. But the old man always thought of her as feminine and as something that gave or withheld great favours, and if she did wild or wicked things it was because she could not help them."

-E. Hemingway-

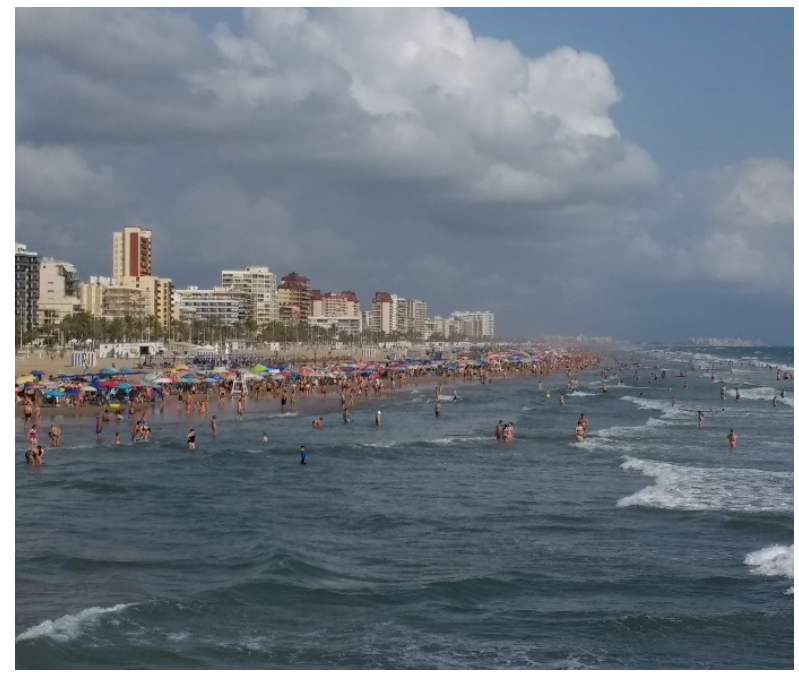


Mapping indicators of the beach state along the coast may provide support for decision-making processes. As it has been shown in the previous chapters, Satellite-Derived Shorelines and beach width are two key geomorphological features that may be efficiently defined along large coastal segments and periods, constituting indicators of the beach state.

Among the different physical aspects that contribute to define the potential attractiveness of the beaches for beachgoers (Micallef and Williams, 2002) beach width has great value, even economically quantifiable (Silberman \& Klock, 1988). Besides, this physical aspect defines the carrying capacity of the beach (Cifuentes, 1992; Rodella et al., 2017), and also has consequences for the adjacent territory (Gormsen, 1997). Associated with the attraction caused by the recreational function, different services with a direct impact on the economy or the value of the land and properties are developed on the coastal front (Pompe \& Rinehart, 1994). Given the scarcity of uniform and continuously updated data on beach morphology, few articles have focused on the effect of geomorphological characteristics on beach functions (e.g. Ballesteros et al., 2018; Jiménez et al., 2011).

This raises the possibility of using indicators of the morphological state of the beaches, such as the width, to define their influence on the recreational function of the beach. Indicators could be integrated with other pre-existent databases of the coastal area, such as those referring to the land use in the coastal front and beach infrastructures that may indicate the level of use that the beaches are sustaining. The integration of up-to-date geomorphological indicators with data characterizing the development of the recreational function along the coast would allow mapping segments in which beach functions are jeopardized along time. This information may be essential for coastal managers for prioritizing actions.

With all this in mind, this chapter describes a regional monitoring of the beach width along time and its link with the recreational use of these spaces in order to map the affection of the morphology on the recreational function. For this purpose, shorelines automatically derived from Landsat 8 satellite were employed, covering up to 83 dates (2013 - 2016) and $150 \mathrm{~km}$ of beaches. The study included the microtidal beaches of the Gulf of Valencia, a strongly developed coast with intensive use in the western Mediterranean. Beach widths were defined in alongshore coastal segments of 80-meter length. Annual mean width and annual percentiles appeared as representative statistics of the beach state and the most unfavorable widths occurred throughout the year. Considering these statistical descriptors, beach segments were classified according to their adequacy to sustain a recreational function. The integration of descriptors of the beach width and use of the beach data on a regional scale offers a holistic approach to identify potentially problematic segments, crucial information for coastal managers. 


\subsection{Introduction}

Beaches are natural environments able to provide protective, habitat, and recreational functions (Prodger et al., 2016). The latter one constitutes an important socioeconomic resource (Alexandrakis et al., 2015; Gopalakrishnan et al., 2011, Gormsen, 1997) in areas as the Mediterranean, where 500 million tourists per year are forecasted for 2030 (UNWTO, 2013). Beaches are worldwide threatened by erosive processes (Bird, 2013; Cooper \& McKenna, 2008). At the regional level, they are motivated by disturbances in sediment transport and its entry into the coastal system. Worldwide, higher global temperatures will alter hydrodynamics and rise sea level (Nicholls \& Cazenave, 2010; Slott et al., 2006) with forecasts ranging from 0.45 to $0.82 \mathrm{~m}$ by 20812100 according to the IPCC Fifth Assessment Report (IPCC, 2014) under the worst-case scenario of $2.6-4.8^{\circ} \mathrm{C}$ global warming. Alterations of the shoreline position and reductions of the beach surface jeopardize the maintenance of the beach functions. This may result in loss of habitats (Feagin et al., 2005; Fish et al., 2005), increased coastal flooding (Hinkel et al., 2013), and a threat to the tourism industry and the economy associated with the recreational function (Gopalakrishnan et al., 2011; Phillips \& Jones, 2006).

The management of the beaches considering their recreational function has become a great concern of Integrated Coastal Zone Management (Micallef \& Williams, 2002). The need for certain physical characteristics in order to maintain the beach functions makes it necessary to pay special attention to their morphology (Ballesteros et al., 2018; Jiménez et al., 2011). Focusing on the characteristics of the beach from the recreational point of view, different authors have emphasized the necessity of a favorable sediment status and have even defined a minimum beach width. Although the criteria are heterogeneous, most authors have pointed out that a width below 30 $35 \mathrm{~m}$ would be detrimental to the development of recreational beach functions (Alemany, 1984; Houston, 1996; Jiménez et al., 2011; Sardá et al., 2009; Yepes, 2002). Likewise, Valdemoro and Jiménez (2006) pointed out that previous surveys (CEDEX, 2000; Jiménez \& Sánchez-Arcilla, 2001; Villares, 1999) identified the excessive beach width as a problematic issue for recreational purposes, as users may perceive it as uncomfortable (Cabezas-Rabadán et al., 2019a). Recently, the width of the beach has begun to be used by administrations to regulate the use of the beaches and the development of activities, as in the Territorial Action Plan for Green Coastal Infrastructure (PATIVEL) for the Valencian region in Spain (GVA, 2018).

Considering the management associated to the beach morphology, it is essential to identify processes and to quantify the dynamics of key parameters through the implementation of longterm monitoring (Defeo et al., 2009; Micallef \& Williams, 2002) that supply up-to-date and objective information. Therefore, it is necessary to define parameters or indicators for describing the coastal state (Giardino et al., 2014; Van Koningsveld et al., 2005). Shoreline position and beach width seem useful for that purpose. In order to define them, traditional methods as photointerpretation (Ford, 2013; Jones et al., 2009; Morton et al., 2004) only provide measurements at specific moments. Among the most recent techniques, DGPS allows surveying large areas (Pardo-Pascual et al., 2005; Psuty \& Silveira, 2011) although they require in-situ data acquisition while video-based techniques (Aarninkhof et al., 2003; Davidson et al., 2007; Sánchez-García, et 
al., 2017) are limited to a local scale. By contrast, remote sensing is a potential source of useful data for coastal planning as it offers a continuous record of data of the whole terrestrial surface, even in remote areas (Cenci et al., 2017; Guariglia et al., 2006). Since 2008, Landsat mission has offered free available satellite medium-resolution imagery of the last three decades with worldwide coverage. Different algorithms have been developed in order to overcome the restriction of an excessively coarse spatial resolution (30 m) and to allow defining Satellite-Derived Shorelines (SDS) with sub-pixel precision (Almonacid-Caballer, 2014; Foody et al., 2005; Hagenaars et al., 2018; Li \& Gong, 2016; Liu et al., 2016, 2017; Pardo-Pascual et al., 2012, 2018). Recently, SHOREX has appeared as a system that offers an automated definition of the shoreline position at major spatial and temporal scales (Palomar-Vázquez et al., 2018). Although the accuracy of this methodology is lower than that of traditional sources, it opens a new scenario with many available measurements throughout the year. The intra-annual changes can reflect the beach response to storms and other events (Cabezas-Rabadán et al., 2018; Pardo-Pascual et al., 2014) allowing an approach to the most unfavorable situations for the maintenance of beach functions throughout the year (Cabezas-Rabadán \& Pardo-Pascual, 2017), unknown with traditional techniques.

Continuous monitoring of shoreline data has great potential to characterize beach morphology as well as to quantify key parameters of the beach state and its dynamism. These data would be especially interesting for management if it was possible to integrate them with information on the recreational function of beaches. It would allow the identification of beach segments in which their physical characteristics (such as emerged width) conflicts with their use. The integration of data related to the human use of the beaches as well as their morphology can be achieved by applying GIS tools to coastal areas (Anfuso \& Martínez, 2009; Cenci et al., 2017).

Based on tens of Landsat 8 subpixel shorelines per year, the main goals of this work are (i) quantifying statistical descriptors of the beach width after monitoring its intra-annual variability, and (ii) integrating width descriptors and recreational use data to identify segments with negative influence on the recreational function.

The work is carried out on the microtidal beaches of the Gulf of València (Spanish Mediterranean). This coast faces high anthropogenic pressure and recreational use as well as erosive problems, constituting a representative example of the coastal areas in which this application of the shoreline data would be useful for coastal management.

\subsection{Study area}

The analysis was developed on the beaches of the Gulf of Valencia, on the east coast of the Iberian Peninsula, between the Ebro Delta and the Sant Antoni Cape (Fig. 5.1). This coast constituted a sedimentary cell nowadays fragmented by different artificial sediment traps (Pardo-Pascual \& Sanjaume, 2019). It has an average astronomical tidal range below $20 \mathrm{~cm}$ and small waves $\left(H_{s}=\right.$ $0.7 \mathrm{~m} ; \mathrm{T}_{\mathrm{p}}=4.2 \mathrm{~s}$ ). Nevertheless, during storms the water level position can raise up $1.32 \mathrm{~m}$, and the significant height of the waves can reach $6.55 \mathrm{~m}$, and $15 \mathrm{~s}$ of peak period (Pardo-Pascual et al., 2014; Pardo-Pascual \& Sanjaume, 2019), causing important losses of sediment on the beach. 

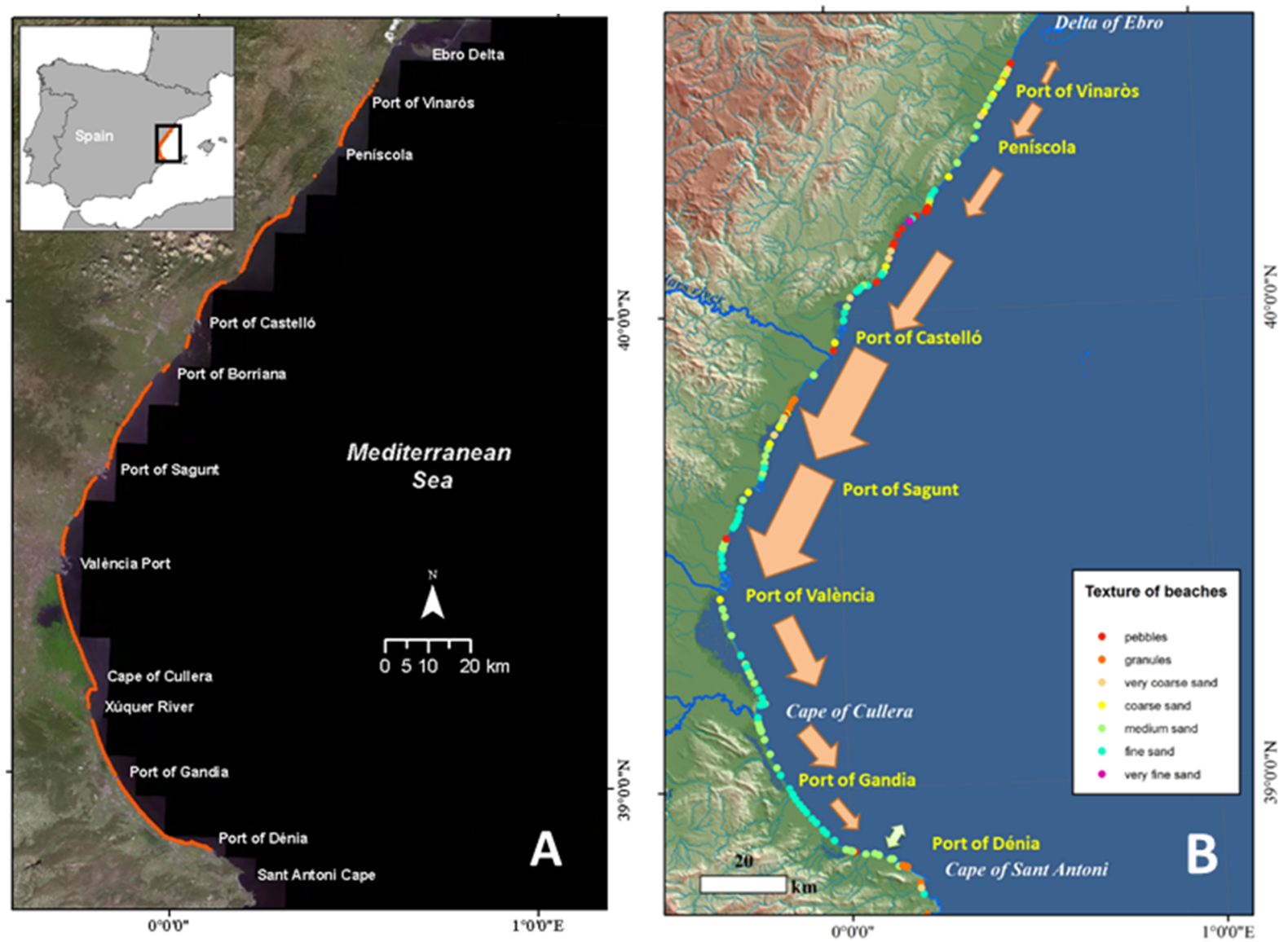

Fig. 5.1. A) Study area along the Gulf of Valencia and the main ports and alongshore obstacles. B) Transport pattern (arrows) along the study area and Sediment texture distribution (MAGRAMA, 2007).

This area has a strong littoral drift that provokes southerly sand transport and contributes to the distribution of the sediment alongshore (Fig. 5.1B) sometimes interrupted by the presence of civil engineering structures (Sanjaume \& Pardo-Pascual, 2005). It is a sedimentary coast composed mainly of medium and fine sandy beaches, all of which also include some stretches of granules and gravel (MAGRAMA, 2007; Pardo-Pascual \& Sanjaume, 2019; Sanjaume, 1985). In the Valencian region, practically all the beaches are equipped for leisure purposes (Obiol-Menero, 2003). They are intensively used and constitute the basic resource of the tourist industry. The recreational value of these spaces provides important benefits to the society, and this sector contributes to the economy of the Valencian region with more than $14 \%$ of the regional GNP (Rico-Amorós, OlcinaCantos, \& Sauri, 2009).

A process of tourist-residential urbanization has been developed linked to the recreational use of the beaches. Buildings and constructions have been located very close to the coastline, and a large number of groins (141) and marinas (16) have been built (Pardo-Pascual \& Sanjaume, 2019). This high anthropogenic pressure has greatly degraded the littoral and contributed to a significant coastal erosion (Obiol-Menero, \& Pitarch-Garrido, 2011; Yepes \& Medina, 2005) that affects over $26 \%$ of the region (EC, 2009). This phenomenon has led to numerous anthropogenic actions and nourishment projects in order to maintain the beach size (Hanson et al., 2002). During the period 1983-2002, 287 actions were carried out and budgeted at $€ 170$ million, with an average of 15 
actions/year and $€ 0.6$ million/action (Obiol-Menero, 2003). The maintenance of the beaches is a responsibility of the Directorate General of Coast (DGC) part of the Ministry of Environment, although it is managed by different units such as the Valencian Demarcation, responsible for developing regional policies (Barragán-Muñoz, 2010).

\subsection{Data}

Two are the main inputs for the present paper:

On the one hand, a set of Satellite-Derived Shorelines (SDS) from Landsat 8/OLI (Operational Land Imager) between May $23^{\text {rd }}, 2013$, and December $27^{\text {th }}, 2016$. Shoreline positions were defined from the short-wave infrared band (SWIR-1, 1566-1651 nm, 30m/pixel) using the SHOREX system following a well-established methodology (Palomar-Vázquez et al., 2018) reaching a subpixel accuracy of 6.6 m RMSE (Pardo-Pascual et al., 2018).

The study area (Gulf of Valencia, eastern Spain) is covered by Landsat paths 198 and 199, rows 32 and 33 (Fig. 5.2). The available number of images was not homogeneous along the study area: Sectors B and C, that covered most of the coast, had an overlap of scenes and up to 77 and 83 shorelines respectively (Fig. 5.3) while, at the northern and southern extremes, sectors A and D only had 32 and 36 shorelines.

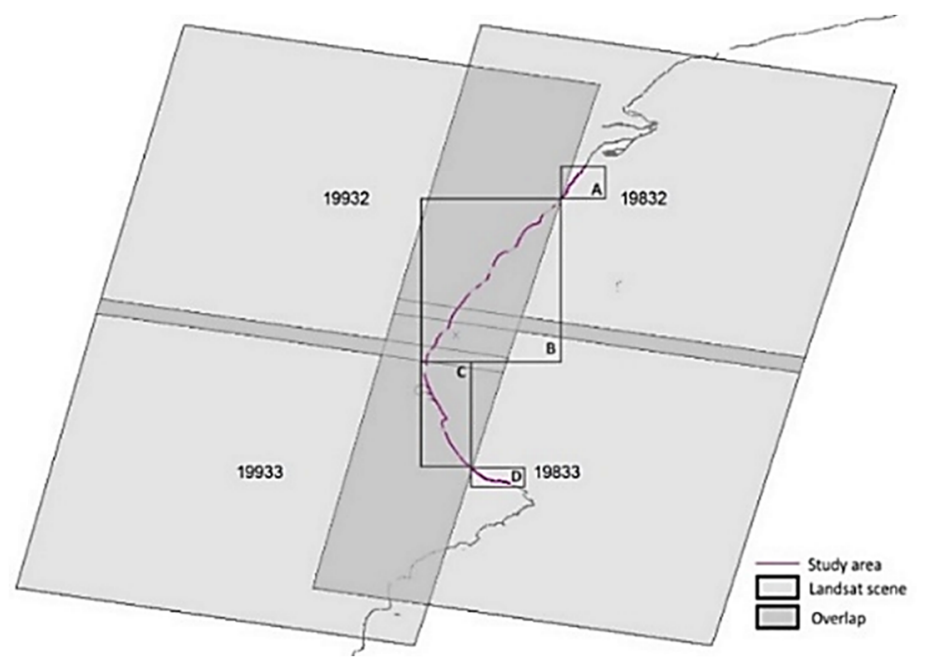

Fig. 5.2. Considering the number of available images (and therefore potential shorelines to be defined) there are four different sectors. B and C comprise the overlap of Landsat paths 198 and 199 (highlighted). Images available free of charge from the USGS archive (http://glovis.usgs.gov/).

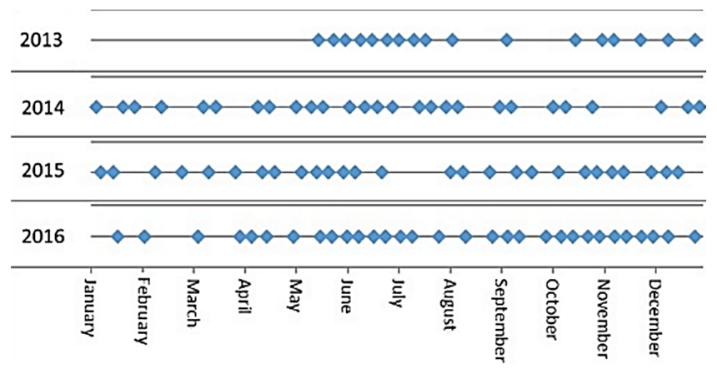

Fig. 5.3. Example of Landsat 8 imagery used in sector $C$, the one with more available images. Gaps in shoreline data availability appeared due to the cloudy days. Furthermore, there were no images available for the first months of 2013 as the satellite had just been launched 
On the other hand, for defining the recreational use of each beach segment the information of two public and open databases were analyzed: the Spanish Catalogue of Beaches (MAPAMA, 2017) and the Land Cover and Use Information System of Spain SIOSE (IGN, 2011). The Catalogue of Beaches provided descriptive information about the state, characteristics, and management of the beaches. It was used to define the level of facilities' supply and the occupancy rate. The SIOSE 2011 database was used as land use input: for each 80-meter analysis segment, the existence of coverage associated with the recreational use of the beach and the tourism sector (residential, hotel, commercial or camping use) was determined. In those cases, the distance from each beach segment to those coverages was identified. The data about beach width and beach usage were combined using GIS tools in order to obtain a beach recreational usage indicator for each segment.

\subsection{Methodology}

The methodology here described creates a bridge between SDS and recreational use of the beach data. Firstly, the beach width is defined and classified in terms of adequacy for sustaining the recreational function. Secondly, the recreational function of the beaches is parameterized. Finally, both sources are linked in order to define the influence of the widths on the recreational function.

\subsubsection{Definition of the beach width}

In order to determine the width, the inland boundaries of the beaches were defined as the inner limit with the promenade or the closest buildings, vegetation or dunes. This line was digitalized in GIS software using PNOA orthophotographies of the study area with $0.25 \mathrm{~m}$ spatial resolution (IGN, 2015). The inner line was fixed or almost stable along the study period, and the error associated with the photointerpretation clearly presented a lower magnitude than the definition of the shoreline position. The length of the segment of $80 \mathrm{~m}$ was chosen for the analysis as it was considered adequate to detect problematic segments while avoiding occasional width changes related to erosion at the inner edge of the beach, or due to small-scale formations on the coastline such as beach cusps. Therefore, the inner line was divided alongshore into $80 \mathrm{~m}$ segments, and the shoreline points of each date were associated with the closest segment. For each segment, the distance from each satellite shoreline to the inner line gives the average subaerial beach width on every available date. (Fig. 5.4). 


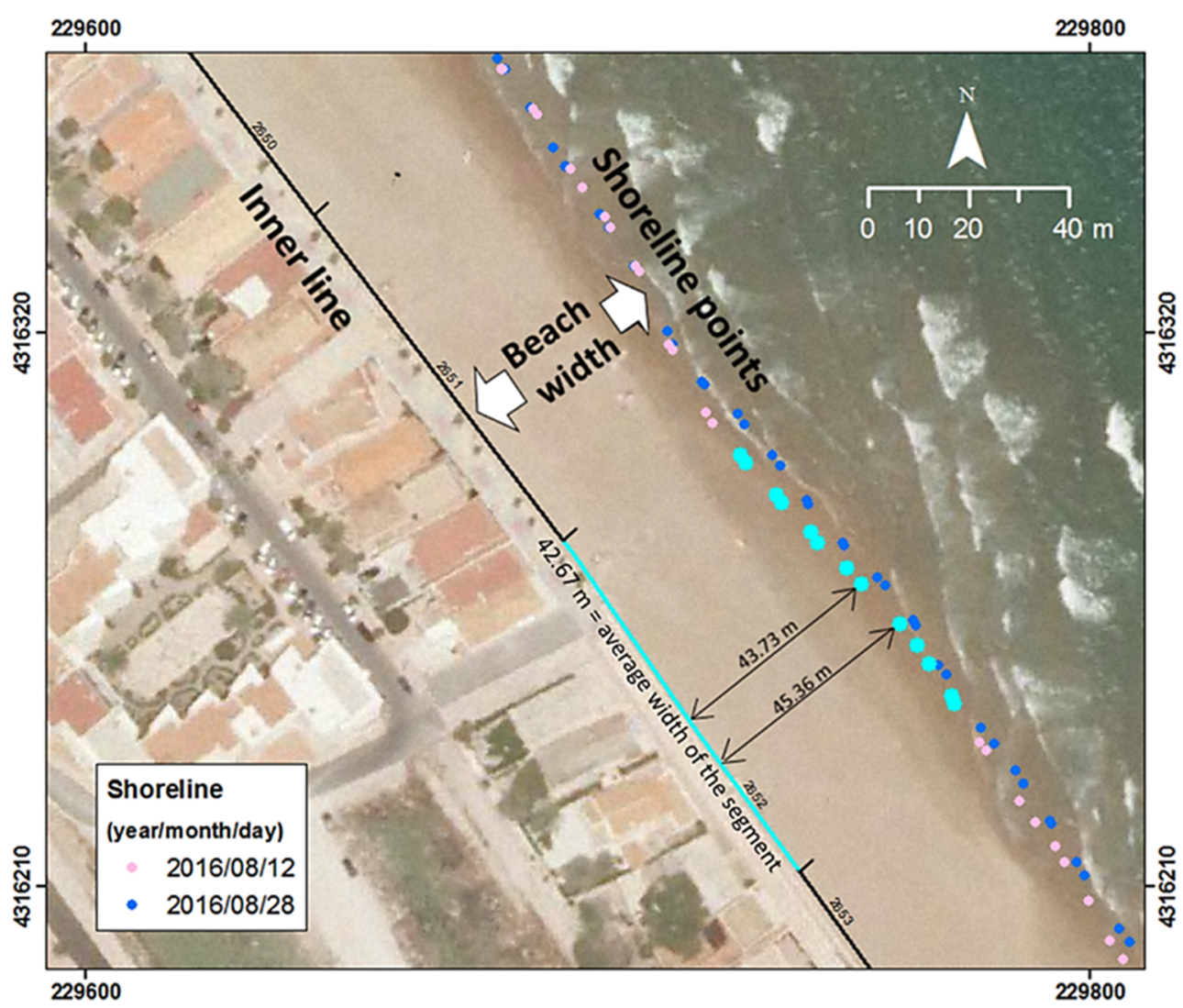

Fig. 5.4. Detail of the shoreline points of 12th and 28th of August, 2016 and the inner line segments of $80 \mathrm{~m}$ length used as a reference. Beach width on the highlighted $80 \mathrm{~m}$ segment was calculated as the average distance to the associated shoreline points on the date 2016/08/28 (42.67 m). The distances of two shoreline points are shown as an example (45.73 and $45.36 \mathrm{~m})$. ETRS89 UTM31N.

Different statistics were defined as potential descriptors of the beach width:

-Annual mean width (AMW), as the average of all the widths recorded over each year.

-Annual percentiles $P_{10}, P_{15}, P_{20}, P_{30}$, and $P_{50}$, being percentile $P_{n}$ the distance at which $n \%$ of the points are located more inland.

\subsubsection{Definition of criteria for detecting segments with inadequate width for the recreational function}

Widths below (or above) certain thresholds may be perceived as negative by beachgoers. Different works have defined 30-35 m as the minimum beach width (Alemany, 1984; Lozoya et al., 2011; Sardá et al., 2009; Yepes, 2002), while other works support the existences of a negative perception of excessive widths (Cabezas-Rabadán et al., 2019a; Valdemoro \& Jiménez, 2006).

Following the previous criteria and according to the width data, beach segments were classified reflecting their inadequacy for sustaining the recreational function (Table 5.1). Segments narrower than $30 \mathrm{~m}$ were considered to have an insufficient width and therefore problematic for the recreational function, and they were given a problematic value of 2 . Similarly, those under $15 \mathrm{~m}$ (i.e. half of the problematic threshold) were defined as very narrow and received an associated value of 3. Otherwise, segments wider than $120 \mathrm{~m}$, four times the problematic threshold had their 
width defined as very wide and received a value of 1, considering the disturbance of having to walk to reach the areas close to the shore. Finally, segments between 30 and $120 \mathrm{~m}$ wide were considered adequate for the recreational use and therefore their inadequacy value was 0 . Following these criteria, an analysis of the width situation on the beaches of the Gulf of Valencia was carried out.

Table 5.1. Classification of beach segments according to their width and their inadequacy for maintaining the recreational function.

\begin{tabular}{c|cccc} 
Beach width $(\mathrm{m})$ & $<15$ & $15-30$ & $30-120$ & $>120$ \\
\hline Classification & Very narrow & Narrow & Adequate & Very wide \\
Inadequacy value & 3 & 2 & 0 & 1 \\
\hline
\end{tabular}

The next step is to define how to use the beach width descriptors previously described (AMW or percentiles) to decide whether a segment is adequate or not for recreational use. In order to analyze the strictness of the descriptors when detecting inadequate widths, we compared the number of detected segments employing each parameter as well as considering the width data of the different years. A comparison of the use of the width parameters $P_{10}$ and the annual mean width (AMW) was carried out on beach segments experiencing problems associated with insufficient widths. Those segments were selected as in that area the General Directorate of Sustainability of the Coast and the Sea (DGCS) repeatedly carried out nourishments considered as necessary for recovering the beach after storm episodes.

\subsubsection{Width influence on the recreational function of the beach}

The existence of excessive or insufficient beach widths presents an inconvenience to the recreational function of the beaches. However, it finally depends not only on the width but also on the recreational use of the beach. Therefore, for each analysis segment, the recreational use of the beach was defined considering the occupancy rate, the facilities supply, and the development as a recreational space and tourist resort of the beach itself and the surrounding land (Fig. 5.5). From the Spanish Catalogue of Beaches (MAPAMA, 2017) we defined indicators rating the beach occupancy (low use "1"; medium use, "2"; high use " 3 ") and the facilities supply (low-equipped "1"; semi-equipped "2"; full-equipped "3"). The recreational and tourist development of the beach was defined according to SIOSE 2011 (IGN, 2011) rating the presence of land cover associated with recreational use in the vicinity of the beach (Non-existent, "1"; existent located less than $500 \mathrm{~m}$ away, "2"; located less than 150 m away, "3"). These values were averaged for each segment in order to define the "recreational use" of the beach, with values ranging from 1 to 3.

\begin{tabular}{|c|c|c|c|}
\hline Beach width & $\begin{array}{c}\text { Width } \\
\text { - inadequacy } \\
(0-3)\end{array}$ & Width influence & $\begin{array}{l}\text { Very high (9) } \\
\text { High (6) }\end{array}$ \\
\hline $\begin{array}{c}\text { Occupancy rate } \\
\text { Facilites supply } \\
\text { Land cover }\end{array}$ & $\begin{array}{c}\mathrm{X} \\
\text { Recreational } \\
\text { use } \\
(1-3)\end{array}$ & $\begin{array}{c}\text { - on recreational } \\
\text { function }\end{array}$ & $\begin{array}{l}\text { Middle (3-4) } \\
\text { Low (1-2) }\end{array}$ \\
\hline
\end{tabular}

Fig. 5.5. Methodology for obtaining indicators of (i) the width inadequacy for sustaining the recreational use and (ii) the recreational use. They are combined in order to define the width influence on the recreational function. 
This parameter was combined in a matrix (Table 5.2) with the width inadequacy (very narrow " 3 ", narrow " 2 ", very narrow " 1 " or adequate " 0 ") defined according to, on the one hand, the percentiles 10 and 90 and, on the other hand, the annual mean width.

Table 5.2. Width influence on the recreational function of the beach.

\begin{tabular}{ll|ccc}
\multicolumn{2}{c|}{$\begin{array}{c}\text { Beach width }(\mathrm{m}) \text { and } \\
\text { inadequacy value }\end{array}$} & \multicolumn{4}{c}{$\begin{array}{c}\text { Recreational use } \\
\text { Intermediate (2) }\end{array}$} & High (3) \\
\hline 30-120 m, adequate & $(0)$ & 0 & 0 & 0 \\
$>120 \mathrm{~m}$, very wide & $(1)$ & 1 & 2 & 3 \\
$15-30 \mathrm{~m}$, narrow & $(2)$ & 2 & 4 & 6 \\
$<15 \mathrm{~m}$, very narrow & $(3)$ & 3 & 6 & 9 \\
\hline
\end{tabular}

The width influence on the recreational function of the beach was defined according to the different values of the matrix as non-existent " 0 ", low "1-2", middle "3-4", high "6" or very high "9". This analysis was implemented in GIS in order to obtain the values along the whole study area.

\subsection{Results}

\subsubsection{Characterization of the beach width}

Shoreline positions were defined by points along $154 \mathrm{~km}$ of the coast for the period $2013-2016$. Figure 5.6 shows, for three 80-meter analysis segments (A, B, and C) the distances to the coastline points recorded on the different dates of 2016. These distances define the beach width following the methodology shown in Fig. 5.4. Several points can be seen vertically aligned for each date given that not every point in an $80 \mathrm{~m}$ segment has the same distance to the inner line. This variability is caused by high alongshore fluctuations (as shown in Fig. 5.4). At the same time, significant changes appeared throughout the year, apparently following an annual oscillation. 

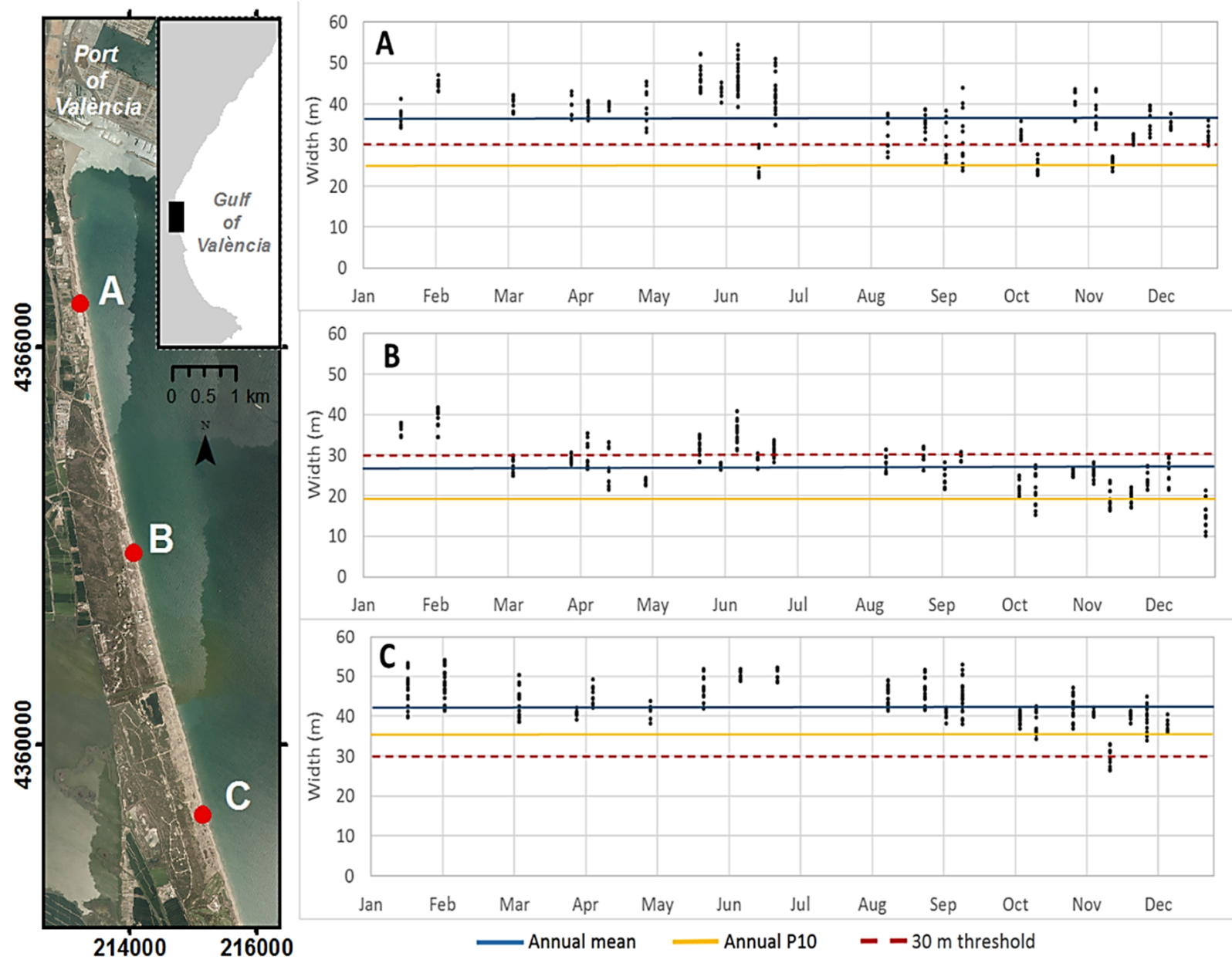

Fig. 5.6. On three analysis segments of the same coastal sector: shoreline points along 25 dates from 2016 employed for defining the annual mean width (AMW) and the annual $10^{\text {th }}$ percentile $(\mathrm{m})$, and the problematic threshold of $30 \mathrm{~m}$.

Following this example, the annual mean width (AMW) was defined for all the beach segments of the Gulf of Valencia from the width values registered during 2016 (Fig. 5.7, 5.8). There was a great diversity of widths, ranging from 3.5 up to $195 \mathrm{~m}$. The mean width during the year 2016 was $51.90 \mathrm{~m}$ and the median was $44.91 \mathrm{~m}$. Nevertheless, the vast majority of beaches had an AMW between 30 and $45 \mathrm{~m}$ (37.6\%) and between 45 and $60 \mathrm{~m}$ (25.1\%). Beaches wider or narrower were progressively less common. This is of interest considering the potentially insufficient or excessive widths for recreational use. An important percentage appeared below the $30 \mathrm{~m}$ threshold (12.8\%), while very few beaches were narrower than the critical $15 \mathrm{~m}$ (1.3\%). About wide beaches, a significant amount presented between 60 and $120 \mathrm{~m}$ (20.7\%), but the percentage of those wider than the $120 \mathrm{~m}$ threshold was very small (3.8\%). 


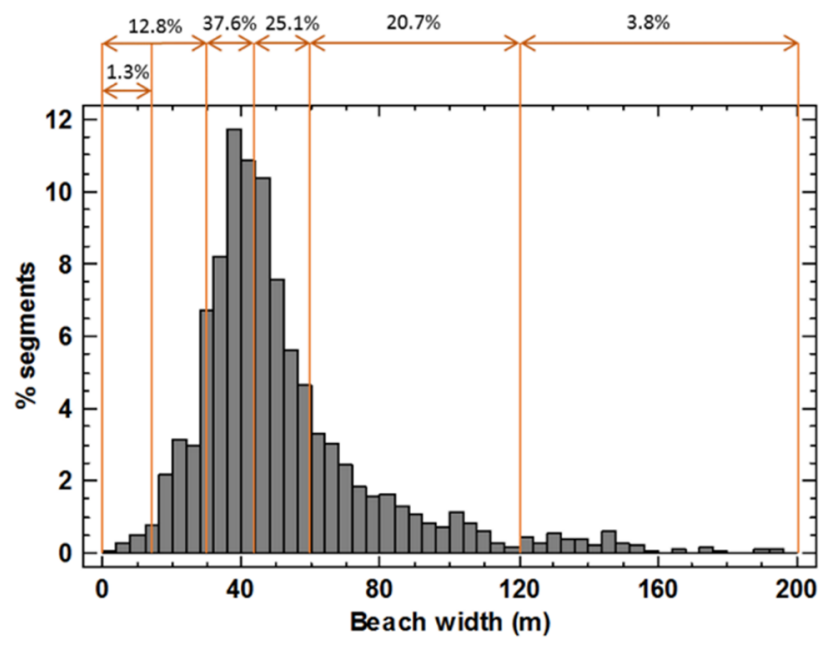

Fig. 5.7. Annual mean width of the beach segments $(\mathrm{m})$ considering the shoreline positions along 2016.

Fig. 5.6 also shows that several punctual measurements were very distant from their respective AMW. As an example, for the segments A, B, and C the minimum widths registered $(22.20,10.10$, and $26.39 \mathrm{~m}$ respectively) were well below the annual mean widths $(37.27,27.94$, and $43.20 \mathrm{~m}$ ). Considering this, $\mathrm{P}_{10}$ was calculated as a parameter to express the width based on all the data but giving more weight to the most unfavorable cases. The values of $\mathrm{P}_{10}(26.45,19.91$, and $36.67 \mathrm{~m})$ appeared remarkably below the AMW. As a result, comparing both statistical descriptors with the problematic threshold (defined as $30 \mathrm{~m}$ ), the width on the segment $C$ is adequate, while the segment $B$ registers insufficient width. Nevertheless, segment A becomes the most interesting: while the AMW $(37.55 \mathrm{~m})$ stayed over the problematic threshold, $\mathrm{P}_{10}(26.86 \mathrm{~m})$ appeared below it. 


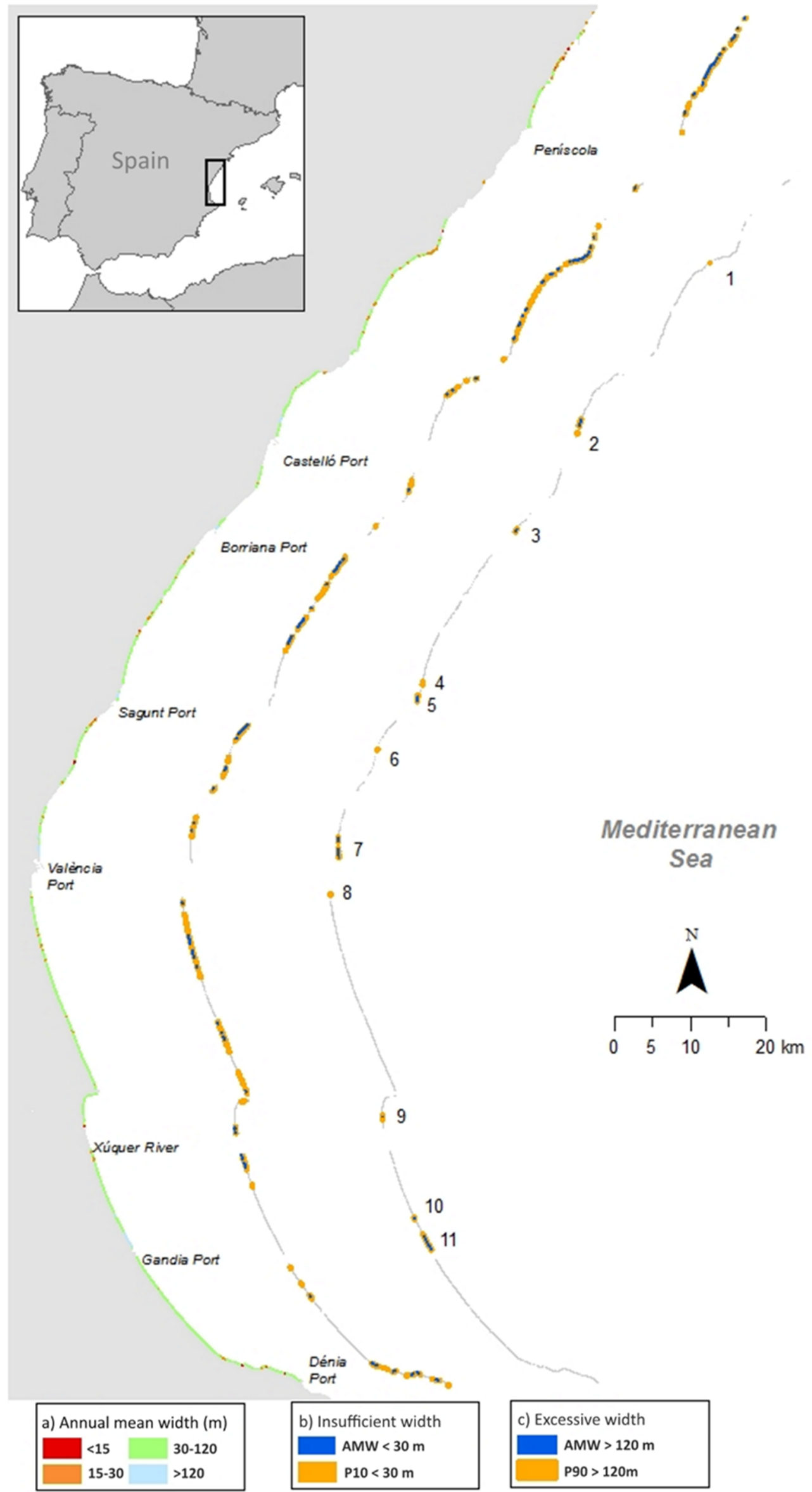

Fig. 5.8. a) Annual mean width (AMW) (m), b) Segments narrower than $30 \mathrm{~m}$, c) segments wider than $120 \mathrm{~m}$. 
The differences between the AMW and the percentiles varied a lot among analysis segments. The average difference between AMW and $\mathrm{P}_{10}$ of the beach widths was $7.9 \mathrm{~m}$. Nevertheless, in some cases, the difference was very small, close to two meters, while in other segments it was greater than $20 \mathrm{~m}$ (Fig. 5.9).

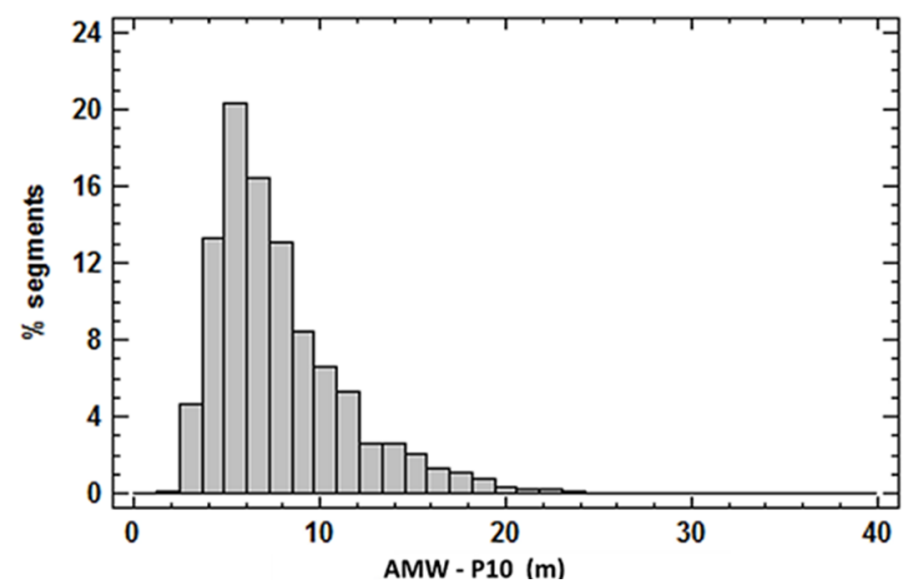

Fig. 5.9. Difference between $A M W$ and $P_{10}$ considering 2016 data and all the segments of the Gulf of Valencia.

Therefore, in several cases, the width characterization varied a lot when using as reference the AMW or annual percentiles. In order to compare the results, the annual percentiles and the AMW were defined for the Gulf of Valencia. Results showed how the use of lower percentiles increased the characterization of segments with lower widths, and vice versa (Fig. 5.10).

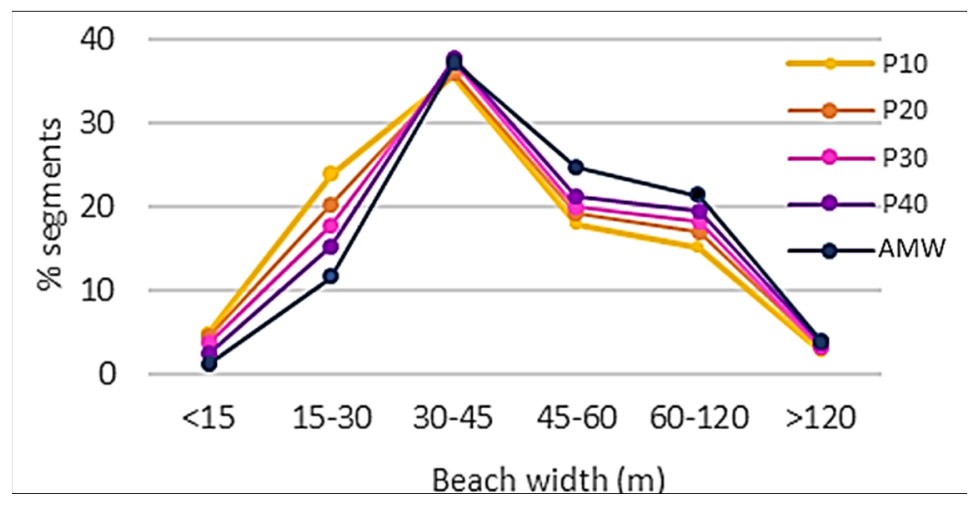

Fig. 5.10. Classification of beach segments employing different percentiles and the AMW from 2016 shoreline data.

While in the case of segments between 30 and $45 \mathrm{~m}$ the differences were small, there were major differences in those segments narrower than $30 \mathrm{~m}$. This is important, as those were the segments that could experience functional problems. Therefore, the identification of the insufficient width situations may be crucial in them. In particular, the AMW was the parameter that identified the fewest number of segments as narrower than $30 \mathrm{~m}$ (and therefore under the problematic width threshold).

The objective was to detect the problematic segments, either too narrow or too wide. While AMW identified few problematic cases, $P_{10}$ and $P_{90}$ were able to detect segments with inadequate widths even when the problematic situation was not constant along the time. The different strictness in the detection occurred similarly the four years analyzed (Fig. 5.11). At the same time, it seemed that the mean position was more stable between the different years than small percentiles that probably were more affected by extreme positions of the shoreline. 


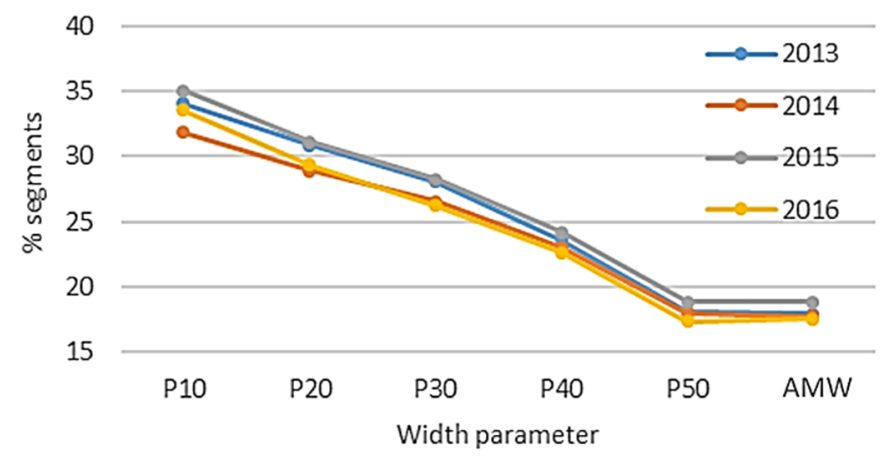

Fig. 5.11. Detection of segments narrower than $30 \mathrm{~m}$ with different width parameters.

Potentially problematic segments (narrower than $30 \mathrm{~m}$ ) were detected along the Gulf of Valencia using both $\mathrm{P}_{10}$ and annual mean width during 2016. The $\mathrm{P}_{10}$ considered as problematic more segments (29\% of the segments) than the annual mean width (13\%) (Fig. 5.12). The most remarkable effect is that the $\mathrm{P}_{10}$ identified problematic areas rather than isolated segments giving geographical robustness to the analysis (Fig. 5.8).

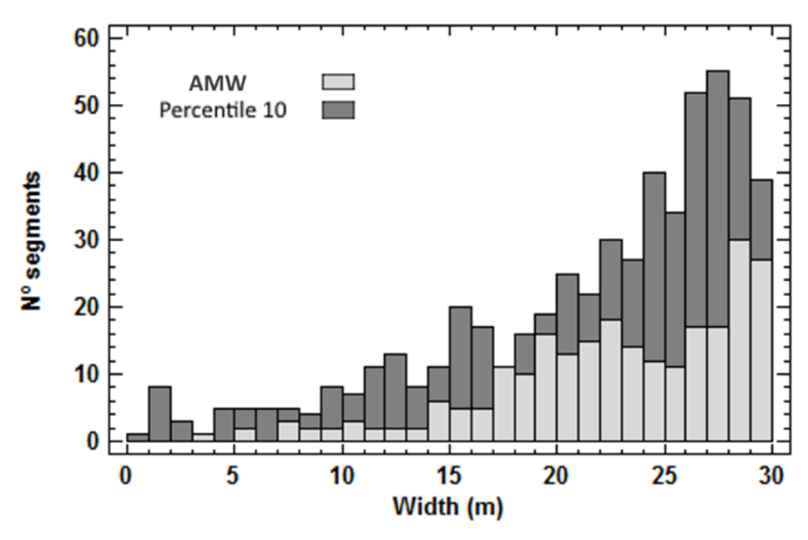

Fig. 5.12. Detection of problematic segments (narrower than $30 \mathrm{~m}$ ) by the parameters annual mean width (AMW) and the $\mathrm{P}_{10}$. The latter one allowed to detect more segments than the AMW.

A comparison between $\mathrm{P}_{10}$ and AMW was made on the erosive beach of Piles, where the width is a problematic issue for the maintenance of beach functions. There, beach nourishments have been repeatedly carried out by the Valencian Demarcation of the Directorate General of Coast (DGC): $6500 \mathrm{~m}^{3}$ of sand were supplied between December 2016 and March 2017 trying to compensate for the damage caused by the storm events of November and December 2016. Previously, $2530 \mathrm{~m}^{3}$ were dumped between October and November 2015, and more recently $2960 \mathrm{~m}^{3}$ in November 2017. Despite the evident erosive problems, the AMW of 2016 was over the problematic threshold of $30 \mathrm{~m}$. On the contrary, $\mathrm{P}_{10}$ was sufficiently restrictive and considered the most adverse positions registered throughout the year. This allowed the identification of all the beach segments that experienced functional problems (Fig. 5.13). 


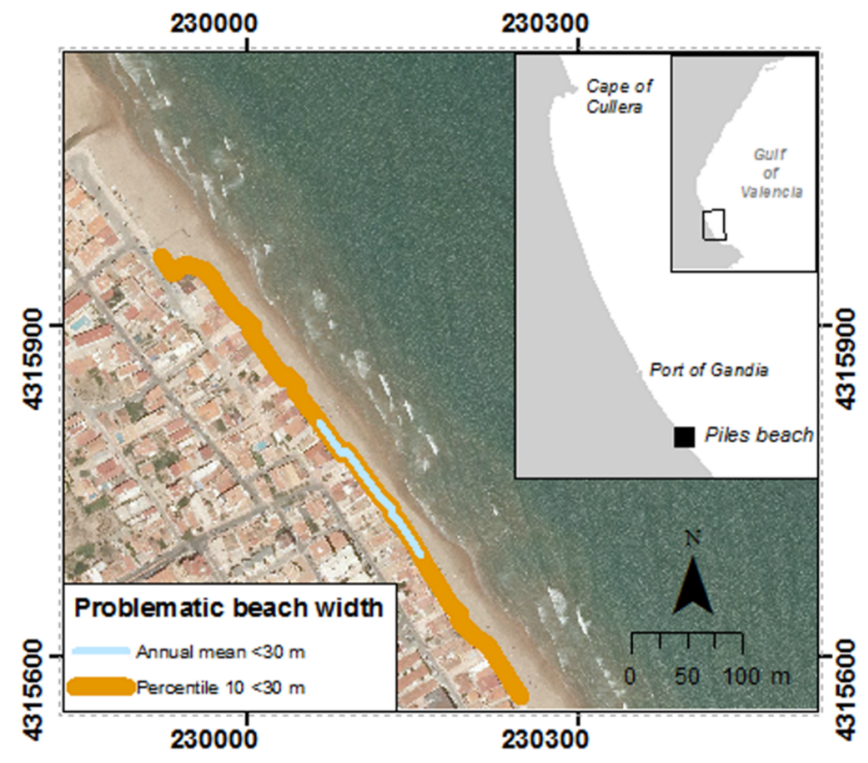

Fig. 5.13. Identification of beach segments narrower than $30 \mathrm{~m}$ according to their AMW (thin line) and the $\mathrm{P}_{10}$ (thick line) of 2016 on the erosive beach of Piles, south of Gandia Port. $P_{10}$ allows better identification of the problematic segments. PNOA orthophoto, ETRS89 UTM 31N.

Too wide beaches can also be problematic for recreational functions. Therefore, segments wider than the 120 m threshold were identified according to both the AMW and the $P_{90}$. In several cases, the AMW was below the threshold although the $\mathrm{P}_{90}$ exceeded it. According to the $\mathrm{P}_{90}$, the stricter parameter, $7.68 \mathrm{~km}$ of beaches were identified as wider than $120 \mathrm{~m}$ (almost $5 \%$ of the studied area). Eleven different sectors along the Gulf of Valencia could be identified considering consecutive segments with a very wide width (Table 5.3, Fig. 5.8). These sectors were sediment accumulations located mainly north of obstacles to the longshore sediment transport (Fig. 5.1). Some of them were jetties which aim is to support and to maintain a wide beach (sectors 1 and 6 ), while jetties associated with sectors 8 and 9 attempt to protect the accumulation in the mouth of Xúquer and Túria rivers. Nevertheless, the majority of very wide sectors were associated with ports $(2,3,4,5,7$, and 11). Especially remarkable due to their length were the sectors $2(1.1 \mathrm{~km}), 7(1.7 \mathrm{~km})$ and $11(2.2 \mathrm{~km})$, associated to Castelló, Valencia, and Gandia ports, all of them leaning on their northern jetties.

Table 5.3. Segments wider than $120 \mathrm{~m}$ according to the $P_{90}$ and 2016 shoreline data, as well as their AMW and the associated disturbance elements.

\begin{tabular}{ccccc} 
Sector & Beach & Length $(\mathrm{m})$ & Annual mean width $(\mathrm{m})$ & Associated disturbance element \\
\hline 1 & Torreblanca & 80 & 100.2 & Groins for sand accumulation \\
2 & Castelló & 1120 & 126.3 & Castelló Port \\
3 & Borriana & 400 & 139.9 & Borriana Port \\
4 & Canet & 320 & 108.8 & Canet Port \\
5 & Sagunt & 880 & 136.5 & Sagunt Port \\
6 & El Puig & 240 & 109.7 & Jetties for sand accumulation \\
7 & Malvarrosa & 1760 & 147.8 & Valencia Port \\
8 & Pinedo & 160 & 146.9 & Jetties at Túria river mouth, Valencia Port \\
9 & Sant Antoni & 320 & 113.5 & Jetties at Xúquer river mouth \\
10 & Ahuir & 160 & 116.8 & Vaca River mouth \\
11 & Gandia Nord & 2240 & 137.6 & Gandia Port \\
\hline
\end{tabular}




\subsubsection{Width influence on the recreational function}

The negative influence on the recreational function was defined considering both the recreational use of the beach and the width inadequacy (Table 5.4).

The Gulf of Valencia showed high recreational use of the beaches: only $14.28 \%$ of the segments had a low recreational use, while $42.16 \%$ and $43.56 \%$ had intermediate and high use respectively. The recreational function of the beach was mostly developed on beaches with an adequate width (30-120 m). According to the AMW, 35.75\% of these segments had an intermediate use, and 37.10 $\%$ had high use. Nevertheless, it is important to notice that several times segments with inadequate width also fostered recreational functions. Although it was very rare on segments narrower than $15 \mathrm{~m}(1.30 \%)$, it was quite common on segments between 15 and $30 \mathrm{~m}$, which plenty of times fostered intermediate (5.47 \%) and high recreational use (2.50\%). The opposite situation appeared on very wide beaches (more than $120 \mathrm{~m}$ ), the majority of which had a high use (3.65\%).

When considering the classification of segments according to the widths defined by $\mathrm{P}_{10}$ and $\mathrm{P}_{90}$ percentiles it appeared a similar pattern. Nevertheless, a higher percentage of segments appeared associated with inadequate widths. Thereby, high recreational use was identified in a higher percentage of segments narrower than $15 \mathrm{~m}$ (1.15\%) and between 15 and $30 \mathrm{~m}$ (7.5\%) than with the AMW. Similarly, intermediate recreational use was experienced by segments between 15 and $30 \mathrm{~m}$ (10.42), and below $15 \mathrm{~m}$ (2.50\%).

Table 5.4. Distribution of segments (\%) according to their recreational use and beach width, defined both by the annual mean width (AMW) and $\mathrm{P}_{10}$ and $\mathrm{P}_{90}$.

\begin{tabular}{c|cccc|cccc} 
\% of segments & \multicolumn{3}{|c|}{ Width defined by AMW $(\mathrm{m})$} & \multicolumn{4}{c}{ Width defined by $\mathrm{P}_{10}$ and $\mathrm{P}_{90}(\mathrm{~m})$} \\
\hline Recreational use & $<15$ & $15-30$ & $30-120$ & $>120$ & $<15$ & $15-30$ & $30-120$ & $>120$ \\
Low & 0.16 & 3.54 & 10.58 & 0.00 & 1.30 & 5.84 & 7.09 & 0.05 \\
Intermediate & 0.83 & 5.47 & 35.75 & 0.10 & 2.50 & 10.42 & 28.82 & 0.42 \\
High & 0.31 & 2.50 & 37.10 & 3.65 & 1.15 & 7.50 & 30.38 & 4.53 \\
\hline
\end{tabular}

The negative influence of width on the recreational function was considerably smaller when considering the AMW instead of the percentiles 10 and 90 (Fig. 5.14). Thereby, according to the mean, in $16.6 \%$ of the segments the width negatively affected the recreational function of the beach. On the contrary, when using percentiles the influence appeared in $33.7 \%$ of the cases. This occurred similarly in all the levels of influence. 


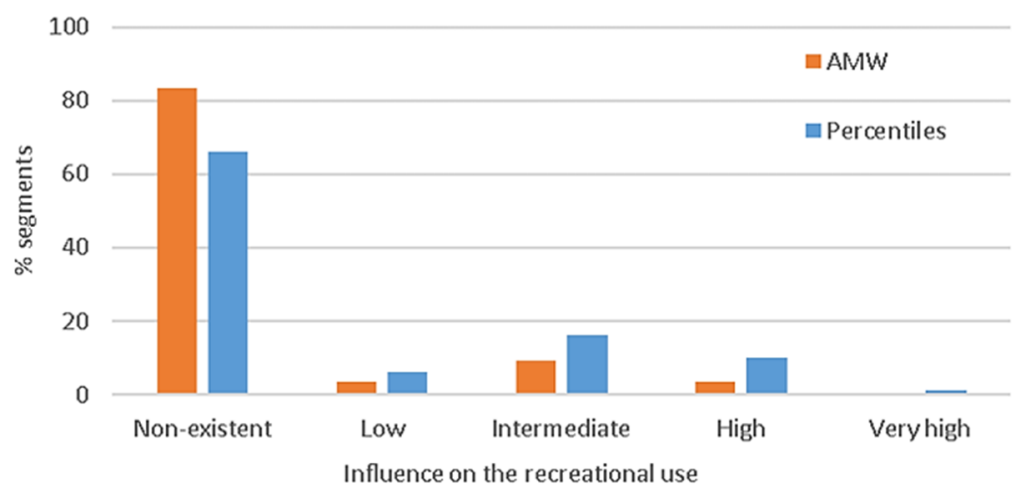

Fig. 5.14. Segments affected by an inadequate width on the recreational use. Width inadequacy has been defined according to the percentiles 10 and 90 (blue) and the annual mean width (AMW).

Percentiles proved to be more restrictive parameters for defining the width inadequacy. Therefore, the inadequacy defined from them was finally combined in GIS software with the recreational use data in order to elaborate cartography about the influence on the recreational function along the whole study area. The cartography shows the influence with a high level of detail, and it allows its visualization in GIS software in combination with other layers of information.

Figure 5.15 shows the negative influence on the recreational use on the $35 \mathrm{~km}$ of coastline located at the southern end of the study area, between the municipalities of Gandia and Dénia. This section is of great interest since it presented important contrasts in beach width and use. Although most segments had high anthropic pressure and recreational use, the north of Gandia showed an important stretch of beach with low recreational use, which contrasted with the high use of most of the beaches in the same municipality. In terms of beach widths, the vast majority of the segments were between 30 and 120 m wide. However, to the north of the port of Gandia, some stretches exceeded $120 \mathrm{~m}$, resulting in a low and medium influence on the recreational function of the beaches. On the other hand, south of this port (between the municipalities of Daimús and Oliva) there were several narrow segments with high influence. Finally, in the most southern stretch of coast (municipality of Dénia) numerous segments were narrow (15-30 m) or very narrow (below $15 \mathrm{~m})$. This, in turn, resulted in very high influence on those segments with high recreational use. While some municipalities (as Oliva, Dénia, or Gandia) have coastal fronts of several km, others only cover a few hundred meters. An extreme case of this irregularity is Dénia, which presents a municipal surface fragmented. Likewise, the municipalities that cover a greater stretch of coast presented greater differences inside the municipality. In this case, the municipality of Gandia stands out: while some segments were wider than $120 \mathrm{~m}$ and had a high recreational use, others were narrower than $15 \mathrm{~m}$ and showed low use. 


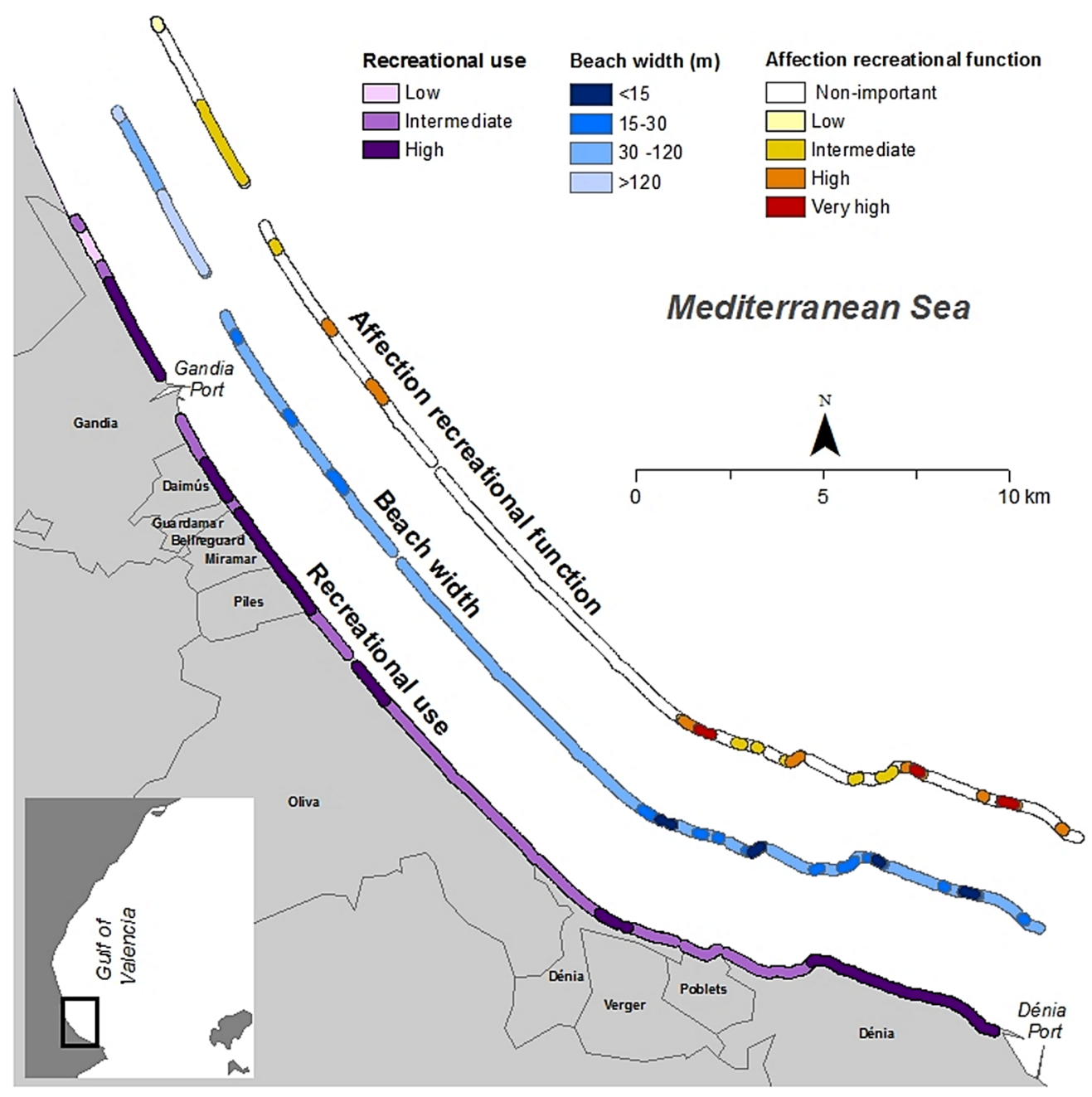

Fig. 5.15. Detail of the recreational use, beach width $(\mathrm{m})$, and influence on the recreational function defined along $36 \mathrm{~km}$ sector of the studied coast.

\subsection{Discussion}

Proper management and planning of the coast require updated, continuous, homogeneous, and organized data. Simple and objective methodologies are necessary for describing the state and changes of the coast through indicators (Giardino et al., 2014; Van Koningsveld et al., 2005). Although different techniques could have been used for defining the shoreline position, this work employs as input data Satellite-Derived Shorelines (SDS) with subpixel accuracy automatically defined from satellite imagery by the SHOREX system (Palomar-Vázquez et al., 2018). Shoreline positions were defined up to 83 dates on the beaches throughout the Gulf of Valencia along the period 2013 - 2016. The availability of shoreline positions data on a large number of dates provides information about the intra-annual variability (Cabezas-Rabadán et al., 2018) and the most unfavorable state of the beaches throughout the year (Cabezas-Rabadán \& Pardo-Pascual, 2017). These data make it possible to robustly define the mean width, an indicator of the beach state useful in evolutionary studies (Almonacid-Caballer et al., 2016). However, the annual mean width (AMW) can differ greatly from the widths recorded at the most unfavorable times throughout the year, in which the beach is too narrow and it cannot fulfill its functions. The annual percentiles represent an approximation to those situations. They are defined from a large volume of data 
accomplishing the needs of a robust approach (Cenci et al., 2017). When trying to detect segments with either a very wide or insufficient width for the recreational function of the beach, $\mathrm{P}_{10}$ appears as a more restrictive parameter than the annual mean. While the latter one may hide a significant number of dates in which recreational function is negatively affected by insufficient width, $\mathrm{P}_{10}$ detects as problematic between two and 2.5 times more segments. This pattern occurred similarly considering the shoreline data of the different studied years. The values of both width parameters were compared on a beach with proven situations of insufficient width and, while the AMW was inefficient in the definition of problematic segments, $\mathrm{P}_{10}$ gave more weight to the most unfavorable positions and identified the problematic segments properly. It would confirm that the $\mathrm{P}_{10}$ is a more sensitive parameter to the extreme events registered differently each year, also supported by the fact that $P_{10}$ varied more between the different years.

After characterizing the beach widths throughout the Gulf of Valencia, the identification of problematic width segments was carried out. Contiguous segments along large coastal sectors were identified due to their insufficient width using $P_{10}$, as opposed to the AMW, giving geographical robustness to the analysis. Widths under $30 \mathrm{~m}$ appeared at the northern end of the Gulf of Valencia associated with enclosed and pebble beaches (Fig. 5.1B). However, the central and southern half of the Gulf also showed segments with insufficient widths, confirming a change in the cumulative trend of these sandy beaches associated with the structural scarcity of sediments suggested by other works (Pardo-Pascual \& Sanjaume, 2019). Likewise, very wide were also identified and, although the proportion of affected segments was relatively small, they had remarkable widths. Beaches too narrow or too wide demonstrates the existence of large imbalances in the distribution of the sediment. It is mainly a consequence of anthropogenic actions modifying the morphology of this coast (Obiol-Menero, 2003; Pardo-Pascual \& Sanjaume, 2019). In most of the cases, it is partially caused by the presence of obstacles to longitudinal transport as ports and groins (Fig. 5.1B) on a coast with important alongshore transport (Fig 5.1A). Up to 13.5 million $\mathrm{m}^{3}$ of sand were dumped along $100 \mathrm{~km}$ of the Valencian coast between 1982 and 2002 (Obiol-Menero, 2003), mainly as a local response to the erosive retreatments of touristic beaches. In parallel, punctual hard solutions have been constructed due to the same reasons. Nevertheless, the large imbalances of sediment along the Gulf of Valencia show the inefficiency of the local solutions in solving a regional problem, as they do not show benefits in the middle and long term. In fact, hard solutions displace the erosive problems or even increase their magnitude affecting larger areas.

As a result, several conflictive sectors were detected due to either insufficient or excessive width: in $10 \%$ of the segments $(15.3 \mathrm{~km})$ the influence on recreational function was high, and in $1 \%$ of them $(1.8 \mathrm{~km})$ it was very high. The results also show how beach width, recreational use, and, therefore, the influence on the recreational function had a high variability along the coast, even inside a municipality. It appeared a discrepancy between these parameters and the municipal boundaries. This discrepancy was accentuated by the heterogeneity in size and shape of the municipalities as the length of the stretch of coastline corresponding to each of them is very variable. The width thresholds in which the beach starts to be perceived as too narrow or too wide 
are not precisely defined yet, and they could be different on each beach. Nevertheless, it seems clear that beachgoers may perceive inadequate widths as a negative aspect of the beach, conditioning the type of user by increasing the density, reducing the number of visitors or even impeding the use the beach (Cabezas-Rabadán et al., 2019a; Valdemoro \& Jiménez, 2006). Furthermore, the value of properties on the seafront, as well as hotel prices, appear linked to the beach width (Gopalakrishnan et al., 2011; Pompe \& Rinehart, 1994; Rigall-I-Torrent et al., 2011). In the Gulf of Valencia, the exploitation of the beaches and the littoral through sun and beach tourism has an extreme socio-economic value (Obiol et al., 2011). Therefore, the maintenance of beach widths able to sustain the recreational function must draw the attention of coastal managers. The subaerial surface is a dynamic aspect that should condition beach exploitation (Valdemoro \& Jiménez, 2006). In fact, the Valencian region has begun to regulate the use and activities on the beaches based on, among other criteria, the width of the beach (GVA, 2018). Thus, shoreline position and width data integration in GIS result of great interest for coastal managers as they allow the detection of conflict zones and prioritize actions.

Shoreline position and beach width data, as well as the statistical descriptors of their annual variability, may help to fill the shortage and fragmentation of long-term data able to describe coastal dynamics or the human impacts on the system (Defeo et al., 2009). The data provided can be of great interest as an input of the beach integrated assessment tools, which aim is monitoring, detecting conflicts, and acting as a management framework for beaches from a holistic approach (Lucrezi et al., 2016). Shoreline positions, as well as the width of the beach, could be used as valuable descriptors of the state of the beaches, to quantify their changes and their erosive potential.

This study has defined the width and the uses of the beach for alongshore segments of $80 \mathrm{~m}$ long. Studies with a similar purpose have worked on larger coastal sections such as at the municipal level (Ballesteros et al., 2018). However, that scale makes it impossible to distinguish the status of different beaches within the same municipality or even parts of the same beach, and it blurs the reality because municipalities have very different surfaces. While allowing a detailed view of the problematic segments, the analysis carried out offers a large-scale vision extending beyond administrative boundaries and covering the entire region and the sediment cell, probably the most reasonable scale for defining the state of the sediment (Marchand et al., 2011). It allows the analysis of the causes and solutions to these problems from a broader perspective. Most of the erosive problems in the studied beaches affect the whole Gulf of Valencia, as they are strongly related to a regional sediment depletion (Pardo-Pascual \& Sanjaume, 2019; Sanjaume \& Pardo-Pascual, 2005). Thus, the study of the phenomenon and its possible solutions should be based on a largescale approach, in line with managers' preference for a holistic view of the entire system (Giardino et al., 2014).

Employing this large-scale vision, several very wide sectors were identified. Given the artificial origin of these accumulations and their conflict with the recreational function, they could be cataloged as sources of sand. Identifying sediment reservoirs with appropriate features becomes essential for the management (Marchand et al., 2011) of a coast as the Valencian one, that has a 
strong recreational use as well as experiences erosive processes (Cabezas-Rabadán et al., 2019a). This is in line with the "Strategic sediment reservoirs", a key concept for erosion management according to the Eurosion project. These reservoirs could be a significant source of sediment with proper characteristics for nourishments and therefore a partial solution to the sand scarcity of environmental and economic impact lower than seabed extraction or hard measures (Gault et al., 2011). This would constitute an attempt to re-establish the balance of the system, and it matches the sand bypass already proposed for local specific erosion problems in the Valencian Region (Yepes \& Medina, 2005).

Apart from supplying updated data, the shoreline can be defined by historical images allowing retrospective analyses. Thus, it is possible to quantify the current state, but also to analyze its evolutionary and cyclical patterns, or to predict the state in the near future. This is especially remarkable in Mediterranean coasts, where management shows a lack of anticipation to the problems (Valdemoro \& Jiménez, 2006) with measures usually taken in a reactive way from a local perspective are commonly taken (EC, 2004). Sea level rise will require estimates of the changes, different in each region, in order to assess the impacts and the adaptation alternatives (Nicholls \& Cazenave, 2010). The availability of coastal morphological data in large temporal and spatial scales integrated with data of the human use of the coast can be a great help in planning responses to these future scenarios.

Nevertheless, it is important to notice that the analysis has been limited by certain elements. First, there is limited availability and distribution of images throughout the year, which is not homogeneous. Likewise, during storms satellite images are not available due to the presence of cloud masses (Pardo-Pascual et al., 2014), which means that the smallest widths recorded annually are always greater than those that actually occur. Therefore, the measured widths and the identification of problematic segments are more conservative. The results are also affected by the precision of the algorithm employed when defining the shoreline position.

Previous works defined an RMSE of $6.6 \mathrm{~m}$ for Landsat 8 shorelines on sandy beaches and microtidal coasts (Pardo-Pascual et al., 2018). In order to evaluate to which extent the uncertainty in the shoreline definition conditions the results of the study, it is necessary to analyze the variability of the lines analyzed over the studied years. Analyzing all the segments throughout 2016 it is observed that only $0.8 \%$ of them present variability in a range smaller than the $6.6 \mathrm{~m}$ of the uncertainty of the method. Therefore, even assuming that the level of precision in the determination of each of the lines can be improved, it is evident that the results are robust. There are important differences in the width defined for each segment within each date. This is due to the fact that the shoreline and the inner line of the beach are not completely parallel and do not have rectilinear morphologies. About the shoreline, it experiences oscillations associated with high-detailed morphological formations (as beach cusps) as well as the wave's swash. About the inner line of the beach, considered constant along the studied period, it has curvatures due to the location of the buildings, promenades, and dunes. The studied coast is very artificialized and microtidal, with a very stable inner line, and therefore it can be considered constant. Nevertheless, it is possible that other coasts registered marked changes in the morphology over time. The 
appropriateness of the length of the analized segments $(80 \mathrm{~m})$ and the possibility of using a shorter length to homogenize the width in each of them can, therefore, be discussed. Finally, it is necessary to point out that, although beach width is a very useful parameter for characterizing the state of Mediterranean and microtidal beaches, it may be useful in other environments with a higher tidal range.

Considering SDS as input, the results of the analysis carried out can be improved in the future as long as this data source improves its precision. The availability of new data sources, as satellite Sentinel-2 images, will allow achieving higher levels of accuracy, as well as an increase in the frequency of data capture. Sentinel-2A and Sentinel-2B in combination with Landsat-8 will provide a global median average revisit interval of 2.9 days ( $L i \&$ Roy, 2017). This opens up new possibilities in the use of SHOREX for the analysis and monitoring of changes caused by storms and human actions.

\subsection{Conclusions}

This paper offers a new perspective for using SDS in the management of microtidal environments, especially on beaches with a high tourist use as happens in most of the Mediterranean. The supply of key data for studying the beach state and their impact on the human exploitation of these spaces may help managers in prioritizing actions, as well as in planning strategies against sea level rise and erosive patterns from large spatial and temporal scales.

The systematic recording of beach widths throughout the year on 80-meter segments allows obtaining and analyzing representative statistics of the morphology of the beaches in a simple way. Beach width and its annual variability appear as useful descriptors of the beach state. They may help in understanding the impact of beach morphology in the human exploitation of these spaces. Annual percentiles are intuitive and objective descriptors for characterizing the intraannual variability. $P_{10}$ offers an approach to the most unfavorable situations registered throughout the year. It has greater sensitivity to detect unfavorable widths than the annual mean width. $\mathrm{P}_{10}$ allows identifying as problematic coherent geographic zones instead of small disconnected segments. It proves its consistency and robustness for mapping beaches with problems in maintaining their key functions.

Too narrow and wide beach segments have been detected along the Gulf of València. The results are consistent with previous works and show the existence of sediment imbalances consequence of the anthropogenic interventions that have modified the coastal morphology. The detection of these segments allows studying the morphological state of beaches on their use and recreational function. The combination of width data with information about the recreational use allowed identifying segments in which width is inadequate and negatively affects the recreational function. The integration in GIS software offers a regional view of the entire sedimentary cell and, simultaneously, a detailed view of the most conflictive segments within each municipality. It can be appreciated that these problems are not associated with municipal boundaries and that, therefore, neither should managers' responses be. 



\section{Chapter 6}

\section{Shoreline variability from Sentinel-2: an approach for estimating beach sediment size?}

The content of this chapter is currently under review in the journal 'Marine Geology'

"Desde aquí, desde mi casa, veo la playa vacía ya lo estaba hace unos días, ahora está llena de lluvia y tú ahí sigues sin paraguas, sin tu ropa, paseando como una tarde de julio, pero con frío y tronando

\footnotetext{
¿Se puede saber qué esperas? ¿que te mire y que te seque? ¿que te vea y que me quede tomando la luna juntos? La luna, tú y yo expectantes a que pase algún cometa o baje un platillo volante Y la playa llora y llora..."
}

-I. Ferreiro-

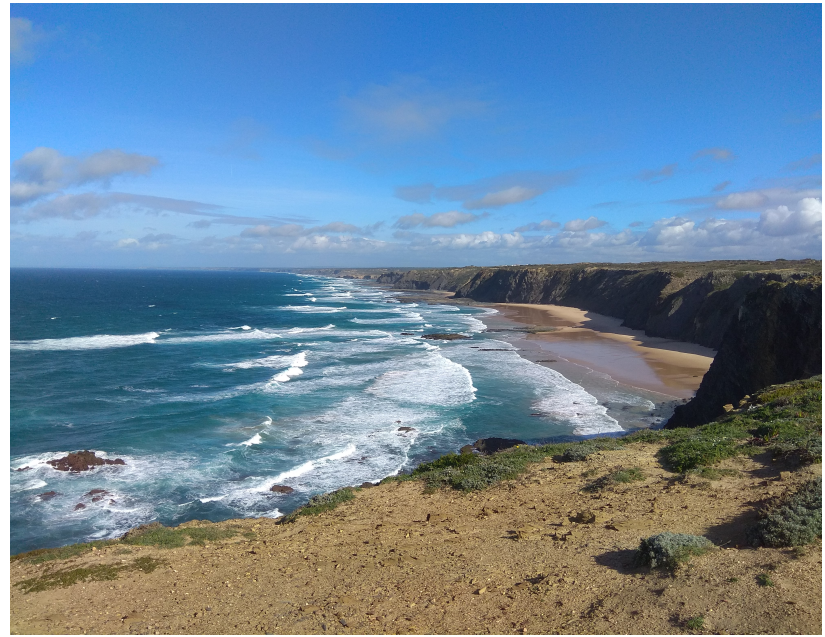


As it has been shown in the previous chapters, the high repeatability in the acquisition of satellite images allows to define the shoreline position in many occasions along the year by means of the Satellite-Derived Shorelines. Large shoreline datasets can potentially be useful in describing beach morphodynamics (Short \& Hesp, 1982). This is due to the fact that shoreline changes are to a great extent conditioned by the geomorphological characteristics of the beach. Specifically, beach-face slope and sediment grain size are two interrelated aspects that play a key role in shoreline variability (Dean, 1973). Although they constitute a relationship crucial for the behavior of the beaches, it is not well studied across the entire sedimentary spectrum.

Sediment grain size is an essential indicator for characterizing the beach state due to its capacity to condition the dynamism as well as the functions of the beach. As it has been concluded in chapter 2, it plays a major role in defining the perception of the beach that beachgoers have. To provide updated information on this parameter is very costly using traditional techniques, so coastal managers usually face a lack of data.

Defining shoreline variability from packages of SDS raises the possibility of studying the relationship with key geomorphological characteristics as beach-face slope and sediment grain size. This would increase the understanding of their relationship, opening up the possibility of estimating them.

In this work, shoreline variability is defined from a set of SDS extracted for a period of three and a half years from Sentinel 2 imagery using SHOREX. The variability is then related to a large dataset of grain-size samples at microtidal Valencian beaches (Western Mediterranean). Both parameters present an inverse and non-linear relationship controlled by the beach-face slope. High shoreline variability appears associated with fine sands, followed by a rapid decrease (shifting point about medium/coarse sand) and subsequent small depletions as grain sizes increases. The relationship between both parameters has been described by a numerical function that offers moderatelyhigh correlation (R2 about 0.70) when considering samples at 137 open beaches. The definition of the variability is addressed employing different proxies, coastal segment lengths, and quantity of SDS under diverse oceanographic conditions, allowing to examine the effect they have on the relation with the sediment size. The work offers a better understanding of the mutual connection between sediment size, beach-face slope and shoreline variability. The established relationship allows a rough estimation of sediment grain size from remote sensing data which can be very helpful for certain coastal management purposes. 


\subsection{Introduction}

Beaches are highly dynamic and changing natural environments that provide protection to the coast, habitat for unique species, and constitute a basic recreational resource for coastal societies. Given the importance of these functions it is a primary goal to define the state of the beaches and understand their behavior so as to improve their management. Sediment size and slope are key geomorphological elements for characterizing the beaches as they appear interrelated with each other and with the oceanographic conditions (Bascom, 1951; Carter, 1988; Wright \& Short, 1984). These geomorphological aspects condition beach functions by defining the abundance of biota (Lastra et al., 2006), beachgoers perception (Cabezas-Rabadán et al., 2019a) and safety (Benedet, Finkl \& Klein, 2006), and beach response to stress factors as storms (Pardo-Pascual et al., 2014; Reyes et al., 1999; Qi et al., 2010).

Due to the important role grain size plays its characterization is fundamental for decision-making and planning, as well as for forecasting purposes through modeling. However, the insufficient detailed data usually leads to oversimplifications of the grain-size distribution hampering advances in coastal modeling (Buscombe et al., 2014). The quantification of sediment grain size by traditional techniques is a time-consuming task that hinders the collection of repetitive data over long coastal segments. They require in-situ sampling together with the subsequent characterization in the laboratory by sieving or the use of laser particle-sizer. Different methods have been proposed to reduce the costs of data obtention. At the microscale level, photogrammetric techniques allow quantifying the grain size (e.g. Baptista et al., 2012; Barnard et al., 2007; Buscombe et al., 2014; Buscombe \& Masselink, 2009; Rubin, 2004; Warrick et al., 2009) applying processing algorithms over images. Trying to reach a larger coverage, terrestrial laser scanner (TLS) has been repeatedly employed for modeling river bed roughness and estimating surface sedimentology (e.g. Brasington et al., 2012; Heritage \& Milan, 2009). Different approaches have appeared sustained in the use of unmanned aerial vehicles (UAV) (e.g. Bae et al., 2019; Dugdale, et al., 2010; Kim et al., 2019; Tamminga et al., 2015; Vázquez-Tarrío et al., 2017) although comparisons between studies and validations are scarce, and only the highest image resolutions seem to offer acceptable results for quantifying finer grains (Bae et al., 2019). Due to the important field and processing efforts those techniques require, any of them constitutes a valid option for estimating grain size along large territories. In order to increase the spatial coverage, airborne solutions (e.g. Manzo et al., 2015; Rainey et al., 2003) and satellite images have been proposed to obtain macroscale information. The characterization of soil properties and the mapping of the distribution of intertidal surface sediments have been addressed from mid-resolution imagery (e.g. Yates et al., 1993), synthetic-aperture radar (e.g. Melsheimer et al., 1999; Ullmann \& Stauch, 2020; Van der Wal et al., 2005), and their combination (e.g. Park, 2019; Van der Wal \& Herman, 2007). However, those techniques are constrained by the coarse resolution of the images. Taking all this into account, and despite the rapid development of remote sensing methodologies, no single technique is capable of carrying out an efficient quantification of the grain size at the mesoscale level. While some of them maintain the need for intensive fieldwork tasks, others only lead to a rough classification of the sediment. 
Many studies have analyzed the relationship between sediment grain size, slope, and beach morphology (e.g. Dean, 1973; Mclean \& Kirk, 1969; Masselink \& Short 1993; Scott et al., 2011; Vellinga, 1984). Grain size is a major factor defining the slope (Bascom, 1951; McLean \& Kirk, 1969) as coarser grains are associated with higher infiltration and lower backwash transport of sediment, leading to higher slopes (Davidson-Arnott, 2010; Reis \& Gama, 2010). Different numerical models have been formulated to describe slope as a function of the grain size (e.g. Flemming 2011; Kim et al., 2014; Reis \& Gama, 2010; Soares, 2003; Sunamura, 1984), most of the times employing linear equations adjusted by measurements on sandy beaches. In a recent work, Bujan et al. (2019) compiled from literature a large number of grain size and slope measurements. Even though the high scattering of the data the meta-analysis evidenced that the relation between both parameters does not follow a simple trend. The data distribution was fitted with a function that starts with gentle slopes associated with fine sand grains, experiences a steep increase as sediment size grows, and around medium/coarse sand it shifts and becomes gentle for coarser grains.

The shoreline position is a representative feature of the morphology of the beach and useful for describing its behavior (Boak \&Turner, 2005). Thus, the mobility of a beach, defined by Dolan et al. (1978) as the standard deviation of the mean shoreline position, was related to the morphodynamic state of the beach (Short \& Hesp, 1982). Numerous works have quantified shoreline changes to characterize beach dynamics, understand their nature, and forecast its changes. Many of the recent works in coastal changes have defined the shoreline by fieldwork (e.g. Hansen \& Barnard, 2010; Mole et al., 2012) or videomonitoring (e.g. Miller \& Dean, 2007; Stieve et al., 2002; Turki et al., 2013), limiting the spatial and/or temporal extension of the work. Recent remote sensing methodologies allow defining the position of the shoreline from freely available mid-resolution satellite imagery using subpixel extraction algorithms (e.g. Bishop-Taylor et al., 2019; Pardo-Pascual et al., 2018; Vos et al., 2019a,b). SHOREX system (Palomar-Vázquez et al, 2018, Sánchez-García et al., 2020) allows to efficiently extract Satellite Derived Shorelines (SDS) at regional scale from Sentinel-2 imagery offering accuracy levels of similar magnitude than videomonitoring at different types of coast (Cabezas-Rabadán et al., 2020; Sánchez-García et al., 2020). SDS obtained with this methodology have been proved to be useful to characterize the width of the beaches and its sub-annual changes (Cabezas-Rabadán et al., 2019b), even of limited magnitude (Cabezas-Rabadán et al., 2019c,d). For the moment, SDS have barely been used to obtain information about other geomorphological aspects of the beach. Only very recently, Vos et al. (2020) have exploited the relation between shoreline changes and beach-face slope by estimating the latter one from SDS by frequency domain analysis. Considering the forehead stated relationship between grain size and beach-face slope, it is expected that beaches with coarser material and steeper slopes will show lower shoreline variabilities. This is due to the fact that sealevel changes (either cyclical or punctual) will be translated into different horizontal displacements of the shoreline depending on the beach-face slope.

The capacity to efficiently define shoreline variability from SDS may be helpful for exploring the interrelations between sediment size, beach slope, and shoreline changes. Establishing this relationship may lead to a rough characterization of sediment size along large beach segments 
from a freely-available source of data. Taking this into account, the main goal of this work is to characterize the relationship between sediment size and shoreline variability determined from multiple Sentinel-2 derived shorelines. The study aims (i) to propose a numerical description of the relation, (ii) to examine how oceanographic conditions, amount of SDS, and employed proxies condition the quantification of the variability, and (iii) to assess the potential for estimating sediment grain size from shoreline variability.

\subsection{Regional setting}

The study took place along the beaches of the Gulf of Valencia (Eastern Spain, Iberian Peninsula), a coastal segment approximately $200 \mathrm{~km}$ long between the Ebro Delta and the Girona river mouth (Fig. 6.1). It is a sedimentary coast mainly composed of medium and fine sandy beaches together with some gravel and pebbly ones (Pardo-Pascual \& Sanjaume, 2019; Sanjaume, 1985). Beaches face SE in the northern half of the Gulf, and NE in its southern half. The coast has an average astronomical tidal range below $20 \mathrm{~cm}$ with small waves ( $\mathrm{Hs}=0.7 \mathrm{~m} ; \mathrm{Tp}=4.2 \mathrm{~s}$; Fig. 6.2). It is a lowenergy environment, although during storms waves may reach significant heights of $6.55 \mathrm{~m}$ and $15 \mathrm{~s}$ of peak period, mainly from NE-E, and sea level may increase by $1.32 \mathrm{~cm}$ (Pardo-Pascual \& Sanjaume, 2019). The distribution of the sediment along the region was previously conditioned by a strong southerly littoral drift. Nevertheless, this natural regime is altered by many hard structures as ports and groins. They form a chain of artificial sediment traps that prevent the free distribution of the sediment (Pardo-Pascual \& Sanjaume, 2019). Along with these constructions, numerous nourishment projects have been carried out during the last decades (Hanson et al., 2002; ObiolMenero, 2003) in an attempt to maintain their width and carrying capacity. The southern end of the Gulf of Valencia has not been considered in the work because, on the one hand, there is no consistent information available on the repeated anthropogenic actions carried out in that sector and, on the other hand, the existence of submerged rocky formations condition shoreline mobility in a very different way from the rest of the beaches.

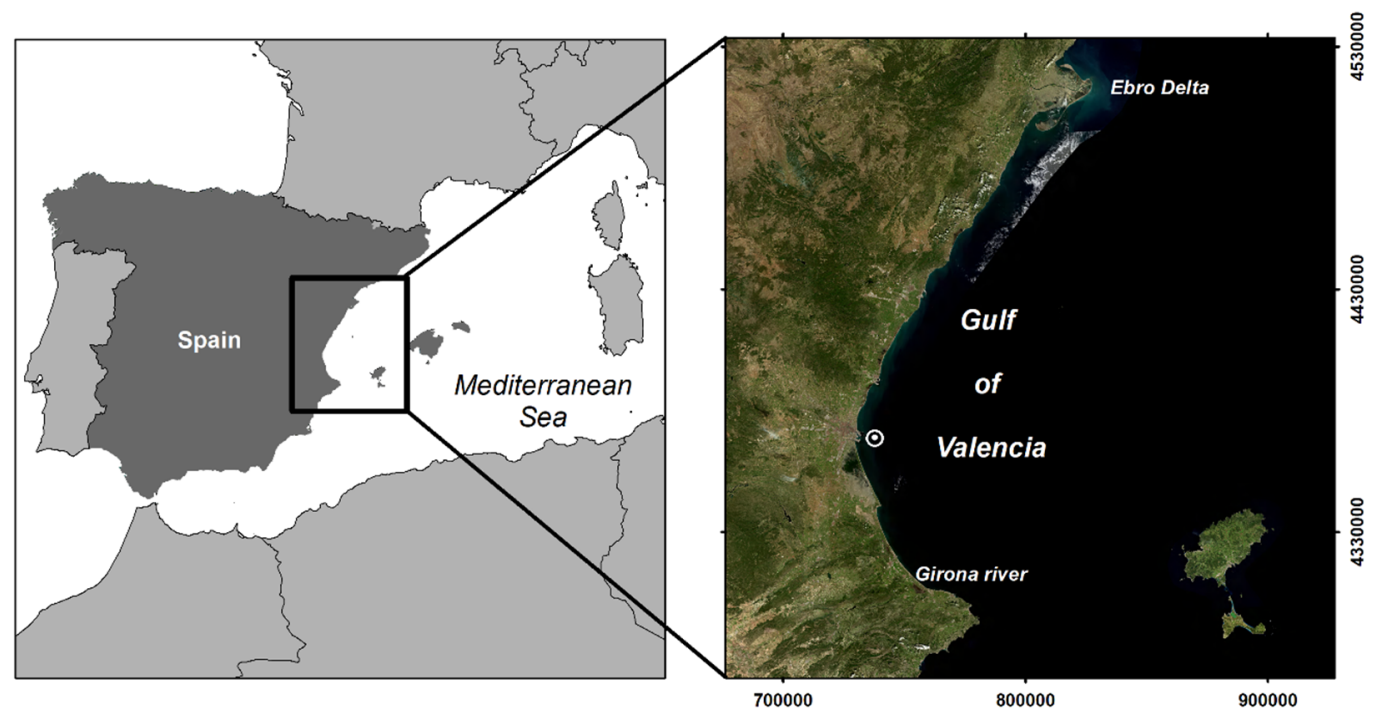

Fig. 6.1. Regional setting covering the beaches along the Gulf of Valencia (W Mediterranean), between the Ebro Delta and the mouth of the Girona river. The white point indicates the location for which the historical wave data has been acquired. 


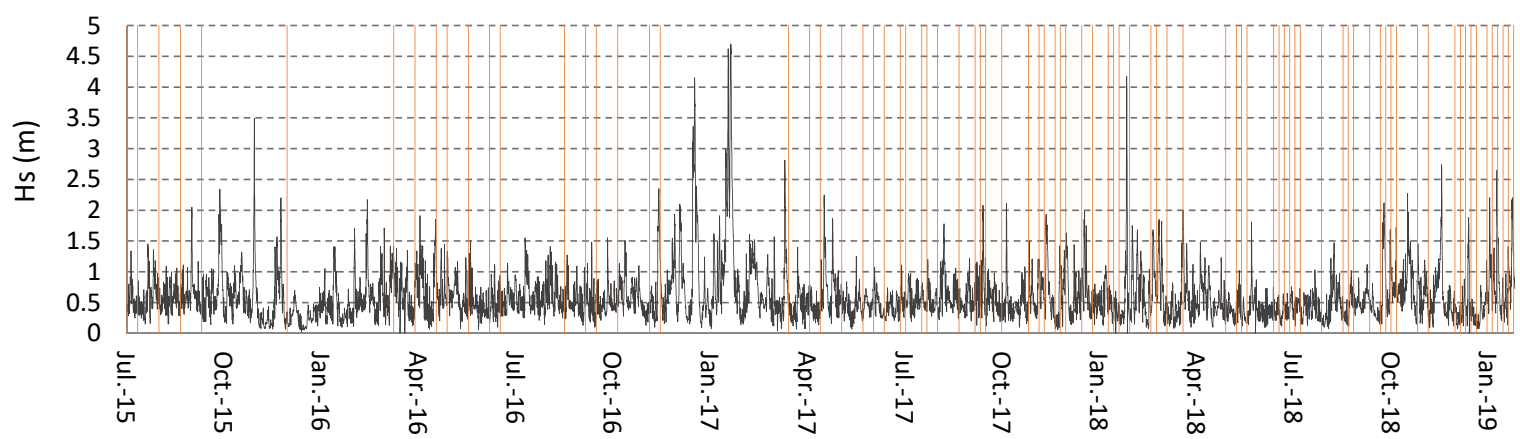

Fig. 6.2. In black color, significant wave height $(\mathrm{m})$ for the coastal segment around the Valencia Port (Spanish Port Authority, SIMAR point 2081114) along the study period (2015-2019). In orange, Sentinel-2 considered for SDS extraction. The presence of clouds over the shore is the cause of data gaps, forcing to use a slightly smaller quantity of images at certain segments. The images were downloaded free of charge from the Copernicus Open Access Hub (https://scihub.copernicus.eu/).

\subsection{Methods}

The work is mainly supported by two data sets available at the same study sites: on the one hand, satellite-derived shorelines used to quantify the shoreline variability and, on the other hand, sediment grain size data.

\subsubsection{Satellite Derived Shorelines}

Shoreline position was defined along the Gulf of Valencia from Sentinel-2 Level-1C MSI imagery from July 2015 (starting with the first image acquired by the satellite) to January 2019 (Fig. 6.2). After discarding those images affected by major cloud coverage 95 images/dates were considered for the study. From these images, SDS were defined as the water/land intersection at the instant each image was acquired. They were extracted employing SHOREX (Palomar-Vázquez et al., 2018; Sánchez-García et al., 2020) and a workflow similar to the one followed by Cabezas-Rabadán et al. (2019c). SHOREX applies the sub-pixel algorithmic solution proposed by Pardo-Pascual et al. (2012) to define shoreline points located alongshore every $5 \mathrm{~m}$. Those SDS offer an estimated accuracy of $3.01 \mathrm{~m}$ RMSE according to previous assessments at similar micro-tidal beaches (Sánchez-García et al., 2020). The extraction algorithm operates over the Short-Wave Infrared bands (SWIR1) using a third-degree polynomial and 3x3 analysis kernel (60 m when considering Sentinel-2 images). This causes that the extraction works optimally on relatively straight coasts, with an increasing error in segments adjacent to elements causing abrupt changes in the orientation of the shore. For this reason, extremely short beach segments (tens of meters long) delimited by rigid structures (e.g. breakwaters and jetties) have been discarded.

\subsubsection{Sediment grain size}

The information regarding sediment size was mainly obtained from a public database of the Spanish Ministry of Environment (ECOLEVANTE, 2010). Sampling locations were distributed along the beach segments of the Gulf of Valencia about every $500 \mathrm{~m}$. Samples were acquired at different depths defining cross-shore transects with a Van Veen grab sampler during 2006 - 2007 (center and southern sectors of the study area respectively) and 2010 (northern sector). The grain size was characterized by sieving $100 \mathrm{gr}$ of sediment using a nested column of 13 mesh strainers from 64 
$\mathrm{mm}$ to $0.063 \mathrm{~mm}$. It allowed defining the median grain diameter $\left(D_{50}\right)$ according to Folk \& Ward parameters (1957) allowing their classification in grades (Wentworth, 1922). The study focuses on the samples at $0 \mathrm{~m} \mathrm{MSL}$ as the sediment at that point is considered to be closely related to shoreline behavior.

It is important to underline that sediment samples and SDS are not synchronous in time. In order to address this issue, a second and smaller dataset has been defined from five sampling campaigns. A total of 28 more recent (between years 2015 and 2020) and spatially-coincident samples have been compared with those composing the initial sediment dataset (Fig. 6.3). The pairs of data show a linear fit (slope about 1) with both populations follow an identical pattern. While 24 of the new samples (86\%) maintained the original grades, 4 changed their classification shifting to an adjacent grade, leading to an average difference of $D_{50}$ of $15 \%$. Thus, changes in grain size that occurred between the sediment dataset and SDS definition can be considered to be of moderate magnitude, validating the use of the first granulometric dataset.

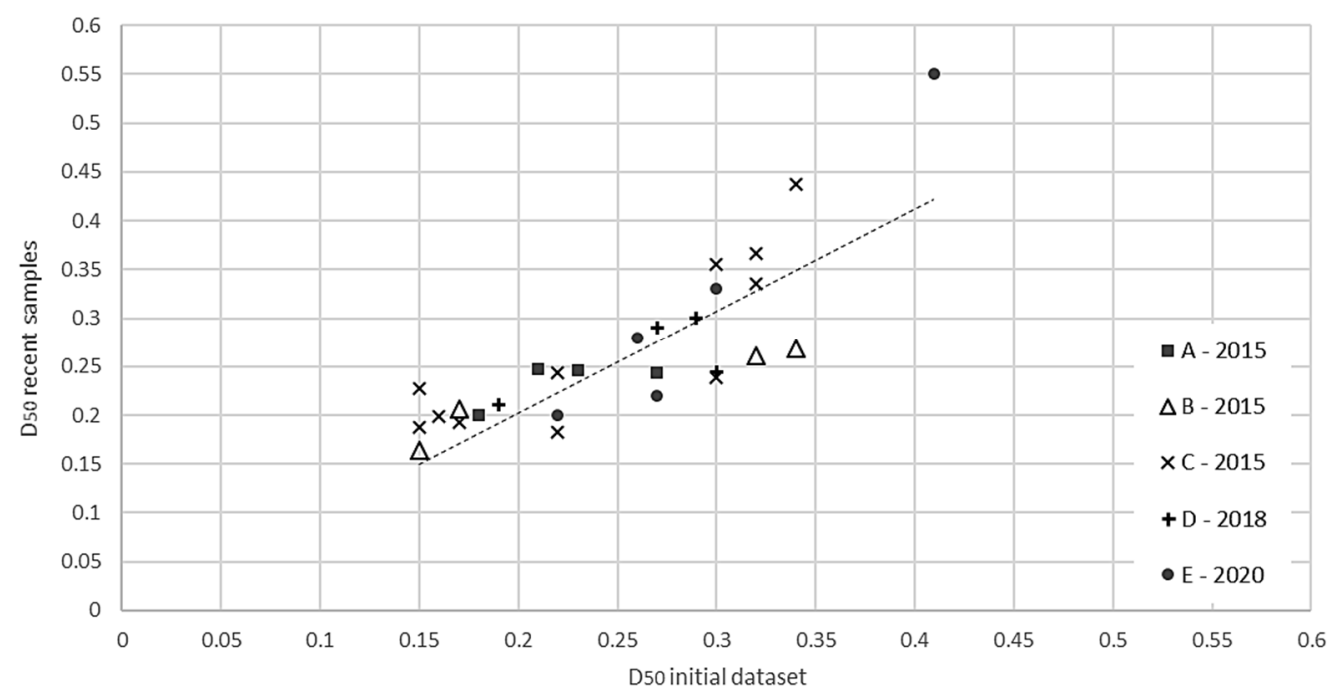

Fig. 6.3. Comparison of the median grain size of the samples composing the original and the most recent datasets, following the linear fit $y=0.986 x+0.018$. Five packages of samples compose the most recent dataset: $A$ was acquired in 2015 by Cabezas-Rabadán (2015); B in 2015 by Soriano-González (2015); C in 2015 by Pardo-Pascual et al. (2016); while $D$ and $E$ in 2018 and 2020 for the elaboration of different technical reports by the DGSCM (Directorate-General for the Sustainability of the Coast and Sea) for supporting nourishment and emergency actions carried out in coordination with the Spanish Ministry of Environment.

\subsubsection{Study sites}

A total of 193 study sites were defined matching the pre-existent sediment sampling locations. They appear distributed alongshore about every $500 \mathrm{~m}$, although individual sites were expressly defined for shorter beach segments. Study sites were located on beaches where the variability of the shoreline is directly related to the slope of the beach face. Thus, coastal formations other than beaches were discarded from the work. Similarly, segments in which shoreline mobility is conditioned by processes originated landwards (stream mouths) or by human interventions (nourishments carried out by the Ministry of the Environment's Directorate General of Coasts) were discarded. 
Landforms and offshore obstacles define the coastal shape and may condition shoreline mobility. In order to analyze their influence on the behavior of the shore, the study sites considered in the analysis were classified as follows (Fig. 6.4):

-Open beaches (137 sites): those in which sediment moves freely, without significant elements that could influence wave conditions. They are exposed to waves from NE, E, and SE.

-Enclosed beaches (56 sites): those in which incident waves clearly differ from those recorded along the study area. This group includes beaches enclosed due to nearby coastal engineering structures as jetties, groins, and exempt dikes, as well as small natural pocket beaches.
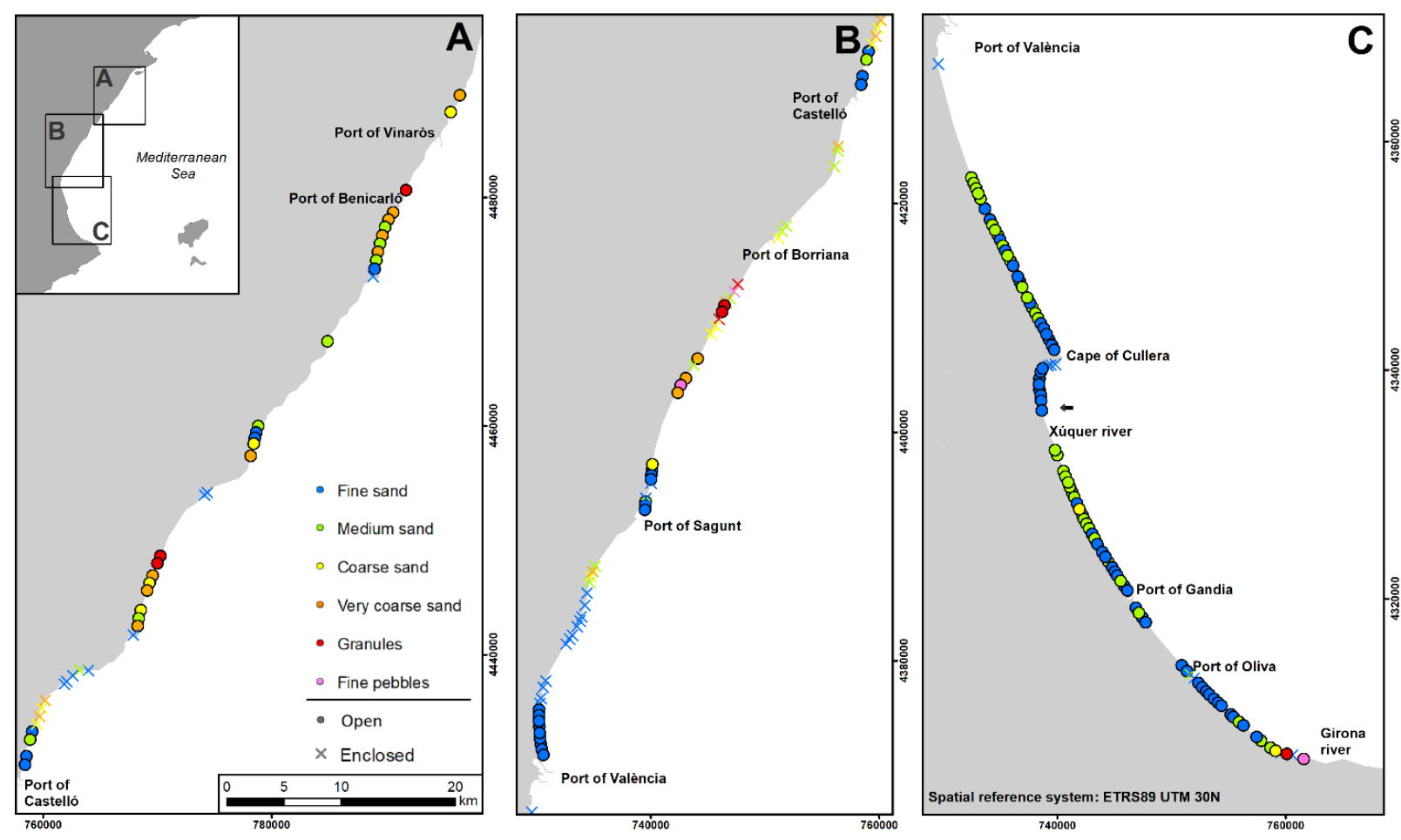

Fig. 6.4. Sampling locations along the Gulf of Valencia. Grain sizes of the beaches are represented by different colors and the morphological classification by symbols (circles and crosses for open and enclosed beaches respectively). The black arrow identifies the site used in Fig. 6.5 for describing the definition of SDS variability.

\subsubsection{Quantifying shoreline variability and its relation with grain size}

Grain-size data were paired with the shoreline variability at each study site. The variability was quantified with GIS software from the SDS following the methodology described in CabezasRabadán et al. $(2019 b, c)$. In order to do so, the inner limit of the beach was defined by photointerpretation of orthophotographies. That inner limit was considered as a constant baseline from which the distance to the points that compose each SDS were measured (Fig. 6.5), constituting beach widths. For each study site and date, the average beach width was defined, constituting a relative position of the shoreline. 
Three parameters were combined to define the shoreline variability:

-(i) Shoreline segment's length. Two different shoreline lengths were employed at each study site for defining the variability in order to compare the effect of small morphological formations (e.g. beach cusps). Thus, the segments of SDS employed in the analysis were selected using 100 and $200 \mathrm{~m}$ buffers around the sediment samples.

-(ii) Variability proxy. In order to quantify the shoreline variability, the standard deviation (hereafter $\sigma$ ) and the maximum range were defined considering the average SDS position on different dates (Fig. 6.5). The standard deviation has been stated by previous works as representative of beach variability (e.g. Dolan et al. 1978; Guillén et al., 1999; Short \& Hesp, 1982; Stieve et al., 2002), while the range is directly related to the maximum changes that the total water level (TWL) and beachface morphology experience.

-(iii) Period and quantity of SDS. The intra-annual variability was defined considering the corresponding SDS, and using the previously described proxies and segments of analysis. This allowed to analyze the influence of the number of SDS considered as well as the associated oceanographic conditions.

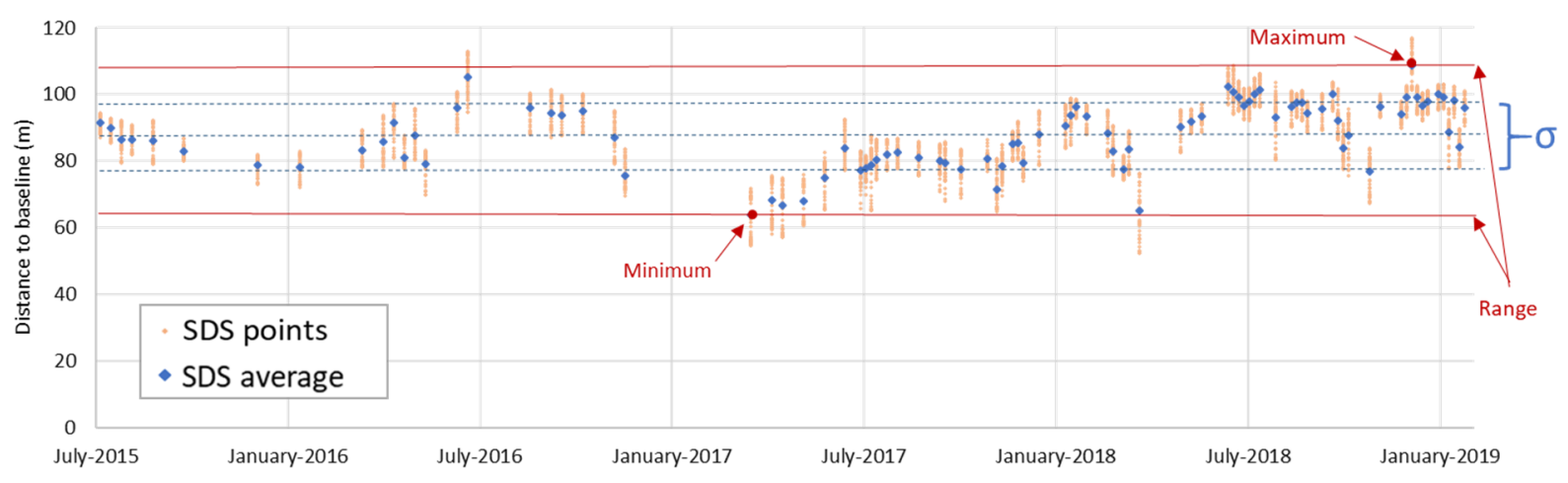

Fig. 6.5. This figure represents, at one sampling location (see Fig. 6.4, C section), the distances between the baseline and the points that compose each SDS (points in light orange, considering a $100 \mathrm{~m}$ buffer), as well as their average blue point). The proxy standard deviation ( $9.76 \mathrm{~m}$, dashed line in blue) was derived considering all SDS average distances while the range ( $45.08 \mathrm{~m}$, solid line in red) was defined as the difference between the furthest SDS (107.74 $\mathrm{m})$ and the closest one $(63.66 \mathrm{~m})$.

Subsequently, shoreline variability was defined at each study site through the combination of different proxies, lengths of shoreline segments, and periods of time. Variability values were paired with grain-size data from the most recent dataset available. Different numerical functions were tested to describe the shape of the distribution across the full grain-size spectrum. The goodness of fit of the optimal model was compared when combining different parameters for defining the variability. 


\subsection{Results}

\subsubsection{Grain size and shoreline variability data pattern}

Shoreline variability was defined based on different proxies. The average values of the variability proxies were obtained for the different sediment-size categories (Fig. 6.6).

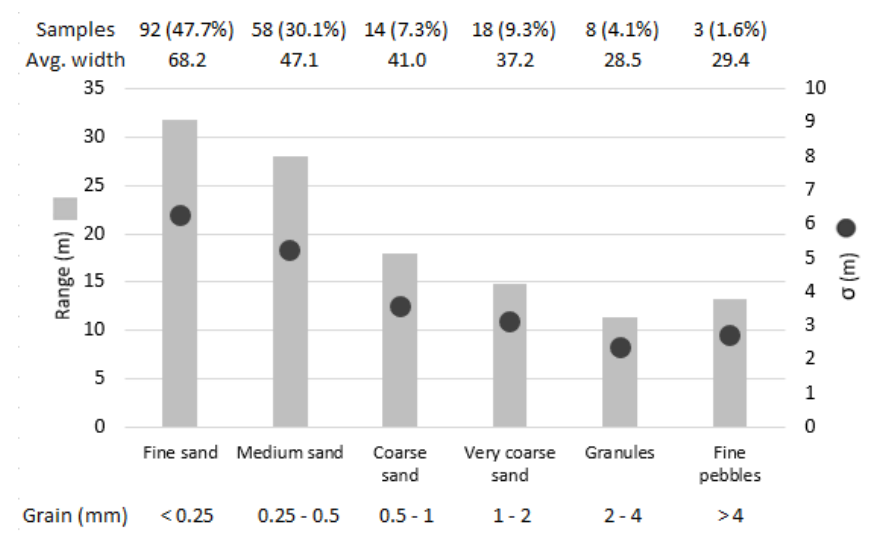

Fig. 6.6. For the different grain size grading categories (according to Wentworth, 1922): number of samples, average beach width $(\mathrm{m})$, and average range (grey boxes) and standard deviation (black dots) of the SDS as variability proxies when considering $100 \mathrm{~m}$ buffers.

Throughout the sediment size spectrum there is an evident gradation in the number of samples analyzed, values of shoreline variability, and beach width, all of them decreasing as grain size increases. Regarding the availability of samples (193) there is a significant imbalance along the grain-size spectrum. A greater quantity of samples (47.7\%) appear associated with fine sand (being the smallest sample of $D_{50}=0.14 \mathrm{~mm}$ ). The availability of samples decreases progressively through medium sand (30.1\%), coarse (7.3\%) and very coarse sand (9.3\%), granules (4.1\%), and fine pebbles (only $1.6 \%$, being $4.66 \mathrm{~mm}$ the coarsest sample size). Concerning beach width, fine sand samples appear linked with wider beach segments (average width over $65 \mathrm{~m}$ ) while granules and fine pebbles are associated with much narrower beaches (almost $30 \mathrm{~m}$ in both cases). Shoreline variability, defined by range and standard deviation proxies, presents a gradient with the highest values associated with fine sand (average range of $31.8 \mathrm{~m}$ and $\sigma$ of $6.3 \mathrm{~m}$ ) and decreasing towards granules and fine pebbles, showing both similar variabilities (range and $\sigma$ about $12 \mathrm{~m}$ and $2.5 \mathrm{~m}$ respectively).

When considering each sample in combination with the associated shoreline variability the data present a remarkable scattering, although their distribution shows a clear pattern in which both parameters present an inverse and non-linear relationship (Fig. 6.7). The scattering is especially remarkable for fine and medium sand samples, which show range values between $11 \mathrm{~m}$ and 63.5 $\mathrm{m}$. The scattering and the variability decrease towards coarser sediments with an inflexion in this trend about the medium and coarse sand categories. From this point, samples continue to show similar minimum ranges near $10 \mathrm{~m}$, while most of the highest range values remain below $20 \mathrm{~m}$. This reduction is maintained throughout the rest of the spectrum, with no samples of granules or pebbles showing range values greater than $20 \mathrm{~m}$. 


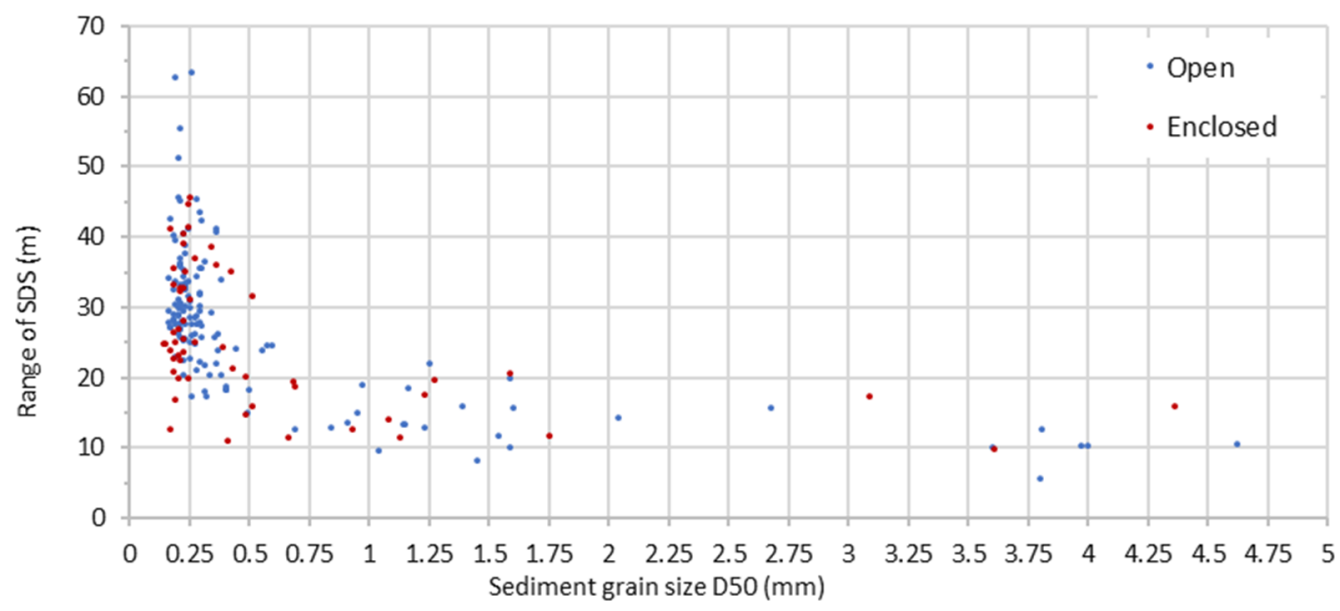

Fig. 6.7. Grain size of the sediment sample expressed as $D_{50}$ versus the variability of the shoreline position expressed as the range between the most landward and seaward SDS included in a $100 \mathrm{~m}$ buffer. Samples appear classified as open beaches (blue) and enclosed beaches (red).

With regard to the morphology of the beaches, the general pattern of those enclosed is similar to the open ones. Nevertheless, several samples at enclosed beaches showed greater scattering from the general pattern. As they may experience different wave incidence and in order to be more consistent it was decided to not consider them when establishing the numerical grain size variability relationship. Subsequent analyses have therefore been carried out only considering open beaches (137 study sites).

\subsubsection{Numerical description of the relationship}

Different numerical models were tested to describe the data pattern registered across the full range of grain sizes considering sediment samples of open beaches. The equation with two terms that best describes the relationship between grain size as a function of shoreline variability data has been defined as follows:

$\mathrm{Y}=\frac{1}{\mathrm{a}+\mathrm{b} * \ln (\mathrm{X})}$

being $Y$ the shoreline variability, and $X$ the sediment grain size. The deduced logarithmic function describes the inverse and non-linear relationship between both parameters (Fig. 6.7). The model represents high values of shoreline variability associated with fine sand followed by a rapid decrease and, subsequently, very small depletions as sediment size continues to increase. The turning point is linked to $D_{50}$ values close to $0.5 \mathrm{~mm}$.

Table 6.1. Correlation (expressed as the coefficient of determination $\mathrm{R}^{2}$ ) when describing SDS variability as a function of grain size (following Ec. 1, $n=137$ ). Different variability proxies and segment lengths are considered.

\begin{tabular}{cc|cc}
\multicolumn{2}{c|}{$100 \mathrm{~m}$} & \multicolumn{2}{c}{$200 \mathrm{~m}$} \\
\hline Range & $\sigma$ & Range & $\sigma$ \\
\hline 0.682 & 0.671 & 0.658 & 0.693 \\
\hline
\end{tabular}

The function offers a moderately-high agreement, explaining about $70 \%$ of the shoreline variability as a function of grain size. The goodness of fit of the model was compared when defining the variability by combining different variability proxies and coastal segment lengths (Table 6.1). Similar 
results are obtained when employing $\sigma$ or range as proxies of shoreline variability. The same applies when defining the length of the segments of analysis with $100 \mathrm{~m}$ or $200 \mathrm{~m}$ buffers around sediment samples. In particular, the best results are achieved by logarithmic functions (Fig. 6.8) using the $\sigma$ as variability proxy over coastal lengths defined by $200 \mathrm{~m}$ buffers ( $2=0.69)$, although it is a very close correlation to the one obtained when using the range and $100 \mathrm{~m}$ buffers ( $\mathrm{R} 2=$ 0.68).
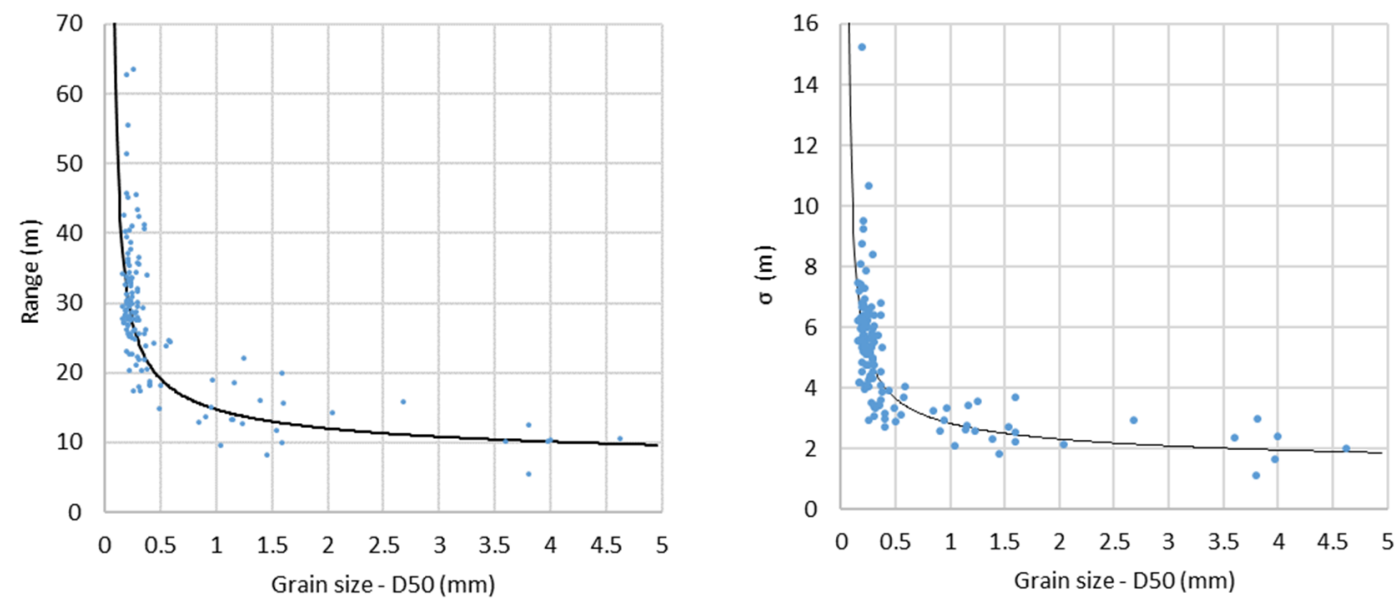

Fig. 6.8. Shoreline variability as a function of sediment grain size. On the left, the relationship is defined for $100 \mathrm{~m}$ buffers by the equation: range $=1 /\left(0.0675+0.0234^{*} \ln \left(D_{50}\right)\right)$. On the right, for $200 \mathrm{~m}$ buffers, $\sigma=1 /\left(0.3522+0.1143 * \ln \left(D_{50}\right)\right)$.

\subsubsection{Annual variability, amount of SDS and oceanographic conditions}

Shoreline variability experiences significant changes over the years (Fig. 6.9). Expressed as average range, the variability shows a higher value for the period 2015-2019 (27 $\mathrm{m}$ ) than when individually considering the different years. The year 2018 is the one with the largest average range $(24 \mathrm{~m})$, followed by 2016 (14.5 m) and 2017 (15.2 m). In contrast, 2015 and 2019 present substantially lower variability ( $7 \mathrm{~m}$ and $11 \mathrm{~m}$ respectively).

The distribution of variability with regard to different sediment sizes also experiences changes during the different years. In general, there is a gradation of variability from the finest to the coarsest sediment. Thus, during the period 2015-2019 the average range decreases progressively from fine sand $(31.8 \mathrm{~m})$ to granules and fine pebbles, that register an average range below half of it (11.4 $\mathrm{m}$ and $13.3 \mathrm{~m}$ ). The distribution is very similar in 2018 and, although the variability values are reduced, the gradient is maintained for the rest of the years.

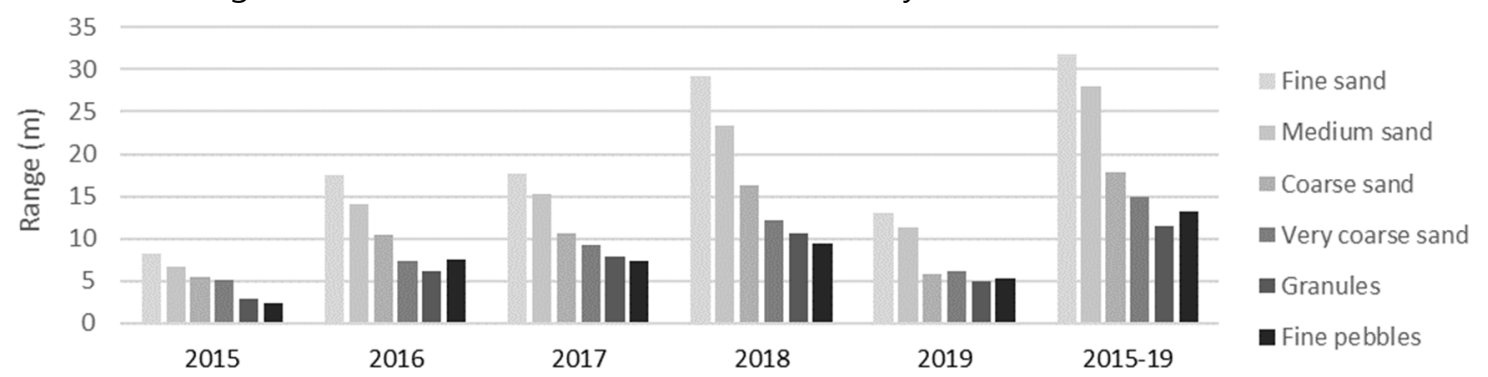

Fig. 6.9. Average SDS variability on beaches with different sediment grain size (grouped in categories shown in different colors) during different years. The variability is shown as the range of SDS on coastal segments defined by $100 \mathrm{~m}$ buffers. 
The goodness of fit of the model describing the shoreline variability as a function of the grain size was analyzed when defining the variability annually instead of for the whole period. The highest goodness of fit is obtained considering the period 2015-2019 (i.e. with the whole set of SDS), and it is lower when only SDS of a single year are considered (Table 6.2). Nevertheless, there are important differences between the years. The highest goodness of fit for a single year appears in 2018, the year with the highest availability of SDS. It is followed by 2017 and 2016 both by fit values and amount of available SDS, while 2015 and 2019 have much fewer SDS and offer much worse fit values. With regard to the proxies and lengths of coastal segments, the fit is similar for any combination of them as it occurs for the period 2015-2019.

Table 6.2. Statistical relationship between grain size and shoreline variability according to Ec. 1. The goodness of fit is expressed as coefficient of determination R2. Columns show the correlation values for different periods. The column on the right $\left(^{*}\right)$ only considers SDS associated with the 30 highest and the 30 lowest sea-level registers (about half of the available SDS for the whole period).

\begin{tabular}{cccccccccc} 
& Period & 2015 & 2016 & 2017 & 2018 & 2019 & $2015-2019$ & $2015-19 *$ \\
\hline \multirow{2}{*}{ Range } & no. SDS & 9 & 18 & 38 & 47 & 6 & 118 & 60 \\
& $100 \mathrm{~m}$ & 0.035 & 0.451 & 0.466 & 0.561 & 0.379 & 0.682 & 0.694 \\
& $200 \mathrm{~m}$ & 0.167 & 0.493 & 0.422 & 0.63 & 0.352 & 0.658 & 0.698 \\
\hline \multirow{2}{*}{$\boldsymbol{\sigma}$} & $100 \mathrm{~m}$ & 0.035 & 0.5 & 0.506 & 0.595 & 0.369 & 0.671 & 0.694 \\
& $200 \mathrm{~m}$ & 0.188 & 0.491 & 0.519 & 0.631 & 0.363 & 0.693 & 0.706 \\
\hline
\end{tabular}

A higher amount of SDS when defining the shoreline variability appears associated with higher goodness of the fit grain size - shoreline variability (Fig. 6.10, a), although this trend is not very strong and it is sustained by a low amount of data. The figure also points out that the amount of SDS does not increase linearly the ability of their derived variability to deduce grain size. The goodness of fit only improves about 10\% when using 118 SDS (period 2015-2019) instead of only 47 SDS. Moreover, important differences appear when comparing the two years with limited SDS availability. It is noteworthy that 2019 with only 6 SDS registers substantially better goodness of fit than 2015 with 9 SDS, suggesting that the amount of SDS is not the only relevant factor. Thus, for a certain period the goodness of the grain size - variability fit appears also linked to the recorded magnitude of shoreline change (Fig. 6.10 b). Higher shoreline variability values, expressed by the proxy annual range, appear linked to higher goodness of fit with sediment size. This relationship $\left(R^{2}=0.89\right)$ is stronger than that one registered with the amount of SDS used to define the shoreline variability, as it can be seen by comparing (a) and (b) scatter plots. 

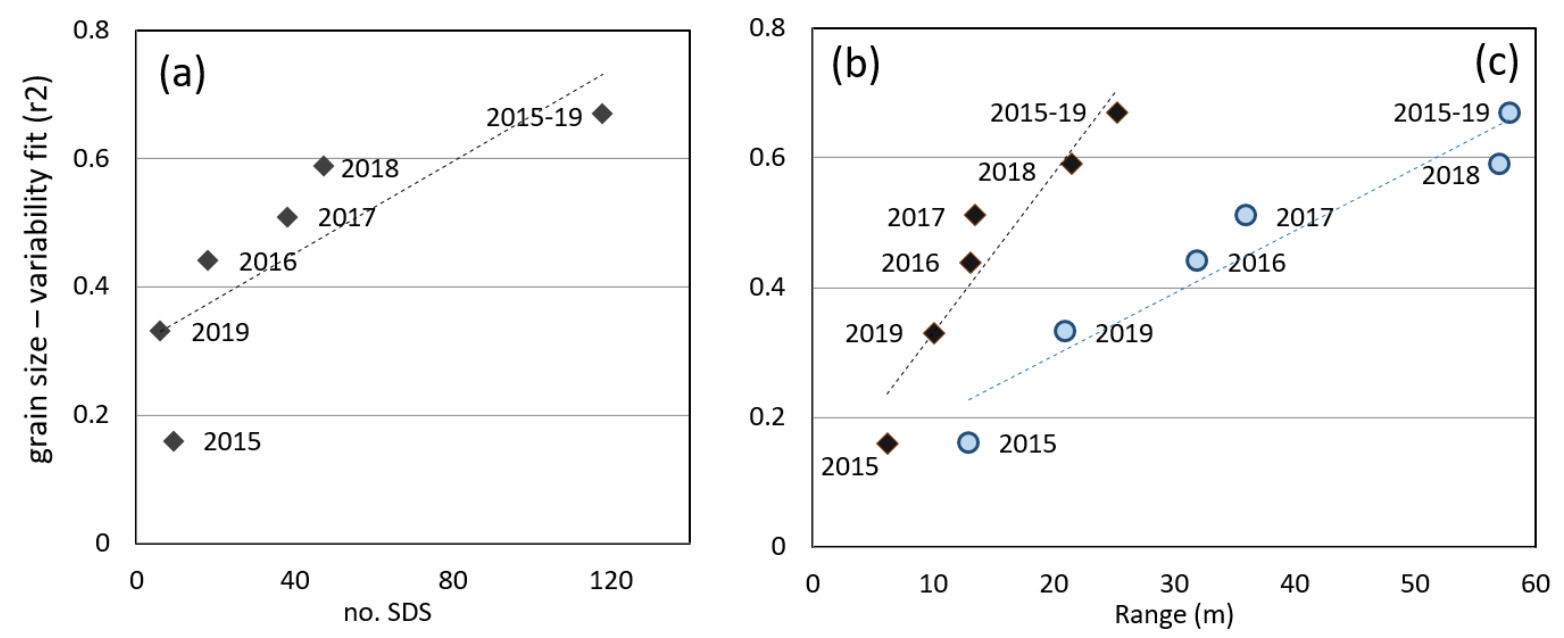

Fig. 6.10. Plots of the annual goodness of the fit grain size - variability as $\sigma$ (Y-axis) versus (X-axis): (a) amount of SDS considered, (b) average range of shoreline change, and (c) range of the sea level change coinciding with the instant of SDS acquisition. All variability values were defined for $200 \mathrm{~m}$ buffers.

The magnitude of shoreline variability seems to play a major role in the fit of this parameter with grain size. As shoreline changes are conditioned by sea level, its annual influence on SDS position was also explored. Sea level data at the time of acquisition of each SDS were identified and their annual range was calculated. They were compared with the annual goodness of grain size variability fit, showing a clear linear relationship $\left(R^{2}=0.93\right)$ between both variables (Fig. $\left.6.10 \mathrm{c}\right)$. In line with that, considering the SDS acquired during the period 2015-2019 those associated with the highest and lowest sea levels were selected (almost 25\% for each case, a total of 60 SDS). Even though this way only half of the SDS were being considered (50.5\%), variability was defined resulting in a goodness of fit with grain size slightly better $(0.71 \%)$ than when considering all the available SDS (118) (Table 6.2, right column).

\subsubsection{Estimation of sediment size from shoreline variability}

The previously proposed relationship between shoreline variability and grain size leads to the possibility of roughly estimating one parameter from the other. Having this goal in mind, the equation that better defines the texture of the sediment as a function of shoreline variability has been identified. For this purpose, the variability proxies that achieved a higher goodness of fit with sediment data have been used, leading to the equation:

$\mathrm{D}_{50}=\mathrm{e}^{\left(\mathrm{a}+\frac{\mathrm{b}}{\sigma}\right)}$

being $D_{50}$ the parameter for characterizing mean grain size and $\sigma$ the standard deviation along a coastal segment defined by $200 \mathrm{~m}$ buffers. Considering the previous results, only the SDS corresponding to the highest and lowest sea levels were considered. The formula was plotted together with the data showing how the general shape is well represented (Fig. 6.11), being the vast majority of points included inside the prediction interval. Nevertheless, the range of the spectrum associated with the coarsest sizes has a significant scarcity of data, with higher scattering and several points falling outside the prediction bands. 


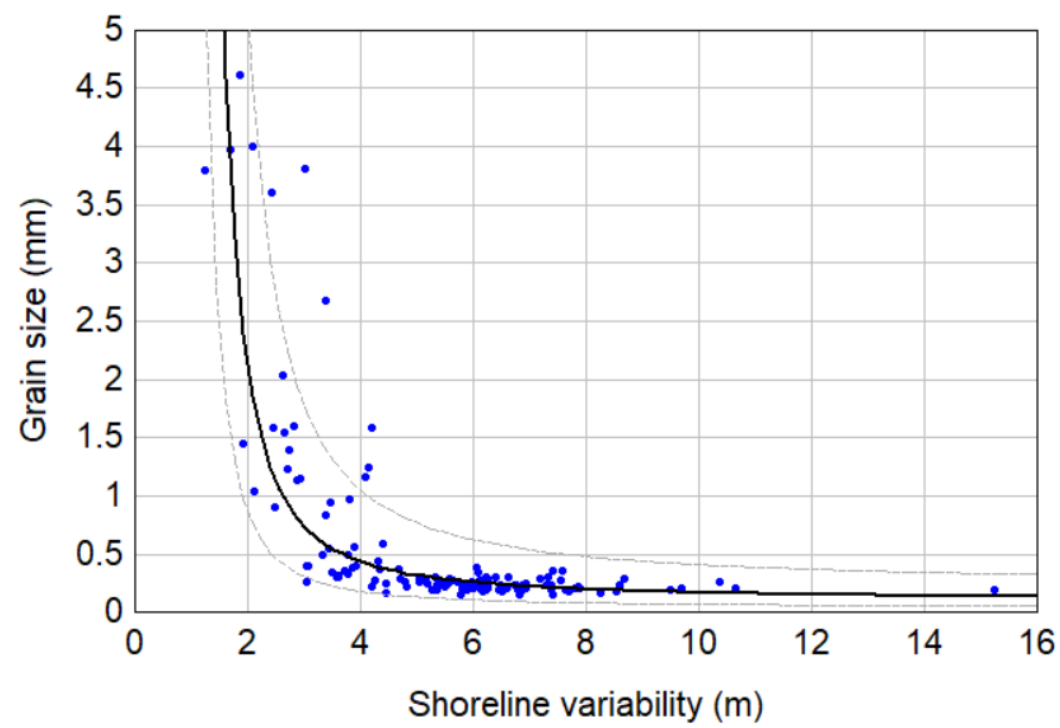

Fig. 6.11. Estimation of the grain size $\left(D_{50}\right.$, in $\left.\mathrm{mm}\right)$ as a function of shoreline variability $(\sigma$, in $\mathrm{m})$ according to Ec. 2 and the fit: $a=-2.38847 ; b=6.25775$, and 95\% prediction interval.

In order to assess the capacity of this equation to predict the grain size, $D_{50}$ was estimated at each study site given the shoreline variability. Differences between predicted and observed grain sizes were calculated (Table 6.3) for the different sediment size categories. For this analysis granules and fine pebbles were considered together due to the small number of available samples. Small errors appear associated with fine and medium sand (with an average overestimation of the real size of $0.04 \mathrm{~mm}$ and $0.03 \mathrm{~mm}$ respectively). The errors increase along coarse and very coarse sand (average underestimation of $0.14 \mathrm{~mm}$ and $0.35 \mathrm{~mm}$ ) and granules and fine pebbles (average underestimation about $0.21 \mathrm{~mm}$, and the highest $\sigma$ of the errors).

Table 6.3. Average, maximum and range of error $(\mathrm{mm})$ when estimating the parameter $\mathrm{D}_{50}$ from shoreline variability. Positive errors represent an overestimation of the real value, and negative errors an underestimation.

\begin{tabular}{c|ccccc} 
Size & Fine sand & $\begin{array}{c}\text { Medium } \\
\text { sand }\end{array}$ & Coarse sand & $\begin{array}{c}\text { Very coarse } \\
\text { sand }\end{array}$ & $\begin{array}{c}\text { Granules and } \\
\text { pebbles }\end{array}$ \\
\hline Samples & 61 & 48 & 8 & 12 & 8 \\
Average & 0.04 & 0.03 & -0.14 & -0.35 & -0.21 \\
$\sigma$ & 0.05 & 0.12 & 0.05 & 0.63 & 4.72 \\
\hline
\end{tabular}

The predicted categories were compared with the actual ones. The confusion matrix (Table 6.4) shows how more than half of the samples (53\%) have been properly classified, although an important proportion of them have been incorrectly classified, mainly in adjacent categories. Samples classified as fine sand were mostly correct ( 0.83 users' accuracy), although many were missing as they were wrongly predicted to be medium sand. The confusion also took place the opposite way, with several medium sand samples being classified as fine and coarse sand. From the coarse sands, the confusion increases greatly. 
Table 6.4. Confusion matrix comparing the number of samples at a certain predicted size category with the actual category and the number of samples. The correct samples are highlighted in bold.

\begin{tabular}{|c|c|c|c|c|c|c|}
\hline Measured category & Fine sand & $\begin{array}{c}\text { Medium } \\
\text { sand }\end{array}$ & Coarse sand & $\begin{array}{c}\text { Very coarse } \\
\text { sand }\end{array}$ & $\begin{array}{c}\text { Granules and } \\
\text { Pebbles }\end{array}$ & $\begin{array}{c}\text { Producer's } \\
\text { accuracy }\end{array}$ \\
\hline Fine sand & 34 & 27 & 0 & 0 & 0 & 0.56 \\
\hline Medium sand & 10 & 31 & 7 & 0 & 0 & 0.65 \\
\hline Coarse sand & 0 & 3 & 4 & 1 & 0 & 0.5 \\
\hline Very coarse sand & 0 & 3 & 6 & 2 & 1 & 0.17 \\
\hline Granules and Pebbles & 0 & 0 & 2 & 3 & 3 & 0.38 \\
\hline User's accuracy & 0.77 & 0.48 & 0.21 & 0.33 & 0.75 & 0.54 \\
\hline
\end{tabular}

It is important to note that confusion is more likely associated with samples in which grain size is close to the boundaries of each category. Thus, for the majority of cases of confusion ( $92 \%$ of the errors) a neighboring category is predicted, leading to $96 \%$ of the samples classified either correctly or in the adjacent categories.

\subsection{Discussion}

Advances in shoreline extraction techniques make it possible to accurately and efficiently define the position of the shoreline at regional scale -hundreds of kilometers- along time from freely available mid-resolution satellite imagery (Sánchez-García et al., 2020). This work demonstrates that SDS may enable the estimation of a key geomorphological parameter of the beaches as the grain size of the sediment. In order to do so, SDS extracted with subpixel accuracy from Sentinel2 images using SHOREX allow defining the shoreline variability at the micro-tidal Gulf of Valencia, spanning a wide spectrum of beach typologies. Variability values were related to grain size samples covering from fine sand to granules, allowing the definition of a non-linear function that describes the relation.

\subsubsection{Considerations with regard to the sediment}

The Gulf of Valencia is a coast mainly composed by sandy beaches, which causes a heterogeneous distribution of samples along the grain size spectrum with a much larger proportion of fine and medium sand. However, the high volume of samples offers good enough coverage to represent the pattern of shoreline variability across the grain size spectrum. It is important to underline that the two main datasets employed in this work are not synchronous: sediment samples were obtained during the period 2006-2010 while SDS correspond to the period 2015-2019, leading to an average time lag of 9 years. Nevertheless, the study takes place along a low energetic coast, and segments directly affected by human interventions have not been included in the work since they could blur the relationship between shoreline changes and grain size. Therefore, no major size changes were expected between datasets. More recent samples have revealed small size variations at the study sites, validating the grain size dataset and its comparison with SDS data.

The dataset represents the size of the beach-face sediment by the parameter $D_{50}$. It is assumed that the grains at this point are the main responsible for the morphological response of the shore to oceanographic conditions. It is true that at certain coasts, considerable heterogeneity may be observed in the sediment both along time and space (Huisman et al., 2016; Prodger et al., 2016). 
Therefore, a single parameter derived from punctual samples may not be completely representative of the composition of the sediment (Holland \& Elmore 2008) of each study site, with changes taking place even inside each cross-shore profile. Medina et al. (1994) pointed out the existence of a cyclical redistribution of different grain sizes along a profile that remains constant as a whole. In that case, the variability of the shoreline would not only be related to punctual sediment characteristics but the overall composition of the profile. An oversimplified characterization of the sediment may be problematic when there is a mixed texture of gravel and sand. Nevertheless, the analysis relating grain size and shoreline variability requires working with a single representative value of the sediment. The Gulf of Valencia only shows a small proportion of beaches with a bimodal distribution, many times originated by human actions (ECOLEVANTE, 2010, Sanjaume, 1985), making their presence in the study very small and minimizing the effect of that simplification. Despite the recognition of all the previous limitations, the approach sustained on a single beach-face sample followed in this work may be a good starting point for exploring the relation of sediment size with shoreline variability.

\subsubsection{Causes and meaning of shoreline variability}

Grain size is a major factor defining beach slope which, in turn, contributes to define shoreline changes. Slope and shoreline variability are affected by several factors of which grain size is a major but single one. Thus, substantial scattering of the data and moderate correlations are expected when exploring the relationship between those parameters. Despite these issues, when pairing the datasets of both elements the data pattern clearly shows an inverse power-law relationship between them. Fine-sediment beaches experience high variability of the shoreline while larger grain sizes experience much more moderate changes. Starting from high values associated with fine grains, variability describes a rapid decrease with a shifting point at the boundary between medium and coarse sand (about $D_{50}=0.5 \mathrm{~mm}$ ). This shifting point is consistent with the data pattern in the preliminary analysis by Cabezas-Rabadán et al. (2017). Their work, sustained on a reduced set of samples covering from fine to coarse sand, showed a non-linear pattern with a shift in shoreline variability around the medium/coarse sand boundary. Sustained on a larger number of samples, the present study offers broader coverage of the grain-size spectrum. It makes it possible to fit a numerical function to the data pattern to describe about $70 \%$ of the variability as a function of the grain size (Ec. 1).

The inverse and non-linear relationship between grain size and shoreline variability is largely a consequence of how the latter one is determined by the beach-face slope. In turn, the slope would be related to the size of the sediment in a non-linear way according to recent deductions by Bujan et al. (2019). Their meta-analysis shows a data pattern in which slope is gentle at fine-sediment beaches but increases rapidly to reach an almost steady situation at coarser sediment sizes. Then, an increased hydraulic conductivity would be the cause of this shifting point, leading to infiltrationdominated beaches. A maximum value (about $\tan \beta=0.2$ ) is not exceeded no matter how much grain size increases, probably leading to the stabilization of shoreline variability. The relationship was described by Bujan et al. (2019) with the equation $\tan \beta=a\left(D_{50}-0.125\right) b+c$, very similar but inverse to the one proposed in the present work relating grain size and shoreline variability. 
At this point it is interesting to explore which other factors come into play in this relationship and how they influence it. Bearing in mind the goal of linking grain size and changes of the shoreline position, it is crucial to select the proxies to represent the variability. Different parameters were combined in order to determine which achieve higher correlations with the $D_{50}$. The standard deviation of the shoreline position and its maximum range were tested as variability proxies. The first one, proposed by Dolan et al. (1978) is representative of the mobility of the beach and its morphodynamic state (Short \& Hesp, 1982). This proxy may offer higher robustness and be less likely affected by eventual SDS inaccuracies. On the other hand, the maximum range may be easily related to the maximum shoreline oscillations caused by changes of the beach-face morphology and the water level. The variability defined by both proxies (range and standard deviation) varies linked to grain size with similar patterns for both proxies, also reaching similar goodness of fit with grain size data (Table 6.1). Thus, both proxies can be considered as representatives of the mobility of the beach and its typology in terms of responding to oceanographic factors.

Since punctual grain size samples are related to shoreline changes it is essential to define the coastal segment being considered. Too short segments may cause an overestimation of specific shoreline changes not necessarily related to the general slope and grain size of the sector (e.g. undulations due to beach cusps, small puddles of water on the beach surface). On the contrary, longer stretches lead to a more robust definition of the shoreline changes, but at expenses of blurring the differences between adjacent study sites. Results were similar when considering segments defined by 100 and $200 \mathrm{~m}$ buffers (Table 6.1). With this in mind, a more robust quantification of the variability would be reached by considering longer coastal segments together with the standard deviation. This proxy has the advantage of not being so jeopardized by the punctual errors of the SDS as, a result of the automatic extraction, shorelines may be affected by the presence of puddles and accumulations of water, parcels of very dense vegetation, and shadows near the shore. On the contrary, the maximum range in combination with $100 \mathrm{~m}$ buffer would offer a closer approach to extreme shoreline situations, as well as potentially allowing define the variability from only two SDS. Nevertheless, such assumption would require to analyze to what extent the use of fewer SDS affects the definition of the variability, as well as to determine which SDS should be used for this purpose.

The goodness of fit between grain size data and shoreline variability appears influenced by the amount of SDS considered in the definition of the latter. When defining the variabilities associated to a single year, they show smaller magnitudes than when considering the period 2015-2019 and a lower agreement with grain size data (Table 6.2). As the amount of SDS increases a better adjustment is achieved (Fig. 6.10, a), suggesting that a poor fit may be caused by an insufficient number of shoreline records. However, this only happens up to a certain amount of SDS. After that point the annual variability stabilizes, possibly because the amount of SDS is sufficient to accurately represent the actual changes in the shore. This would highlight the differences along the grain size spectrum, leading to a higher agreement with grain size. The optimum amount of SDS, at least for this micro-tidal environment, seems to be slightly higher than the 47 shorelines 
of 2018. The variability defined that year presents a goodness of fit with grain size data similar to that achieved when considering the SDS of the entire study period (118).

Results clearly show how as the variability recorded in the different periods increases so does its agreement with grain size (Fig. 6.10,b). Therefore, the amount of SDS would not be the only essential element for a strong fit between grain size and shoreline variability data. On the contrary, those SDS considered must be associated with moments in which the shoreline experiences the greater changes. Shoreline changes are caused by both beach-face morphology and water level changes, being the latter one mainly influenced by sea level. Previous studies using SDS from Landsat 8 imagery (Almonacid-Caballer et al., 2016) identified relations between annual sea level variations and SDS variability. This same idea is reinforced here: when satellite images are acquired at instants with greater sea-level changes SDS have greater possibilities of defining high variability proxies that, in turn, may lead to a stronger agreement with sediment size (Fig. 6.10c). Following this, SDS associated with maximum sea-level changes were selected and, despite being close to half of all the available, they defined shoreline variability with the best goodness of fit with grain size (Table 6.2). This supports the idea that it is possible to achieve good results with a lower number of SDS as long as they are representative of the greatest shoreline changes. On the other hand, storm episodes can modify the morphology of the beach leading to greater changes in the shoreline position. However, cloudy conditions may prevent the extraction of SDS from satellite images, leading to an under-representation of variability (Cabezas-Rabadán et al., 2019d). This is especially remarkable in the years 2015 and 2017 in which SDS could not be acquired simultaneously to important wave episodes (Fig. 6.2).

As the volume of available samples at enclosed beaches is relatively low, the influence that different beach configurations and oceanographic conditions have on shoreline variability has been analyzed in a merely qualitative way. At enclosed beaches shoreline variability as a function of grain size presents more scattered data. This could be caused by the fact that defensive structures may lead to lower exposure to higher waves, which in turn would translate into lower run-up and fewer extreme episodes potentially captured by the SDS. At the same time, the lower capacity to rearrange the morphology of the beach-face would alter the slope-sediment-wave interdependence (Carter, 1988) followed by the open beaches of the region. Protected beaches may show steeper slopes for a given grain size than exposed ones (Wiegel, 1964). A steeper slope combined with fewer extreme wave episodes could cause abnormally low variability experience by some beaches of the study area. In contrast, enclosed beaches with coarser sand may have a lower slope and a profile more dissipative than expected, probably resulting in relatively high variability for a certain grain size.

\subsubsection{Estimation of sediment size from shoreline variability}

The established correlation between SDS variability and the size of beach-face particles suggests that it is possible to estimate one parameter from the other. Thus, a key characteristic of the sediment as the $D_{50}$ would be quantified covering large coastal stretches from freely-available Sentinel-2 imagery avoiding the necessity of intensive fieldwork. The ability of the model (Ec. 2) for predicting grain size from shoreline variability was assessed, indicating a moderately-high 
accuracy in defining the median diameter. More than half of the samples were properly classified according to their grading (Tables 6.3,6.4), with most of the errors appearing when incorrectly assigning samples to the adjacent grade. Results were promising for fine to coarse sands, showing poor results for pebbles and granules. This occurred as these sizes are associated with a similar magnitude of shoreline variability, and the slight differences they experience (if any) are by far exceeded by other methodological errors as those associated with the SDS definition. All this makes the method inadequate for distinguishing among the coarser grades of sediment.

In no case this approach is intended to substitute highly accurate techniques as the sieving. Nevertheless, it represents a great advance over other remote sensing techniques as no single one is capable of carrying out an efficient quantification of the sediment size at the meso or macroscale level. Although photogrammetric techniques, TLS, and drone-based procedures (e.g. Buscombe et al., 2014; Heritage \& Milan, 2009; Kim et al., 2019) constitute useful alternatives to acquire data while reducing time consumption, all of them maintain the need for fieldwork which makes them very expensive to adopt at regional scale. On the other hand, airborne-based methodologies, as well as those sustained in SAR and optical satellite imagery are restricted by the resolution of the input data, only leading to coarse classifications that distinguish elements as dry and wet sand or mud (Manzo et al., 2015; Van Der Wal \& Herman, 2007).

The proposed methodology faces several limitations. First of all, prediction ability is high for fine and medium sand, but quite poor for coarser sediments. Partly this could be caused by the fact that the sediment data set is highly unbalanced, with a greater number of fine samples. A higher availability of coarse samples could allow a better definition of the numerical function and, therefore, a higher prediction ability along the coarser part of the spectrum. Similarly, and although it is beyond the scope of this work, a more detailed characterization of the sediment (e.g. through increased sample coverage or the inclusion of other descriptive parameters such as classification) could offer a deeper understanding of the influence it has on the dynamism of the shore, helping to shape more precisely the numerical function.

The methodology has been tested at the micro-tidal and low-energetic Gulf of Valencia, but certain issues must be addressed in order to apply this methodology to different coastal types. Bujan et al. (2019) have recently clarified the slope - grain size relationship through a meta-analysis sustained on worldwide data acquired at different coastal types. It suggests that the relation, as well as the model proposed in the present study (which is closely dependent on it), may be also valid at other coastal environments. Considering the results of the current work, the relationship between parameters and the estimation capacity may weaken when combining beach segments with a different incidence of waves such as those constrained by structures or with a different orientation. Different tides and energetic conditions may pose challenges to SDS extraction and reduce their accuracy. Each SDS is an instantaneous simplification of the alongshore undulated water-land interface, which is conditioned by small coastal formations and swash/backwash processes that cause different degrees of humidity or water inundation on the beach-face (Cabezas-Rabadán et al., 2020). SDS define such an extremely dynamic element from coarsepixeled satellite imagery, which leads to a non-negligible error that may translate into scattering 
and increasing variability values. Nevertheless, although they may pose new extraction challenges, the larger shoreline displacements linked to tidal excursions may offer a stronger relation with the slope of the beach-face and the sediment grain size minimizing the influence of extraction errors. Results obtained in the present work at a coast where these changes are minor invites to be optimistic with regard to its application on coasts with higher tidal range. Validations of the extractions system SHOREX on more energetic and/or macro-tidal coasts are needed to fully ensure the accuracy on any type of coast. Nevertheless, assessments under high-energy wave conditions (Sánchez-García et al., 2019) and meso-tidal exposed beaches (Cabezas-Rabadán et al., 2020) show accuracies lower but of similar magnitude than at the Mediterranean (Sánchez-Garcia et al., 2020).

Apart from constituting an important descriptor of the beach state and its changes (CabezasRabadán et al., 2019b,c) the present work highlights the potential of SDS for deriving interesting geomorphological data. The approach followed in this study estimates grain size from shoreline changes, a relationship that is conditioned by the beach slope. In relation with that but following a different methodology Vos et al. (2020) have recently proposed the employment of time series of SDS to quantify the slope of the beach by frequency domain analysis, reaching high correlations with the validation data. Both works serve to illustrate the significant correlation between sediment size, slope and shoreline variability. This shows the great potential that large sets of shoreline positions have for coastal characterization and monitoring.

\subsection{Conclusions}

Shorelines extracted from a freely accessible data source as Sentinel-2 mid-resolution imagery allow defining shoreline variability at regional scale as a representative parameter of beach mobility. The median grain size of the beach-face sediment appears related with the shoreline variability in a non-linear way along the grain-size spectrum. Thus, a different pattern of variability is experienced by beach segments with sediment size respectively coarser and smaller than $D_{50} \approx$ $0.5 \mathrm{~mm}$. The numerical definition of shoreline variability as a function of grain size and vice versa, with an agreement about $70 \%$, allows to address a rough estimation of the sediment size. The relationship between both parameters appears as dependent on methodological aspects as the amount of available SDS and the proxy used for defining the variability, as well as on oceanographic conditions that may blur the correlation and limit their future applications. Furthermore, the proposed functions cannot be considered as definitive since they have been deduced from a dataset unbalanced along the grain size spectrum. Despite these limitations, the proposed technique may provide a fairly accurate overview of the sediment grading along large coastal section from mid-resolution satellite imagery. This approach, scarcely explored so far, offers key information for describing beach-face geomorphology and understanding its dynamism without the necessity of in-situ data. Given the results obtained it is reasonable to think that shoreline variability may be successfully defined in different coastal types. Such estimation would allow to greatly reduce the temporal and economic cost of data acquisition that is a limiting factor in different branches of coastal characterization and modeling. 



\section{Chapter 7}

\section{Conclusions, management implications and future perspectives}

"El mar limpia, oxigena, el pantano pudre. [...] La orilla del mar no ha sido un lugar hospitalario $y$, excepto en algunos promontorios, ha permanecido desierta hasta hace unos decenios, en que se empezó a edificar en no importa qué sitio. Los nombres de los lugares guardan la memoria de lo que fueron. Barrizales. Charcas. Fangales. Balsas para la explotación de la sal. Mi padre ha sentido especial desprecio por la gente que compra chalets y apartamentos en esos terrenos ganados al pantano. En realidad, ha despreciado a cuantos han llegado a la comarca atraídos por la llamada del mar. Golfos. Aventureros. Especuladores. La costa es un sitio pernicioso, decía. El mar trae o atrae la basura, aquí se instala lo peor."

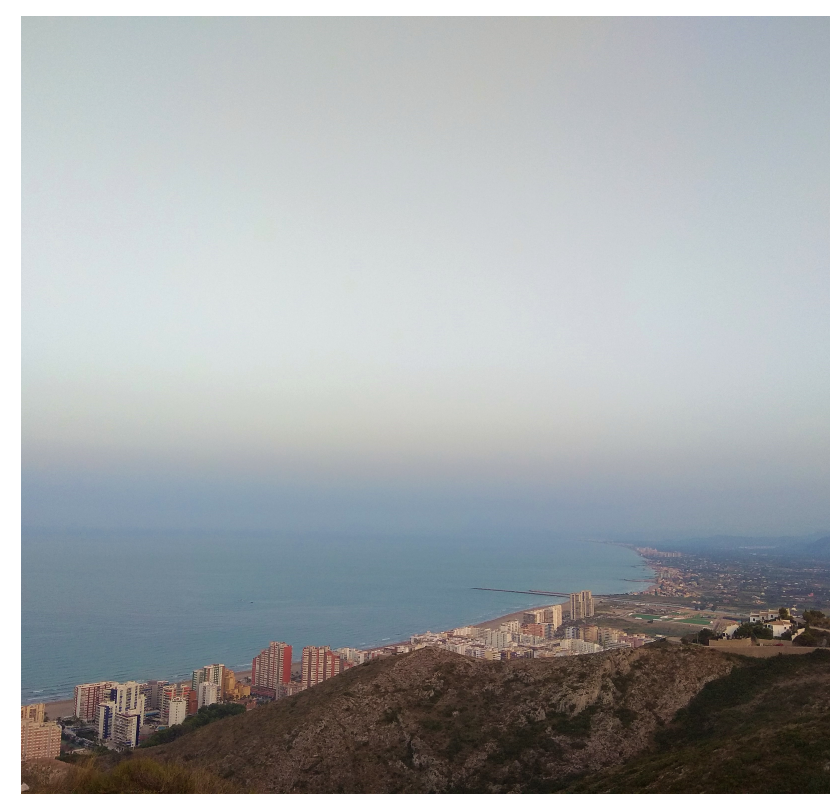

-R. Chirbes- 
This thesis proposes methodologies able to derive from remote sensing useful information to answer questions arising from coastal management. To this end, a whole set of solutions are presented for describing the geomorphology of the beaches and their dynamism along large coastal stretches from the novel sources of information that remote sensing offers. This chapter summarizes the main results together with their implications for coastal management and the associated future research challenges. 


\subsection{The necessity of geomorphological indicators for improving beach management}

In the first place, this research improves the comprehension of the influence of geomorphological characteristics of the beaches on the functions they develop, paying special attention to the recreational one (Chapter 2). The analysis of users' perceptions and preferences at six beaches with different geomorphological characteristics has allowed identifying their role as motivators for choosing a certain beach. Concerning the management, it follows a rigid and homogeneous approach partly due to the lack of enough data regarding users and physical aspects. This scarcity of data impedes to rigorously define the needed actions based on proper criteria and leads to shortsighted decision-making that often damages the environment.

All this evidences that an updated characterization of the geomorphology is essential for supporting an efficient management. Having this in mind, the definition of potential indicators of the beach state becomes particularly important. The successive chapters of this thesis propose methodologies to define geomorphological indicators over space and time. Firstly, SDS extraction methodology is adapted and validated at tidal and exposed coastal environments (Chapter 3). Subsequently, SDS potential to derive useful indicators as beach width for monitoring beach dynamism has been explored (Chapter 4). In turn, beach width datasets have been used to map the effect of the morphology on recreational function (Chapter 5). Finally, the relationship between shoreline variability and grain size has been defined in an attempt to estimate the latter (Chapter $6)$.

\subsection{Adaptation and validation of SDS extraction at different coastal types}

The extraction system SHOREX makes it possible to define large volumes of SDS from midresolution satellite imagery (Palomar-Vázquez et al., 2018). Adopting this methodology as a source of information for beach monitoring requires to carry out tests of the resulting SDS on different typologies of real scenarios. In parallel to the development of extraction methods, tests have been carried out at seawalls, lakes, and microtidal beaches (Table 7.1). However, large SDS datasets on tidal and relatively energetic beaches had not been tested so far. The experiment at Faro Beach has adapted and assessed SDS extraction considering a large variety of oceanographic conditions (Chapter 4). On this coast, SDS offer slightly worse accuracy (4.58 m and $5.77 \mathrm{~m}$ RMSE for Sentinel2 and Landsat- 8 imagery respectively) but of the same order of magnitude than the last assessments at Mediterranean beaches (Sánchez-García et al., 2020). 
Table 7.1. Assessments of SDS from different satellites using SHOREX. Accuracy expressed as RMSE (m).

\begin{tabular}{|c|c|c|c|c|c|c|}
\hline Publication & $\begin{array}{c}\text { Pardo-Pascual } \\
\text { et al., } 2012 \\
\end{array}$ & $\begin{array}{l}\text { Pardo-Pascual } \\
\text { et al., } 2018 \\
\end{array}$ & $\begin{array}{c}\text { Palomar-Vázquez } \\
\text { et al., } 2019 \\
\end{array}$ & $\begin{array}{c}\text { Sánchez-García } \\
\text { et al., } 2019 \\
\end{array}$ & $\begin{array}{l}\text { Sánchez-García } \\
\text { et al., } 2020 \\
\end{array}$ & $\begin{array}{c}\text { Cabezas-Rabadán et } \\
\text { al., } 2020\end{array}$ \\
\hline Location & $\begin{array}{c}\text { Castelló, } \\
\text { Borriana } \\
\text { (Valencia, } \\
\text { Spain) }\end{array}$ & $\begin{array}{l}\text { El Saler } \\
\text { (Valencia, } \\
\text { Spain) }\end{array}$ & $\begin{array}{c}\text { Gallocanta } \\
\text { (Aragón, Spain) }\end{array}$ & $\begin{array}{c}\text { Reñaca } \\
\text { (Central Chile) }\end{array}$ & $\begin{array}{l}\text { Cala Millor } \\
\text { (Mallorca, } \\
\text { Spain) }\end{array}$ & $\begin{array}{c}\text { Faro } \\
\text { (Algarve, Portugal) }\end{array}$ \\
\hline $\begin{array}{l}\text { Type of } \\
\text { coast }\end{array}$ & Seawalls & $\begin{array}{l}\text { Mediterranean } \\
\text { sandy beach }\end{array}$ & Shallow lake & $\begin{array}{l}\text { Pacific sandy } \\
\text { beach }\end{array}$ & $\begin{array}{l}\text { Mediterranean } \\
\text { sandy beach }\end{array}$ & $\begin{array}{l}\text { Exposed Atlantic } \\
\text { sandy beach }\end{array}$ \\
\hline Tide & Microtidal & Microtidal & No & Microtidal & Microtidal & Mesotidal \\
\hline Software & SELI & SELI & SHOREX & SHOREX & SHOREX & SHOREX \\
\hline no. of SDS & 45 & 21 & 1 & 7 & 91 & 24 \\
\hline Reference & Photointerpr. & Photogrammetry & GNSS alongsshore & Photogramm.. & Photogramm. & GNSS cross-shore \\
\hline Acquisition & Ortophotos & Simultaneous & Simultaneous & Simultaneous & Simultaneous & Close dates \\
\hline Sentinel 2 & --- & 6.6 & 4.15 & \multirow{2}{*}{4.55} & 3.01 & 4.58 \\
\hline Landsat 8 & --- & 6.6 & --- & & 3.57 & 5.77 \\
\hline Landsat 5,7 & About 5 & $7.4-8.0$ & --- & --- & --- & --- \\
\hline
\end{tabular}

The experiment quantifies the error of SDS for the first time at exposed and mesotidal coasts, offering an accuracy probably good enough to constitute a useful source of beach-face morphological data. It validates the use of SDS as well as deriving associated indicators at a much larger diversity of coasts. This level of accuracy is substantially higher than that offered by other methodologies. Hagenaars et al. (2018) reported at the microtidal Dutch coast errors (bias $\pm \sigma$ ) of $9.5 \pm 16 \mathrm{~m}$ and $10.5 \pm 12 \mathrm{~m}$ for L8 and S2 images respectively. Liu et al. (2017) achieved at an Australian microtidal beach about $10 \mathrm{~m}$ RMSE when comparing full series of SDS from L5, L7, and L8, and 5.7 m RMSE for annual mean shorelines. More recently, Vos et al. (2019a) reported SDS accuracies ranging between $7.2 \mathrm{~m}$ to $11.6 \mathrm{~m}$ RMSE at four microtidal beaches (Australia, New Zealand, and the USA) and $12.7 \mathrm{~m}$ RMSE at a meso/macrotidal beach in France.

\subsection{Characterization of beach dynamism from SDS}

On its own, SDS may not be the most applicable data for beach managers. The availability of large series of SDS poses the challenge of developing procedures to take advantage of them, as well as deriving other useful morphological indicators. An efficient organization of SDS together with defining the beach width enables defining spatial-temporal models. They offer a very intuitive characterization of the state of the beaches, and a quantification of their changes at different spatial and temporal scales (Chap. 4).

In the medium term, the combination of Landsat 5, 7, and 8 satellite imagery offers historical series covering more than 3 decades. This allows hindsight analysis and trend definition with great robustness sustained on the high availability of data. Their regional scale makes it possible to conduct analyses covering the entirety of sedimentary cells. This is of great help for detecting problems as sedimentary imbalances or scarcity, providing clues to identify their origin as well as possible solutions (Chap. 4, 5). 
In the short term, it is possible to quantify the morphological response of the beach to natural events as storms, or artificial events as sand nourishments, dredgings, or the construction of obstacles to the alongshore transportation. Post-event storm monitoring from remote sensing has recently been approached by videomonitoring, LIDAR, and UAV. However, the repeatability of satellite imagery along wide coastal segments makes it possible to compare the impact and recovery on beaches of the same region (Chap. 4). Concerning human actions, the quantification of the beach dynamism through spatial-temporal models offers essential information for the proper planning of these types of actions. At the same time, these models make it possible to detect and monitor the morphological effect of nourishments of very small magnitude (only $12,830 \mathrm{~m}^{3}$ have been detected in Chap. 4), allowing to verify their effectiveness.

\subsection{Mapping morphological affections to beach functions}

Beach width plays an essential role in the recreational function of beaches by defining their carrying capacity and users' density (Chapter 2). These data are necessary for an efficient management as they condition the number of users that is possible to host and the number of facilities that must be offered.

Given the continuous monitoring of the shoreline position over time (Chap. 4), it is possible to approach the beach state during its most unfavorable episodes throughout the year. Its integration in GIS software with other pre-existing cartographic databases concerning land and beach use enables to map at regional scale the effects of inadequate widths on the recreational function (Chap. 5). This constitutes a direct application of the indicators as it constitutes essential information for the prioritization of management actions.

\subsection{Exploring beach-face geomorphology from SDS variability}

The availability of information regarding the state of the beaches along the coast allows comparing response patterns on nearby beaches. Different shoreline change patterns appear linked to geomorphological differences (Chap. 4). In line with this, large SDS regional datasets may offer a realistic quantification of the shoreline variability along the coast, and subsequently exploring their relationship with beach-face characteristics as sediment size and slope (Chap. 6). The relationship between these factors has been quite accurately described for a large part of the grain-size spectrum through an inverse power-law function. The work proposes estimating sediment grain size from the values of shoreline variability. This would make it possible to characterize from remote sensing an indicator very costly to define by traditional techniques. Although grain size is only been roughly estimated, it still constitutes promising progress considering its influence on the functions of the beach (Chap. 2).

\subsection{Future perspectives \& management implications}

Recently, different works on the dynamism and state of the beaches have been tackled from a global perspective. They have taken advantage of the capacity offered by cloud-computing platforms to organize large sets of satellite images and to sustain efficient and repeatable workflows (e.g. Luijendijk et al., 2018; Mentaschi et al., 2018). These tools represent a paradigm 
shift in terms of the maximum space-time coverage that can be achieved. However, certain studies as the analysis of beach loss phenomena and their future perspectives require an in-depth understanding of particular geomorphological characteristics at local scales (Cooper et al., 2020). The above methodologies have a limited performance at fine spatial scales, in part, due to the moderate level of precision they offer. This issue could be solved by integrating tools for SDS definition at subpixel level as SHOREX with the platform Google Earth Engine as proposed by Vos et al. (2019b). In any case, the definition of large SDS datasets involves the challenge of deriving indicators capable of representing a complex reality in a way simple and intuitive enough for facilitating the management actions.

The methodologies proposed in this thesis offer a precise characterization of the dynamism of the beaches at different spatial and temporal scales along whole sedimentary cells. This could serve as a basis for the implementation of regional monitoring systems, which would cover the current lack of information. All this responds to the need for integrated and regional management of the coast and the beaches based on objective and updated information (Chap. 2). The advances of this work can be also used as support for forecasting purposes, allowing the identification of segments likely to experience erosion. In relation to human interventions on the coast, an efficient short-term monitoring may help the proper planning of the actions. In turn, it also allows quantifying the effects of the interventions along time and space. This is essential in order to assess the real cost-benefit that these actions offer to society. The Administration should encourage surveillance and monitoring programs to verify the effectiveness of this type of actions.

It is important to emphasize that managers and data suppliers should not exclusively focus on favoring recreational function and the protection of human interests. This would mean falling into an anthropocentric view and leaving aside the much-needed ecosystem perspective (Cooper \& Jackson, 2019). Although it has not been approached in this thesis, morphological information derived from shoreline data may be considered for assessing risks to the ecosystems and its functionality. This should take into consideration when prioritizing actions in order to shift towards a more sustainable management of the coast.

The fate of coasts and beaches around the globe is on the one hand linked to climate change, which brings sea-level rising and higher frequency and magnitude of storm events and, on the other hand, to the effect of human actions. Coastal societies are going to have to deal with the consequences of this phenomena. They will have to adapt to them, for which they will have to face important engineering and socioeconomic challenges. High-value conurbations within richer and urban regions may be protected from flood damages by constructing coastal defenses (Vousdoukas et al., 2020b), while rural and poorer territories may be forced to retreat (Hinkel et al., 2018). Despite the enormous economic effort and social impact in the short term, the progressive deconstruction appears on many coasts of the world as the only plausible solution to maintain the beach resource. Thus, beaches without artificial impediments to shoreline migration are not necessarily meant to disappear, but to retreat (Cooper et al., 2020).

In any case, it should not be ignored that erosion phenomena and coastal conflicts associated with beach morphology are already evident worldwide nowadays, greatly threatening the maintenance 
of beach functions. Adaptation and planning strategies and short-term actions must be supported by robust and updated characterization of the coast to minimize the impacts and ensure their effectiveness. Thus it is essential to continue developing and implementing methods to address a holistic understanding of the coastal system, only then will it be possible to make correct diagnoses of the state and the existing problems, and define effective solutions.

\subsection{Key findings}

The key findings of this thesis have been:

1) Certain characteristics as the geomorphological features condition the recreational function of the beach through users' preferences and perceptions. Management actions, of significant economic and environmental cost, are directed to the maintenance of the physical space, without enough data justifying them. Decision-making, usually uniform and rigid, could be improved if it was conducted from a regional scale and sustained in objective and updated information.

2) It is possible to define Satellite-Derived Shorelines from L8 and S2 satellite imagery with high accuracy at different types of coasts, such as mesotidal exposed beaches.

3) Efficient SDS extraction is possible on a regional and medium-term scale. SDS allow characterizing beach state and monitoring the response of the beach to storms and human actions at different spatial and temporal scales.

4) Indicators of the morphological state derived from SDS such as beach width allow mapping segments in which the morphology affects the recreational function.

5) Shoreline variability can be quantified from large SDS datasets. Its relationship with sediment grain size has been defined, offering a rough estimation of the latter.

Overall, this thesis proposes methodologies to derive from remote sensing geomorphological indicators to enhance the management of the beaches. 



\section{References}

Aarninkhof, S. G., Turner, I. L., Dronkers, T. D., Caljouw, M., Nipius, L. (2003). A video-based technique for mapping intertidal beach bathymetry. Coastal Engineering, 49(4), 275-289. https://doi.org/10.1016/S03783839(03)00064-4

Alemany, J. (1984). Estat d'utilització de les platges del litoral català. Barcelona: Departament de Política Territorial i Obres Públiques, Generalitat de Catalunya, Barcelona, 95 pp.

Alexandrakis, G., Manasakis, C., Kampanis, N. A. (2015). Valuating the effects of beach erosion to tourism revenue. A management perspective. Ocean \& Coastal Management, 111, 1-11. https://doi.org/10.1016/j.ocecoaman.2015.04.001

Almonacid-Caballer, J. (2014). Detección subpixel de la línea de costa. PhD thesis. Universitat Politècnica de València. Valencia, 365 pp. http://dx.doi.org/10.1016/j.margeo.2015.12.015

Almonacid-Caballer, J. (2015). Extraction of shorelines with sub-pixel precision from Landsat images (TM, ETM+, OLI). Revista de Teledetección, (43), 97-99.

Almonacid-Caballer, J., Sánchez-García, E., Pardo-Pascual, J. E., Balaguer-Beser, A. A., Palomar-Vázquez, J. (2016). Evaluation of annual mean shoreline position deduced from Landsat imagery as a mid-term coastal evolution indicator. Marine Geology, 372, 79-88. https://doi.org/10.1016/j.margeo.2015.12.015

Almonacid-Caballer, J., Pardo-Pascual, J., Ruiz, L. (2017). Evaluating fourier cross-correlation sub-pixel registration inlandsat images. Remote Sensing, 9(10), 1051.https://doi.org/10.3390/rs9101051

Alves, B., Benavente, J., Ferreira, Ó. (2014). Beach users' profile, perceptions and willingness to pay for beach management in Cadiz (SW Spain. Journal of Coastal Research, 70, 521-526. https://doi.org/10.2112/SI70088.1

Alves, B., Ballester, R., Rigall-I-Torrent, R., Ferreira, Ó., Benavente, J. (2017). How feasible is coastal management? A social benefit analysis of a coastal destination in SW Spain. Tourism Management, 60, 188200. https://doi.org/10.1016/j.tourman.2016.12.004

Amelung, B., Viner, D. (2006). Mediterranean tourism: Exploring the future with the tourism climatic index. Journal of Sustainanle Tourism, 14, 349-366. https://doi.org/10.2167/jost549.0

Aminrad, Z., Zakaria, S.Z.B.S., Hadi, A.S. (2011). Influence of Age and Level of Education on Environmental Awareness and Attitude: Case Study on Iranian Students in Malaysian Universities. The Social Sciences. 6, 15-19. https://doi.org/10.3923/sscience.2011.15.19

Andriolo, U., Almeida, L. P., Almar, R. (2018). Coupling terrestrial LiDAR and video imagery to perform 3D intertidal beach topography. Coastal Engineering, 140, 232-239.

https://doi.org/10.1016/j.coastaleng.2018.07.009

Anfuso, G., Martínez, J. Á. (2009). Assessment of coastal vulnerability through the use of GIS tools in south sicily (Italy). Environmental Management, 43(3), 533-545. https://doi.org/10.1007/s00267-008-9238-8

Angnuureng, D.B., Almar, R., Senechal, N., Castelle, B., Addo, K.A., Marieu, V., Ranasinghe, R. (2017). Shoreline resilience to individual storms and storm clusters on a meso-macrotidal barred beach. Geomorphology 290, 265-276. https://doi.org/10.1016/j.geomorph.2017.04.007 
Anthony, E. J. (2013). Storms, shoreface morphodynamics, sand supply, and the accretion and erosion of coastal dune barriers in the southern North Sea. Geomorphology 199, 8-21. https://doi.org/10.1016/j.geomorph.2012.06.007

Aragonés, L., García-Barba, J., García-Bleda, E., López, I., Serra, J.C. (2015). Beach nourishment impact on Posidonia oceanica: Case study of Poniente Beach (Benidorm, Spain). Ocean Engineering, 107, 1-12. https://doi.org/10.1016/j.oceaneng.2015.07.005

Archetti, R. (2009). Quantifying the Evolution of a Beach Protected by Low Crested Structures Using Video Monitoring. Journal of Coastal Research. Volume 25, Issue 4: pp. 884 - 899. https://doi.org/10.2112/070994.1

Areizaga, J., Sanò, M., Medina, R., Juanes, J. (2012). Improving public engagement in ICZM: A practical $\begin{array}{llll}\text { approach. Journal of Environmental Management, 123-135. } & \text { 109, }\end{array}$ https://doi.org/10.1016/j.jenvman.2012.05.006

Ariza, E., Jiménez, J.A., Sardá, R. (2008a). A critical assessment of beach management on the Catalan coast. Ocean \& Coastal Management. 51, 141-160. https://doi.org/10.1016/j.ocecoaman.2007.02.009

Ariza, E., Sardá, R., Jiménez, J.A., Mora, J., Ávila, C. (2008b). Beyond Performance Assessment Measurements for Beach Management: Application to Spanish Mediterranean Beaches. Coastal Management, 36, 47-66. https://doi.org/10.1080/08920750701682023

Ariza, E., Jiménez, J.A., Sardá, R., Villares, M., Pinto, J., Fraguell, R., Roca, E., Marti, C., Valdemoro, H., Ballester, R., Fluvia, M. (2010). Proposal for an integral quality index for urban and urbanized beaches. Environmental Management, 45, 998-1013. https://doi.org/10.1007/s00267-010-9472-8

Ariza, E. (2011). An analysis of beach management framework in Spain. Study case: the Catalonian coast. Journal of Coastal Conservation 15, 445-455. https://doi.org/10.1007/s11852-010-0135-y

Ariza, E., Jiménez, J.A., Sardá, R. (2012) An Interdisciplinary Analysis of Beach Management in the Catalan Coast (North-Western Mediterranean). Coastal Management 40, 442-459. https://doi.org/10.1080/08920753.2012.692308

Bae, S., Yu, J., Wang, L., Jeong, Y., Kim, J., Yang, D. Y. (2019). Experimental analysis of sand grain size mapping using UAV remote sensing. Remote Sensing Letters, 10(9), 893-902. https://doi.org/10.1080/2150704x.2019.1629713

Ballesteros, C., Jiménez, J. A., Valdemoro, H. I., Bosom, E. (2018). Erosion consequences on beach functions along the Maresme coast (NW Mediterranean, Spain). Natural Hazards, 90(1), 173-195. https://doi.org/10.1007/s11069-017-3038-5

Baptista, P., Bastos, L., Bernardes, C., Cunha, T., Dias, J. (2008). Monitoring sandy shores morphologies by DGPS - a practical tool to generate digital elevation models. Journal of Coastal Research, 1516-1528. https://doi.org/10.2112/07-0861.1

Baptista, P., Cunha, T. R., Gama, C., Bernardes, C. (2012). A new and practical method to obtain grain size measurements in sandy shores based on digital image acquisition and processing. Sedimentary Geology, 282, 294-306. https://doi.org/10.1016/j.sedgeo.2012.10.005

Barbier, E. B., Hacker, S. D., Kennedy, C., Koch, E. W., Stier, A. C., Silliman, B. R. (2011). The value of estuarine and coastal ecosystem services. Ecological monographs, 81(2), 169-193. https://doi.org/10.1890/10-1510.1 
Barnard, P. L., Rubin, D. M., Harney, J., Mustain, N. (2007). Field test comparison of an autocorrelation technique for determining grain size using a digital 'beachball'camera versus traditional methods. Sedimentary Geology, 201(1-2), 180-195. https://doi.org/10.1016/j.sedgeo.2007.05.016

Barragán-Muñoz, J. M. (2010). Coastal management and public policy in Spain. Ocean \& Coastal Management, 53(5-6), 209-217. https://doi.org/10.1016/j.ocecoaman.2010.04.006

Bascom, W. N. (1951). The relationship between sand size and beach-face slope. Eos, Transactions American Geophysical Union, 32(6), 866-874. A GU 32 (6), 866-874. https://doi.org/10.1029/TR032i006p00866

Benedet, L., Finkl, C. W., Klein, A. H. F. (2006). Morphodynamic classification of beaches on the Atlantic coast of Florida: geographical variability of beach types, beach safety and coastal hazards. Journal of Coastal Research, 360-365.

Bernatchez, P., Fraser, C. (2012). Evolution of coastal defence structures and consequences for beach width trends, Québec, Canada. Journal of Coastal Research, 28(6), 1550-1566. https://doi.org/10.2112/JCOASTRESD-10-00189.1

Bird, E. C. F. (1996). Beach management. John Wiley \& Son Ltd. Chichester, UK. 292 pp.

Bird, E. C. F. (2013). Coastal geomorphology: an introduction (2nd ed.). Wiley. New York. 436 pp.

Bishop-Taylor, R., Sagar, S., Lymburner, L., Alam, I., Sixsmith, J. (2019). Sub-pixel waterline extraction: Characterising accuracy and sensitivity to indices and spectra. Remote Sensing, 11(24), 1-23. https://doi.org/10.3390/rs11242984

Boak, E. H., Turner, I. L. (2005). Shoreline definition and detection: a review. Journal of Coastal Research, 688-703. https://doi.org/10.2112/03-0071.1

Bouvier, C., Balouin, Y., Castelle, B. (2017). Video monitoring of sandbar-shoreline response to an offshore submerged structure at a microtidal beach. Geomorphology, 295, 297-305. https://doi.org/10.1016/j.geomorph.2017.07.017

Bramwell, B. (2011). Governance, the state and sustainable tourism: A political economy approach. Journal of Sustainable Tourism. 19, 459-477. https://doi.org/10.1080/09669582.2011.576765

Brasington, J., Vericat, D., Rychkov, I. (2012). Modeling river bed morphology, roughness, and surface sedimentology using high resolution terrestrial laser scanning. Water Resources Research, 48(11). https://doi.org/10.1029/2012wr012223

Breton, F.E.A., Clapés, J., Marquès, A., Priestley, G.K. (1996). The recreational use of beaches and consequences for the development of new trends in management: the case of the beaches of the Metropolitan Region of Barcelona (Catalonia, Spain). Ocean \& Coastal Management. 32, $153-180$. https://doi.org/10.1016/S0964-5691(96)00032-4

Brooks, S. (2020). Disappearing beaches. Nature Climate Change, 10, $188-190$. https://doi.org/10.1038/s41558-019-0656-9

Brown A.C., McLachlan A. (2002) Sandy shore ecosystems andthe threats facing them: some predictions for the year 2025.Environmental Conservation,29, 62-77 
Bujan, N., Cox, R., Masselink, G. (2019). From fine sand to boulders: Examining the relationship between beach-face slope and sediment size. Marine Geology, 417, 106012. https://doi.org/10.1016/j.margeo.2019.106012

Burvingt, O., Masselink, G., Russell, P., Scott, T. (2017). Classification of beach response to extreme storms. Geomorphology, 295, 722-737. https://doi.org/10.1016/j.geomorph.2017.07.022

Buscombe, D., Masselink, G. (2009). Grain-size information from the statistical properties of digital images of sediment. Sedimentology, 56(2), 421-438. https://doi.org/10.1111/j.1365-3091.2008.00977.x

Buscombe, D., Rubin, D. M., Lacy, J. R., Storlazzi, C. D., Hatcher, G., Chezar, H., Wyland, R., Sherwood, C. R. (2014). Autonomous bed-sediment imaging-systems for revealing temporal variability of grain size. Limnology and Oceanography: Methods, 12(6), 390-406. https://doi.org/10.4319/lom.2014.12.390

Cabezas-Rabadán, C. (2015). Análisis de la línea de costa y su relación con los parámetros morfológicos en playas de la Safor. Master thesis. Universitat de València, València. 105 pp. Retrieved from https://gvacartografic.wordpress.com/2016/12/15/analisis-de-la-linea-de-costa-y-su-relacion-con-losparametros-morfologicos/

Cabezas-Rabadán, C., Almonacid-Caballer, J., Pardo-Pascual, J.E., Soriano-González, J. (2017). Variabilidad de la línea de costa a partir de imágenes de satélite y su relación con la textura del sedimento. I Congress in Geomatics Engineering, 5-6 July, Valencia. https://doi.org/10.4995/CIGeo2017.2017.6628

Cabezas-Rabadán, C., Pardo-Pascual, J.E. (2017). Monitorizando la anchura de las playas mediante imágenes Landsat 8 en costas micromareales mediterráneas. Geo-Temas 17, 159-162.

Cabezas-Rabadán, C., Pardo-Pascual, J.E., Palomar-Vázquez, J., Almonacid-Caballer, J., Fernández-Sarría, A. (2018). La posición de la línea de costa extraída de imágenes satelitales como herramienta de seguimiento y análisis de cambios en playas mediterráneas. In: López-García, et al. (eds.), XVIII Congreso Nacional de Tecnologías de La Información Geográfica. Departament de Geografia. Universitat de València, València, pp. 36-46.

Cabezas-Rabadán, C., Rodilla, M., Pardo-Pascual, J. E., Herrera-Racionero, P. (2019a). Assessing users' expectations and perceptions on different beach types and the need for diverse management frameworks along the Western Mediterranean. Land Use Policy, 81, 219-231. https://doi.org/10.1016/j.landusepol.2018.10.027

Cabezas-Rabadán, C., Pardo-Pascual, J. E., Palomar-Vázquez, J. M., Fernández-Sarría, A. (2019b). Characterizing beach changes using high-frequency Sentinel-2 derived shorelines on the Valencian coast (Spanish Mediterranean). Science of The Total Environment, 691, 216-231. https://doi.org/10.1016/j.scitotenv.2019.07.084

Cabezas-Rabadán, C., Pardo-Pascual, J.E., Palomar-Vázquez, J., Almonacid-Caballer, J., Fernández-Sarría, A. (2019c). Monitorización de la respuesta de playas Mediterráneas a temporales y actuaciones antrópicas mediante imágenes Landsat. GeoFocus. № 23. http://dx.doi.org/10.21138/GF.640

Cabezas-Rabadán, C., Pardo-Pascual, J. E., Almonacid-Caballer, J., Rodilla, M. (2019d). Detecting problematic beach widths for the recreational function along the Gulf of Valencia (Spain) from Landsat 8 subpixel shorelines. Applied Geography, 110. https://doi.org/10.1016/j.apgeog.2019.102047 
Cabezas-Rabadán, C., Pardo-Pascual, J.E., Palomar-Vázquez, J., Fernández-Sarría. A. (2019e) Análisis y caracterización de cambios en playas valencianas mediante líneas de costa derivadas de Sentinel-2. In: Durán, R., et al. (Eds.) X Jornadas de Geomorfología Litoral, 4-6 Sep., Castelldefels

Cabezas-Rabadán, C., Pardo-Pascual, J.E., Palomar-Vázquez, J., Ferreira, Ó., Costas, S. (2020). Satellite derived shorelines at an exposed meso-tidal beach. In: Malvárez, G. and Navas, F. (eds.), Global Coastal Issues of 2020. Journal of Coastal Research, SI 95, 1027-1031. Coconut Creek (Florida), ISSN 0749-0208. https://doi.org/10.2112/S195-200.1

Camarero, L., (2006). Medio ambiente y sociedad: elementos de explicación sociológica. Thompson, Madrid. Cambrils-Camarena, J.C., Nácher Escriche, J.M. (2005). Reposicionamiento en destinos maduros: El caso de Gandía. Estudios Turísticos 166, 115-131.

Capacci, S., Scorcu, A.E., Vici, L. (2015). Seaside tourism and eco-labels: The economic impact of Blue Flags. Tourism Management 47, 88-96. https://doi.org/10.1016/j.tourman.2014.09.003

Carter, R. W. G. (1988). Coastal Environments. An Introduction to the Physical, Ecological and Cultural Systems of Coastlines. Academic Press. London. 617 p

Casella, E., Rovere, A., Pedroncini, A., Stark, C. P., Casella, M., Ferrari, M., Firpo, M. (2016). Drones as tools for monitoring beach topography changes in the Ligurian Sea (NW Mediterranean). Geo-Marine Letters, 36(2), 151-163. https://doi.org/10.1007/s00367-016-0435-9

Castelle, B., Marieu, V., Bujan, S., Splinter, K. D., Robinet, A., Sénéchal, N., Ferreira, S. (2015). Impact of the winter 2013-2014 series of severe Western Europe storms on a double-barred sandy coast: Beach and dune erosion and megacusp embayments. Geomorphology, 238, 135-148. https://doi.org/10.1016/j.geomorph.2015.03.006

CEDEX, Centro de Estudios y Experimentación de Obras Públicas (2000). Desarrollo de metodología para la evaluación de la calidad de las aguas y arenas en zonas deC58:C63 baño. Madrid, 116 pp.

Cenci, L., Disperati, L., Persichillo, M. G., Oliveira, E. R., Alves, F. L., Phillips, M. (2017). Integrating remote sensing and GIS techniques for monitoring and modeling shoreline evolution to support coastal risk management. GIScience Remote Sensing, 55(3), 1-21. https://doi.org/10.1080/15481603.2017.1376370

Cervantes, O., Espejel, I., Arellano, E., Delhumeau, S. (2008). Users' perception as a tool to improve urban beach planning and management. Environental Management. 42, 249-264. https://doi.org/10.1007/s00267008-9104-8

Chen, W.W., Chang, H.K. (2009). Estimation of shoreline position and change from satellite images considering tidal variation. Estuarine, Coastal and Shelf Science, 84(1), 54-60. https://doi.org/10.1016/j.ecss.2009.06.002

Chen, C.L., Teng, N. (2016). Management priorities and carrying capacity at a high-use beach from tourists' perspectives: A way towards sustainable beach tourism. Marine Policy 74, $213-219$. https://doi.org/10.1016/j.marpol.2016.09.030

Cifuentes, M. (1992). Determinación de capacidad de carga turística en áreas protegidas. Costa Rica: Biblioteca Orton IICA/CATIE. 
CMA, Conselleria de Agricultura, Medio Ambiente, Cambio Climático y Desarrollo Rural. (2015). Espacios protegidos Red Natura 2000. Generalitat Valenciana. [WWW Document]. URL http://www.agroambient.gva.es/web/espacios-protegidos/espacios-red-natura-2000 (accessed 2.3.18).

Cocozza, C., Parente, A., Zaccone, C., Mininni, C., Santamaria, P., Miano, T. (2011). Comparative management of offshore posidonia residues: Composting vs. energy recovery. Waste Management, 31, 78-84. https://doi.org/10.1016/j.wasman.2010.08.016

Cooke, B. C., Jones, A. R., Goodwin, I. D., Bishop, M. J. (2012). Nourishment practices on Australian sandy beaches: a review. Journal of environmental management, 113, 319-327. https://doi.org/10.1016/j.jenvman.2012.09.025

Cooper, J. A. G., McKenna, J. (2008). Social justice in coastal erosion management: The temporal and spatial dimensions. Geoforum, 39(1), 294-306. https://doi.org/10.1016/j.geoforum.2007.06.007

Cooper, A., Jackson, D. W. (2019). Coasts in peril? A shoreline health perspective. Frontiers in Earth Science, 7, 1-8. https://doi.org/10.3389/feart.2019.00260

Cooper, A., Masselink, G., Coco, G., Short, A., Castelle, B., Rogers, K., Green, A.N, Kelley, J.T, Pilkey, O.H, Jackson, D. (2020). Sandy beaches can survive sea-level rise. Preprint in EarthArXiv https://doi.org/10.31223/osf.io/4md6e

Costa, M., Silva, R. and Vitorino, J. (2001). Contribuição para o estudo do clima de agitação marítima na costa portuguesa. In: 2as Jornadas Portuguesas Engenharia Costeira e Portuária. International Navigation Association

CREM. (2000). Feasibility and Market Study for a European Eco-Label for Tourist Accommodations (FEMATOUR). Amsterdam.

Davidson, M., Van Koningsveld, M., de Kruif, A., Rawson, J., Holman, R., Lamberti, A., Aarninkhof, S. (2007). The CoastView project: Developing video-derived Coastal State Indicators in support of coastal zone management. Coastal Engineering, 54(6-7), 463-475. https://doi.org/10.1016/j.coastaleng.2007.01.007

Davidson-Arnott R.G.D. (2010). Introduction to coastal process-es and geomorphology. United States of America by Cam-bridge University Press, New York.

Dean, R. G. (1973). Heuristic models of sand transport in the surf zone. In First Australian Conference on Coastal Engineering, 1973: Engineering Dynamics of the Coastal Zone (p. 215). Institution of Engineers, Australia.

Defeo, O., McLachlan, A., Schoeman, D. S., Schlacher, T. A., Dugan, J., Jones, A., Scapini, F. (2009). Threats to sandy beach ecosystems: A review. Estuarine, Coastal and Shelf Science. https://doi.org/10.1016/j.ecss.2008.09.022

DeRuick, Soares, McLachlan, De Ruyck, M.C., Soares, A.G., Mclachlan, A. (1997). Social Carrying Capacity as a Management Tool for Sandy Beaches. Journal of Coastal Research, 13, 822-830.

Díaz-Almela, E., Duarte, C.M. (2008). Management of Natura 2000 habitats. Posidonia beds (Posidonion oceanicae). European Commission.

Do, A. T., de Vries, S., Stive, M. J. (2018). The Estimation and Evaluation of Shoreline Locations, ShorelineChange Rates, and Coastal Volume Changes Derived from Landsat Images. Journal of Coastal Research. 
Dolan, R., Hayden, B., Heywood, J. (1978). Analysis of coastal erosion and storm surge hazards. Coastal Engineering, 2, 41-53. https://doi.org/10.1016/0378-3839(78)90004-2

Dolan, R., Davis, R.E., (1992). An intensity scale for Atlantic coast northeast storms. Journal of Coastal Research, 8, 352-364

Dolch, T., Schernewski, G. (2002). Eutrophication by the Oder River: implications for tourism and sustainable development of the coastal zone, in: Proceedings of the 2nd International Conference on Sustainable Management of Transboundary Waters in Europe. Miedzyzdroje, Poland, pp. 301-304.

Dorsch, W., Newland, T., Tassone, D., Tymons, S., Walker, D. (2008). A Statistical Approach to Modelling the Temporal Patterns of Ocean Storms. Journal of Coastal Resarch, 246, 1430-1438. https://doi.org/10.2112/070847.1

Duarte, C.M. (2004). How can beaches be managed with respect to seagrass litter? European seagrasses: an introduction to monitoring and management, pp. 83-84.

Dugdale, S. J., Carbonneau, P. E., Campbell, D. (2010). Aerial photosieving of exposed gravel bars for the rapid calibration of airborne grain size maps. Earth Surface Processes and Landforms: The Journal of the British Geomorphological Research Group, 35(6), 627-639. https://doi.org/10.1002/esp.1936

EC, European Comission. (2004). Living with coastal erosion in Europe: Sediment and Space for Sustainability: PART I - Major findings and Policy Recommendations of the EUROSION project. Directorate General Environmen. Luxembourg. 40 pp.

EC, European Comission. (2009). The Economics of Climate Change Adaptation in EU Coastal Areas. Policy Research Corporation, Spain, 15 pp. (accessed 05.09.2018). Retrieved from: https://ec.europa.eu/maritimeaffairs/sites/maritimeaffairs/files/docs/body/spain_en.pdf

ECOLEVANTE, 2010. Estudio ecocartográfico del litoral de las provincias de Alicante y Valencia. Dirección General de Costas (España).

Farris, A. S., List, J. H. (2007). Shoreline change as a proxy for subaerial beach volume change. Journal of Coastal Research, 23(3 (233)), 740-748. https://doi.org/10.2112/05-0442.1

Feagin, R. A., Sherman, D. J., Grant, W. E. (2005). Coastal erosion, global sea-level rise, and the loss of sand dune plant habitats. Frontiers in Ecology and the Environment, 3(7), 359-364. https://doi.org/https://doi.org/10.1890/1540-9295(2005)003[0359:CEGSRA]2.0.CO;2

Fernández-Sarría, A., Pardo-Pascual, J.E., Palomar-Vázquez, J., Almonacid-Caballer, J., Cabezas-Rabadán., C. (2018). Cartografiado y cuantificación de los cambios morfológicos en las dunas de Oliva usando LiDAR y fotogrametría automatizada desde UAV. XVIII Congreso Nacional de TIG, 20-22 Jun., València.

Ferreira, Ó., (2006). The role of storm groups in the erosion of sandy coasts. Earth Surface Processes and Landforms. https://doi.org/10.1002/esp.1378

Finkl, C.W., Walker, H.J. (2004). Beach nourishment. M. Schwartz (Ed.), The encyclopedia of coastal science, Kluwer Academic, Dordrecht, The Netherlands, pp. 37-54

Fish, M. R., Côté, I. M., Gill, J. A., Jones, A. P., Renshoff, S., Watkinson, A. R. (2005). Predicting the impact of sea-level rise on Caribbean sea turtle nesting habitat. Conservation Biology, 19(2), 482-491. https://doi.org/10.1111/j.1523-1739.2005.00146.x 
Fleiss, J.L., Levin, B., Paik, M.C. (2004). Statistical Methods for Rates and Proportions. Technometrics 46, 263264. https://doi.org/10.1002/0471445428

Flemming, B. W. (2011). Geology, Morphology, and Sedimentology of Estuaries and Coasts. In: Treatise on Estuarine and Coastal Science. Academic Press, Waltham, pp. 7-38. https://doi.org/10.1016/B978-0-12$374711-2.00302-8$

Folk, R. L., Ward, W. C. (1957). Brazos River bar [Texas]; a study in the significance of grain size parameters. Journal of Sedimentary Research, 27(1), 3-26.

Foody, G.M., Muslim, A.M., Atkinson, P. M. (2005). Super-resolution mapping of the waterline from remotely sensed data. International Journal of Remote Sensing, 26(24), 5381-5392. https://doi.org/10.1080/01431160500213292

Foody, G.M., Muslim, A.M., Atkinson, P.M. (2003). Superresolution mapping of the shoreline through soft classification analyses. IEEE Transactions on Geoscience and Remote Sensing, 3429-3431.

Ford, M. (2013). Shoreline changes interpreted from multi-temporal aerial photographs and high resolution satellite images: Wotje Atoll, Marshall Islands. Remote Sensing of Environment, 135, 130-140. https://doi.org/10.1016/j.rse.2013.03.027

Gallagher, E. L., MacMahan, J., Reniers, A. J. H. M., Brown, J., Thornton, E. B. (2011). Grain size variability on a rip-channeled beach. Marine Geology, 287(1-4), 43-53. https://doi.org/10.1016/j.margeo.2011.06.010

Gault, J., O'Hagan, A. M., Cummins, V., Murphy, J., Vial, T. (2011). Erosion management in Inch beach, South West Ireland. Ocean \& Coastal Management, 54(12), 930-942.

https://doi.org/10.1016/j.ocecoaman.2011.05.005

Gens, R. (2010). Remote sensing of coastlines: detection, extraction and monitoring. International Journal of Remote Sensing, 31(7), 1819-1836. https://doi.org/10.1080/01431160902926673

Ghosh, M. K., Kumar, L., Roy, C. (2015). Monitoring the coastline change of Hatiya Island in Bangladesh using remote sensing techniques. ISPRS Journal of Photogrammetry and Remote Sensing, 101, 137-144. https://doi.org/10.1016/j.isprsjprs.2014.12.009

Giardino, A., Santinelli, G., Vuik, V. (2014). Coastal state indicators to assess the morphological development of the Holland coast due to natural and anthropogenic pressure factors. Ocean and Coastal Management, 87, 93-101. https://doi.org/10.1016/j.ocecoaman.2013.09.015

Gonçalves, J. A., Henriques, R. (2015). UAV photogrammetry for topographic monitoring of coastal areas. ISPRS Journal of Photogrammetry and Remote Sensing, 104, 101-111. https://doi.org/10.1016/j.isprsjprs.2015.02.009

Gopalakrishnan, S., Smith, M. D., Slott, J. M., Murray, A. B. (2011). The value of disappearing beaches: A hedonic pricing model with endogenous beach width. Journal of Environmental Economics and Management, 61(3), 297-310. https://doi.org/10.1016/j.jeem.2010.09.003

Gormsen, E. (1997). The impact of tourism on coastal areas. GeoJournal, 42(1), 39-54. https://doi.org/10.1023/A:1006840622450

Gössling, S., Hall, C.M. (2006). Uncertainties in predicting tourist flows under scenarios of climate change. Clim. Change 79, 163-173. https://doi.org/10.1007/s10584-006-9081-y 
Guariglia, A., Buonamassa, A., Losurdo, A., Saladino, R., Trivigno, M. L., Zaccagnino, A., Colangelo, A. (2006). A multisource approach for coastline mapping and identification of shoreline changes. Annals of Geophysics, 49 (1). https://doi.org/10.4401/ag-3155

Guillén, J., Stive, M. J. F., Capobianco, M. (1999). Shoreline evolution of the Holland coast on a decadal scale. Earth Surface Processes and Landforms: The Journal of the British Geomorphological Research Group, 24(6), 517-536. https://doi.org/10.1002/(SICI)1096-9837(199906)24:6<517::AID-ESP974>3.0.CO;2-A

Guizar-Sicairos, M., Thurman, S. T., Fienup, J. R. (2008). Efficient subpixel image registration algorithms. Optics Letters, 33(2), 156-158. http://dx.doi.org/10.1364/OL.33.000156

GVA, Generalitat Valenciana (2018). Territorial Action Plan for Green Coastal Infrastructure of the Valencian region (PATIVEL) (2018). Generalitat Valenciana (Spain). Valencian Decree 58/2018. DOGV 11.05.2018

Hagenaars, G., de Vries, S., Luijendijk, A. P., de Boer, W. P. Reniers, A. J. H. M. (2018). On the accuracy of automated shoreline detection derived from satellite imagery: A case study of the Sand Motor mega-scale nourishment. Coastal Engineering, 133: 113-125 https://doi.org/10.1016/j.coastaleng.2017.12.011

Halkos, G., Matsiori, S. (2012). Determinants of willingness to pay for coastal zone quality improvement. J. Socio. Econ. 41, 391-399. https://doi.org/10.1016/j.socec.2012.04.010

Hansen, G., Stone, D., Auffhammer, M., Huggel, C., Cramer, W. (2016). Linking local impacts to changes in climate: a guide to attribution. Reg. Environ. Change 16, 527-541. Hansen, G., Stone, D., Auffhammer, M., Huggel, C., Cramer, W. (2016). Linking local impacts to changes in climate: a guide to attribution. Regional Environmental Change 16, 527-541. doi: 10.1007/s10113-015-0760-y

Hansen, J. E., Barnard, P. L. (2010). Sub-weekly to interannual variability of a high-energy shoreline. Coastal Engineering, 57(11-12), 959-972. https://doi.org/10.1016/j.coastaleng.2010.05.011

Hanson, H., Brampton, A., Capobianco, M., Dette, H.H., Hamm, L., Laustrup, C., Lechuga, A., Spanhoff, R. (2002). Beach nourishment projects, practices, and objectives - A European overview. Coastal Engineering, 47(2), 81-111. https://doi.org/10.1016/S0378-3839(02)00122-9

Hinkel, J., Aerts, J. C., Brown, S., Jiménez, J. A., Lincke, D., Nicholls, R. J., Addo, K. A. (2018). The ability of societies to adapt to twenty-first-century sea-level rise. Nature Climate Change, 8(7), 570-578. https://doi.org/10.1038/s41558-018-0176-z

Hinkel, J., Nicholls, R. J., Tol, R. S. J. J., Wang, Z. B., Hamilton, J. M., Boot, G., Klein, R. J. T. T. (2013). A global analysis of erosion of sandy beaches and sea-level rise: An application of DIVA. Global and Planetary Change, 111, 150-158. https://doi.org/10.1016/j.gloplacha.2013.09.002

Heritage, G. L., \& Milan, D. J. (2009). Terrestrial laser scanning of grain roughness in a gravel-bed river. Geomorphology, 113(1-2), 4-11. https://doi.org/10.1016/j.geomorph.2009.03.021

Holland, K.T. Elmore, P.A. (2008). A review of heterogeneous sediments in coastal environments. EarthScience Reviews, 89(3-4),116-134. https://doi.org/10.1016/j.earscirev.2008.03.003

Holman, R.A., Sallenger Jr, A.H., Lippmann, T.C.D., Haines, J.W. (1993). The application of video image processing to the study of nearshore processes. Oceanography 6 (3), 78-85

Houston, J. R. (1996). Beach fill design. In P. L.-F. Liu (Ed.), Advances in Coastal and Ocean Engineering (pp. 199-230). Cornell. https://doi.org/10.1142/9789812797575_0005 
Huisman, B. J. A., De Schipper, M. A., Ruessink, B. G. (2016). Sediment sorting at the Sand Motor at storm and annual time scales. Marine Geology, 381, 209-226. https://doi.org/10.1016/j.margeo.2016.09.005

IGN,Instituto Geográfico Nacional (2011). SIOSE 2011.

IGN,Instituto Geográfico Nacional (2015). Plan Nacional de Ortofoto Aérea (PNOA)

IPCC. Intergovernmental Panel on Climate Change (2014). Climate Change 2014: Synthesis Report. Contribution of Working Groups I, II and III to the Fifth Assessment Report of the Intergovernmental Panel on Climate Change. In R. K. Meyer L. A. Pachauri (Eds.) (p. 151). Geneva, Switzerland.

James, R.J. (2000). From beaches to beach environments: Linking the ecology, human-use and management of beaches in Australia. Ocean \& Coastal Management. 43, 495-514. https://doi.org/10.1016/S09645691(00)00040-5

Jara, M. S., González, M., Medina, R. (2015). Shoreline evolution model from a dynamic equilibrium beach profile. Coastal Engineering, 99, 1-14. https://doi.org/10.1016/j.coastaleng.2015.02.006

Jaramillo, C., Sánchez-García, E., Jara, M. S., González, M., \& Palomar-Vázquez, J. M. (2020). Subpixel Satellite-Derived Shorelines as Valuable Data for Equilibrium Shoreline Evolution Models. Journal of Coastal Research.

Jiménez, J. A, Sánchez-Arcilla, A. (2001). Estudio sobre el estado de la Platja de sa Riera. Technical Report, Laboratori d'Enginyeria Maritima, UPC, Barcelona.

Jiménez, J. A., Gracia, V., Valdemoro, H. I., Mendoza, E. T., Sánchez-Arcilla, A., Tonatiuh Mendoza, E., Sánchez-Arcilla, A. (2011). Managing erosion-induced problems in NW Mediterranean urban beaches. Ocean and Coastal Management, 54(12), 907-918. https://doi.org/10.1016/j.ocecoaman.2011.05.003

Jiménez, J. A., Valdemoro, H. I., Bosom, E., Sánchez-Arcilla, A. Nicholls, R. J. (2017). Impacts of sea-level riseinduced erosion on the Catalan coast. Regional Environmental Change, 17, 593-603. https://doi.org/10.1007/s10113-016-1052-x

Jones, B. M., Arp, C. D., Jorgenson, M. T., Hinkel, K. M., Schmutz, J. A., Flint, P. L. (2009). Increase in the rate and uniformity of coastline erosion in Arctic Alaska. Geophysical Research Letters, 36(3). https://doi.org/10.1029/2008GL036205

Julià, T. (2003). El temporal de mar de noviembre de 2001 y sus efectos en el litoral catalán. Universitat Politècnica de Catalunya. Dept. d'Enginyeria Hidràulica, Marítima i Ambiental.

Karunarathna, H., Pender, D., Ranasinghe, R., Short, A.D., Reeve, D.E. (2014). The effects of storm clustering on beach profile variability. Marine Geology. https://doi.org/10.1016/j.margeo.2013.12.007

Katsanevakis, S. et al. (2011). Ecosystem-based marine spatial management: Review of concepts, policies, tools, and critical issues. Ocean \& Coastal Management. 54, 807-820. https://doi.org/10.1016/j.ocecoaman.2011.09.002

Kim, H., Hall, K., Jin, J.-Y., Park, G.-S., Lee, J. (2014). Empirical estimation of beach-face slope and its use for warning of berm erosion. Journal of Measurements in Engineering 2 (1), $29-42$.

Kim, K. L., Kim, B. J., Lee, Y. K., Ryu, J. H. (2019). Generation of a large-scale surface sediment classification map using unmanned aerial vehicle (UAV) data: A case study at the Hwang-do tidal flat, Korea. Remote Sensing, 11(3), 229. https://doi.org/10.3390/rs11030229 
Klein, R. J., Smit, M. J., Goosen, H., Hulsbergen, C. H. (1998). Resilience and vulnerability: coastal dynamics or Dutch dikes?. Geographical Journal, 259-268. https://doi.org/10.2307/3060615

Koutrakis, E., Sapounidis, A., Marzetti, S., Marin, V., Roussel, S., Martino, S., Fabiano, M., Paoli, C., Rey-Valette, H., Povh, D., Malvárez, C.G. (2011). ICZM and coastal defence perception by beach users: Lessons from the Mediterranean coastal area. Ocean \& Coastal Management. 54, 821-830. https://doi.org/10.1016/j.ocecoaman.2011.09.004

Lastra, M., de La Huz, R., Sánchez-Mata, A. G., Rodil, I. F., Aerts, K., Beloso, S., López, J. (2006). Ecology of exposed sandy beaches in northern Spain: environmental factors controlling macrofauna communities. Journal of Sea Research, 55(2), 128-140. https://doi.org/10.1016/j.seares.2005.09.001

Le Cozannet, G., Oliveros, C., Brivois, O., Giremus, A., Garcin, M., \& Lavigne, F. (2020). Detecting Changes in European Shoreline Evolution Trends Using Markov Chains and the Eurosion Database. Frontiers in Marine Science, 7, 326. https://doi.org/10.3389/fmars.2020.00326

Leatherman, S. P., Zhang, K., Douglas, B. C. (2000). Sea-level rise shown to drive coastal erosion. EOS Transactions, 81, 55-57.

Li, W., Gong, P. (2016). Continuous monitoring of coastline dynamics in western Florida with a 30-year time series of Landsat imagery. Remote Sensing of Environment, 179, 196-209. https://doi.org/10.1016/j.rse.2016.03.031

Li, J., Roy, D. (2017). A Global Analysis of Sentinel-2A, Sentinel-2B and Landsat-8 Data Revisit Intervals and Implications for Terrestrial Monitoring. Remote Sensing, 9(9), 902. https://doi.org/10.3390/rs9090902

Liu, Q., Trinder, J., Turner, I. (2016). A comparison of sub-pixel mapping methods for coastal areas. ISPRS Annals. 2016, 3, 67-74. https://doi.org/10.5194/isprs-annals-iii-7-67-2016

Liu, Q., Trinder, J., Turner, I. (2017). Automatic super-resolution shoreline change monitoring using Landsat archival data: A case study at Narrabeen-Collaroy Beach, Australia. Journal of Applied Remote Sensing, 11 https://doi.org/10.1117/1.jrs.11.016036

López-del-Pino, F., Grisolía, J.M. (2017). Pricing Beach Congestion: An analysis of the introduction of an access fee to the protected island of Lobos (Canary Islands). Tourism Economics. 24, 449-472. https://doi.org/10.1177/1354816617740065

López-Olivares, D. (2003). La evaluación de los recursos territoriales turísticos de carácter básico: El caso de las playas del norte de la Comunidad Valenciana. Investigaciones Geográficas 32, 111-135. https://doi.org/10.14198/INGEO2003.32.04

Lozoya, J.P., Sardá, R., Jiménez, J.A. (2011). A methodological framework for multi-hazard risk assessment in beaches. Environmental Science and Policy, 14(6), 685-696. https://doi.org/10.1016/j.envsci.2011.05.002

Lozoya, J.P., Sardá, R., Jiménez, J.A. (2014). Users expectations and the need for differential beach management frameworks along the Costa Brava: Urban vs. natural protected beaches. Land use policy 38, 397-414. https://doi.org/10.1016/j.landusepol.2013.12.001

Lubczonek, J. (2017). Application of Sentinel-1 imageries for shoreline extraction. In 2017 18th International Radar Symposium (IRS) (pp. 1-9). IEEE. 
Lucrezi, S., Saayman, M. (2014). Beachgoers' Demands vs . Blue Flag Aims in South Africa. Journal of Coastal Research. 316, 1478-1488. https://doi.org/10.2112/JCOASTRES-D-14-00062.1

Lucrezi, S., Saayman, M., Van der Merwe, P. (2015). Managing beaches and beachgoers: Lessons from and for the Blue Flag award. Tourism Management. 48, 211-230. https://doi.org/10.1016/j.tourman.2014.11.010

Lucrezi, S., Saayman, M., Van der Merwe, P. (2016). An assessment tool for sandy beaches: A case study for integrating beach description, human dimension, and economic factors to identify priority management issues. Ocean \& Coastal Management, 121, 1-22. https://doi.org/10.1016/j.ocecoaman.2015.12.003

Ludka, B.C., Guza, R.T., O'Reilly, W.C., (2018). Nourishment evolution and impacts at four southern California beaches: A sand volume analysis. Coastal Engineering. https://doi.org/10.1016/j.coastaleng.2018.02.003

Luijendijk, A., Hagenaars, G., Ranasinghe, R., Baart, F., Donchyts, G., Aarninkhof, S. (2018). The State of the World's Beaches. Scientific reports, 8.

MAGRAMA, Ministerio de Agricultura, Alimentación y Medio Ambiente. (2007). Estudio ecocartográfico del litoral de las provincias de Alicante y Valencia. Retrieved from http://www.mapama.gob.es/es/costas/temas/proteccion-costa/ecocartografias/ecocartografiavalencia.aspx

Manzo, C., Valentini, E., Taramelli, A., Filipponi, F., Disperati, L. (2015). Spectral characterization of coastal sediments using field spectral libraries, airborne hyperspectral images and topographic LiDAR data (FHyL). International Journal of Applied Earth Observation and Geoinformation, 36, 54-68. https://doi.org/10.1016/j.jag.2014.11.003

MAPAMA, Ministerio de Agricultura y Pesca, Alimentación y Medio Ambiente (2017) Catálogo de playas [WWW Document]. URL http://www.mapama.gob.es/es/cartografia-y-sig/ide/descargas/costas-mediomarino/guia-playas-descargas.aspx (accessed 2.3.18).

Marchand, M. (2010). Concepts and Science for Coastal Erosion Management. Concise report for policy makers. Deltares, Delft. 2010

Marchand, M., Sanchez-Arcilla, A., Ferreira, M., Gault, J., Jiménez, J. A., Markovic, M., Sutherland, J. (2011). Concepts and science for coastal erosion management-An introduction to the Conscience framework. Ocean \& Coastal Management, 54(12), 859-866. https://doi.org/10.1016/j.ocecoaman.2011.06.005

Marin, V., Palmisani, F., Ivaldi, R., Dursi, R., Fabiano, M. (2009). Users' perception analysis for sustainable beach management in Italy. Ocean \& Coastal Management. 52, 268-277. https://doi.org/10.1016/j.ocecoaman.2009.02.001

Martin, K. L., Adams, L. C. (2020). Effects of Repeated Sand Replenishment Projects on Runs of a BeachSpawning Fish, the California Grunion. Journal of Marine Science and Engineering, 8(3), 178.

Mas-Parera, L., Blázquez-Salom, M. (2005). Anàlisi de la freqüentació d'ús a les platges i estudi de paràmetres de sostenibilitat associats. Doc. d'Analisi Geogr. 15-40.

Masselink, G., Short, A. D. (1993). The effect of tide range on beach morphodynamics and morphology: a conceptual beach model. Journal of coastal research, 785-800.

McKenna, J., Williams, A.T., Cooper, J.A.G. (2011). Blue Flag or Red Herring: Do beach awards encourage the public to visit beaches? Tour. Manag. 32, 576-588. https://doi.org/10.1016/j.tourman.2010.05.005 
McLean, R. F., Kirk, R. M. (1969). Relationships between grain size, size-sorting, and foreshore slope on mixed sand-shingle beaches. New Zealand Journal of Geology and Geophysics, 12(1), 138-155. https://doi.org/10.1080/00288306.1969.10420231

Medina, R., Losada, M. A., Losada, I. J., Vidal, C. (1994). Temporal and spatial relationship between sediment grain size and beach profile. Marine Geology, 118(3-4), 195-206. https://doi.org/10.1016/00253227(94)90083-3

Melsheimer, C., Tanck, G., Gade, M., Alpers, W. (1999). Imaging of tidal flats by the SIR-C/X-SAR multifrequency/multi-polarisation synthetic aperture radar. Operational Remote Sensing for Sustainable Development, edited by GJA Nieuwenhuis, RA Vaughan \& M Molenaar (Balkema, Rotterdam), 189-192

Mentaschi, L., Vousdoukas, M. I., Pekel, J. F., Voukouvalas, E., \& Feyen, L. (2018). Global long-term observations of coastal erosion and accretion. Scientific reports, 8(1), 1-11.

Micallef, A., Williams, A. T. (2002). Theoretical strategy considerations for beach management. Ocean and Coastal Management, 45(4-5), 261-275. https://doi.org/10.1016/S0964-5691(02)00058-3

Miller, J. K., Dean, R. G. (2007). Shoreline variability via empirical orthogonal function analysis: Part II relationship to nearshore conditions. Coastal Engineering, 54(2), 133-150. https://doi.org/10.1016/j.coastaleng.2006.08.014

Milligan, J., O'Riordan, T., Nicholson-Cole, S.A., Watkinson, A.R. (2009). Nature conservation for future sustainable shorelines: Lessons from seeking to involve the public. Land use policy 26, 203-213. https://doi.org/10.1016/J.LANDUSEPOL.2008.01.004

Mir-Gual, M., Pons, G.X., Martín-Prieto, J.A., Rodríguez-Perea, A. (2015). A critical view of the Blue Flag beaches in Spain using environmental variables. Ocean \& Coastal Management. 105, 106-115. https://doi.org/10.1016/j.ocecoaman.2015.01.003

Mole, M. A., Davidson, M. A., Turner, I. L., Splinter, K. D., Goodwin, I. D., Short, A. D. (2012). Modelling multidecadal shoreline variability and evolution. https://doi.org/10.9753/icce.v33.sediment.98

Monioudi, I.N., Velegrakis, A.F., Chatzipavlis, A.E., Rigos, A., Karambas, T., Vousdoukas, M.I., Hasiotis, T., Koukourouvli, N., Peduzzi, P., Manoutsoglou, E., Poulos, S.E., Collins, M.B. (2017). Assessment of island beach erosion due to sea level rise: The case of the Aegean archipelago (Eastern Mediterranean). Nat. Hazards Earth Syst. Sci. 17, 449-466. https://doi.org/10.5194/nhess-17-449-2017

MOPU, Ministerio de Obras Públicas (1970). Playas. Modelos, tipos y sugerencias para su ordenación. Madrid. 64 pp.

Morales, J. A. (Ed.). (2019). The Spanish Coastal Systems: Dynamic Processes, Sediments and Management. Springer. https://doi.org/10.1007/978-3-319-93169-2

Morgan, R. (1999). A novel, user-based rating system for tourist beaches. Tourism Management. 20, 393410. https://doi.org/10.1016/S0261-5177(99)00015-1

Morton, R.A. (1991). Accurate shoreline mapping: past, present, and future. In: Coastal sediments (pp. 9971010). ASCE. 
Morton, R.A., Miller, T.L., Moore, L.J. (2004). National assessment of shoreline change: Part 1: Historical shoreline changes and associated coastal land loss along the U.S. Gulf of Mexico: U.S. Geological Survey Open-file Report 2004-1043, 45p

Muñoz, J. M. B. (2003) Coastal zone management in Spain (1975-2000). Journal of coastal Research, 19, 314325.

Muñoz-Pérez, J. J., de San Roman-Blanco, B. L., Gutierrez-Mas, J. M., Moreno, L., Cuena, G. J. (2001). Cost of beach maintenance in the Gulf of Cadiz (SW Spain). Coastal engineering, 42(2), 143-153. https://doi.org/10.1016/S0378-3839(00)00054-5

Nelson, C., Morgan, R., Williams, A.T., Wood, J. (2000). Beach awards and management. Ocean Coast. Manag. 43, 87-98. https://doi.org/10.1016/S0964-5691(99)00068-X

Nicholls, R. J., Cazenave, A. (2010). Sea-level rise and its impact on coastal zones. Science, 328(5985), 15171520. https://doi.org/10.1126/science. 1185782

Nordstrom KF. (2004). Beaches and dunes of developed coasts. Cambridge, UK: Cambridge University Press. 338 pp.

Obiol-Menero, E. M. (2003). La regeneración de playas como factor clave del avance del turismo valenciano. Cuadernos de Geografía. Universidad de Valencia, (73-74), 121-145.

Obiol-Menero, E. M., Pitarch-Garrido, M. D. (2011). El litoral turístico valenciano. intereses y controversias en un territorio tensionado por el residencialismo. Boletin de la Asociación de Geografos Espanoles, (56), $177-200$.

Olsen, S.B., Page, G.G., Ochoa, E. (2009). The analysis of governance responses to ecosystem change: A handbook for assembling a baseline, LOICZ Reports and Studies. GKSS Research Center, Geesthacht.

Onofri, L., Nunes, P.A.L.D. (2013). Beach "lovers" and "greens": A worldwide empirical analysis of coastal tourism. Ecological Economics. 88, 49-56. https://doi.org/10.1016/j.ecolecon.2013.01.003

Orams, M.B. (1997). The effectiveness of environmental education: can we turn tourists into "greenies"?" Progress in tourism and hospitality research 3, 295-306. https://doi.org/10.1002/(SICl)10991603(199712)3:4<295::AID-PTH85>3.3.CO;2-4

Padua, S.M. (1994). Conservation Awareness through an Environmental Education Programme in the Atlantic Forest of Brazil. Environmental Conservation. 21, 145-151. https://doi.org/10.1017/S0376892900024577

Pagán, J. I., Aragonés, L., Tenza-Abril, A. J., Pallarés, P. (2016). The influence of anthropic actions on the evolution of an urban beach: Case study of Marineta Cassiana beach, Spain. Science of the Total Environment, 559, 242-255. https://doi.org/10.1016/j.scitotenv.2016.03.134

Pagán, J. I., López, I., Aragonés, L., Garcia-Barba, J. (2017). The effects of the anthropic actions on the sandy beaches of Guardamar del Segura, Spain. Science of the Total Environment, 601, 1364-1377. https://doi.org/10.1016/j.scitotenv.2017.05.272

Pajak, M. J., Leatherman, S. (2002). The high water line as shoreline indicator. Journal of Coastal Research, 329-337. 
Palazón, A., Aragonés, L., López, I. (2016). Evaluation of coastal management: Study case in the province of Alicante, Spain. Science of the Total Environment, 572, 1184-1194. https://doi.org/10.1016/j.scitotenv.2016.08.032

Palomar-Vázquez, J., Almonacid-Caballer, J., Pardo-Pascual, J. E., Cabezas-Rabadán, C., Fernández-Sarría, A. (2018). Sistema para la extracción masiva de líneas de costa a partir de imágenes de satélite de resolución media para la monitorización costera: SHOREX. In: López-García, et al. (eds.), XVIII Congreso de Tecnologías de la Información Geográfica, pp. 36-46, 20-22 Jun., València.

Palomar-Vázquez, J., Pardo-Pascual, J.E., Cabezas-Rabadán, C., Alonso-Aransay, D. (2019). Monitorizando los cambios de superficie y volumen de la Laguna de Gallocanta mediante imágenes Landsat-8 y Sentinel2. In: Durà et al. (eds.), X Jornadas de Geomorfología Litoral, 4-6 Sep., Castelldefels.

Pardo-Pascual, J. E. (1991). La erosión antrópica en el litoral valenciano. PhD thesis. Generalitat Valenciana. Conselleria d'Obres Públiques, Urbanisme i Transports. 240 pp.

Pardo-Pascual, J. E. Sanjaume, E. (2001). Análisis multiescalar de la evolución costera. Cuadernos de Geografía, (69), 95-125.

Pardo-Pascual, J., García-Asenjo, L., Palomar-Vázquez, J., Garrigues-Talens, P. (2005). New methods and tools to analyze beach-dune system evolution using a Real-Time Kinematic Global Positioning System and Geographic Information Systems. Journal of Coastal Research, SI 49, 34-39.

Pardo-Pascual, J. E., Almonacid-Caballer, J., Ruiz, L. A., Palomar-Vázquez, J. (2012). Automatic extraction of shorelines from Landsat TM and ETM+ multi-temporal images with subpixel precision. Remote Sensing of Environment, 123, 1-11. https://doi.org/10.1016/j.rse.2012.02.024

Pardo-Pascual, J. E., Almonacid-Caballer, J., Ruiz, L. A., Palomar-Vázquez, J., Rodrigo-Alemany, R. (2014). Evaluation of storm impact on sandy beaches of the Gulf of Valencia using Landsat imagery series. Geomorphology, 214, 388-401. https://doi.org/10.1016/j.geomorph.2014.02.020

Pardo-Pascual, J., Sánchez-García, E., Almonacid-Caballer, J., Palomar-Vázquez, J., Priego de los Santos, E., Fernández-Sarría, A., Balaguer-Beser, Á. (2018). Assessing the Accuracy of Automatically Extracted Shorelines on Microtidal Beaches from Landsat 7, Landsat 8 and Sentinel-2 Imagery. Remote Sensing, 10(2), 326. https://doi.org/10.3390/rs10020326

Pardo-Pascual, J.E., Roca-Moya, R., Segura-Beltran, F. (2019). Análisis de la evolución de la línea de costa entre Alcossebre y Orpesa a partir de fotografía aérea (1956-2015). https://doi.org/10.7203/CGUV.102.14511

Pardo-Pascual, J. E., Sanjaume, E. (2019). Beaches in Valencian Coast. In: Morales, J. (Ed.) The Spanish Coastal Systems (pp. 209-236). Cham, Springer International Publishing. https://doi.org/10.1007/978-3-319-93169$2 \_10$

Park, N. W. (2019). Geostatistical integration of field measurements and multi-sensor remote sensing images for spatial prediction of grain size of intertidal surface sediments. Journal of Coastal Research, 90(SI), 190196. https://doi.org/10.2112/si90-023.1

Parkinson, R. W., Ogurcak, D. E. (2018). Beach nourishment is not a sustainable strategy to mitigate climate change. Estuarine, Coastal and Shelf Science, 212, 203-209. 
Peña-Alonso, C., Ariza, E., Hernández-Calvento, L., Pérez-Chacón, E. (2018). Exploring multi-dimensional recreational quality of beach socio-ecological systems in the Canary Islands (Spain). Tourism Management. 64, 303-313. https://doi.org/10.1016/j.tourman.2017.09.008

Pereira da Silva, C. (2002). Beach carrying capacity assessment: how important is it? Journal of coastal Research. 197, 190-197.

Peterson, C.H., Bishop, M.J. (2005). Assessing the environmental impacts of beach nourishment. Bioscience 55, 887-896. https://doi.org/10.1641/0006-3568(2005)055[0887:ateiob]2.0.co;2

Phillips, M. R., Jones, A. L. (2006). Erosion and tourism infrastructure in the coastal zone: Problems, consequences and management. Tourism Management, 27(3), 517-524. https://doi.org/10.1016/j.tourman.2005.10.019

Pompe, J. J., Rinehart, J. R. (1994). Estimating the effect of wider beaches on coastal housing prices. Ocean and Coastal Management, 22(2), 141-152. https://doi.org/10.1016/0964-5691(94)90016-7

Prati, G., Albanesi, C., Pietrantoni, L., Airoldi, L. (2016). Public perceptions of beach nourishment and conflict management strategies: A case study of Portonovo Bay in the Adriatic Italian Coast. Land use policy 50, 422-428. https://doi.org/10.1016/j.landusepol.2015.06.033

Prodger, S., Russell, P., Davidson, M., Miles, J., Scott, T. (2016). Understanding and predicting the temporal variability of sediment grain size characteristics on high-energy beaches. Marine Geology, 376, 109-117. https://doi.org/10.1016/j.margeo.2016.04.003

Psuty, N. P., Silveira, T. M. (2011). Tracking Coastal Geomorphological Change: an application of protocols to collect geotemporal data sets at the national level in the US. Journal of Coastal Research, (64), 1253-1257.

Pye, K., Blott, S. J. (2016). Assessment of beach and dune erosion and accretion using LiDAR: impact of the stormy 2013-14 winter and longer term trends on the Sefton Coast, UK. Geomorphology, 266, 146-167. https://doi.org/10.1016/j.geomorph.2016.05.011

Qi, H., Cai, F., Lei, G., Cao, H., Shi, F. (2010). The response of three main beach types to tropical storms in South China. Marine Geology, 275(1-4), 244-254. https://doi.org/10.1016/j.margeo.2010.06.005

Rainey, M. P., Tyler, A. N., Gilvear, D. J., Bryant, R. G., McDonald, P. (2003). Mapping intertidal estuarine sediment grain size distributions through airborne remote sensing. Remote Sensing of Environment, 86(4), 480-490. https://doi.org/10.1016/S0034-4257(03)00126-3

Ramis, C., Alonso, S., Homar, R.R. V. (2001). Análisis preliminar del temporal del 10 al 12 de Noviembre de 2001 en Baleares. Universitat de les Illes Balears.

Ranasinghe, R., Holman, R., Schipper, M. de, Lippmann, T., Wehof, J., Duong, T.M., Roelvink, D., Stive, M. (2012): Quantifying nearshore morphological recovery time scales using argus video imaging: Palm Beach, Sydney and Duck, North Carolina. Coastal Engineering. pp. 1-7. https://doi.org/10.9753/icce.v33.sediment.24

Rao, K. N., Subraelu, P., Rao, T. V., Malini, B. H., Ratheesh, R., Bhattacharya, S., \& Rajawat, A. S. (2008). Sealevel rise and coastal vulnerability: an assessment of Andhra Pradesh coast, India through remote sensing and GIS. Journal of Coastal Conservation, 12(4), 195-207. 
Ray, G. C. (1988). "Ecological diversity in coastal zones and oceans," in Biodiversity, ed. E. O.Wilson, Washington,DC:National Academy of Sciences/Smithsonian Institution, 36-50.

Reis, A. H., Gama, C. (2010). Sand size versus beach-face slope - An explanation based on the Constructal Law. Geomorphology, 114(3), 276-283. http://dx.doi.org/10.1016/j.geomorph.2009.07.008

Reyes, J. L., Martins, J. T., Benavente, J., Ferreira, O., Gracia, F. J., Alveirinho-Dias, J. M., López-Aguayo, F. (1999). Gulf of Cadiz beaches: a comparative response to storm events. Boletín-Instituto Español de Oceanografía, 15(1/4), pp. 221-228.

Rico-Amorós, A. M., Olcina-Cantos, J., Sauri, D. (2009). Tourist land use patterns and water demand: Evidence from the Western Mediterranean. Land Use Policy, 26(2), $493-501$. https://doi.org/10.1016/j.landusepol.2008.07.002

Rigall-I-Torrent, R., Fluvià, M., Ballester, R., Saló, A., Ariza, E., Espinet, J. M. (2011). The effects of beach characteristics and location with respect to hotel prices. Tourism Management, 32(5), 1150-1158. https://doi.org/10.1016/j.tourman.2010.10.005

Roca, E., Riera, C., Villares, M., Fragell, R., Junyent, R. (2008). A combined assessment of beach occupancy and public perceptions of beach quality: A case study in the Costa Brava, Spain. Ocean \& Coastal Management. 51, 839-846. https://doi.org/10.1016/j.ocecoaman.2008.08.005

Roca, E., Villares, M. (2008). Public perceptions for evaluating beach quality in urban and semi-natural environments. Ocean \& Coastal Management. 51, 314-329. https://doi.org/10.1016/j.ocecoaman.2007.09.001

Roca, E., Villares, M., Ortego, M.I. (2009). Assessing public perceptions on beach quality according to beach users' profile: A case study in the Costa Brava (Spain). Tourism Management. 30, 598-607. https://doi.org/10.1016/j.tourman.2008.10.015

Rodella, I., Corbau, C., Simeoni, U., Utizi, K. (2017). Assessment of the relationship between geomorphological evolution, carrying capacity and users' perception: Case studies in Emilia-Romagna (Italy). Tourism Management. 59, 7-22. https://doi.org/10.1016/j.tourman.2016.07.009

Roig-Munar, F.X. (2001). El conocimiento de la Posidonia oceanica y sus funciones ecológicas como herramienta de gestión litoral. La realización de encuestas a los usuarios de playas y calas de la isla de Menorca. Papeles de Geografía. 34, 271-280.

Roig-Munar, F.X. (2003). Análisis de la relación entre capacidad de carga física y capacidad de carga perceptual en playas naturales de la Isla de Menorca. Investigaciones geográficas 31, 107-118.

Roig-Munar, F.X., Fraile-Jurado, P., Peña-Alonso, C. (2018). Analysis of Blue Flag Beaches Compared with Natural Beaches in the Balearic Islands and Canary Islands, Spain. In: Botero C., Cervantes O., F.C. (Ed.), Beach Management Tools - Concepts, Methodologies and Case Studies. Springer, Cham, pp. 545-559. https://doi.org/10.1007/978-3-319-58304-4_26

Rubin, D. M. (2004). A simple autocorrelation algorithm for determining grain size from digital images of sediment. Journal of Sedimentary Research, 74(1), 160-165. https://doi.org/10.1306/052203740160

Rumbold, D.G., Davis, P.W., Perretta, C. (2001). Estimating the effect of beach nourishment on Caretta caretta (Loggerhead Sea Turtle) nesting. Restor. Ecol. 9, 304-310. https://doi.org/10.1046/j.1526100X.2001.009003304.x 
Saleem, A., Awange, J. L. (2019). Coastline shift analysis in data deficient regions: Exploiting the high spatiotemporal resolution Sentinel-2 products. Catena, 179, 6-19. https://doi.org/10.1016/j.catena.2019.03.023

Sánchez-García, E. (2019). Photogrammetry and image processing techniques for beach monitoring. PhD dissertation. Universitat Politècnica de València. València, 324 pp. https://doi.org/10.4995/Thesis/10251/123956

Sánchez-García, E., Balaguer-Beser, A., Pardo-Pascual, J. E. (2017). C-Pro: A coastal projector monitoring system using terrestrial photogrammetry with a geometric horizon constraint. ISPRS Journal of Photogrammetry and Remote Sensing, 128, 255-273. https://doi.org/10.1016/j.isprsjprs.2017.03.023

Sánchez-García, E., Briceño, I., Palomar-Vázquez, J., Pardo-Pascual, J., Cabezas-Rabadán, C., Balaguer-Beser, Á. (2019). Beach Monitoring Project on Central Chile. In: $5^{\text {a }}$ Conferência sobre Morfodinâmica Estuarina e Costeira, MEC2019. 20-24 Jun., Lisboa. ISSN: 978-989-20-9612-4

Sánchez-García, E., Palomar-Vázquez, J. M., Pardo-Pascual, J. E., Almonacid-Caballer, J., Cabezas-Rabadán, C., Gómez-Pujol, L. (2020). An efficient protocol for accurate and massive shoreline definition from midresolution satellite imagery. Coastal Engineering, 103732. https://doi.org/10.1016/j.coastaleng.2020.103732

Sancho-García, A., Guillén, J., Ojeda, E. (2013). Storm-induced readjustment of an embayed beach after modification by protection works. Geo-Marine Letters, 33(2-3), 159-172.

Sanjaume, E. (1985). Las costas valencianas: sedimentología y morfología. PhD Thesis. Universitat de València, València. 201 pp.

Sanjaume, E. Pardo-Pascual, J.E. (2003). Pascual, J. E. P., \& Saumell, E. S. (2003). Características sedimentológicas y morfológicas de los espacios costeros de transición situados al sur de la desembocadura del Xúquer. Cuadernos de geografía, (73), 183-206.

Sanjaume, E., Pardo-Pascual, J.E. (2005). Erosion by human impact on the Valencian coastline (E of Spain). Journal of Coastal Research, 76-82.

Sanjaume, E., Pardo-Pascual, J.E. (2007). Cambios de tendencias recientes en la evolución costera del golfo de Valencia: análisis espaciales y sedimentológicos. Actas de las Jornadas Técnicas "Las nuevas técnicas de información geográfica al servicio de la gestión de zonas costeras: Análisis de la evolución de playas y dunas, $5-11$.

Sanjaume, E., Pardo-Pascual, J.E. (2019). Littoral Dunes on Valencia Coast. In: Morales, J. (Ed.) The Spanish Coastal Systems. Springer International Publishing, Cham, pp. 631-659. https://doi.org/10.1007/978-3-31993169-2_27

Santos, I.R., Friedrich, A.C., Wallner-Kersanach, M., Fillmann, G. (2005). Influence of socio-economic characteristics of beach users on litter generation. Ocean \& Coastal Management. 48, 742-752. https://doi.org/10.1016/j.ocecoaman.2005.08.006

Sanz-Blas, S. (2006). Turismo de litoral: líneas de actuación para el logro de un desarrollo sostenible. Estudios turísticos 61-83.

Sardá, R., Mora, J., Ariza, E., Avila, C., Jimenez, J. A. (2009). Decadal shifts in beach user sand availability on the Costa Brava (Northwestern Mediterranean Coast). Tourism Management, 30(2), 158-168. https://doi.org/10.1016/j.tourman.2008.05.011 
Sardá, R., Valls, J.F., Pintó, J., Ariza, E., Lozoya, J.P., Fraguell, R.M., Martí, C., Rucabado, J., Ramis, J., Jiménez, J.A. (2015). Towards a new Integrated Beach Management System: The Ecosystem-Based Management System for Beaches. Ocean \& Coastal Management. 118, 167-177. https://doi.org/10.1016/j.ocecoaman.2015.07.020

Schlacher, T. A., Noriega, R., Jones, A., Dye, T. (2012). The effects of beach nourishment on benthic invertebrates in eastern Australia: impacts and variable recovery. Science of the Total Environment, 435, 411417.

Schlacher, T. A., Schoeman, D. S., Dugan, J., Lastra, M., Jones, A., Scapini, F., McLachlan, A. (2008). Sandy beach ecosystems: key features, sampling issues, management challenges and climate change impacts. Marine ecology, 29, 70-90. https://doi.org/10.1111/j.1439-0485.2007.00204.x

Schmidt, L., Prista, P., Saraiva, T., O'Riordan, T., Gomes, C. (2013). Adapting governance for coastal change in Portugal. Land use policy 31, 314-325. https://doi.org/10.1016/J.LANDUSEPOL.2012.07.012

Scott, T., Masselink, G., Russell, P. (2011). Morphodynamic characteristics and classification of beaches in England and Wales. Marine Geology, 286(1-4), 1-20. https://doi.org/10.1016/j.margeo.2011.04.004

Segura-Beltran, F., Pardo-Pascual, J. E. (2019). Fan Deltas and Floodplains in Valencian Coastal Plains. The Spanish Coastal Systems (pp. 489-516). Cham, Springer International Publishing. https://doi.org/10.1007/978-3-319-93169-2_21

Sénéchal, N., Coco, G., Castelle, B., Marieu, V. (2015). Storm impact on the seasonal shoreline dynamics of a meso- to macrotidal open sandy beach (Biscarrosse, France). Geomorphology 228, 448-461. https://doi.org/10.1016/j.geomorph.2014.09.025

Sénéchal, N., Castelle, B., R. Bryan, K. (2017). Storm Clustering and Beach Response. In: Ciavola, P., Coco, G., Sénéchal, N., Castelle, B., R.Bryan, K. (Eds.), Coastal Storms. John Wiley Sons, Ltd, Chichester, UK, pp. 151174. https://doi.org/10.1002/9781118937099.ch8

Short, A. D., Hesp, P. A. (1982). Wave, beach and dune interactions in southeastern Australia. Marine geology, 48(3-4), 259-284. https://doi.org/10.1016/0025-3227(82)90100-1

Silberman, J., Klock, M. (1988). The recreation benefits of beach renourishment. Ocean and Shoreline Management, 11(1), 73-90.

Slott, J. M., Murray, A. B., Ashton, A. D., Crowley, T. J. (2006). Coastline responses to changing storm patterns. Geophysical Research Letters, 33(18). https://doi.org/10.1029/2006GL027445

Soares, A.G. (2003). Sandy Beach Morphodynamics and Macrobenthic Communities in Temperate, Subtropical and Tropical Regions: A Macroecological Approach. Ph.D. University of Port Elizabeth, Port Elizabeth, South Africa.

Song, J., Fu, X., Wang, R., Peng, Z. R., Gu, Z. (2018). Does planned retreat matter? Investigating land use change under the impacts of flooding induced by sea level rise. Mitigation and Adaptation Strategies for Global Change, 23(5), 703-733. https://doi.org/10.1007/s11027-017-9756-x

Song, Y., Liu, F., Ling, F., Yue, L. (2019). Automatic Semi-Global Artificial Shoreline Subpixel Localization Algorithm for Landsat Imagery. Remote Sensing, 11(15), 1779. https://doi.org/10.3390/rs11151779 
Speybroeck, J., Bonte, D., Courtens, W., Gheskiere, T., Grootaert, P., Maelfait, J.P., Mathys, M., Provoost, S., Sabbe, K., Stienen, E.W.M., Van Lancker, V., Vincx, M., Degraer, S. (2006). Beach nourishment: An ecologically sound coastal defence alternative? A review. Aquatic conservation: Marine and Freshwater ecosystems. 16, 419-435. https://doi.org/10.1002/aqc.733

Splinter, K.D., Strauss, D.R., Tomlinson, R.B. (2011). Assessment of post-storm recovery of beaches using video imaging techniques: A case study at Gold Coast, Australia. IEEE Trans. Geoscience and Remote Sensing. 49, 4704-4716. https://doi.org/10.1109/TGRS.2011.2136351

Splinter, K.D., Carley, J.T., Golshani, A., Tomlinson, R. (2014). A relationship to describe the cumulative impact of storm clusters on beach erosion. Coastal Engineering. 83, 49-55. https://doi.org/10.1016/j.coastaleng.2013.10.001

Stafford, D. B. (1971). An Aerial Photographic Technique for Beach Erosion Surveys in North Carolina (No. CERC-TM-36). The Coastal Engineering Research Center (CERC) of the U.S. Army Engineer Waterways.

Stive, M. J., Nicholls, R. J., DeVriend, H. J. (1991). Sea-level rise and shore nourishment: a discussion. Coastal Engineering, 16, 147-163. https://doi.org/10.1016/0378-3839(91)90057-N

Stive, M. J., Aarninkhof, S. G., Hamm, L., Hanson, H., Larson, M., Wijnberg, K. M., Nicholls, R.J, Capobianco, M. (2002). Variability of shore and shoreline evolution. Coastal engineering, 47(2), 211-235.

Stockdon, H.F., Sallenger, A.H., List, J.H., Holman, R.A. (2002). Estimation of shoreline position and change using airborne topographic lidar data. Journal of coastal Research, 18, 502-513.

Stronkhorst, J., Huisman, B., Giardino, A., Santinelli, G. and Duarte Santos, F. (2018). Sand nourishment strategies to mitigate coastal erosion and sea level rise at the coast of Holland (The Netherlands) and Aveiro (Portugal) in the 21st century, Ocean \& Coastal Management, 156: 266-276. https://doi.org/10.1016/j.ocecoaman.2017.11.017

Sunamura, T. (1984). Quantitative predictions of beach-face slopes. Geological Society of America Bulletin, 95(2), 242-245. https://doi.org/10.1130/0016-7606(1984)95<242:QPOBS>2.0.CO;2

Sutherland, J., Gouldby, B. (2003). Vulnerability of coastal defences to climate change, in: Proceedings of the Institution of Civil Engineers-Water and Maritime Engineering. Thomas Telford Ltd, pp. 137-145. https://doi.org/10.1680/wama.156.2.137.38008

Tamminga, A., Hugenholtz, C., Eaton, B., Lapointe, M. (2015). Hyperspatial remote sensing of channel reach morphology and hydraulic fish habitat using an unmanned aerial vehicle (UAV): A first assessment in the context of river research and management. River Research and Applications, 31(3), 379-391. https://doi.org/10.1002/rra.2743

Thieler, E.R., Himmelstoss, E.A., Zichichi, J.L., Ergul, A. (2009). Digital Shoreline Analysis System (DSAS) version 4.0- An ArcGIS extension for calculating shoreline change. U.S. Geological Survey. Open-File Rep. 2008 1278. https://doi.org/10.3133/ofr20081278

Tsai, V. J. (1993). Delaunay triangulations in TIN creation: an overview and a linear-time algorithm. International Journal of Geographical Information Science, 7(6), 501-524.

Turki, I., Medina, R., Gonzalez, M., Coco, G. (2013). Natural variability of shoreline position: Observations at three pocket beaches. Marine Geology, 338, 76-89. https://doi.org/10.1016/j.margeo.2012.10.007 
Turner, I. L., Harley, M. D., Drummond, C. D. (2016). UAVs for coastal surveying. Coastal Engineering, 114, 19-24. https://doi.org/10.1016/j.coastaleng.2016.03.011

Ullmann, T., Stauch, G. (2020). Surface Roughness Estimation in the Orog Nuur Basin (Southern Mongolia) using Sentinel-1 SAR Time Series and Ground-Based Photogrammetry. Remote Sensing, 12(19), 3200. https://doi.org/10.3390/rs12193200

UN, United Nations, Department of Economic and Social Affairs, Population Division (2015). World Population Prospects: The 2015 Revision, Key Findings and Advance Tables. Working Paper No. ESA/P/WP.241

UNWTO, World Tourism Organization. (2013). UNWTO Annual Report 2013. Madrid.

Valdemoro, H. I., Jiménez, J. A. (2006). The Influence of Shoreline Dynamics on the Use and Exploitation of Mediterranean Tourist Beaches. Coastal Management, 34(4), 405-423. https://doi.org/10.1080/08920750600860324

Van Der Wal, D., Herman, P. M. (2007). Regression-based synergy of optical, shortwave infrared and microwave remote sensing for monitoring the grain-size of intertidal sediments. Remote Sensing of Environment, 111(1), 89-106. https://doi.org/10.1016/j.rse.2007.03.019

Van Koningsveld, M., Davidson, M. A., Huntley, D. A. (2005). Matching Science with Coastal Management Needs: The Search for Appropriate Coastal State Indicators. Journal of Coastal Research West Palm Beach, 21, 399-411. https://doi.org/10.2112/03-0076.1

Vandebroek, E., Lindenbergh, R., van Leijen, F., de Schipper, M., de Vries, S. and Hanssen, R. (2017). Semiautomated monitoring of a mega-scale beach nourishment using hig-resolution TerraSAR-X satellite data, Remote Sensing, 9, 633. https://doi.org/10.3390/rs9070653

Vaz, B., Williams, A.T., Pereira da Silva, C., Phillips, M. (2009). The importance of user 's perception for beach management. Journal of Coastal Research. 56, 1164-1168.

Vázquez-Tarrío, D., Borgniet, L., Liébault, F., Recking, A. (2017). Using UAS optical imagery and SfM photogrammetry to characterize the surface grain size of gravel bars in a braided river (Vénéon River, French Alps). Geomorphology, 285, 94-105. https://doi.org/10.1016/j.geomorph.2017.01.039

Vellinga, P. (1984). A tentative description of a universal erosion profile for sandy beaches and rock beaches. Coastal engineering, 8(2), 177-188. https://doi.org/10.1016/0378-3839(84)90012-7

Viaña-Borja, S. P., Ortega-Sánchez, M. (2019). Automatic Methodology to Detect the Coastline from Landsat Images with a New Water Index Assessed on Three Different Spanish Mediterranean Deltas. Remote Sensing, 11(18), 2186

Villares, M. (1999). Percepció dels impactes estètics i mediambientals de la regeneració de platges. Ph.D. Thesis, University of Barcelona, Barcelona, 465 pp.

Vos, K., Harley, M. D., Splinter, K. D., Simmons, J. A., Turner, I. L. (2019a). Sub-annual to multi-decadal shoreline variability from publicly available satellite imagery. Coastal Engineering, 150, 160-174. https://doi.org/10.1016/j.coastaleng.2019.04.004 
Vos, K., Splinter, K. D., Harley, M. D., Simmons, J. A., Turner, I. L. (2019b). CoastSat: A Google Earth Engineenabled Python toolkit to extract shorelines from publicly available satellite imagery. Environmental Modelling Software, 122, 104528. https://doi.org/10.1016/j.envsoft.2019.104528

Vos, K., Harley, M. D., Splinter, K. D., Walker, A., Turner, I. L. (2020). Beach slopes from satellite-derived shorelines. Geophysical Research Letters, e2020GL088365. https://doi.org/10.1002/essoar.10502903.1

Vousdoukas, M. I., Ferreira, P. M., Almeida, L. P., Dodet, G., Psaros, F., Andriolo, U.,Taborda, R., Nobre Silva, A., Ruano, A., Ferreira, Ó. (2011). Performance of intertidal topography video monitoring of a meso-tidal reflective beach in South Portugal. Ocean Dynamics, 61(10), 1521-1540.

Vousdoukas, M. I., Wziatek, D., Almeida, L. P. (2012). Coastal vulnerability assessment based on video wave run-up observations at a mesotidal, steep-sloped beach. Ocean Dynamics, 62(1), 123-137. https://doi.org/10.1007/s10236-011-0480-x

Vousdoukas, M. I., Ranasinghe, R., Mentaschi, L., Plomaritis, T. A., Athanasiou, P., Luijendijk, A., Feyen, L. (2020a). Sandy coastlines under threat of erosion. Nature Climate Change, 10, pages260-263. http://dx.doi.org/10.1038/s41558-020-0697-0

Vousdoukas, M.I., Mentaschi, L., Ciscar, J. C., Hinkel, J., Ward, P. J., Feyen, L. (2020b). Economic incentives for raising coastal flood defenses in Europe. Preprint in EarhAxiv. https://doi.org/10.31223/osf.io/wu4r6

Wang, C., Zhang, J., Ma, Y. (2010). Coastline interpretation from multispectral remote sensing images using an association rule algorithm. International Journal of Remote Sensing, 31(24), 6409-6423. https://doi.org/10.1080/01431160903413739

Warrick, J. A., Rubin, D. M., Ruggiero, P., Harney, J. N., Draut, A. E., Buscombe, D. (2009). Cobble Cam: Grainsize measurements of sand to boulder from digital photographs and autocorrelation analyses. Earth Surface Processes and Landforms: The Journal of the British Geomorphological Research Group, 34(13), 1811-1821. https://doi.org/10.1002/esp.1877

Wentworth, C. K. (1922). A scale of grade and class terms for clastic sediments. The journal of geology, 30(5), 377-392.

White, M., Smith, A., Humphryes, K., Pahl, S., Snelling, D., Depledge, M. (2010). Blue space: The importance of water for preference, affect, and restorativeness ratings of natural and built scenes. Journal of Environmental Psychology, 30(4), 482-493.

Wiegel, R. (1964). Oceanographical Engineering, Englewood Cliffs, New Jersey: Prentice Hall.

Williams, A. T., Rangel-Buitrago, N., Pranzini, E., Anfuso, G. (2018). The management of coastal erosion. Ocean \& Coastal Management, 156, 4-20. https://doi.org/10.1016/j.ocecoaman.2017.03.022

Williams, A.T., Micallef, A. (2009). Beach management: Principles and practices. Earthscan Publications Ltd. https://doi.org/10.1111/j.1475-4959.2010.00360_1.x

Willis, C. M., Griggs, G. B. (2003). Reductions in fluvial sediment discharge by coastal dams in California and implications for beach sustainability. The Journal of Geology, 111(2), 167-182.

Wright, L. Short, A. (1984). Morphodynamic variability of surf zones and beaches: a synthesis. Marine Geology. 56 (1-4), 93-118. https://doi.org/10.1016/0025-3227(84) 90008-2. https://doi.org/10.1016/0025$3227(84) 90008-2$ 
Yates, M.L., Guza, R.T., O'Reilly, W.C. (2009). Equilibrium shoreline response: Observations and modeling. Journal of Geophysical Research: Oceans, 114 (C09014): 1-16. https://doi.org/10.1029/2009JC005359

Yepes, V. (2002). Ordenación y gestión del territorio turístico. Las playas. In: Blanquer (Ed.). Valencia: Tirant lo Blanch. pp. 549-579

Yepes, V., Medina, J.R. (2005). Land Use Tourism Models in Spanish Coastal Areas. A Case Study of the Valencia Region. Journal of Coastal Research, (49), 83-88.

Yepes, V., Medina, J.R. (2007). Gestión de playas encajadas de uso intensivo. Libro de Resúmenes de Las IX Jornadas Españolas de Ingeniería de Costas y Puertos. San Sebastián, pp. 175-176.

Zar, J.H. (1999). Biostatistical analysis. Prentice Hall, New York. 



\section{Acknowledgements}

This research integrates findings and results obtained within the framework of the contract FPU15/04501 granted to the author by the Spanish Ministry of Education, Culture, and Sports, which has allowed this doctoral thesis to become a reality. The research has been supported by the funds of the project RESETOCOAST, by the Ministry of Economy, Industry, and Competitiveness (chapters 2 to 5), and the project MONOBESAT PID2019-111435RB-100 by the Ministry of Science, Innovation, and Universities (chapter 6). About my stay in Portugal, it was possible with the funds of the Erasmus+ program. The contribution of Ó. Ferreira was funded by EW-COAST (PTDC/CTA-OHR/28657/2017) and by FCT and Univ. Algarve through the grant UID/MAR/00350/2013, while S. Costas' was funded by IF/01047/2014. The following institutions have provided free access to essential data for the development of the publications that constitute this thesis: ESA and USGS for the satellite imagery; Puertos del Estado, and the Portuguese Hydrographic Institute in collaboration with CIMA for supplying oceanographic data; Ministry MITECO and DGSCM for data regarding beach sedimentology and nourishments. 
Y ahora algo más personal...

De los más de cuatro años que ha durado esta aventura me llevo muchos recuerdos: un par de discos duros llenos hojas de cálculo, 'shapes'y blocs de notas, un buen puñado de conocimientos adquiridos, unas cuantas anécdotas divertidas sobre los días de trabajo de campo, y esta disertación que estás leyendo. Pero sin duda alguna, lo que más valoro son las lecciones aprendidas y el trato con las diferentes personas con las que he tenido el placer de encontrarme.

En primer lugar, esta investigación no habría tenido lugar sin la gente que ha participado en mi formación académica. Especial estima les tengo al campus de Gandia donde cursé el grueso de mis estudios, y a la Facultad de Geografía, mi última parada antes de embarcarme en esta tesis. De esos años me llevo un grato recuerdo de profesores y compañeros que alimentaron mi curiosidad y ganas de aprender.

A mis directores de tesis les agradezco el animarme a embarcarme en este proyecto. En numerosas ocasiones me han conseguido convencer de la utilidad de esta investigación, de los resultados obtenidos, y de la necesidad de, en ocasiones, "sacar la banda a pasear". Esto es de agradecer teniendo en cuenta mi habitual escepticismo, junto al hecho de que en un proyecto de esta duración y dimensiones en ocasiones resulta difícil saber si se está avanzando por el camino correcto. Su aporte de ideas y supervisión ha sido esencial para empujarme en las fases de estancamiento, y además, han actuado como compañeros de batalla frente a la absurda burocracia que padece la investigación científica en este país. Por encima de todo me quedo con las enriquecedoras discusiones que hemos tenido sobre el medio ambiente y los espacios costeros (¿Qué va a pasar? ¿cómo actuar? ¿cuál es nuestro papel y el del mundo académico...?).

Agradezco a Óscar y Susana recibirme y acompañarme en mi paso por el Algarve, confiando en que no desapareciese con su GPS tragado por el mar. De ese lluvioso y oscuro invierno, además de la sensación de almorzar sopa y cenar maravilloso pescado a la hora de la merienda me traigo otras grandes experiencias, nuevas amistades, y reencuentros con viejos conocidos, todo ello mientras admiraba las caprichosas formas de la costa Vicentina, los encantadores rincones y las viñas del Alentejo, y los atardeceres de Ria Formosa.

En un tono algo más personal, mi vida en Valencia ha traído cuatro años intensos, repletos de nuevas experiencias y numerosos vaivenes. Aprecio infinito a esas personas que han ido llenando esta etapa de vida y color, y que han continuado a mi lado a pesar de esa costumbre que tengo de, ocasionalmente, desaparecer de la faz de la Tierra. Tened por seguro que sin esa necesaria desconexión social compartiendo una cerveza, bailando hasta el amanecer, haciendo la croqueta en la arena, escapándonos para respirar el aire de la sierra o perdiéndonos en acampadas sanadoras probablemente habría perdido (un poco más) la cabeza, y que esta tesis aún no estaría acabada.

Estoy encantado con la acogida dispensada por el equipo de cartógrafos, tanto en el trabajo como en mi vida valenciana. Dentro de la escuela, el fantástico trato de toda la gente del CGAT ha hecho que estos años hayan pasado en un abrir y cerrar de ojos. Esta compañía me ha ahorrado miles de horas frente al ordenador con sus dotes de programación y pensamiento ingenieril. Pero por 
encima de todo esto, el pasillo de ese 3er piso se convirtió rápidamente en una segunda casa, desde la hora del desayuno hasta, ya fuera de la escuela, la de la cena. Ese buenrollismo permite afrontar el día a día mejor de lo que nunca habría imaginado.

Relacionado con la categoría de 'afterworks' y demás actividades extraescolares, maravillosa ha sido mi adopción por el grupo de químicos, entre los que parece que sigue aumentando esta plaga de doctores. Geniales las discusiones sobre temas tan variopintos como el precio del alquiler, ciclismo, capitalismo, cationes y 'perriones', todo esto mientras nos comemos EL gazpacho, o nos tomamos la penúltima en 'el raconet dels dijous' o en el Xarly's. Igualment indispensable tota eixa gentola de les comarques centrals i dels pobles de 'moatros' per fer-me sentir a qualsevol lloc com a casa, ja siga compartint sofà, dies de caseta, o mandarines.

Me resulta imposible desligar la aventura de estos años de los compañeros de piso. Han sido muchos días aguantándonos, compartiendo noches de teletrabajo, desayunos de sábado y viajes al super. De todos me llevo mil momentos, aunque para el recuerdo quedan los encuentros culinarios: la receta maestra del arroz al horno (propiedad compartida), gluhweins, nits de sushi, pozales de lentejas o, cuando el nivel de víveres bajaba y la vagancia nos vencía, falafels benimacleteros y pizzas de nuestra trattoria favorita. Recuerdo obligado para el mañico con el que he vivido (y convivido) tantos años, y al experto del titanio y cristalicos varios, con numerosos consejos académicos (y ajedrecísticos) durante la recta final de la tesis.

Estéis o no físicamente cerca, sé que me tenéis bien acompañado. Me refiero a mes amis parisiens, falleret de pura cepa de acento gaditano, compañero de granulometrías introductor al mundo del rap, crazy bichos-palo lady, canarios por el mundo, doctora-de-verdad-de-las-quecuran-gente, chomskysta de los grandes lagos, con mención especial para la chica rara que me acompañó desde nuestro aterrizaje en Valencia en aquel ya lejano 2015. Agradezco la compañía, descubriendo juntos infinidad de cosas, así como los ánimos y el empujón para comenzar esta aventura. Sois personas maravillosas, y sé que aunque lo intentase no me libraría de vosotras.

Algo parecido ocurre con la familia. laio, mientras redactaba las anteriores páginas me acordé de ti montones de veces, con tu energía, y aconsejándome que estudiase inglés. laia, Tio, gracias por estar siempre a una llamada de distancia. Mamá, papá, gracias por la acogida temporal durante los tiempos doblemente convulsos de redacción de tesis y de confinamiento estricto. Y bueno, por apoyarme infinitamente. Gracias a todos por los mil y un consejos, y por seguir ahí siempre. 


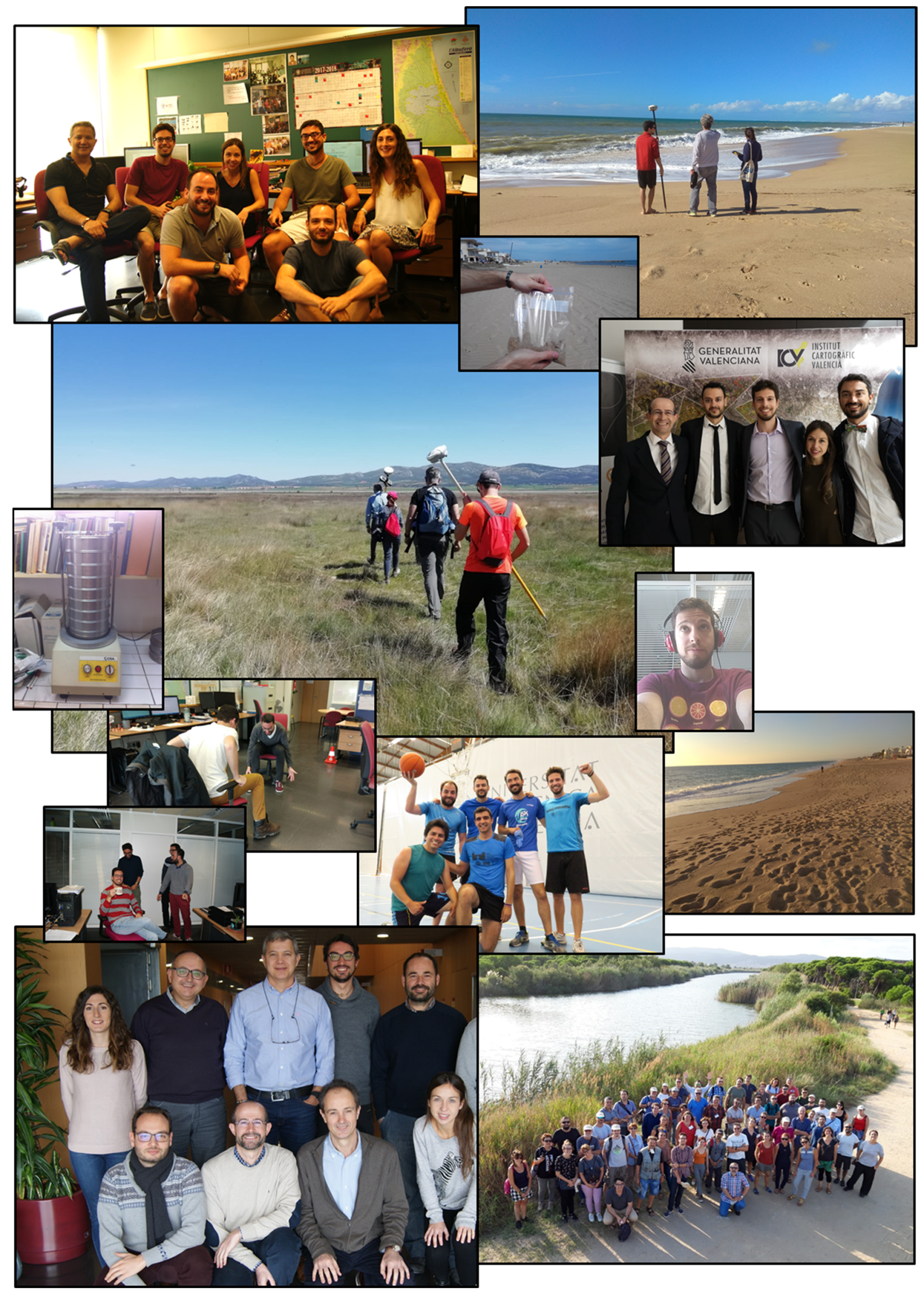




\section{About the author}

Research activity and scientific contributions during the elaboration of this thesis:

\section{Projects}

This PhD position has been supported by the funds of the contract FPU 15/04501 by the granted by the Spanish Ministry of Education, Culture and Sports. At the same time, some works have been carried out associated with the research projects RESETOCOAST supported by the Ministry of Economy, Industry, and Competitiveness, and MONOBESAT by the Ministry of Science, Innovation, and Universities in which the author and some of the co-authors have participated.

\section{Papers and publications}

Cabezas-Rabadán, C., Rodilla, M., Pardo-Pascual, J.E., Herrera-Racionero, P. (2019). Assessing user's expectations and perceptions on different beach types and the need for diverse management frameworks along the Western Mediterranean. Land Use Policy, 81, 219 - 231.

https://doi.org/10.1016/j.landusepol.2018.10.027

Cabezas-Rabadán, C., Pardo-Pascual, J. E., Almonacid-Caballer, J., Rodilla, M. (2019). Detecting problematic beach widths for the recreational function along the Gulf of Valencia (Spain) from Landsat 8 subpixel shorelines. Applied Geography, 110.

https://doi.org/10.1016/j.apgeog.2019.102047

Cabezas-Rabadán, C., Pardo-Pascual, J. E., Palomar-Vázquez, J. M., Fernández-Sarría, A. (2019). Characterizing beach changes using high-frequency Sentinel-2 derived shorelines on the Valencian coast (Spanish Mediterranean). Science of The Total Environment, 691, 216-231. https://doi.org/10.1016/j.scitotenv.2019.07.084

Cabezas-Rabadán, C., Pardo-Pascual, J.E., Palomar-Vázquez, J., Almonacid-Caballer, J., FernándezSarría, A. (2019). Monitorización de la respuesta de playas Mediterráneas a temporales y actuaciones antrópicas mediante imágenes Landsat. GeoFocus. № 23.

http://dx.doi.org/10.21138/GF.640

Cabezas-Rabadán, C., Pardo-Pascual, J.E., Palomar-Vázquez, J., Ferreira, Ó., and Costas, S. (2020). Satellite derived shorelines at an exposed meso-tidal beach. In: Malvárez, G. and Navas, F. (eds.), Global Coastal Issues of 2020. Journal of Coastal Research, Special Issue No. 95, pp. 1027-1031. Coconut Creek (Florida), ISSN 0749-0208. https://doi.org/10.2112/SI95-200.1

Cabezas-Rabadán, C., Pardo-Pascual, J.E. (2017). Monitorizando la anchura de las playas mediante imágenes Landsat 8 en costas micromareales Mediterráneas. Geotemas. 17, pp. 159 - 162. ISSN 1576-5172

Sánchez-García, E., Palomar-Vázquez, J. M., Pardo-Pascual, J. E., Almonacid-Caballer, J., CabezasRabadán, C., Gómez-Pujol, L. (2020). An efficient protocol for accurate and massive shoreline definition from mid-resolution satellite imagery. Coastal Engineering, 103732. https://doi.org/10.1016/j.coastaleng.2020.103732 
Cabezas-Rabadán, C., Pardo-Pascual, J. E., Palomar-Vázquez, J. M. Shoreline variability from Sentinel-2: an approach for estimating beach sediment size? (Under review in the journal 'Marine Geology').

\section{Conferences}

Cabezas-Rabadán, C., Almonacid-Caballer, J., Pardo-Pascual, J.E., Soriano-González, J. (2017). Variabilidad de la línea de costa a partir de imágenes de satélite y su relación con la textura del sedimento. / Congress in Geomatics Engineering, 5-6 Jul. Valencia.

Cabezas-Rabadán, C., Pardo-Pascual, J.E. (2017). Monitorizando la anchura de las playas mediante imágenes Landsat 8 en costas micromareales mediterráneas. IX Jornadas de Geomorfología Litoral, 13-15 Sep., Menorca.

Cabezas-Rabadán, C., Pardo-Pascual, J.E., Palomar-Vázquez, J., Almonacid-Caballer, J., FernándezSarría, A. (2018). La posición de la línea de costa extraída de imágenes satelitales como herramienta de seguimiento y análisis de cambios en playas Mediterráneas. XVIII Congreso Nacional de TIG, 20-22 Jun., València.

Fernández-Sarría, A., Pardo-Pascual, J.E., Palomar-Vázquez, J., Almonacid-Caballer, J., CabezasRabadán., C. (2018). Cartografiado y cuantificación de los cambios morfológicos en las dunas de Oliva usando LiDAR y fotogrametría automatizada desde UAV. XVIII Congreso Nacional de TIG, 20-22 Jun., València.

Cabezas-Rabadán, C. (2018). Attendance and volunteering work at the International Geoscience and Remote Sensing Symposium 2018 (IGARSS), 22nd - 27th July, València.

Sánchez-García, E; Briceño, I., Palomar-Vázquez, J., Pardo-Pascual, J., Cabezas-Rabadán, C., Balaguer-Beser, Á. (2019). Beach Monitoring Project on Central Chile. $5^{a}$ Conferência sobre Morfodinâmica Estuarina e Costeira, MEC2019, 20-24 jun, Lisboa. ISSN: 978-989-20-9612-4

Cabezas-Rabadán, C., Pardo-Pascual, J.E., Palomar-Vázquez, J., Fernández-Sarría. A. (2019). Análisis y caracterización de cambios en playas valencianas mediante líneas de costa derivadas de Sentinel-2 X Jornadas de Geomorfología Litoral, 4-6 Sep., Castelldefels.

Palomar-Vázquez, J., Pardo-Pascual, J.E., Cabezas-Rabadán, C., Alonso-Aransay, D. (2019). Monitorizando los cambios de superficie y volumen de la Laguna de Gallocanta mediante imágenes Landsat-8 y Sentinel-2. X Jornadas de Geomorfología Litoral, 4-6 Sep., Castelldefels.

\section{Resarch stay}

Research stay at CIMA, Universidade do Algarve (Portugal) under the supervision of Prof. Óscar Ferreira during 3 months, from November 2018 to February 2019. 


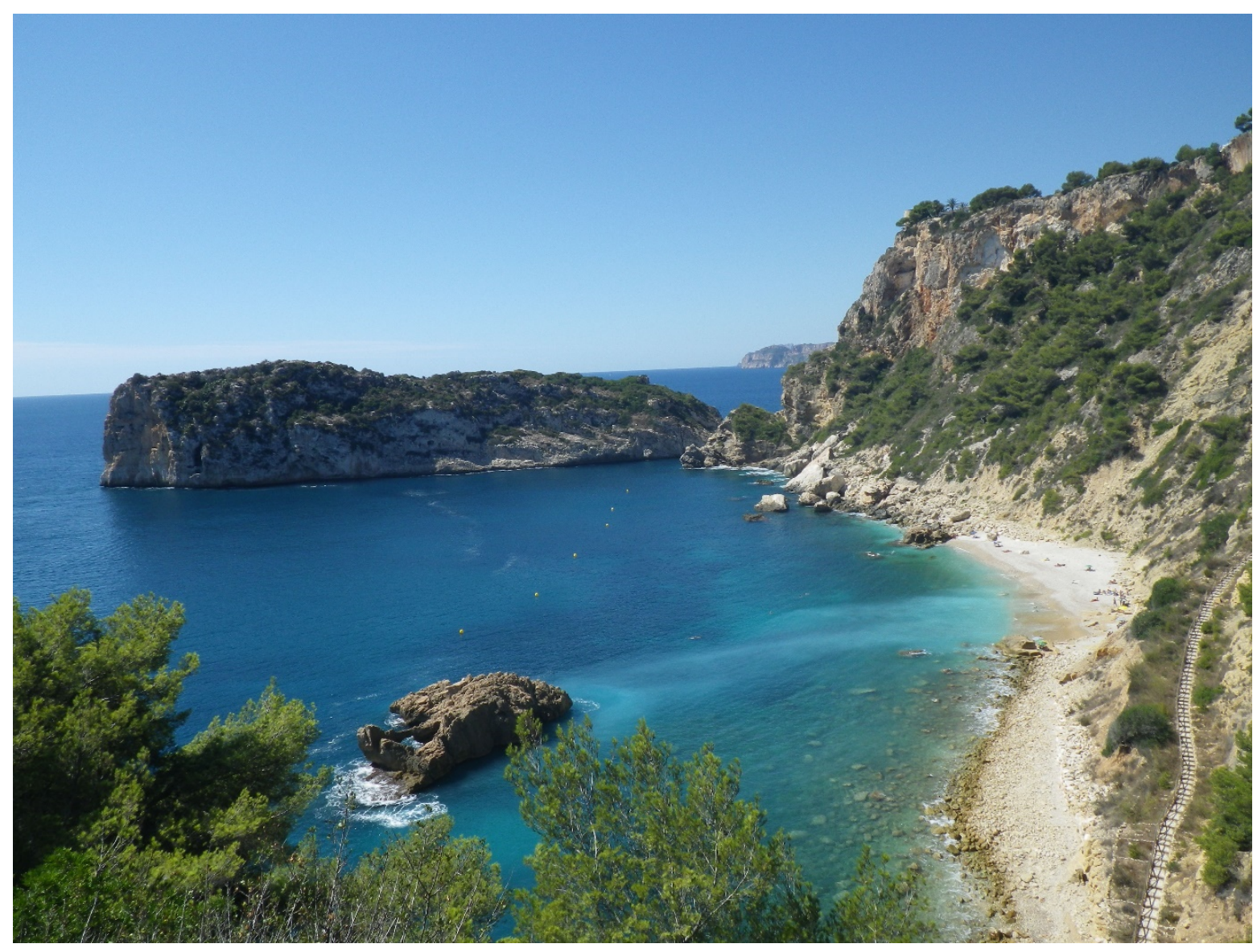

"Me bastaba con ver las olas ir y venir a mis pies y el perfil de los islotes reflejándose en el mar para sentirme en paz con el universo. Luego estaban los olores: el de los cañaverales, dulzón y verde como la brisa que lo traía desde la ladera; el de la arena, húmedo como las olas que la mojaban al ritmo de las mareas; el de las barcas de pesca, preñado de sal y yodo y agitado y esparcido por el cabeceo de éstas. Olores que te embriagaban y que se volvían tangibles cuando, en la noche, el mar desaparecía"

-J. Llamazares- 
